Ahmed Ezzat Labib

Enforcing Customization in e-Learning Systems: an Ontology and Product Line Based Approach

PhD Thesis. September 2017
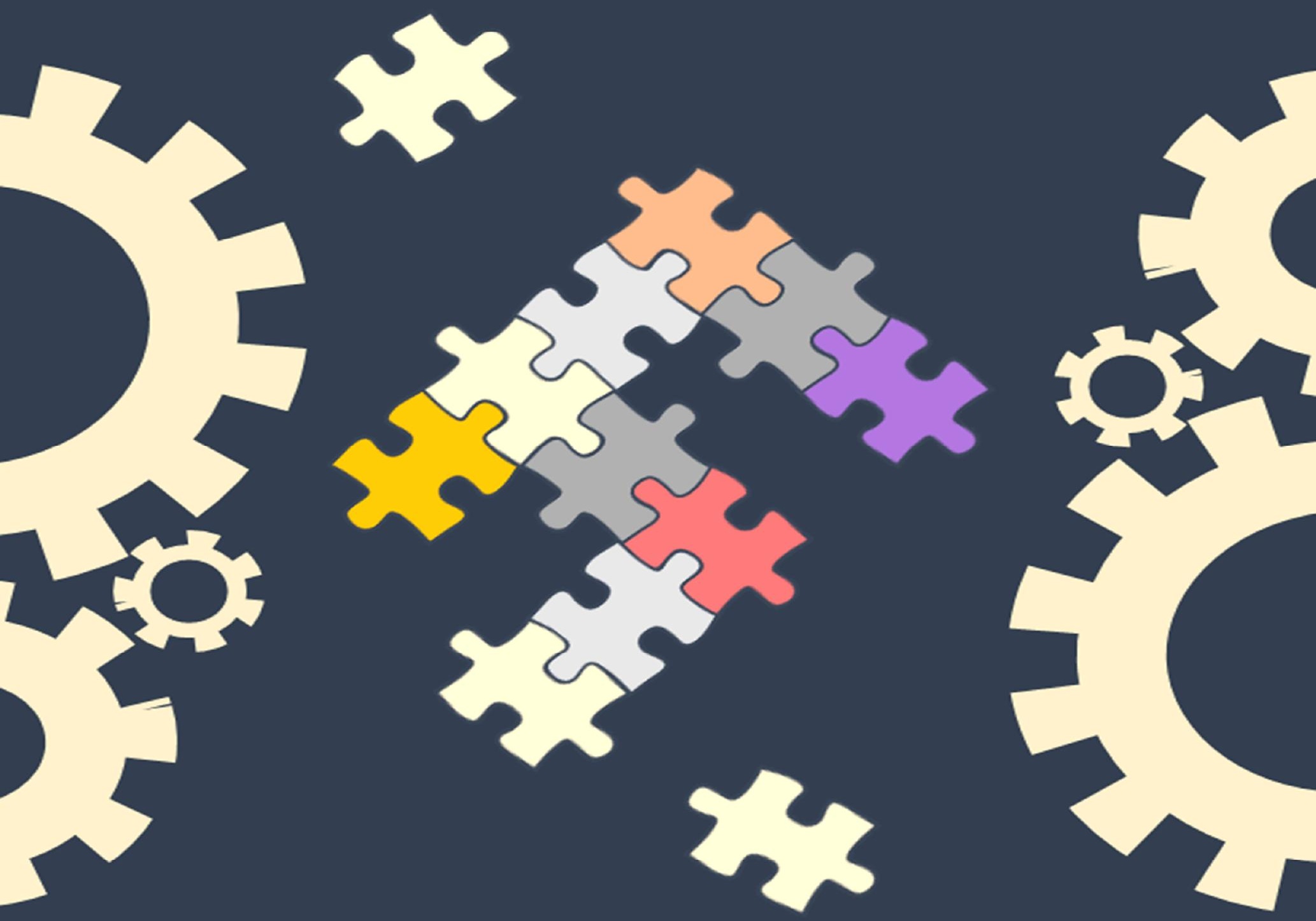


\title{
Enforcing Customization in e-Learning Systems: an Ontology and Product Line Based Approach
}

\author{
A hmed Ezzat Labib A wad Ragab \\ A Thesis Submitted for the Degree of \\ DOCTOR OF PHILOSOPHY IN COMPUTER SCIENCE \\ Department of Information Systems and Computation \\ UNIVERSITAT POLITÈCNICA DE VALÈNCIA \\ Supervised by \\ Dr. José Hilario Canós Cerdá \\ Dr. M aría Carmen Penadés Gramage

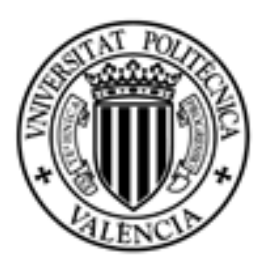 \\ UNIVERSITAT \\ POLITĖCNICA \\ DE VALÈNCIA
}

Valencia, September 2017 


\section{SUPERVISORS}

Dr. José Hilario Canós Cerdá - U niversitat Politécnica de Valéncia, Spain

Dr. M aría Carmen Penadés Gramage - Universitat Politécnica de Valéncia, Spain

\section{THESISDEFENSE COMITTEE MEMBERS}

Dr. García Peñalvo, Francisco José - U niversidad deSalamanca, Spain

Dr. Oliver Villarroya, Francisco Javier - U niversitat Politècnica de València, Spain

Dr. M ena Nieto, Eduardo - U niversidad de Zaragoza, Spain

A hmed Ezzat Labib, Enforcing Customization in e-Learning Systems: an Ontology and Product Line Based A pproach. Programa de doctorado en Informática. This work has been partially supported by Erasmus M undus (W elcome Project) and the Spanish MINECO under grant CALPE (TIN2015-68608-R). PhD Thesis @ 2017 Ahmed Ezzat Labib, Valencia, Spain. All rights are reserved. Printed in Spain. 


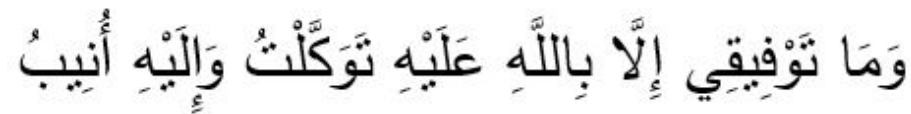

And my success (in my task) can only comefrom Allah. In Him I trust, and unto Him I look.

- Holy Qur'an

Chapter Hud, Verse 88 



\section{Dedication}

To the loving memory of my late parents. I miss you in every moment.

To my beloved Sara, for accompanying me on this road with such patience, affection and support; but aboveall, for helping meto forget thebad moments and making each of them so special.

To my sister and her husband, Shaimaa and Ahmed, for their encouragement, support, and for getting my smilestarted.

To my whole family: my children Mohamed and Yassin, my cousin Samia, my father-in-law Ahmed, my mother-in-law Azza, my aunt Nabila, my uncle Alaa, my brother-in-law Hamoda and Hossam El Sayeh, for their understanding, involvement in my efforts, and support during all these months that havehad to do without my.

I love all of you. 




\section{Abstract}

In the era of e-Learning, educational materials are considered a crucial point for all the stakeholders. On the one hand, instructors aim at creating learning materials that meet the needs and expectations of learners easily and effectively; On the other hand, learners want to acquire knowledge in a way that suits their characteristics and preferences. Consequently, the provision and customization of educational materials to meet the needs of learners is a constant challenge and is currently synonymous with technological development. Promoting the personalization of learning materials, especially during their development, will help to produce customized learning materials for specific learners' needs.

The main objective of this thesis is to reinforce and strengthen Reuse, Customization and Ease of Production issues in e-Learning materials during the development process. The thesis deals with the design of a framework based on ontologies and product lines to develop customized Learning Objects (LOs). With this framework, the development of learning materials has the following advantages: (i) large-scale production, (ii) faster development time, (iii) greater (re) use of resources.

The proposed framework is the main contribution of this thesis, and is characterized by the combination of three models: the Content Model, which addresses important points related to the structure of learning materials, their granularity and levels of aggregation; the Customization Model, which considers specific learner characteristics and preferences to customize the learning materials; and the LO Product Line (LOPL) model, which handles the subject of variability and creates matter-them in an easy and flexible way. With these models, instructors can not only develop learning materials, but also reuse and customize them during development.

An additional contribution is the Customization Model, which is based on the Learning Style Model (LSM) concept. Based on the study of seven of them, a Global Learning Style Model Ontology (GLSMO) has been constructed to 
help instructors with information on the apprentice's characteristics and to recommend appropriate LOs for customization.

The results of our work have been reflected in the design of an authoring tool for learning materials called LOAT. We have described its requirements, the elements of its architecture, and some details of its user interface. As an example of its use, we include a case study that shows how it can be used in the development of some simple learning components. 


\section{Resumen}

En la era del e-Learning, los materiales educativos se consideran un punto crucial para todos los participantes. Por un lado, los instructores tienen como objetivo crear materiales de aprendizaje que satisfagan las necesidades y expectativas de los alumnos de manera fácil y efectiva; por otro lado, los alumnos quieren adquirir conocimientos de una manera que se adapte a sus características y preferencias. En consecuencia, la provisión y personalización de materiales educativos para satisfacer las necesidades de los estudiantes es un desafío constante y es actualmente sinónimo de desarrollo tecnológico. El fomento de la personalización de los materiales de aprendizaje, especialmente durante su desarrollo, ayudará a producir materiales de aprendizaje específicos para las necesidades específicas de los alumnos.

El objetivo fundamental de esta tesis es reforzar y fortalecer los temas de Reutilización, Personalización y Facilidad de Producción en materiales de eLearning durante el proceso de desarrollo. La tesis se ocupa del diseño de un marco basado en ontologías y líneas de productos para desarrollar objetos de aprendizaje personalizados. Con este marco, el desarrollo de materiales de aprendizaje tiene las siguientes ventajas: (i) producción a gran escala, (ii) tiempo de desarrollo más rápido, (iii) mayor (re)uso de recursos.

El marco propuesto es la principal aportación de esta tesis, y se caracteriza por la combinación de tres modelos: el Modelo de Contenido, que aborda puntos importantes relacionados con la estructura de los materiales de aprendizaje, su granularidad y niveles de agregación, el Modelo de Personalización, que considera las características y preferencias específicas del alumno para personalizar los materiales de aprendizaje, y el modelo de Línea de productos LO (LOPL), que maneja el tema de la variabilidad y crea materiales de manera fácil y flexible. Con estos modelos, los instructores no sólo pueden desarrollar materiales de aprendizaje, sino también reutilizarlos y personalizarlos durante el desarrollo. 
Una contribución adicional es el modelo de personalización, que se basa en el concepto de modelo de estilo de aprendizaje. A partir del estudio de siete de ellos, se ha construido una Ontología de Modelo de Estilo de Aprendizaje Global para ayudar a los instructores con información sobre las características del aprendiz y recomendarlos apropiados para personalización.

Los resultados de nuestro trabajo se han plasmado en el diseño de una herramienta de autor de materiales de aprendizaje llamada LOAT. Se han descrito sus requisitos, los elementos de su arquitectura, y algunos detalles de su interfaz de usuario. Como ejemplo de su uso, se incluye un caso de estudio que muestra su empleo en el desarrollo de algunos componentes de aprendizaje. 


\section{Resum}

En l'era de l'e-Learning, els materials educatius es consideren un punt crucial per a tots els participants. D'una banda, els instructors tenen com a objectiu crear materials d'aprenentatge que satisfacen les necessitats i expectatives dels alumnes de manera fàcil i efectiva; d'altra banda, els alumnes volen adquirir coneixements d'una manera que s'adapte a les seues característiques i preferències. En conseqüència, la provisió i personalització de materials educatius per a satisfer les necessitats dels estudiants és un desafiament constant i és actualment sinònim de desenvolupament tecnològic. El foment de la personalització dels materials d'aprenentatge, especialment durant el seu desenvolupament, ajudarà a produir materials d'aprenentatge específics per a les necessitats concretes dels alumnes.

L'objectiu fonamental d'aquesta tesi és reforçar i enfortir els temes de Reutilització, Personalització i Facilitat de Producció en materials d'e-Learning durant el procés de desenvolupament. La tesi s'ocupa del disseny d'un marc basat en ontologies i línia de productes per a desenvolupar objectes d'aprenentatge personalitzats. Amb aquest marc, el desenvolupament de materials d'aprenentatge té els següents avantatges: (i) producció a gran escala, (ii) temps de desenvolupament mes ràpid, (iii) major (re)ús de recursos. El marc proposat és la principal aportació d'aquesta tesi, i es caracteritza per la combinació de tres models: el Model de Contingut, que aborda punts importants relacionats amb l'estructura dels materials d'aprenentatge, la seua granularitat i nivells d'agregació, el Model de Línia de Producte, que gestiona el tema de la variabilitat i crea materials d'aprenentatge de manera fàcil i flexible. Amb aquests models, els instructors no solament poden desenvolupar materials d'aprenentatge, sinó que també poden reutilitzar-los i personalitzar-los durant el desenvolupament. Una contribució addicional és el Model de Personalització, que es basa en el concepte de model d'estil d'aprenentatge. A partir de l'estudi de set d'ells, s'ha construït una Ontologia de Model d'Estil d'Aprenentatge Global per a ajudar als instructors amb informació 
sobre les característiques de l'aprenent i recomanar els apropiats per a personalització.

Els resultats del nostre treball s'han plasmat en el disseny d'una eina d'autor de materials d'aprenentatge anomenada LOAT. S'han descrit els seus requisits, els elements de la seua arquitectura, i alguns detalls de la seua interfície d'usuari. Com a exemple del seu ús, s'inclou un cas d'estudi que mostra com és el desenvolupament d'alguns components d'aprenentatge. 


\section{Acknowledgements}

I would like to acknowledge the people who have helped me during these years, and who have shared with me their time, knowledge and friendship.

I want to express my sincere gratitude and appreciation to my supervisors, José Hilario Canós and María Carmen Penadés. Particularly, I would like to thank José Hilario Canós for his encouragement, availability in almost all deadlines, his deep observations, and specially, his excellent and rigorous care when reviewing my researches. I have learned a lot from him not just academically but also personally. I would like to thank María Carmen Penadés for her readiness to help, guidance, support, and helpful discussions, but more importantly, to give me enough confidence and freedom to conduct my research. I am particularly thankful to Abel Gómez Llana for helping me during the first months in the laboratory and with Document Product Line. This thesis would not have been possible without their support, patience and endless guidance.

I would like to thank everyone within the Software Engineering and Information Systems (ISSI) research group, for providing a productive and friendly environment.

This work was partially supported by Erasmus Mundus (Welcome Project) and the Spanish MINECO under grant CALPE (TIN2015-68608-R).

In the Lab 3L03, I didn't take the road to my Ph.D. alone but I was accompanied by my friends; Alex Andrés, Ana Gabriela, Armando Castañeda, and Janio Jadán. I thank all for the great moments we had in the lab and seminars and the delightful time we spent at lunchtime and coffee breaks.

After 5 years in Valencia, I've gained a new culture in a great city with a friendly people. I have met great friends, thanks to M. Maher, Abd El Rahman, Alejandro, Juan V., Uleses for a great time we had in Valencia. Especial thanks to my friends Ahmed Fawzi and Amr Adel for being like brothers to me. 
Finally, I would like to thank all reviewers who pointed out flaws, possible improvements and suggested new directions in my work.

A hmed E , L abib

$S$ eptember 2017

$\overline{\text { viii }}$ 


\section{T able Of CONTENTS}

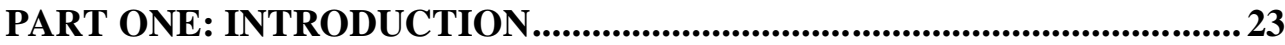

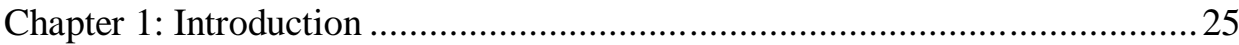

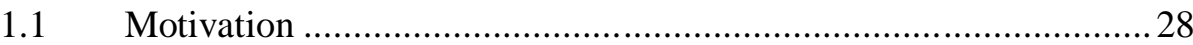

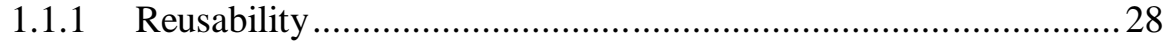

1.1.2 Customization and Personalization ..............................................2 29

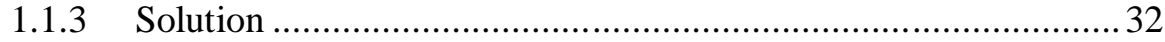

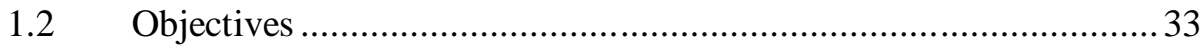

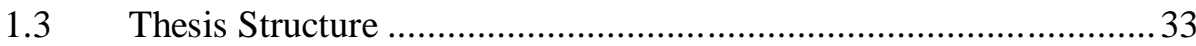

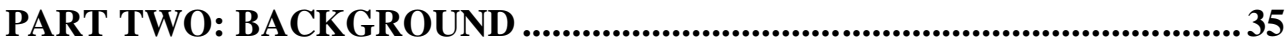

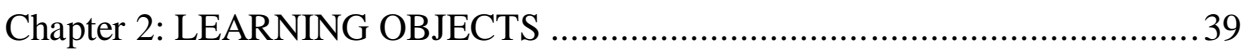

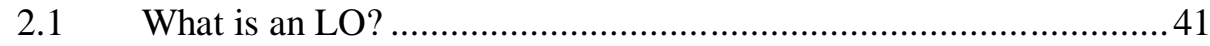

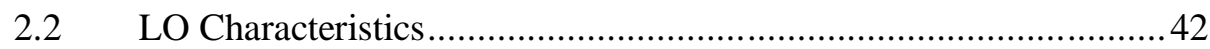

2.3 LO Metadata Standards and Specifications ....................................45

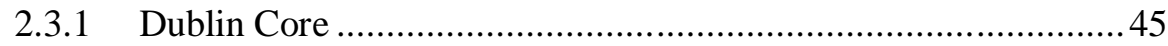

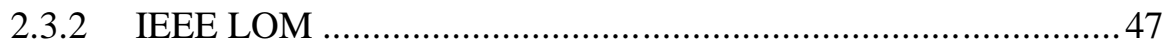

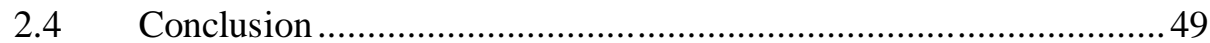

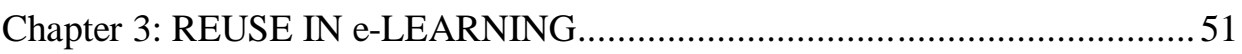

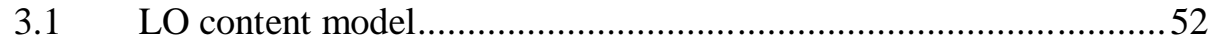

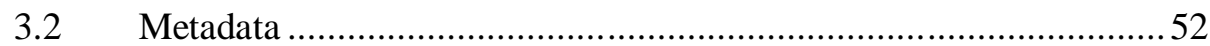

3.3 LO Variability Representation and specification .............................53

3.4 e-Learning Authoring Applications............................................54 


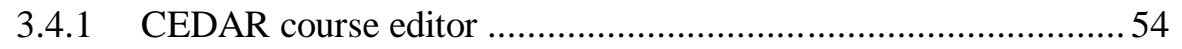

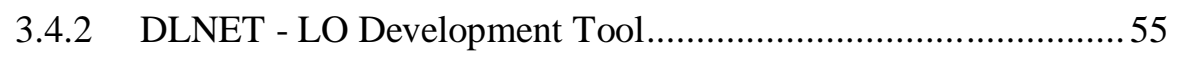

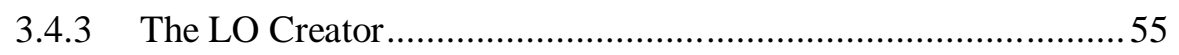

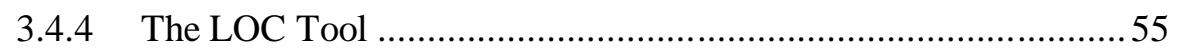

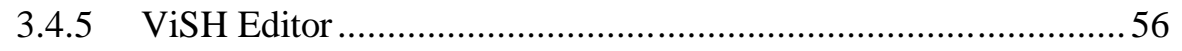

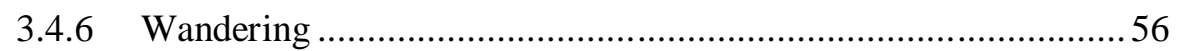

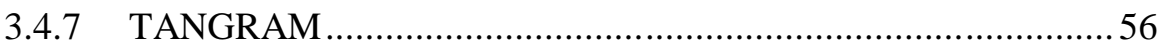

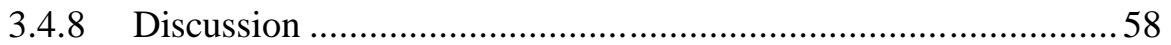

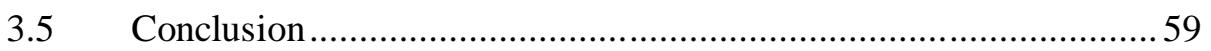

Chapter 4: CUSTOMIZATION IN e-LEARNING ........................................ 61

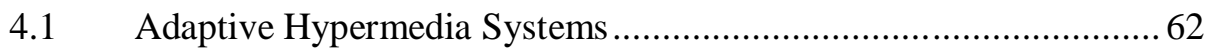

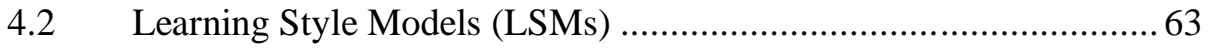

4.2.1 Kolb's Experiential Learning Theory and LSM ......................... 63

4.2.2 The Myer-Briggs Type Indicator Theory .....................................66

4.2.3 The Riding Cognitive Style Model ............................................ 69

4.2.4 Gregorc's Mind Styles Model …................................................ 71

4.2.5 The Felder-Silverman Model..................................................... 73

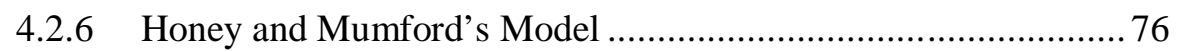

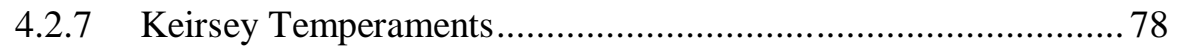

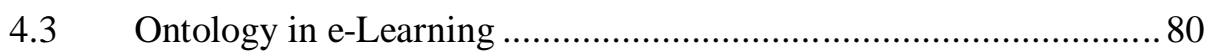

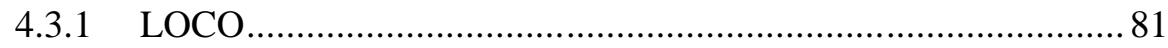

4.3.2 O-DEST

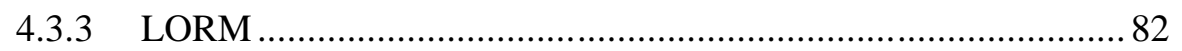

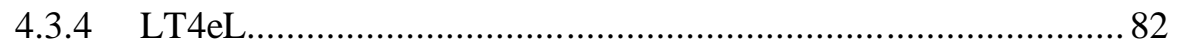




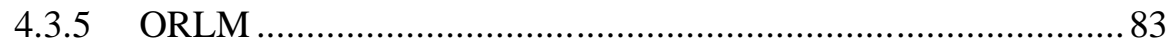

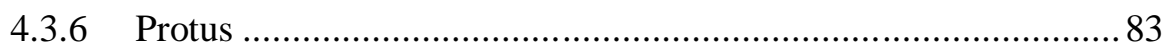

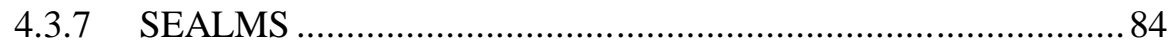

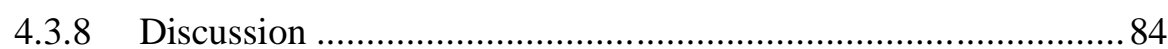

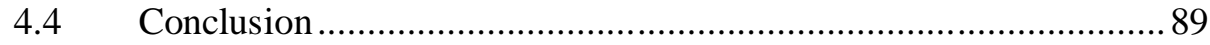

PART THREE: A CONCEPTUAL FRAMEWORK FOR LO DEVELOPMENT BASED ON ONTOLOGY AND PRODUCT LINE

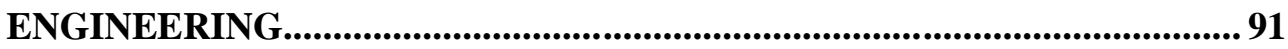

Chapter 5: A Product Line Approach to LO Development ............................... 95

5.1 General description of the proposal............................................97

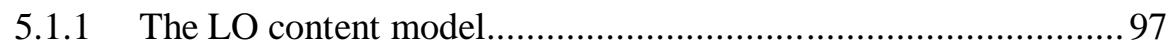

5.1.2 The LO Customization model ................................................... 98

5.1.3 The LO Product Line (LOPL) model .........................................99

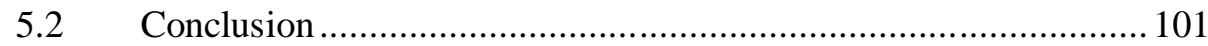

Chapter 6: The LO Content Model ................................................................. 103

6.1 The Cisco RIO content model....................................................... 104

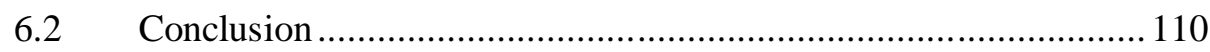

Chapter 7: The Customization Model ............................................................. 111

7.1 The selection criteria of the LSMs ................................................ 115

7.2 The On-To Knowledge - Ontology Development Methodology ... 116

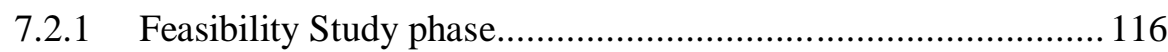

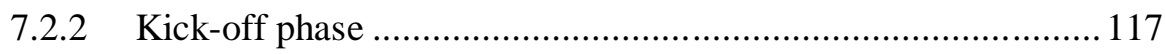

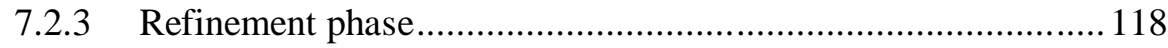

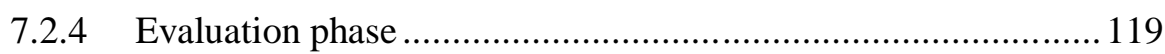

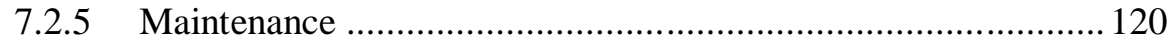


7.3 Developing the Global Learning Style Model Ontology (GLSMO) 120

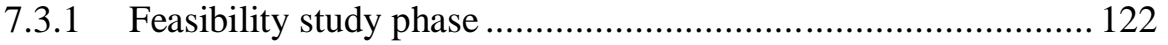

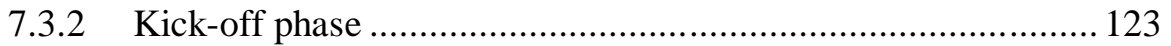

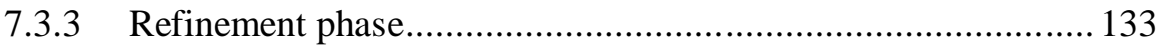

7.3.4 Evaluation and Maintenance phase .......................................... 156

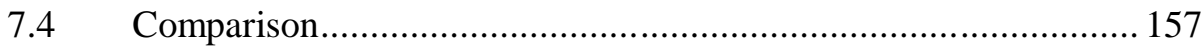

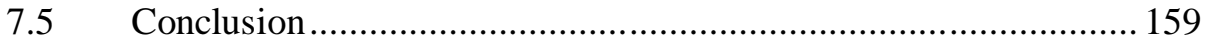

Chapter 8: Product Line-based Development of LOs ....................................... 161

8.1 Software Product Line Engineering and Variability Management . 162

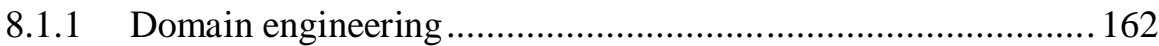

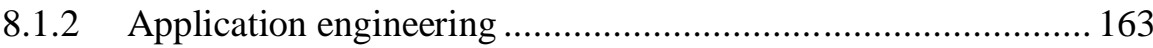

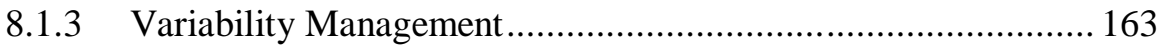

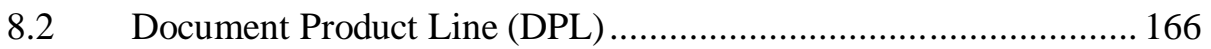

8.3 LO product line (LOPL) approach .............................................. 169

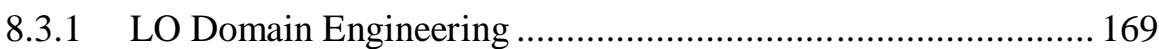

8.3.2 LO Application Engineering ….............................................. 172

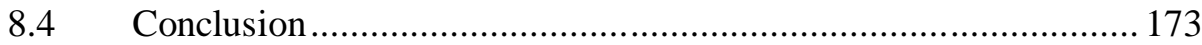

Chapter 9: Towards a tool supporting LO Product Lines .............................. 175

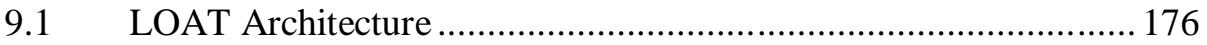

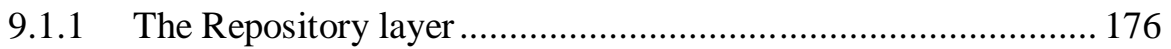

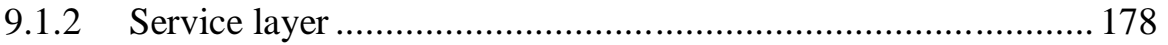

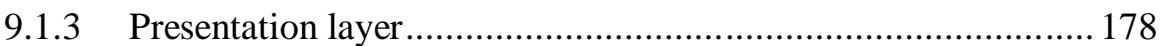

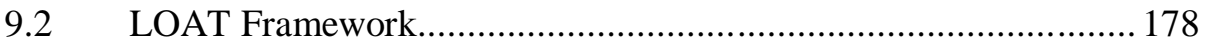

xii 


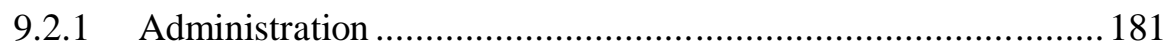

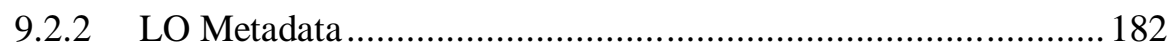

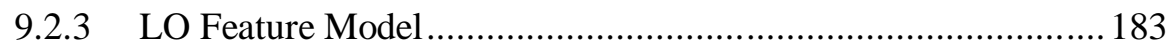

9.2.4 Recommend/Search Relative Components and RIOs ................ 186

9.2.5 Recommend Characteristics .................................................. 187

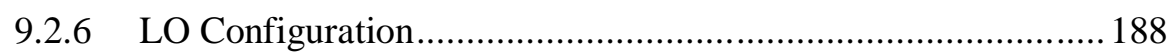

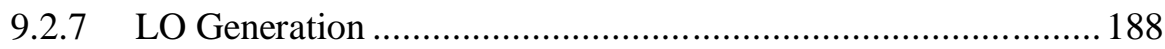

9.3 A Case Study: Generating "If Statement" RIO .............................. 188

9.3.1 The "IF Statement" RIO Metadata............................................... 189

9.3.2 The "IF Statement" RIO Feature Model ................................... 189

9.3.3 Customizing \& Personalizing the "IF Statement" RIO .............. 190

9.3.4 The "IF Statement" RIO Configuration ..................................... 191

9.3.5 The "IF Statement" RIO Generation ............................................ 191

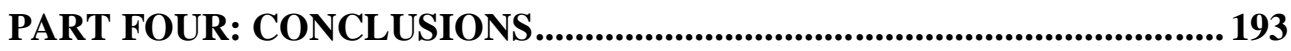

Chapter 10: Conclusions and further work ................................................... 195

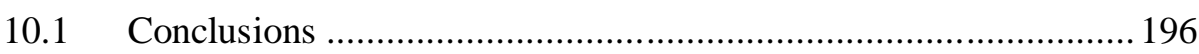

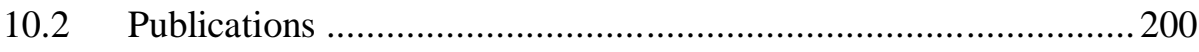

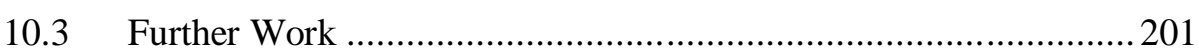

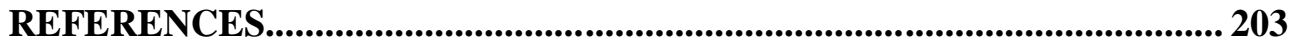

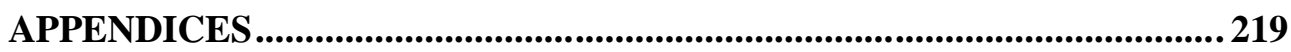




\section{LIST OF FIGURES}

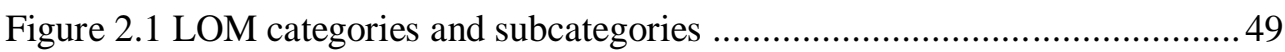

Figure 4.1 The Kolb's four stages and learning styles ......................................65

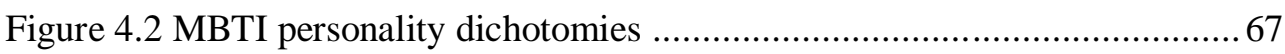

Figure 4.3 The Riding's dimensions and learning styles................................... 70

Figure 4.4 The Gregorc's mind ability dimensions and mind styles.....................73

Figure 4.5 The Felder-Silverman's dimensions .................................................. 74

Figure 4.6 The Honey and Mumford's learning styles........................................77

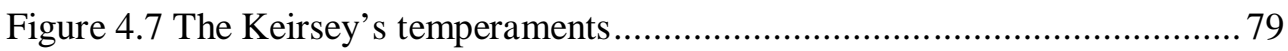

Figure 5.1 The proposed model for LO development ........................................ 97

Figure 6.1 Cisco RIO content model............................................................... 105

Figure 6.2 Cisco RIO content model UML class diagram ................................. 108

Figure 7.1 The On-To-Knowledge five phases.............................................. 117

Figure 7.2 The development strategy of GLSMO ........................................... 121

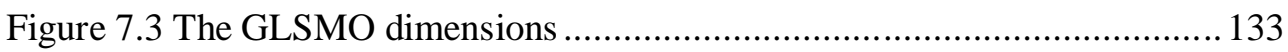

Figure 7.4 A partial view of the GLSMO...................................................... 135

Figure 7.5 A conceptual framework of the GLSMO......................................... 136

Figure 7.6 The UML class diagram for Felder-Silverman local ontology ........... 137

Figure 7.7 UML object diagram represents the S_A_Vi_Sq learning style ......... 138

Figure 7.8 The UML class diagram for Kolb local ontology ............................ 138

Figure 7.9 UML object diagram represents the Diverging learning style ........... 139

Figure 7.10 The UML class diagram for MBTI local ontology.......................... 140

Figure 7.11 UML object diagram represents the ESTJ personality type.............. 141

Figure 7.12 The UML class diagram for Keirsey local ontology ....................... 142

Figure 7.13 UML object diagram represents the Idealist temperament ............... 144

Figure 7.14 The UML class diagram for Riding local ontology ......................... 144

Figure 7.15 UML object diagram represents the Wholist-Imagery cognitive style

Figure 7.16 The UML class diagram for Gregorc local ontology ....................... 146 
Figure 7.17 UML object diagram represents the Concrete-Sequential mind style147

Figure 7.18 The UML class diagram for Honey and Mumford local ontology .... 148

Figure 7.19 An integrated view of GLSMO ...................................................... 149

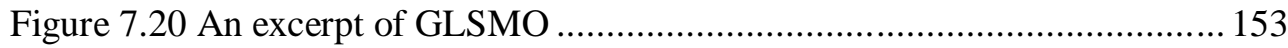

Figure 7.21 The upper-level concepts of GLSMO........................................... 154

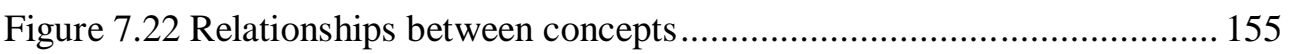

Figure 7.23 Query examples. (a) For finding Learner's Characteristics of Diverging learning style. (b) For bi-learning styles (Converging and Diverging). ............... 156

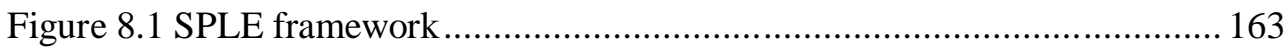

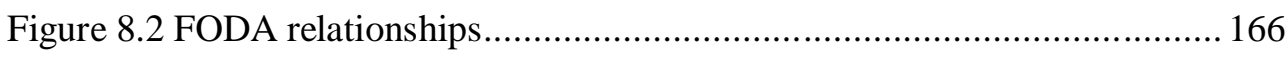

Figure 8.3 DPL framework (Gómez, Penadés, Canós, Borges, \& Llavador, 2014)

168

Figure 8.4 The LO product line process using BPMN ..................................... 170

Figure 8.5 An excerpt of the LO feature model.............................................. 171

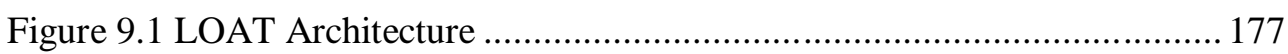

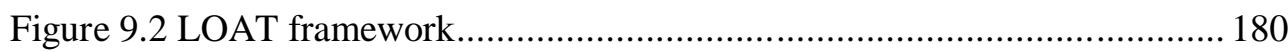

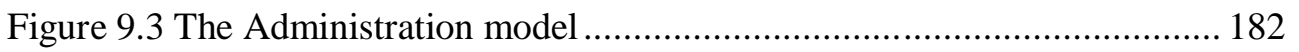

Figure 9.4 The use case diagram for different actor concepts ............................ 183

Figure 9.5 LO Feature Model according to RIO content model ......................... 185

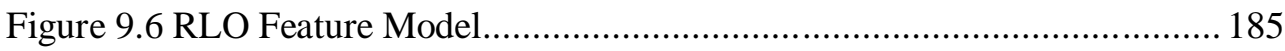

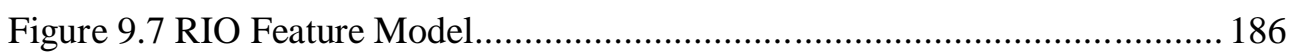

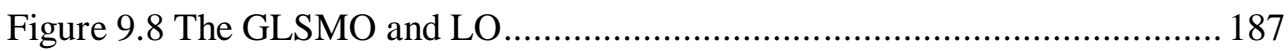

Figure 9.9 The "If Statement" RIO metadata form............................................. 189

Figure 9.10 The "If Statement" RIO feature model ............................................ 190

Figure 9.11 Customizing "If Statement" RIO .................................................... 191

Figure 9.12 the "If Statement" RIO configuration............................................ 192

Figure 9.13 The generated "If Statement" RIO ................................................. 192

xvi 


\section{LIST OF TABLES}

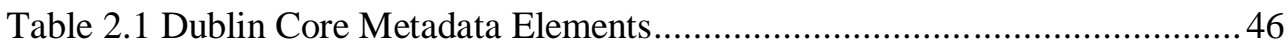

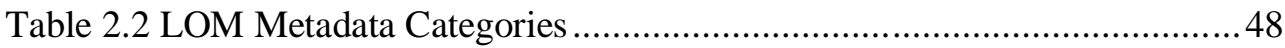

Table 3.1 A comparison of the authoring applications ..........................................58

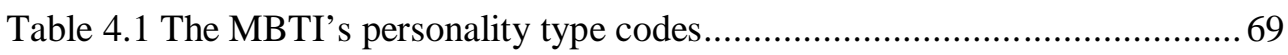

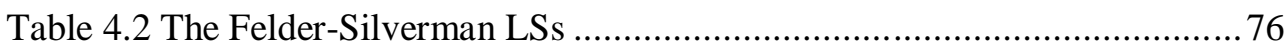

Table 4.3 Comparison of existing personalized e-Learning studies based on

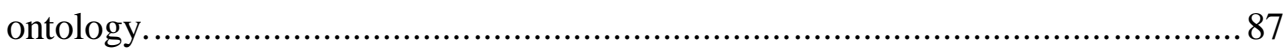

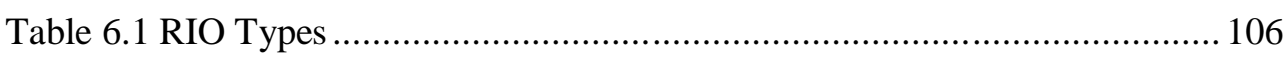

Table 6.2 Overview of content items to be used for RIO and RLO $((\mathrm{M})=$ Mandatory,

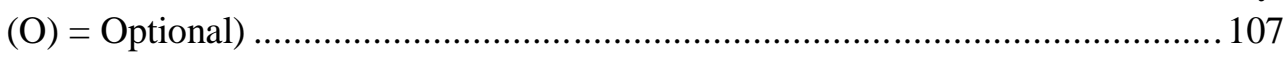

Table 6.3 The Proposed Metadata Profile …….................................................. 108

Table 7.1 The proposed classification of LSMs' concepts ................................. 124

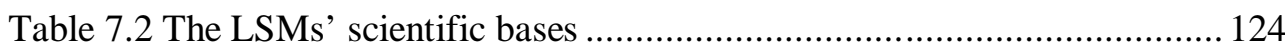

Table 7.3 Some Characteristics related to Dimensions of Learning Style Models 127

Table 7.4 Characteristics of Honey and Mumford's learning styles ................... 129

Table 7.5 The proposed classification of LSMs' dimensions ............................. 130

Table 7.6 The related concepts in GLSMO and LSMs local ontologies .............. 148

Table 7.7 Dimensions mapping between GLSMO and LSMs local ontologies ... 150

Table 7.8 Poles mapping between GLSMO and LSMs local ontologies ............. 151

Table 7.9 Comparison of GLMSO and other personalized e-Learning ontology-

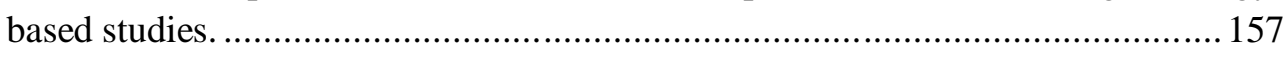

Table 8.1 Structural Relationships in FODA ...................................................... 165

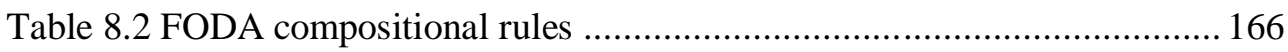

Table 10.1 A comparison LOAT and other authoring applications ..................... 199 



\section{Acronyms}

CLM Customized Learning Materials

CLO Customized Learning Object

CSA Cognitive Styles Analysis

DCMI Dublin Core Metadata Initiative

DPL Document Product Line

ELT Experiential Learning Theory

FM Feature Model

FODA Feature-Oriented Domain Approach

FS-A Felder-Silverman - Active

FS-Gl Felder-Silverman - Global

FS-IN Felder-Silverman - Intuitive

FS-R Felder-Silverman - Reflective

FS-S Felder-Silverman - Sensing

FS-Sq Felder-Silverman - Sequential

FS-Vi Felder-Silverman - Visual 


$\begin{array}{ll}\text { FS-Vr } & \text { Felder-Silverman - Verbal } \\ \text { GLSMO } & \text { Global Learning Style Model Ontology } \\ \text { Gre-A } & \text { Gregorc - Abstract } \\ \text { Gre-C } & \text { Gregorc - Concrete } \\ \text { Gre-R } & \text { Gregorc - Random } \\ \text { Gre-S } & \text { Gregorc - Sequential } \\ \text { ICT } & \text { Information and Communication Technology } \\ \text { IEEE } & \text { Institute of Electrical and Electronics Engineers } \\ \text { IMS } & \text { Instructional Management System project } \\ \text { Kolb-AC } & \text { Kolb - Abstract Conceptualization } \\ \text { Kolb-AE } & \text { Kolb - Active Experimentation } \\ \text { Kolb-CE } & \text { Kolb - Concrete Experience } \\ \text { Kolb-RO } & \text { Kolb - Reflective Observation } \\ \text { LO } & \text { Learning Object } \\ \text { LOAT } & \text { Learning Object Authoring Tool } \\ \text { LOM } & \text { Learning Object Metadata } \\ \end{array}$

$x x$ 
LOPL Learning Object Product Line

LS Learning Style

LSI Learning Styles Inventory

LSM Learning Style Model

LTSC Learning Technologies Standard Committee

MB-Ext Myer-Briggs Type Indicator - Extravert

MB-Fe Myer-Briggs Type Indicator - Feeling

MB-IN Myer-Briggs Type Indicator - Intuitive

MB-Intr Myer-Briggs Type Indicator - Introvert

MB-Jd Myer-Briggs Type Indicator - Judging

MB-Pr Myer-Briggs Type Indicator - Perceiving

MB-S Myer-Briggs Type Indicator - Sensing

MB-Th Myer-Briggs Type Indicator - Thinking

MBTI Myer-Briggs Type Indicator

MDE Model-Driven Engineering

MDWE Model-Driven Web Engineering 


$\begin{array}{ll}\text { OCL } & \text { Object Constraint Language } \\ \text { OWL } & \text { Web Ontology Language } \\ \text { RDF } & \text { Resource Description Frameworks } \\ \text { Rid-A } & \text { Riding - Analytical } \\ \text { Rid-I } & \text { Riding - Imagery } \\ \text { Rid-Vr } & \text { Riding - Verbal } \\ \text { Rid-W } & \text { Riding - Wholist } \\ \text { RIO } & \text { Reusable Information Object } \\ \text { RLO } & \text { Reusable Learning Object } \\ \text { SCORM } & \text { Sharable Content Object Reference Model } \\ \text { SPLE } & \text { Software Product Line Engineering } \\ \text { UML } & \text { Unified Modeling Language } \\ \text { W3C } & \text { World Wide Web Consortium's } \\ \text { XML } & \text { Extensible Markup Language }\end{array}$


Part ONe

INTRODUCTION 



\section{Chapter 1}

\section{Introduction}

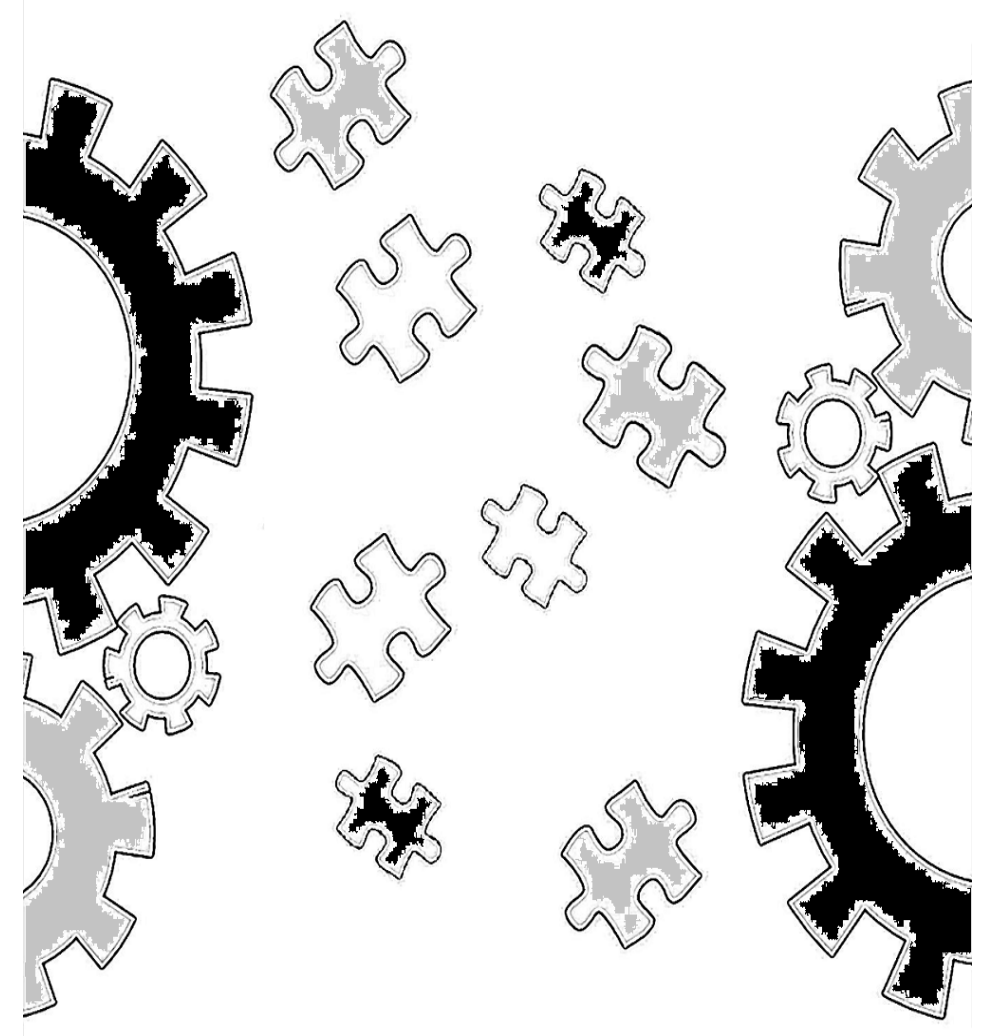


Advances in information systems and internet technologies have changed many human activities, including education and knowledge acquisition, which currently use information systems and internet technologies. Lectures, seminars and educational materials are no longer limited to physical forms, but now take virtual and digital forms. These virtual and digital forms are becoming popular among those interested in educational activities (teachers, learners, etc.). The growth of information technologies in education and the global use of educational environments have created new requirements for the development of interactive learning materials in terms of content reuse, customization and ease of production. These requirements have led research and development efforts towards the development of course materials, training materials, instructor/learner guides, and assessment units, just to name a few artifacts used in learning processes, from sets of reusable, granular, and customized pieces or Customized Learning Objects (CLO).

The term Learning Object (LO) was first introduced in the 1990s. In 1997, L'Allier defined the term LO as:

"The smallest independent structural experience that contains an objective, a learning activity and an assessment" (L'Allier, 1997)

There have been several subsequent efforts in the computer-assisted learning domain to identify a specification of metadata elements to facilitate a global standard for identifying and reusing LOs.

Wiley attached the term "Reusable" to the LO and he defined the Reusable LO (RLO) as:

“any digital resource that can be reused to support learning." (Wiley, 2000)

Wayne Hodgins inspired the idea of LOs from the LEGO blocks. He defined LO as:

“" "prime sized" blocks of content have a fundamental "standard," the equivalent of the "pin size" of the LEGO TM blocks, such that they can be assembled into literally any shape, size, and function." (Hodgins, 2002)

In 2002, the IEEE Learning Technology Standards Committee (LTSC) the 
Learning Object Metadata (LOM) Working Group was the first that used the term LO to describe these small pieces of educational content:

"A learning object is defined as any entity, digital or non-digital, that may be used for learning, education or training" (IEEE-LTSC, 2002)

This definition led to a new vision centered on LO reusability and interoperability, which became the basic building blocks of learning materials which can be reused in different learning contexts.

According the previous definitions, LOs have two fundamental aspects, which are Learning and Reusability. The former means that LOs should be wrapped in a learning intention and centered on a core concept and the latter means the ability to use them in different instructional contexts (this can be done by separating the LO creation and deployment processes).

The community of learners has many different learning preferences and their needs should be considered when learning materials are being developed. This is called customizing or personalizing learning materials.

Nowadays, customization or personalization in e-Learning means the ability to customize several aspects related to the learning environment, such as the learner model (preferences, needs, learning objectives, etc.) and learning materials (Learning Objects, Courses, Exams, etc.). As a matter of fact, the customization process relies heavily on the learner's characteristics, learning preferences, and needs. Several research studies have used various parameters (i.e. knowledge level, learning goals, language preference, learning style) to address the customization idea with learning materials (Essalmi, Ben Ayed, Jemni, Graf, \& Kinshuk, 2015). Using Learning Styles (LSs) as a thesaurus of individual characteristics is a good way to capture learner characteristics and preferences to be exploited in learning material customization.

Taking advantage of LO features and individual LSs will enhance the development of learning material processes if they are integrated in a production framework that facilities the process for non-experts. 


\section{Chapter $\mathbf{1}$}

This thesis is concerned with the design of a conceptual framework for generating customized-reusable LOs. The goal is to support a semi-automatic process for developing learning materials by enforcing LO customization and reuse. The framework presented in this thesis is characterized by the combination of three models: the instructional content model, the personalization (customization) model and the LO Product Line (LOPL) model and this combination is its most important contribution. By this means the course author is not only able to create learning materials, but also to reuse (with several reusing criteria) and customize (with multi LSs) learning materials during the development process using the features of Software Product Line Engineering (SPLE) and Document Product Line (DPL) techniques. Applying SPLE and DPL principles and techniques can help to increase reusability, flexibility and customization in the learning materials development process.

\subsection{Motivation}

The National Center for Education Statistics (Institute of Education Sciences) has reported that approximately 5,750,417 learners were enrolled in distance education courses (degree-granting postsecondary institutions only) in the fall of 2014 (NCES, 2014). This number implies that a vast range of materials had been authored to meet their needs, some of which had been implemented without including issues such as reuse, individual learner differences (customizing) and subsequent development. Some of the limitations of e-Learning applications, especially in learning material authoring tools, include the lack of opportunities for reusability and customization (Kolås, 2005; Truong, 2016), hiding low-level details and not providing authors with helpful recommendations and guidelines.

\subsubsection{Reusability}

Reusability was proposed in the application development domain to improve quality, minimize cost and improve the productivity of software components. Braun defined Reuse as follows:

"The use of existing software components in a new context, either elsewhere in the same system or in another system." (Braun, 2002) 
So far there have been many obstructions to reuse, for instance, missing standards, product copyrights, technology, language, and the culture of sharing.

Traditionally, reuse techniques have been employed in LOs with low granularity levels, which is an important criteria for LO reuse, especially when the LO is focused on a small single concept. Furthermore, Metadata is an important approach which can be used to discover learning materials for (re)use. It can be employed to specify and describe several information about the LO content (i.e. author, learning objective, learner's needs and preferences). Some examples of learning material authoring applications are: (i) CEDAR, a template-based LO tool that gives authors the ability to create and (re)-use LOs and aggregate learning materials from them (Muzio, Heins, \& R. Mundell, 2002); (ii) the LO Creator, an open source LO authoring tool that provides designers with a simple interface and free-style pedagogical design environment (Koohang, Floyd, \& Stewart, 2011); (iii) the ViSH Editor, an open source web-based e-Learning authoring tool that aims to ease the generation of multi-device LOs (Gordillo, Barra, \& Quemada, 2015).

However, reusability during the learning material development process still involves some challenges, including providing authors with LO search and recommendation strategies and, secondly, applying standardization, especially to metadata, to facilitate reuse between different systems. Finally, the learner's needs and preferences should be considered in the development process.

\subsubsection{Customization and Personalization}

Although granularity and metadata can improve the reuse and discoverability of educational materials and make them easier to produce, by themselves they are not enough to customize (personalize) them.

Although Customization and Personalization are not the same, they are in fact two sides of the same coin. Personalization employs adaptivity to tailor content, structure, and presentation to individuals automatically, while Customization provides adaptability for individuals to modify the content presentation, format layouts, and navigation facilities by themselves. Personalization 


\section{Chapter 1.}

is a system-initiated process and needs several adaptive tools, while customization is a user-centered process and needs several adaptable elements provided by the system with which the user can customize the contents according to his preferences and needs.

In the author's opinion, personalization and customization can be used interchangeably. For example, a course designer may perform several customizations of a particular learning material to address the needs and preferences of different learners. Subsequently, the system will personalize (or suggest) the new learning material to a learner with the relevant needs and preferences. This means that personalization and customization may be dependent on each other, or in other words, personalization is the act of customization.

Customizing (personalizing) educational content is chiefly dependent on the various criteria related to the learner's characteristics, preferences and needs. Learners perceive, process, organize, analyze and understand information by different preferences. Paying attention to Learning Styles (LSs) gives opportunities to provide and implement interventions suited to personal demands (Truong, 2016). Learning preferences can also provide valuable advice to both learner and instructor (course author). For learners, knowing their LSs may help to build their self-confidence and self-efficacy, prevent misunderstanding with teachers, enhance study skills and increase the desire to participate in the learning process (Chen \& Chen, 2015; El-Hmoudova, 2015). For instructors, they will be able to introduce reports that enable them to develop their educational planning, understand the learner's learning process and create contents with different designs to match the learner's style (Graf, Kinshuk, \& Liu, 2009; Isik \& Kuzudisli, 2015). The LS domain has dozens of LS models that describe and identify an individual's learning preferences. Frank Coffield made a valuable criticism in (Coffield, Moseley, Hall, \& Ecclestone, 2004). This report identified 71 Learning Style Models (LSMs) and defined an LS family that contains approximately 53 models. Only 13 models concerning the theory of the model and the experimental studies of reliability, validity and pedagogical impact were evaluated in detail.

In the e-Learning domain, LSs can be employed to specify and describe the 
learner's needs and preferences related to a specific learning material. The learner's characteristics or preferences are a key aspect in the LO development context. The LSM is considered as a valuable resource of individual characteristics and preferences and it can also be exploited to enforce LO customization.

\subsubsection{Ontology and Customization (Personalization)}

The semantic web has become the future for the customization (personalization) process in the e-Learning environment (Huang, Liu, Tang, \& Lu, 2011). Several studies have been concerned with the use of semantic web technology, especially ontology, in the customized e-Learning environment (Jovanovic, GaLsevic, Knight, \& Richards, 2007; Begam \& Ganapathy, 2012; Valaski, Malucelli, \& Reinehr, 2011). In learning material creation applications, the use of ontology makes it possible to identify the context they are operating in and the reasons for those contexts. Ontology also supports the reuse of knowledge between authors and application, so that it is helpful for recommending contents to authors concerning the learner's characteristics and preferences.

Examples of frameworks that employ ontology which use LSM for the purpose of learning content creation are: (i) Protus, an adaptive and intelligent web-based Programming TUtoring System, which aims at guiding the learner's activities and recommending appropriate actions during the learning process. It applies the Felder-Silverman LSM to describe and identify the learner's LS (Vesin, Ivanović, Klašnja-Milićević, \& Budimac, 2011); (ii) ORLM, Ontology for Recommended Learning Materials, recommends learning materials according to the learner's LS (Valaski, Malucelli, \& Reinehr, 2011).

However, several limitations have been found in the use of LSMs in the learning materials development process, including the inability to support the instructor with the appropriate contents, relevant to the learner's preferences during the creation process. Another limitation is using a Single-LS model to identify and describe the learner's characteristics and preferences. 
Chapter 1.

Producing a customized learning object requires a deep understanding of the reuse and customizing requirements.

\subsubsection{Solution}

The Software Product Line Engineering (SPLE) approach can be used to manage the variability of LO (the common and variable features) in the development process. Identifying the LO's commonalities and variabilities lead to maximize the reuse. Our proposal aims to implement an LO product line conceptual framework for the development of personalized LOs supported by the Document Product Lines (DPL) method. The DPL framework for variable content document generation is based on the SPLE principles. The LO product line framework relies on two basic assumptions: first, to approach diversity by defining families of LOs according to Cisco's RIO (Reusable Information Object) model (Cisco_Systems, 2003; Barrit, Lewis, \& Wieseler, 1999), which shares some mandatory content and differs in the presence or absence of optional parts; and secondly, generates specific LOs (i.e., members of the family) by selecting the optional parts that are to be included (capturing commonalities and variabilities using Feature Models). During the development process the system recommends various LOs related to the learner's preferences and needs.

The goal pursued by this thesis is to study the different proposals and tools that have appeared to represent, create, and customize (or personalize) LOs in recent years, to analyze their strengths and limitations, and to propose, define, implement and exploit new ideas, in order to improve the existing approaches.

Merging DPL and LSM opens up a new approach to LO development which involves a change in the artifacts and customization processes that are used today: i.e. the LO product line (LOPL) approach and the Global Learning Style Model Ontology (GLSMO). This thesis will focus on the description and employment of LOPL and GLSMO in the development of learning materials (LOs) and how these approaches affect the reusability and customization in the LO domain. It also aims to put this proposal into practice by providing the necessary conceptual framework for creating and producing personalized (customized) LOs. 


\subsection{Objectives}

The educational e-Learning community has achieved significant advances by providing standards, specifications, content models, and applications for the development of learning materials-for instance, the Learning Object Metadata standards (IEEE-LTSC, 2002). However, there is a need to increase, on one hand, the reusability issue during the learning material development process by incorporating different criteria, such as the LO granularity level, metadata, specification and learner characteristics. On the other hand there is a need to increase customization (personalization) during the development process by exploiting the learner's characteristics, preferences, and needs. The objective of this thesis is to provide a conceptual framework to satisfy these needs. Specifically, this thesis aims to:

1. Define a conceptual framework for a Learning Object Product Line (LOPL) using DPL. The conceptual framework composes three different models: Content, Customization and Production.

2. Incorporate the learner's characteristics, preferences, and needs by integrating seven LSMs into a GLSMO.

3. Define a proposal of authoring environment by integrating the GLSMO and LOPL framework to increase flexibility, reusability, and customization during the learning material development process.

Several LO creation tools and various proposals related to LO personalization (using ontology) have been studied and introduced. Moreover, a case study is included of an LO development process (structure and components) based on the proposed methodology.

\subsection{Thesis Structure}

This thesis is structured as follows: in Part two, we introduce the different characteristics, definitions and standards on which the thesis is based. Chapter 2 summarizes the state of the art in several Reuse issues in e-Learning, defines exactly what an LO is, states its characteristics and metadata standards. Chapter 3 and 4 discuss LO reuse criteria and Customization of LOs in e-Learning, define the concept of Adaptive Educational Hypermedia Systems, analyze various LO tools and LO customization strategies, and carry out a comparative analysis to discover new ideas that can be used to improve our approach. 
Chapter 1.

Part three presents our proposal. Chapter 5 outlines the main models used to develop the LO product line approach, the LO content model, the LO customization model and the LO product line model.

Chapter 6 introduces the content model that will be used in the work, discusses the criteria behind the content model selection, and describes the Cisco RIO strategy in detail.

Chapter 7 deals with the importance of learner preferences and characteristics in the e-Learning customization process, gives details of LSMs and the importance of integrating different LSMs into a global model to maximize the customization of learning materials, selects and describes seven LSMs and introduces the criteria behind this selection, describes a well-known method used for ontology construction (On-To-Knowledge), and finally develops our GLSMO, based on two approaches.

Chapter 8 describes a product line-based LO development, gives a short description of SPLE, variability management and DPL, and explains our LO Product Line (LOPL) approach.

Chapter 9 describes the implementation of LOAT to support our method, the LOAT architecture, the LOAT conceptual framework for LO creation, and includes a case study on LO generation by the method proposed in this thesis.

Finally, Part four presents the conclusions and outlines future lines of research. 
PART TWo

BACKGROUND 

Learning objects reusability and customization are two major cornerstones in the e-Learning content development which aim to reduce the development time and to create personalized learning material related to specific learner's preferences and needs. Both reusability and customization have gained great relevance in the e-Learning community and have several points, standards and techniques.

This part of the thesis describes the foundations of these proposals, which provide the background to this thesis. First, chapter 2 introduces the basic concepts of LOs and its related characteristics and metadata standards. Second, chapter 3 describes reuse issues in e-Learning and several e-Learning authoring tools available to develop LOs. Finally, chapter 4 describes the customization concept in e-Learning related to Adaptive Hypermedia Systems, Learning Style Models and the use of ontologies in customization. 



\section{Chapter 2}

\section{LEARNING OBJECTS}

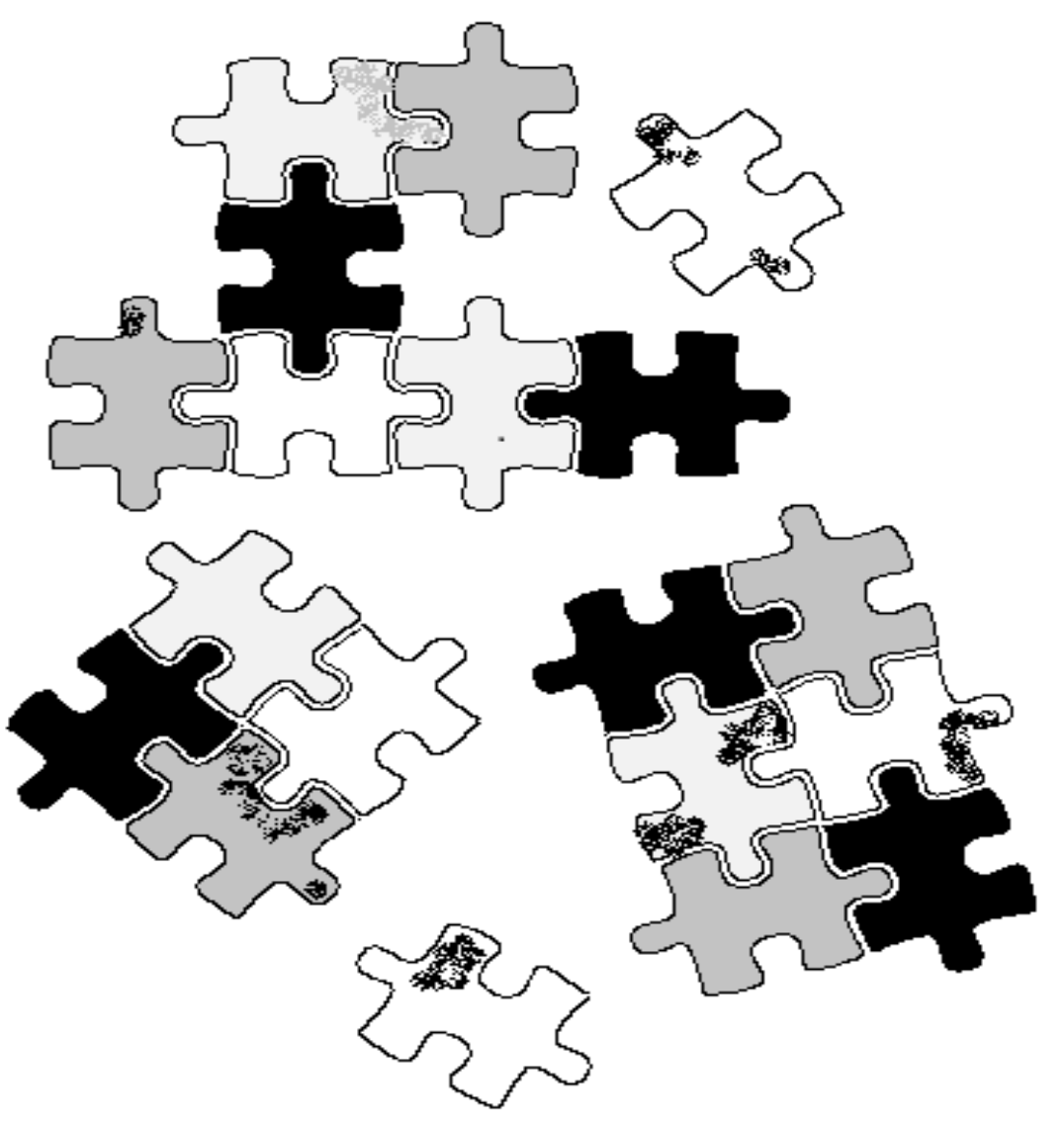


As in the traditional ADDIE instructional design model (Morrison, Ross, Kemp, \& Kalman, 2010), the Learning Object (LO) development process concerns developing all the resources, contents, and properties associated with each LO. Two primary goals in the LO development process should be considered. The first is the ability to Reuse existing learning materials (like LOs). Reuse depends on several factors, such as the nature of the content model and the tools used. The second goal is the ability to Customize or Personalize learning materials to meet the learner's preferences and needs.

LOs were designed and developed to minimize the cost of learning, standardize learning materials, meet the learner' needs and enable the (re)-use of learning content in the learning materials creation process. A successful LO-based authoring tool is leveraged by the LO development process, especially the ability for customization and reusability of LOs to create learning materials (Contents, Practices, Questions, Assessment, Guidelines, etc.). These learning materials are stored as a collection of LOs and each LO is tagged with relevant metadata which can be reused in any learning context or architecture. Metadata is a crucial for LO discovery in Reuse process.

Selecting the appropriate LO content model is an important issue related to the organizational goals. It also considers as a crucial key for instructional reuse, especially, when the LO (at different levels of granularity) have both a small size and is centered on a core or single learning concept. Most LO content models consider the granularity principle but with different facets. Moreover, using suitable LO content model also increases the learner's knowledge retention by offering an encapsulated chunk of information that he can absorb effectively and quickly.

Additionally, the way that LOs' features and characteristics are modeled is a crucial issue for improving the LOs development and reuse. In this context, one of the best known approaches used for variability modeling is the Feature Model (FM). This can be used for the purpose of variability management of LO's features. The feature model is used extensively in Software Product Lines (SPL), so the common and variable features of the LO can be managed using FM in SPLs to increase LO reuse. 
Finally, Ontology, one of the major cornerstones of semantic web technology, is a prominent topic in the IT field, where it provides explicit knowledge representations that make domain knowledge available to systems. In the learning materials creation domain, it is possible to exploit the ontology's ability to access implicit knowledge and introduce explicit information or components (re)-used for creating Customized Learning Materials (CLM).

In this Chapter, we give an overview of LOs definition, characteristics, and standards.

\subsection{What is an LO?}

The idea of LO has been a major point of many discussions and projects of public and private educational organizations, and until now there has been no general agreement as to what a LO is.

There are various definitions, and different synonyms are used for referring to "LOs," such as instructional objects, educational objects, intelligent objects, knowledge objects, instruction components, on-line learning materials, pedagogical document, educational software component, and resource (Gibbons, Nelson, \& Richards, 2002; Agostinho, Bennett, Lockyer, \& Harper, 2004).

Polsani reduces the previous definitions of the LO (that introduced in Chapter 1) to two main fundamental components: a digital format that helps in learning and an interface that contributes to assimilate what has to be learned appropriately. Then, he defined a LO as:

"an independent and self-standing unit of learning content that is predisposed to reuse in multiple instructional contexts." (Polsani, 2003).

Another definition by Sicilia and Garcia appears in (Sicilia \& Garcia, 2003). They added two constraints to Polsani's LO definition. The first is "Learning Objects are digital entities (i.e. digital files or streams)" and the second is that "Learning Objects have a related "metadata" which describes the possible contexts in which they may be used". These metadata contain information about authorship and technical and educational features of the LO. 
David Merrill defined LO as:

"a way to organize a data base (knowledge base) of content resources (text, audio, video, and graphics) so that a given instructional algorithm (predesigned instructional strategy) can be used to teach a variety of different contents.” (Merrill M. , 2002)

Finally, Rodríguez and Ayala defined LO as:

"an informative, digital and interactive entity created for the generation of knowledge, skills, attitudes and values, which can be adapted and reusable in different contexts." (Rodríguez \& Ayala, 2012).

Other definitions can be found in (Murphy, 2004; Gibbons, Nelson, \& Richards, 2002; Agostinho, Bennett, Lockyer, \& Harper, 2004; Ip, Morrison, \& Currie, 2001; Yang \& Yang, 2005).

For the purpose of our research, LOs are digital and self-contained learning materials that are pre-developed and can be used in different e-Learning systems. Additionally, the incorporation of metadata helps instructors and designers discover LOs to be (re)-used later. Also, LOs can be aggregated to form larger learning experiences.

\subsection{LO Characteristics}

Numerous characteristics of LOs have been discussed in the literature including "durability, interoperability, accessibility, reusability, extensibility, productivity and manageability" (Murphy, 2004). Ritzhaupt mentions that the main characteristics of LOs are: accessibility, reusability, interoperability, and adaptability (Ritzhaupt, 2010). Wiley (2000) points to LOs having the potential of reusability, granularity, interoperability and scalability.

There are several characteristics discussed in the literature that we will explain in detail:

1. Technology-Centered: First of all, regarding all LO definitions, LOs must be in a digital format. This makes them easy to create, store, and update. 
2. Accessibility: LOs can be described as digital entities that can be shared and distributed over the Web. So, the Accessibility attribute relates to the ability that LOs to be searchable, accessible, retrievable, and categorizable (Ritzhaupt, 2010).

3. Reusability: One of the most significant advantages of using LOs is that they can be used time after time. Once a LO is developed, it must exhibit flexibility in order to be reused in different instructional contexts, for multiple purposes, and in various applications. LOs must get the balance between being generic and personalized. Reusable, efficient and effective LOs must be able to model "generalization and personalization" to fit your needs (Zapata, V. H. Menendez, \& M. E. Prieto, 2009) (Stone \& Guangzhi, 2014).

4. Interoperability: A major key tenet of LOs is cross compatibility. Learning objects will not have any use or benefit if you cannot integrate them into various e-learning management systems. Interoperability allows you to use content developed by a person or an organization on a given platform in another organization on a different platform (Ritzhaupt, 2010). An interoperable LO enforces reusability and makes accessibility quick and convenient.

5. Adaptability: LOs should be able to be sequenced in a way that they can adapt to a learner's needs. Since not all learners are the same, LOs must be adaptable to suit the needs of learners with varying educational needs. LOs must be easy to adapt, update, and customize.

6. Granularity: LOs are defined as fine units or grains, which can be combined or added in several ways. That serves two main issues. The first is enforcing learning objects reusability. The second is increasing learner's knowledge retention by offering an encapsulated chunk of information that a learner can absorb effectively and quickly.

7. Durability: The retention of an integrity of the LO over time with regard to its content and its delivery mechanism.

8. Learning Objectives: A LO should have and support a specified learning objective/s. This characteristic helps instructors to be able to aggregate several LOs to form an e-learning course with specified learning objective/s. 
9. Metadata: LOs must be labeled with metadata that gives the ability to organize and curate the learning materials properly. Metadata gives the power to find online resources quickly during the design of a learning material or the learning process.

All the previous LO characteristics are used to facilitate re-utilization, distribution, and personalization of educational contents on the internet, where international standards play a great role in their extended use in multiple environments.

Furthermore, LOs give several benefits to actors (administrator, author or instructor, and learner) of the learning process; the following are some of the most important ones (Ritzhaupt, 2010):

a) For learners:

- Customization - courses can be created to adjust individual's needs.

- Learning comes in chunks and small bytes of learning.

- Just-in-time learning.

b) For administrators:

- Courses can be adapted to satisfy the requirements of different individuals.

- Courses can be built using reusable components from a wide range of sources.

- Reducing training duplication costs.

- The byte (small) size of LOs contributes to increasing learning effectiveness.

c) For instructors

- LOs can be created or updated using different authoring tools.

- Supporting multiple delivery formats - The same LOs can be delivered through several platforms.

- Ease of re-construction - LOs give an ability to reconstruct learning material with few or no editions and little effort.

Allowing searching for existing content - metadata associated with LOs allows the instructors to search for existing content. 


\subsection{LO Metadata Standards and Specifications}

During the past few years, some international efforts have been made to define specifications and standards which can facilitate reuse in learning technologies. The need for reusing materials in different platforms for types of students has caused the creation of standards allowing the documentation, search and distribution of educational contents that are generated. Among the most important standards are AICC (Aviation Industry CBT Committee), IMS $^{1}$ developed by the Global Learning Consortium Inc., Sharable Content Object Reference Model $\left(\mathrm{SCORM}^{2}\right)$ developed by Advanced Distributed Learning Initiative, and IEEE Learning Object Metadata $\left(\mathrm{LOM}^{3}\right)$ standard.

We will describe Dublin Core and LOM metadata standard for two reasons. The first is that Dublin Core and LOM metadata standards are widely used by many e-Learning organization and are considered as the basic reference for other specifications. The second reason is that our metadata profile in this thesis depends on both these standards.

\subsubsection{Dublin Core}

The Dublin Core Metadata Initiative $\left(\mathrm{DCMI}^{4}\right)$ is an organization dedicated to promoting the adoption of interoperable metadata standards, and develop metadata vocabularies. The Dublin Core metadata element set is a standard for cross-domain information resource description. The mission of DCMI is to make it easier to find resources using the Internet through the following activities:

1. Developing metadata standards for discovery across domains,

2. Defining frameworks for the interoperation of metadata sets,

3. Facilitating the development of community specific metadata sets that are consistent with 1 and 2.

\footnotetext{
${ }^{1}$ Instructional M anagement System project - www.imsglobal.org.

2 scorm.com

${ }^{3}$ https://standards.ieee.org/findstds/standard/1484.12.1-2002.html

${ }^{4}$ dublincore.org
} 
Chapter 2.

Table 2.1 describes fifteen metadata elements of the Dublin Core specification (The Dublin Core Metadata Element Set, 2001).

Table 2.1 Dublin Core Metadata Elements

\begin{tabular}{ll}
\hline Term Name & Definition \\
\hline Title & A name given to the resource. \\
\hline Creator & $\begin{array}{l}\text { An entity primarily responsible for making the content } \\
\text { of the resource. }\end{array}$ \\
\hline Subject & A topic of the content of the resource. \\
\hline Description & An account of the content of the resource. \\
\hline Publisher & An entity responsible for making the resource available. \\
\hline Contributor & $\begin{array}{l}\text { An entity responsible for making contributions to the } \\
\text { content of the resource. }\end{array}$ \\
\hline Date & A date of an event in the lifecycle of the resource. \\
\hline Type & The nature or genre of the content of the resource. \\
\hline Format & The physical or digital manifestation of the resource. \\
\hline Identifier & $\begin{array}{l}\text { An unambiguous reference to the resource within a } \\
\text { given context. }\end{array}$ \\
\hline Source & $\begin{array}{l}\text { A reference to a resource from which the present re- } \\
\text { source is derived. }\end{array}$ \\
\hline Language & A language of the intellectual content of the resource. \\
\hline Coverage & A reference to a related resource. \\
\hline The extent or scope of the content of the resource. \\
Information about rights held in and over the resource.
\end{tabular}

Additionally, The Dublin Core Metadata Initiative provides access to schemas defining DCMI term declarations represented in various languages such as XML and RDF. 


\subsubsection{IEEE LOM}

The Institute of Electrical and Electronics Engineers (IEEE) is an international organization that develops technical standards and recommendations in industrial fields ranging from computer engineering, telecommunications, and biomedical technology, to electric power, consumer electronics and aerospace engineering, among others. IEEE Learning Technology Standards Committee (LTSC) developed the homonymous standard for learning material (LTSC, 2000). The standard specifies the syntax and semantics of LOM, defined as the attributes required to describe a $\mathrm{LO}$ adequately.

The most commonly recognized IEEE LTSC specification is the LOM specification, which describes learning resources. The IEEE LOM standard is an extension of the Dublin Core, and was approved in 2002 (IEEE-LTSC, 2002). Both IMS and ADL SCORM use the LOM elements and structures in their specifications.

LOM has a hierarchy of elements with nine main categories of metadata. Each category has subcategories, making this standard a complex hierarchy of more than 60 different element definitions.

According to the IEEE LOM standard, a metadata instance for a learning object describes relevant characteristics of the learning object to which it applies. Such characteristics may be grouped into categories as described in Table 2.2 (IEEE-LTSC, 2002).

All the LOM categories and subcategories shown in Figure 2.1, and the full list is available in (IEEE-LTSC, 2002). 
Chapter 2.

Table 2.2 LOM Metadata Categories

Category Description

General General information that describes the learning object as a whole.

Lifecycle $\quad$ Features related to the history and current state of this learning object and those who have affected this learning object during its evolution.

Meta-Metadata Information about the metadata instance itself (rather than the learning object that the metadata instance describes).

Technical Technical requirements and technical characteristics of the learning object.

Educational Educational and pedagogic characteristics of the learning object.

Rights The intellectual property rights and conditions of use for the learning object.

Relation Features that define the relationship between the learning object and other related learning objects.

Annotation Comments on the educational use of the learning object and provides information on when and by whom the comments were created.

Classification Describing the relation of the learning object to a particular classification system. 


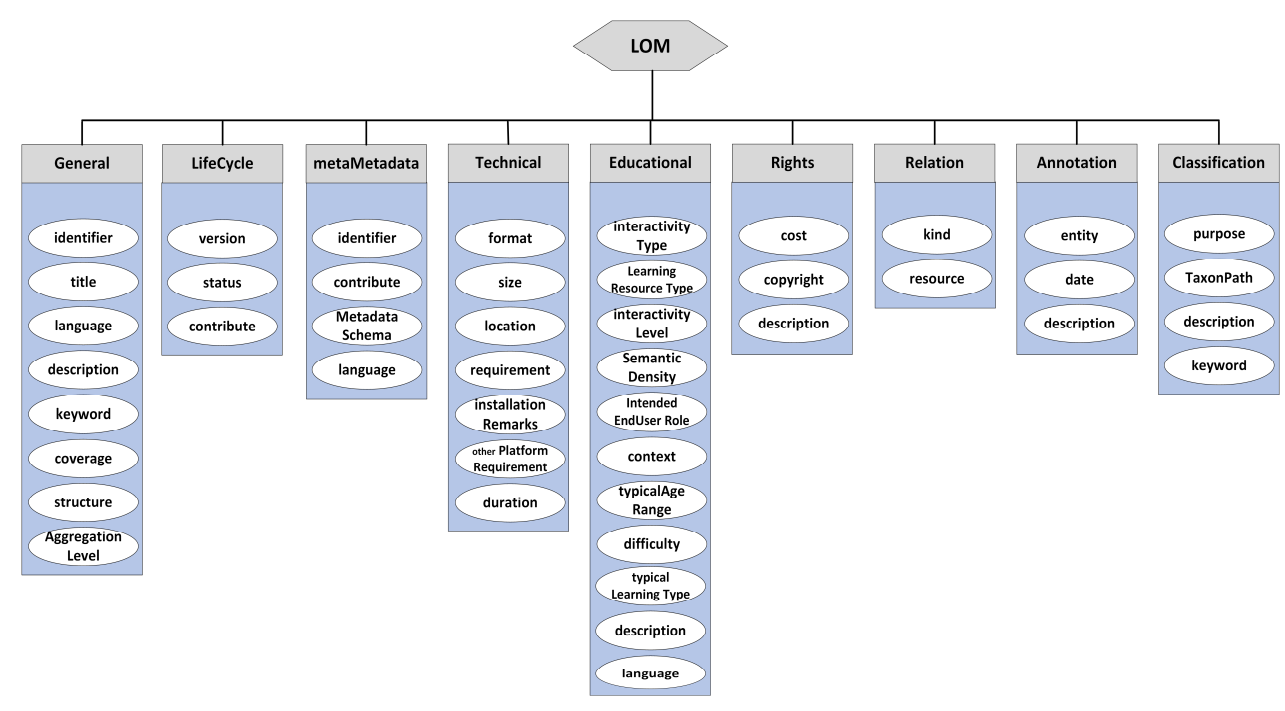

Figure 2.1 LOM categories and subcategories

\subsection{Conclusion}

This chapter has presented a brief overview about the most important concepts of LOs to facilitate the comprehension of the remaining chapters of this thesis. Several aspects of LOs have been discussed such as LOs definitions, characteristics and specifications. 



\section{Chapter 3}

\section{REUSE IN e-LEARNING}

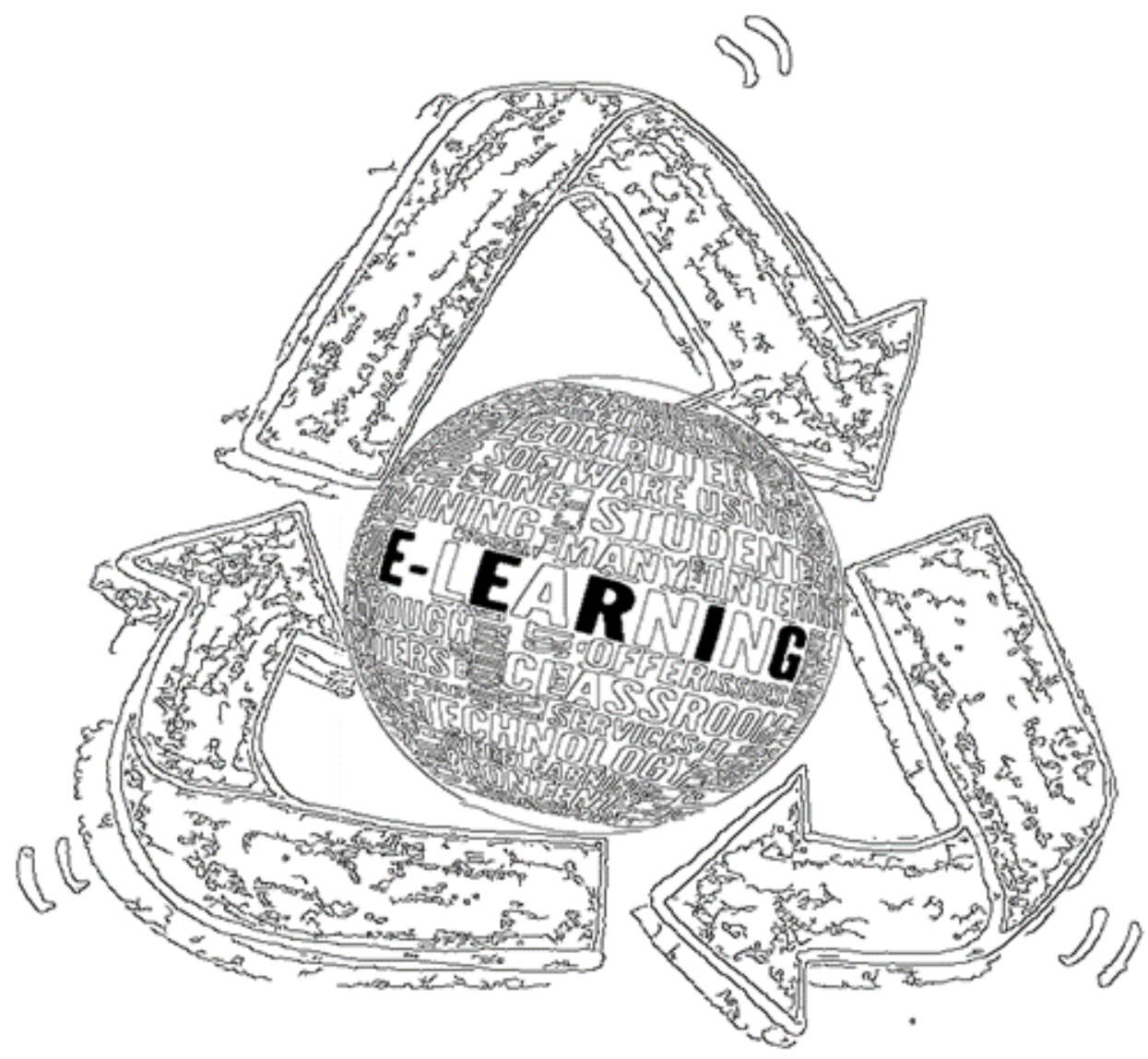




\section{Chapter 3.}

In this chapter, we will discuss in detail the three points which are considered to play key roles in reusability in e-Learning domain and present some examples of authoring applications that used for LOs creation.

\subsection{LO content model}

Based on the administration goals, the LO content model would be identified. So, a major key for deciding the suitability of LO content model is the granularity levels of the LO. In (Nicol, 2004), Duncan referred to granularity as "the size of learning objects" and an important condition for any LO to be shared and reused. Other studies point to LO's granularity and to how LO should be independent (stand-alone) and centralized about a single concept rather than its size consideration (Hamel \& Ryan-Jones, 2002).

Making LOs as small as possible, independent learning pieces, and based upon a core concept (to be learned) allows course authors to easily reuse them without change, or with small changes. In this way, LOs can be combined in various ways in several learning materials (to support course creators' instructional goals) and with different learning tools (Thompson \& Yonekura, 2005).

Certainly, several learning applications (such as authoring tools) considering various LO content models with several granularity levels such as courses, lessons, and modules as LOs. But from an instructional developer's perspective, it may be useful to use a top-down approach in designing learning materials. For example, when designing a course, it is good to move from a high level of granularity down to the conceptual level, but not so far down as the components level. LOs have the greatest potential for reuse when they are based upon a single concept.

\subsection{Metadata}

The LO content model comes with two important points. The first one is that LOs must be provided with several types of metadata to retain high discoverability that enables course creators, instructors, and learners to find, use, and reuse LOs. The second one is that learning materials are composed of a vast number of LOs that must be managed and stored efficiently. 
Most learning materials authoring applications use metadata as a key concept in LO management and discoverability. Each LO is tagged with relevant metadata so that it can be found then (re)-used. The metadata provides descriptive information about the LO and is used for finding or understanding it. Also, it provides administrative information ((Technical, Rights, etc.) needed to manage the LO. Moreover, it provides instructional information that refers to how we use LOs for learning.

As mentioned in Section 2.3, various organizations have defined metadata specifications and standards to facilitate discoverability of LOs. Nonetheless, these standards have failed to addresses several points, such as the educational instructional factors and individual learner differences (LSs), which have a great impact on the reusability, customization issues.

To cover these limitations, it may be a challenge for a LO development methodology to define the metadata profile that meets the objectives of instructors and learners. The metadata should be valuable to meet your needs and requirements, but not burdensome for your instructors or authors to input. Realizing this balance may be critical, because some of the tools that are used in an LO development may not hold all the metadata that the instructor or author wants to include.

\subsection{LO Variability Representation and specification}

To create learning materials from RLOs, firstly, the LOs must be specified and represented. Specification is considered an important part of the development and reuse of LOs. The Feature Model (FM) is a well-known approach used for conceptual modeling and variability management. We propose the use of FM in the specification LOs to control their variability. When reused, such LOs may be combined in different ways to provide high variability of the learning materials.

Variability has a great impact on LO domain, because technology enables us to develop the learning materials in a variety of types, and also the LO domain has several content models (with several variability features) to represent it. 
Chapter 3.

Based on the LO content model which will be used, the LO has several variability points which are managed by FM and FM is also used as a domainindependent high-level specification for LO reuse. The specification, using FM, is a means to represent and model LOs, provides the necessary information for authoring tools to define the LO family and produce LO instances. It is useful to combine the FM specification in the LO domain with a software engineering technique such as SPLE. In this way, the LOs can be developed using FM and SPLE to increase LO Reusability.

\section{4 e-Learning Authoring Applications}

e-Learning authoring applications are software applications used to develop e-Learning materials. Generally, authoring applications have the capabilities to build, modify, and configure e-Learning materials. Some of these applications use the reusable LO to produce learning materials in an efficient way. The primary purpose for any authoring applications is to facilitate the creation process to any kind of user without any technical abilities. In this Section, we will introduce several authoring applications.

\subsubsection{CED AR course editor}

The CEDAR course editor tool allows developers to create, store, use and reuse E-Learning Objects (ELOs) and assemble courses from them (Muzio, Heins, \& R. Mundell, 2002). It is a template-based tool. An ELO, in CEDAR, is identified as a small piece of text, audio, video, interactive component, etc. that is labeled with metadata and stored in a database. Each ELO is labeled with a user-defined key word. No specific metadata standard is used. CEDAR specifies two types of ELO libraries, personal and shared, and the ELO creator has the option to decide whether or not the ELO can be shared with others. Consequently, ELO developers can search the shared ELO library for reusing. The granularity issue in CEDAR concerns only the size, as ELOs are made as small as possible. The defined granularity levels are ELO, topic, unit, and course. CEDAR follows Bloom's taxonomy (Bloom, Englehart, Furst, Hill, \& Krathwell, 1956) as an instructional design methodology for assembling courses. After defining the course in the system, the course developer must specify the learning outcomes at both the course and unit levels. 


\subsubsection{DLNET - LO D evelopment Tool}

DLNET is a user-centric and metadata-centric LO development tool (Mahadevan, 2002). In this tool, the LO creation process relies on three steps: Metadata Collection, Resource Validation, and Packaging. In the Metadata step, the tool collects, processes, stores, and conveys the information about the LO. The IMS standard is used as the metadata standard to implement with the LO development tool. The collected metadata can be packaged and conveyed using an XML file. After metadata collection, the validation step begins. The tool accepts two types of contents: web (html) and non-web. For the web contents, the validation ensures that all contents are located in their predefined resource locator tags, then the validated resources will be collected for packaging. For non-web content, the validation ensures the presence of the file with the resource folder. Finally, the Packaging step bundles the metadata and contents. The IMS content packaging standard was adopted to package the metadata and resource in a learning module.

\subsubsection{The LO Creator}

The LO Creator is an open source learning object authoring tool (Koohang, Floyd, \& Stewart, 2011). There are two main ideas behind this tool. The first is simplicity in designing LOs, which means encouraging the LO designer to insert suitable user interface elements in the design. The second is a free style pedagogical design environment, which gives designers the flexibility to design LOs using learning principles and theories suitable for chosen learners. The LO is composed of one or more slides, so the creator needs to build his/her own LO from predefined slides. These LOs and slides may be shared by all users, with administrative permission, for the purpose of reuse. This tool allows LO creators to build their LOs however they want and according to their audience.

\subsubsection{The LOC Tool}

The LOC (Learning Object Creator) tool, developed at the University of Southampton, is an authoring tool containing an embedded pedagogic template guiding development of effective learning materials (Watson, Dickens, 
Chapter 3.

\& Gilchrist, 2008). The LOs created by the LOC tool have several properties such as; self-contained, consistently styled and sized, focus on a learning point, combine "pedagogic assets" (text, audio/ video links, web links, images, etc.). An activity-based approach is used, joining multi-media assets and pointing to engage the learner in a "learning by doing" type of interaction and active reflection, as they also listen, view, read or write. The LO is associated with a feedback form which helps teachers to enhance the activities.

\subsubsection{ViSH Editor}

The ViSH Editor is an open source web-based e-Learning authoring tool that aims to ease the creation of multi-device LOs (Gordillo, Barra, \& Quemada, 2014; Gordillo, Barra, \& Quemada, 2015). ViSH specifies a special LO model which is quite similar to the LOM standard (IEEE-LTSC, 2002). The ViSH's LO model consists of four granularity levels: atomic level, Slide (or LO) level, Slides level (collection of LOs), and the Interactive Presentation LO level. The tool employs LOM metadata standards for describing LOs. In the LO creation process, authors can insert several types of resources (images, videos, documents, etc.) via their URL. LOs are provided as HTML5 applications and can be exported to SCORM.

\subsubsection{Wandering}

Wandering is a web-based platform for the creation of location-based interactive learning objects (LILOs) (Barak \& Ziv, 2013). Wandering can be used via mobile devices and allows students to create their own LILOs. The tool allows users to search for LILOs created by other users. The Search option enables users to find LILOs by keywords and by their type (Knowledge or Experience). Each LILO is comprised of five parts: Info, Arrival, Action, Tagging, and Characterizing. All LILOs are automatically tagged with the user's information (name, date of birth, address, and interests).

\subsubsection{TANGRAM}

TANGRAM is an integrated learning environment for the domain of Intelligent Information Systems (Jovanovic, GaLsevic, Knight, \& Richards, 2007; 
Jovanović, GaLsević, \& Devedžić, 2006). TANGRAM is a Web application built on top of a repository of educational content and designed to be useful for both content authors and learners concerned in the domain of Intelligent Information Systems. The tool relies on an ontology-based approach for automatic assembly of LOs into personalized learning content. The resulting learning content is personalized according to the user's domain knowledge, preferences, and LS. The tool employs four ontologies: a content structure ontology, the Intelligent Information Systems course Domain ontology, the learning paths ontology, and the user model ontology. The LO granularity level in TANGRAM is based on the Abstract Learning Object Content Model (ALOCoM) (Verbert, Klerkx, Meire, Najjar, \& Duval, 2004). The content unit (LO) in TANGRAM defines a metadata profile to annotate its content units (or LOs). The profile defines a group of elements from the IEEE LOM Metadata Standard. The LOs are disseminated only in the application and no option for exporting is available.

Currently, there are dozens of authoring tools (commercial and open source) available on the web. These tools focus primarily on providing users with the technical means to create learning content (pdf files, packages, web pages, etc.) containing different types of interactive tasks, and little else. For examples:

- eXe - The eXe project is an Open Source authoring application for creating Web educational content (eXe, 2017).

- Xerte - Xerte is an Open Source server-based suite of tools that is "aimed at developers of interactive content who will create sophisticated content with some scripting." (Xerte, 2017)

Our aim is to embed some of the instructional template and learner's activities and preference guidance in the LO development process as well as to develop an authoring tool that is relatively easy to use for instructors and course designers. Thus, the users are instructionally guided and have the ability for customizing through the process of LO development. 
Chapter 3.

\subsubsection{Discussion}

In the author's opinion, there are several criteria to be considered by users when developing learning materials by using authoring applications. Table 3.1 shows a comparison of the authoring applications that were introduced in the previous section, based on the following issues:

- The Metadata standard (M)

- The Instructional Method used to create learning material (IM)

- The Customization and Personalization of learning material (C\&P)

- The learner's Preferences and Needs $(\mathrm{P} \& \mathrm{~N})$

- Employing learner's LS in the development process (LS)

- The use of Semantic Technology (ST)

- Recommending learning materials for customization reusability (R)

Table 3.1 A comparison of the authoring applications

\begin{tabular}{lccccccc}
\hline & M & IM & C\&P & P\&N & LS & ST & R \\
\hline CEDAR & $x$ & $\checkmark$ & $x$ & $x$ & $x$ & $x$ & $x$ \\
\hline DLNET & $\checkmark$ & $x$ & $x$ & $x$ & $x$ & $x$ & $x$ \\
\hline LO Creator & $x$ & $x$ & $\checkmark$ & $x$ & $x$ & $x$ & $x$ \\
\hline LOC Tool & $x$ & $\checkmark$ & $x$ & $x$ & $x$ & $x$ & $x$ \\
\hline Wandering & $x$ & $\checkmark$ & $x$ & $x$ & $x$ & $x$ & $x$ \\
\hline TANGRAM & $\checkmark$ & $x$ & $\checkmark$ & $\checkmark$ & $x$ & $\checkmark$ & $x$ \\
\hline
\end{tabular}

As shown in Table 3.1, an official Metadata standard is limited to three applications: DLNET, ViSH, and TANGRAM. Applying instructional methods to create learning materials is employed in CEDAR, LOC Tool, and TANGRAM. Users can easily customize their learning materials in LO Creator and TANGRAM. The representation of the learner's preferences, needs, 
and LS is available in TANGRAM but there is no information on how to use it in the customization and personalization of learning materials

The employment of learner's LS remains an open issue in the LO development process. Recommending learning materials based on the learner's preferences and LS during the LO's development process is also a challenge that enforces the reusability of LOs.

\subsection{Conclusion}

This chapter has introduced several reuse issues in the e-Learning domain. An overview of LO content model has been presented. The role of LOs variability representation has been discussed. Finally, various LO authoring applications have been investigated. 



\section{Chapter 4}

CUSTOMIZATION IN e-LEARNING

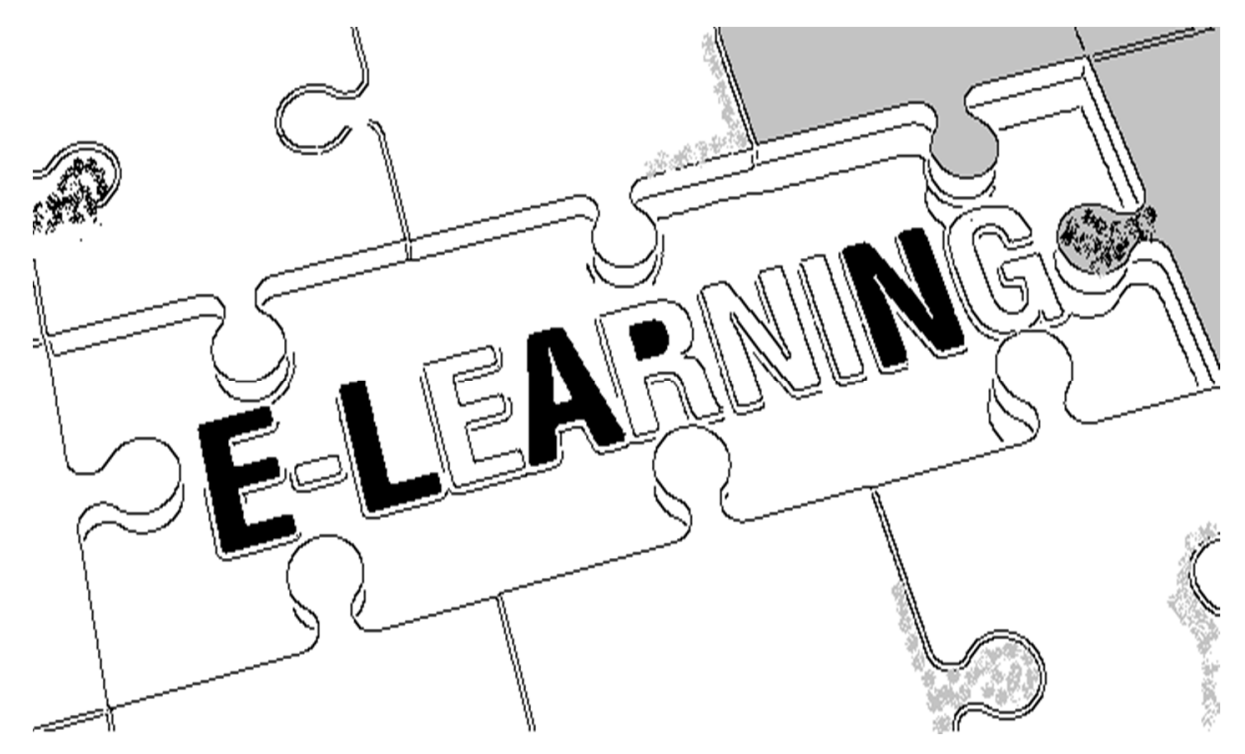


Chapter 4.

\subsection{Adaptive Hypermedia Systems}

Individual differences of learners affect in some way their degree of assimilation of the educational process. Therefore, developing personalized instructional intervention to accommodate learner differences has received great attention. In the early 1990s, a number of researchers begun to explore several ways to personalize the output and the function of hypertext systems to suit the user's preferences (Brusilovsky, 2001). After 1996, thanks to the rapid increase in the use of the Web and the accumulation of research experience in that area, the term Adaptive Hypermedia strongly appeared and a large number of researchers have started to work in this field (Brusilovsky \& De Bra, 1998).

Adaptability and adaptivity are important terms used in the learning systems. Adaptable systems allow learners to modify system environment through certain parameters that related to his/her individual preferences and needs. On the other hand, adaptive systems can be described as systems that automatically adapted to the learners based on the system's information and assumptions about learner's preferences and needs (Oppermann, Rashev, \& Kinshuk, 1997; Burgos, Tattersall, \& Koper, 2007). Learner adaptability and adaptivity in educational systems covered now under the term "personalization".

Adaptive Hypermedia Systems (AHS) provide users with contents and links that related to their preferences and characteristics (BERLANGA \& GARCÍA-PEÑALVO, 2008). Undoubtedly, applying of AHS in the educational domain has added many benefits in the educational process. Adaptive Educational Hypermedia Systems (AEHS), are educational applications that apply AHSs, attempt to improve students comprehension through the learning process by providing them with instructions and contents tailored to their characteristics and preferences (BERLANGA \& GARCÍA-PEÑALVO, 2008). AEHSs reflect learner characteristics, located in the learner model, and apply them to adapt almost educational aspects of the system accordingly (Brusilovsky, 1996). These aspects can be content or navigation assistance (Brusilovsky, 2001). Moreover, AEHSs provide learners with links for several resources and allow them for use these external resources.

62 
The educational systems were learner's individual differences and needs are taken into consideration provide learners with what they need (Brusilovsky, 2001). The crucial point in designing AEHSs is planning adaptation based on which learner's characteristics and needs are to be used and how they are to be used between several factors (i.e. cognitive styles, intellectual ability, learning styles, etc.). One of the most important parameters to be used in AEHSs is Learning Styles (LSs) (Graf, Liu, Kinshuk, Chen, \& Yang, 2009; Özyurt \& Özyurt, 2015). Based on several studies, LSs have had positive influence on the learner's attitudes toward courses and learner's academic achievement in educational systems (Mutlu, 2006; Bozkurt \& Aydoğdu, 2009; Kraus, Reed, \& Fitzgerald, 2001; Popescu, 2010; Shaw, 2012; Özyurt, Özyurt, Güven, \& Baki, 2014; Own, 2006).

There are numerous of research studies claiming that adaptive learning systems based on LSs increase the learner satisfaction level, improve the academic achievement and enhance productivity (Sangineto, Capuano, Gaeta, \& Micarelli, 2008; Graf, Liu, \& Kinshuk, 2010; Popescu, 2010; Tseng, Chu, Hwang, \& Tsai, 2008; Wang F. H., 2008).

According to (Özyurt \& Özyurt, 2015), several Learning Style Models (LSMs) employed in different studies related to AEHS in the interval from 2005 and 2014. For instance, Felder-Silverman LSM was employed in 29 research studies and Kolb LSM was applied in 10 studies and. In addition, Myers-Briggs Type Indicator, Gregorc and Honey \& Mumford LSMs are used in different AEHSs.

\subsection{Learning Style Models (LSMs)}

\subsubsection{Kolb's Experiential Learning Theory and LSM}

David A. Kolb is a professor of organizational behavior at the Weatherhead School of Management, Case Western Reserve University. In 1970, building on the work of Dewey, Lewin, and Piaget (Piaget, 1999), Kolb developed the Experiential Learning Theory (ELT). Kolb defined learning as "the process whereby knowledge is created through the transformation of experience. 


\section{Chapter 4.}

Knowledge results from the combination of grasping and transforming experience" (Kolb \& Kolb, 2005; Kolb \& Kolb, 2006). ELT provides a comprehensive model of the learning process and a multi-linear model of adult development. For Kolb, the experiential learning has six features (Kolb \& Kolb, 2005):

1- Learning is best conceived as a process, not in terms of outcomes.

2- Learning is a continuous process grounded in experience.

3- Learning requires the resolution of conflicts between dialectically opposed modes of adaptation to the world.

4- Learning is a holistic process of adaptation to the world.

5- Learning involves transactions between the person and the environment.

6- Learning is the process of creating knowledge.

Kolb developed a four-stage learning cycle model that describes the experiential learning process. The four-stage learning cycle model consists of two modes, Grasping Experience and Transforming Experience. The former has two dialectical stages: Concrete Experience and Abstract Conceptualization, the latter also has two dialectically stages: Reflective Observation and Active Experimentation. The four stages follow each other in a cycle (see Figure 4.1). The learner can enter the cycle at any point, but the stages should be sequenced.

The ELT model makes the learner continuously decide on the set of learning experiences he or she will apply in a particular learning situation. In grasping experience, the learner grasps new information through experiencing the physical qualities of the world, counting on his or her senses and putting himself or herself in a real situation. In abstract conceptualization, the learner grasps new information through analyzing, thinking, or symbolic representation rather than using his or her sense. Similarly, in transforming experience, some learners tend to carefully observe others who are participating in the situation and reflect on what happens (reflective observation). Other learners prefer to start immediately doing things (active experimentation). The characteristics associated to each dimension/pole are listed in Appendix A1. 


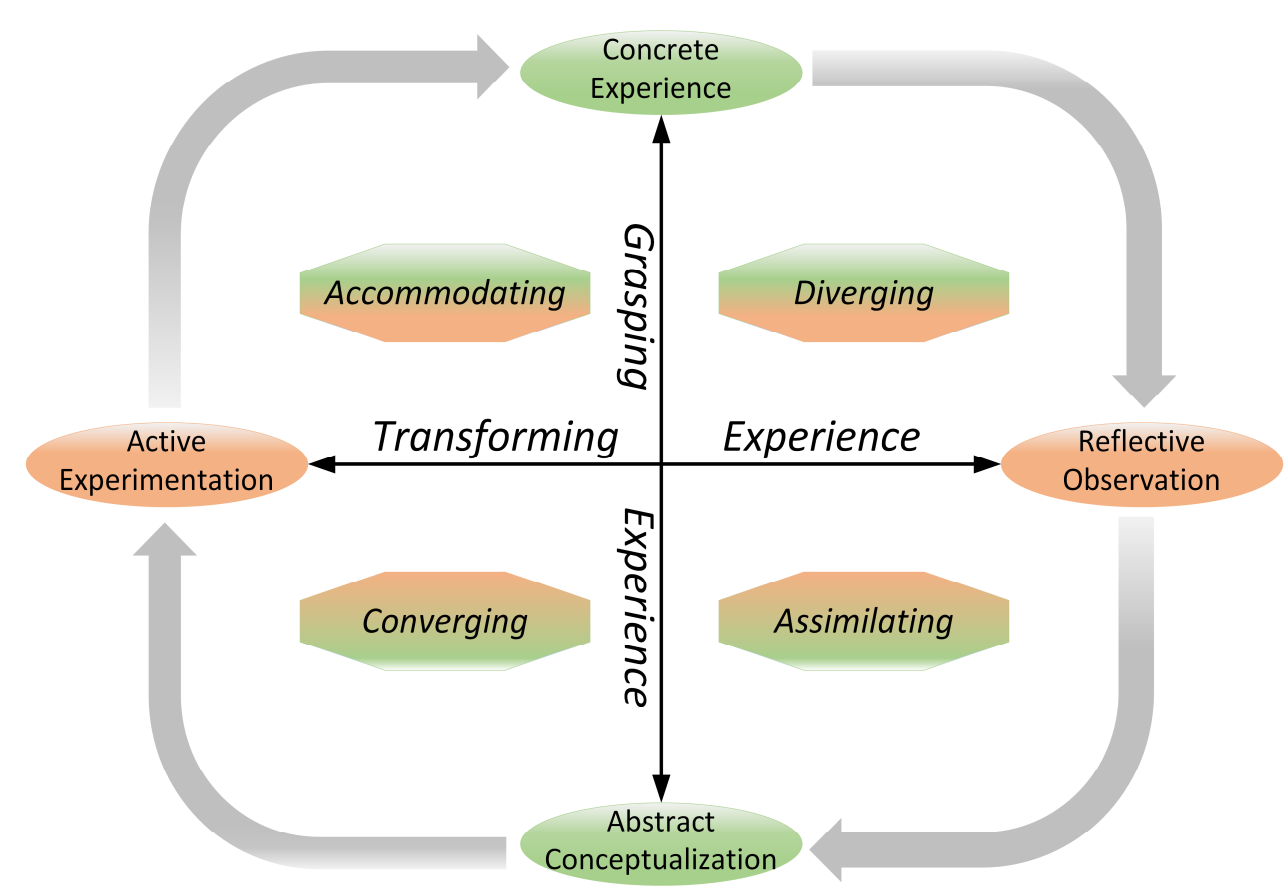

Figure 4.1 The Kolb's four stages and learning styles

In 1971, Kolb developed an original computerized tool to assess and recognize personal LSs (preferences) uniqueness and variability. He called it the Learning Styles Inventory (LSI). Four LSs are identified according to the analysis of the different score patterns from the LSI and previous research. These LSs are related to various approaches to learning.

Kolb believed that anybody learns better when the material is created and presented in an appropriate way with their preferred LS. Some persons may use different LSs in different situations, but most persons tend to prefer one style over the others. Each LS, defined by Kolb, is formed by combining two different modes, one for grasping and the other for transforming experience, as follows:

1. Diverging. The dominant diverging learning preferences are Concrete Experience and Reflective Observation. A person with a Diverging LS performs better in situations that need the generation of ideas, such as brainstorming. They tend to be imaginative, emotional, and like to 
collect vast amounts of information. They have broad cultural interests and the ability to view concrete situations from many different perspectives. Divergers are excellent at working in groups, helping others, listening with an open mind to different points of view and receiving personalized feedback.

2. Assimilating. A person with an assimilating LS has Abstract Conceptualization and Reflective Observation as dominant learning preferences. Assimilators have the ability to understand the global view of information and put it in a logical form. Persons with an Assimilating style are more interested in ideas and abstract concepts and less focused on people. They are more interested in theory that has logical soundness than practical value. They are also able to create theoretical models and like exploring analytical models, reading and lectures.

3. Converging. A person with a Converging LS has Abstract Conceptualization and Active Experimentation as dominant learning preferences. Convergers have the ability to solve problem and then make the decision based on finding solutions to problems. Persons with a Converging LS are more interested in finding practical values than ideas and theories. They prefer to deal with applications, technical tasks and problems rather than social issues. They prefer to experiment with new ideas, simulations, and practical applications.

Accommodating. The accommodators' dominant learning preferences are Concrete Experience and Active Experimentation. A person with an Accommodating LS has the ability to learn through doing, feeling and "hands-on" experience. Accommodators enjoy being involved in new and challenging experiences and implementing plans. They tend to depend on their feelings rather than logical analysis. They also rely on other people to collect information rather than their own analysis. Accommodators are excellent at working with others to get things done.

\subsubsection{The Myer-Briggs Type Indicator Theory}

On the basis of Jung's personality type theory (Jung, 1990), Isabel Briggs Myers and her mother Katherine Cook Briggs developed the Myer-Briggs 
Type Indicator (MBTI) theory and instrument. In 1975, the Center for Applications of Psychological Type (CAPT ${ }^{5}$ ) was co-founded by Isabel Myers and Mary McCaulley, Ph.D. This is a nonprofit organization that supports research on the MBTI instrument (www.myersbriggs.org). According to the CAPT, the MBTI is a validated assessment tool used by over 1.5 million individuals a year to determine personality preference.

The MBTI theory has four personality dichotomies that refer to the individual's personality types or preferences (Myers, McCaulley, Quenk, \& Hammer, 1998), see Figure 4.2. These four dichotomies represent the core functions our personalities perform throughout our lives (gathering information, making decisions, lifestyle attitude, and acquiring energy). Each personality dichotomy has two opposing poles, and each individual tends towards one of these poles in each dichotomy.

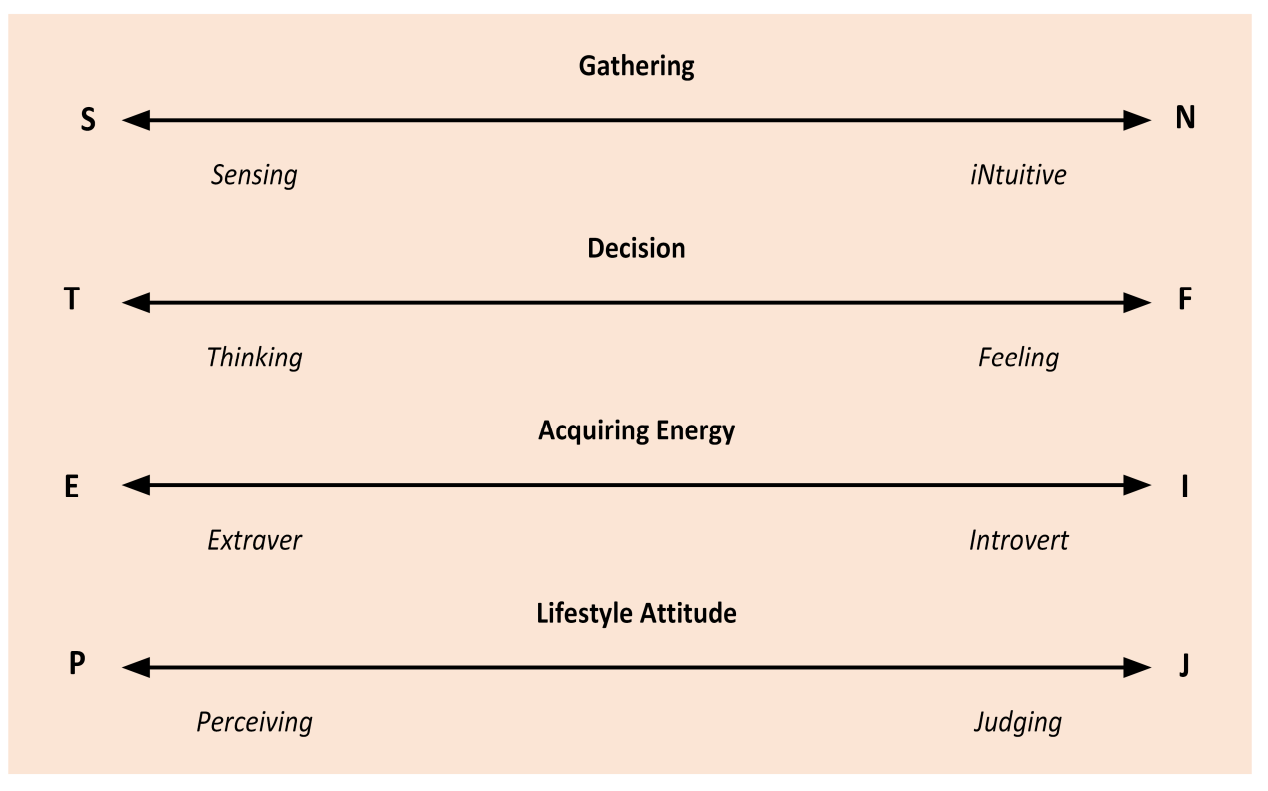

Figure 4.2 MBTI personality dichotomies

${ }^{5}$ https://www.cpp.com/Products/mbti/mbti_info.aspx 


\section{Chapter 4.}

The first dichotomy (Sensing/Intuitive) focuses on how individuals perceive and gather information. People with a Sensing (S) personality function prefer to grasp and receive information literally. They prefer to use their five senses to gather information. On the other hand, people with an Intuitive $(\mathrm{N})$ trait prefer to translate information into possibilities and associations; they prefer to comprehend the global view and ignore the details (Quenk, 2009).

The second dichotomy (Thinking/Feeling) describes how individuals come to decisions and make judgments. People with a Thinking $(\mathrm{T})$ personality function prefer to use analytical logic to come to a decision. They prefer to keep their emotions away from their judgment until after making a decision. People with a Feeling $(\mathrm{F})$ personality function prefer to come to a decision according to the personal impact. They are concerned about the personal impact of the decision on the people around them instead of using logical thinking in making the decision (Quenk, 2009).

The third dichotomy (Extravert/Introvert) explains how an individual acquires energy. People with an Extravert (E) personality prefer to acquire energy through the outside world of people, things, and actions. However, people with an Introvert (I) personality prefer to receive energy through reflection, introspection, and isolation (Quenk, 2009).

The last dichotomy (Perceiving/Judging) determines an individuals' attitude to the outside world (individual lifestyle). People with a Perceiving (P) personality prefer to continue collecting information instead of coming to a decision. They enjoy spontaneity and flexibility in their lives. In contrast, the dominant attitude for Judging (J) people is their decision making. They prefer to work with a set plan (Quenk, 2009). The characteristics associated to each dichotomy/pole are listed in Appendix A1.

The MBTI instrument identifies an individual's preference for each of the four dichotomies to determine the individual's personality type. Because each person has four personality preferences, sixteen unique personality types are generated. Table 4.1 represents a summarized view of the individual personality type codes. 
Table 4.1 The MBTI's personality type codes

\begin{tabular}{llccccc}
\hline & & \multicolumn{2}{c}{ Sensing } & \multicolumn{2}{c}{ iNtuitive } \\
\cline { 3 - 7 } & & & Thinking & Feeling & Thinking & Feeling \\
\cline { 3 - 7 } & & & ST & SF & NT & NF \\
\hline \hline Introvert & Judging & I $-\mathrm{J}$ & ISTJ & ISFJ & INTJ & INFJ \\
\hline Introvert & Perceiving & I $-\mathrm{P}$ & ISTP & ISFP & INTP & INFP \\
\hline Extravert & Perceiving & E - P & ESTP & ESFP & ENTP & ENFP \\
\hline Extravert & Judging & E - J & ESTJ & ESFJ & ENTJ & ENFJ \\
& & & & & & \\
\hline
\end{tabular}

\subsubsection{The Riding Cognitive Style Model}

Richard Riding is director of the Assessment Research Unit at the University of Birmingham. He has extensively researched cognitive style, learning design and personality. He markets the Cognitive Styles Analysis (CSA) instrument privately through learning and training technology.

Frequently, the cognitive style is included under the term 'LS' (Sadler-Smith \& Riding, 1999) but as a construct, it is more widespread, stable and deeprooted than LS. The cognitive style may be defined as 'the way the individual person thinks' and as 'an individual's preferred and habitual approach to organizing and representing information.' (Riding \& Rayner, 1998).

The Riding cognitive style model and the Cognitive Style Analysis instrument were designed as a cognitive-dimensional model (Riding R. , 1991). The model has two independent cognitive-dimensions, one relating to cognitive organization (Wholist-Analytical) and one relating to mental representation (Verbal-Imagery) (see Figure 4.3). 


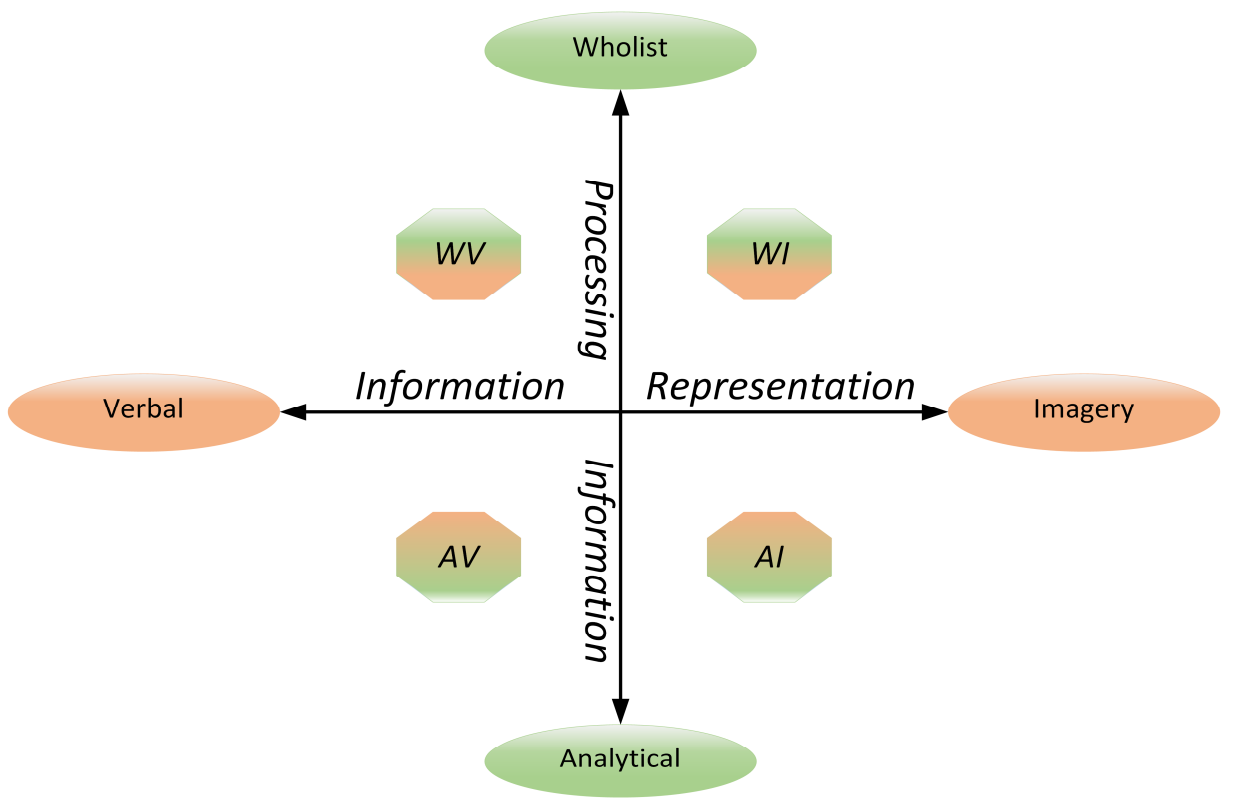

Figure 4.3 The Riding's dimensions and learning styles

The wholist-analytical dimension of cognitive style is derived from the work of Witkin on field dependence and field independence (Witkin, Moore, Goodenough, \& Cox, 1977) and describes personal habitual ways of organizing and processing information. Wholist people can perceive and process information globally, while Analytical people can organize and process information into a number of small parts (Riding R. , 1991). On the other hand, the Verbal/Imagery dimension of cognitive style, dependent on the work of Paivio's dual coding theory (Paivio, 2006), describes the personal habitual mode of the mental representation of information. Verbal persons "consider the information they read, see or listen to, in words or verbal associations", whereas imagery persons prefer to consider information, experience "fluent spontaneous and frequent pictorial mental pictures" (Riding R. , 1991).

On one hand, the wholist-analytical dimension of cognitive style is derived from the work of Witkin on field dependence and field independence (Witkin, Moore, Goodenough, \& Cox, 1977) and describes people's habitual way of organizing and processing information. Wholist people can perceive and process information globally, while Analytical people can organize and process 
information into a number of small parts (Riding R., 1991). On the other hand, the Verbal/Imagery dimension of cognitive style, dependent on the work of Paivio's dual coding theory (Paivio, 2006), describes the human habitual mode of the mental representation of information. Verbal persons "consider the information they read, see or listen to, in words or verbal associations", whereas imagery persons prefer to consider information, experience "fluent spontaneous and frequent pictorial mental pictures" (Riding R. , 1991). The characteristics associated to each dimension/pole are listed in Appendix A1.

Four cognitive styles are generated by the combination of the cognitive-dimensions: Wholist-Imagery, Wholist-Verbal, Analytical-Imagery and Analytical-Verbal (Riding R. , 1991) (Sadler-Smith \& Riding, 1999).

\subsubsection{Gregorc's Mind Styles Model}

Dr. Anthony F. Gregorc, Gregorc Associates Inc. president, is the developer of Gregorc's Mind Styles Model and the Gregorc's Style Delineator. Gregorc's model has two Mind Ability dimensions, namely Perception and Ordering (Gregorc A. F., 1982). Firstly, the Perception mind ability dimension describes the means by which you grasp information by two Mind Preference ways: Concrete and Abstract. The Concrete mind preference explains how individuals prefer to grasp information through their five senses. Concrete persons deal with facts and reality and are interested in practical applications. On the other hand, the Abstract mind preference explains how individuals can visualize information that cannot be seen. Abstract persons tend to be intuitive and imaginative. Secondly, the Ordering mind ability dimension describes the ways in which individuals arrange, order, and reference information through two mind preference ways: Sequential and Random. The Sequential mind preference represents how individuals deal with information in a linear and organized manner. Sequential persons prefer to plan things out step-by-step and are interested in details. The Random mind preference represents how individuals deal with information in chunks and skipping steps. Random persons are able to make connections between concepts and ideas. 


\section{Chapter 4.}

Gregorc defined the Mind Style as consisting of "distinctive behaviors which serve as indicators of how a person learns from and adapts to his environment. It also gives clues as to how a person's mind operates." (Gregorc A. , 1979). Gregorc combines the two mind ability dimensions, as shows in Figure 4.4, leading to four Mind Styles (Gregorc A. , 2006):

- The Concrete Sequential (CS): Perceive the concrete or physical world through the five senses, think in a very linear fashion and have more difficulty considering multiple alternatives or solutions to questions or problems.

- The Abstract Sequential (AS): Can easily grasp abstract concepts, enjoys a very structured classroom environment, prefer to work alone, and continuously consider multiple alternatives and are strong in problem-solving skills.

- The Abstract Random (AR): Can more easily appreciate an unstructured learning environment, want to explore alternatives to questions and/or problems, appreciate hands-on learning activities, and can adapt well to both working independently and in group work settings.

- The Concrete Random $(C R)$ : Are very aware of what is happening externally, prefer a very unstructured learning environment, do not respond well to a step-by-step, logical presentation, tend to think with their emotions, and prefer lots of group work, discussion, and time to reflect on the learning experience.

Everybody can utilize all four mind styles, but for Gregorc, there are inborn preferences towards one or two of them (Gregorc A. , 2006). He also believes that each orientation towards the world has potentially positive and negative attributes and his mission is to prompt self-knowledge, promote depth-awareness of others, foster harmonious relationships, reduce negative harm and encourage right actions (Coffield, Moseley, Hall, \& Ecclestone, 2004). The characteristics associated to each dimension/pole are listed in Appendix A1. 


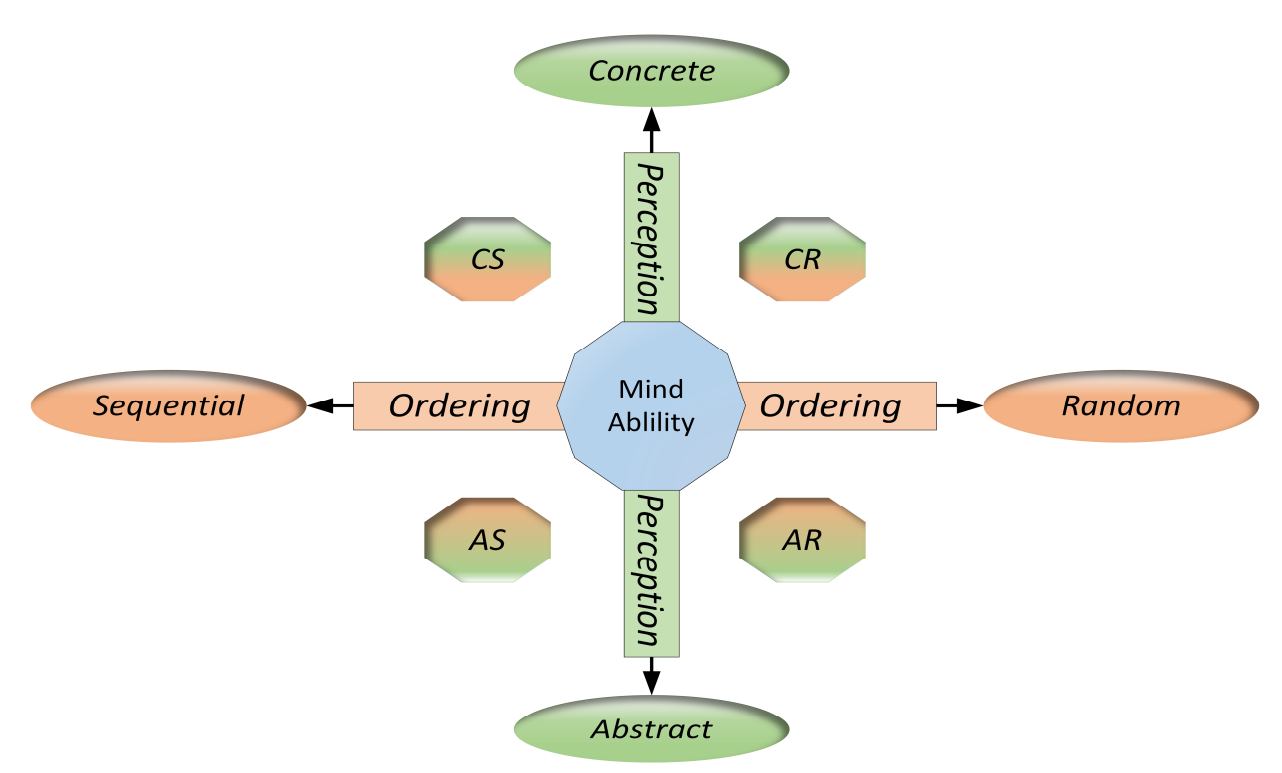

Figure 4.4 The Gregorc's mind ability dimensions and mind styles

\subsubsection{The Felder-Silverman Model}

Dr. Richard M. Felder (Professor Emeritus of Chemical Engineering at North Carolina State University) and Linda K. Silverman (Ph.D. Educational Psychology and Special Education and President of the Institute for the Study of Advanced Development) defined a learning preferences (styles) model for a group of engineering students. The Felder-Silverman model based on Jung's theory (Sensing/Intuition dimension), Kolb's experiential learning (Active/Reflective dimension) and Pask LSM (Sequential/Global dimension) (Pask, 1988). In 1988, the Felder-Silverman original model consisted of five dimensions (Sensing/Intuitive - Visual/Auditory - Inductive/Deductive - Active/Reflective - Sequential/Global) (Felder \& L.K., 1988). But in 2002, Felder dropped the Inductive/Deductive dimension from the model and changed the Auditory to the Verbal, see Figure 4.5.

The Felder-Silverman LSM dimensions are:

1. The information Perception dimension (Sensing - iNtuitive): in 1971, Jung identified Sensing and Intuitive as the two ways in which people tend to perceive information (Jung, 1990). Sensing means gathering 


\section{Chapter 4.}

and observing information through the senses, but Intuition means indirect perception by comprehending the global view of information and ignore the details. Sensory learners are patient with details and concerned with facts, procedures, and concrete contents. In contrast, Intuitive learners tend to be creative, oriented toward principles and theories, and able to discover possibilities and relationships. Everyone uses both abilities, but most people tend to favor one over the other.

2. The information Processing dimension (Active - Reflective): Kolb defined the information processing as the mental process by which the perceived information is converted into knowledge. The information processing dimension is grouped into two categories; Active Experimentation and Reflective Observation. Active means acquiring knowledge by trying things out and testing it in some way. On the other hand, Reflective means acquiring knowledge through thinking about things, then reflecting on the learning materials. Active learners do not learn much in situations that require them to be inactive (passive), they learn well by doing, experimenting and in groups.

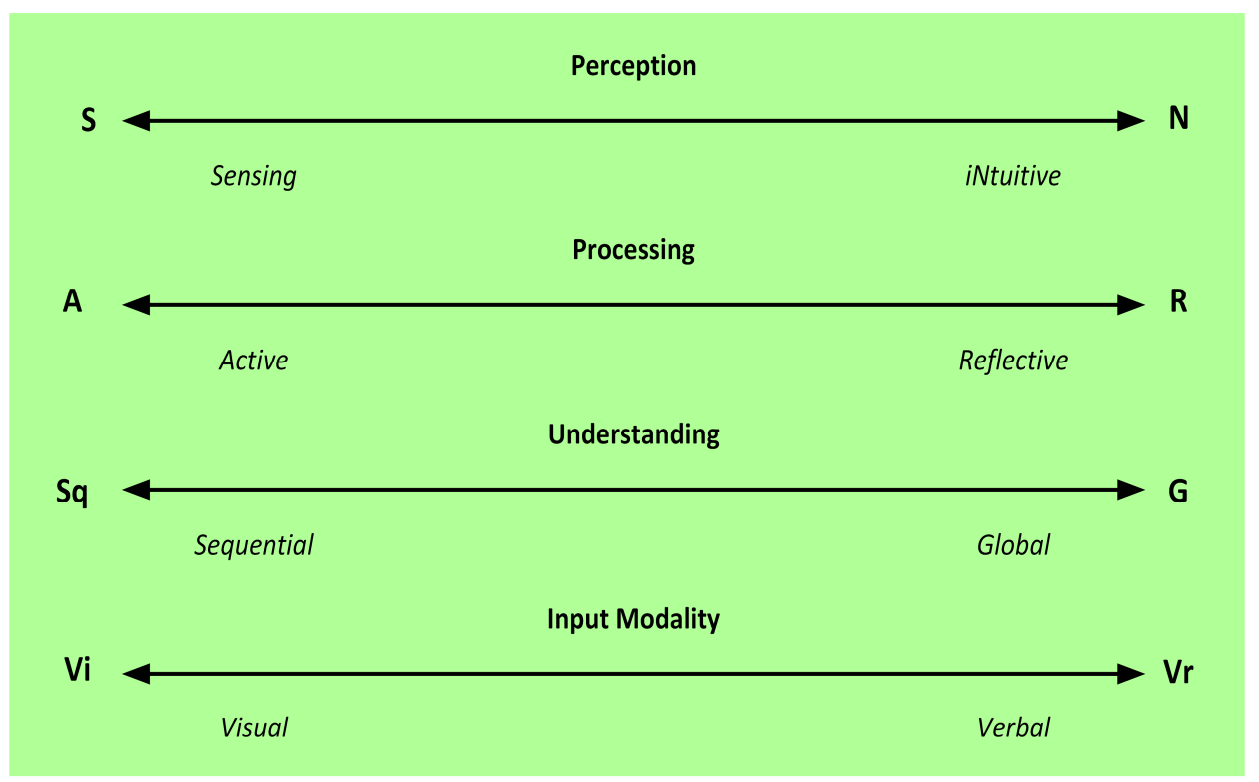

Figure 4.5 The Felder-Silverman's dimensions 
On the contrary, reflective learners do not learn much in situations that provide no opportunity to think about the presented information, they learn well by thinking about information being presented and prefer to work by themselves or in a small group.

3. The Understanding dimension (Sequential - Global): most educational organizations introduce learning materials in a logically ordered structure with the pace of learning associated with a timetable. Some learners are comfortable with this method; they are called Sequential learners. Others, Global learners, cannot learn in this way. They learn in intuitive leaps; they may spend days or weeks unable to understand a simple task until suddenly they get it. Then, they may understand the material very fast and apply it to several problems that may discomfit Sequential learners. Sequential learners learn in small incremental steps, they are interested in details and prefer convergent thinking, linear reasoning, and analysis. In contrast, Global learners understand in intuitive leaps and prefer to use divergent thinking.

4. The Input modality dimension (Visual - Verbal): this dimension describes the preferred mode that learners use to receive information. Visual learners prefer to retain information through what they see (pictures, diagrams, visual demonstration, flow charts, timelines, etc.), whereas Verbal learners prefer to receive information through what they hear and say (discussions, written and spoken demonstration, verbal explanation, explaining to others, etc.).

Felder and Silverman combined the four dimensions to define sixteen LSs (e.g. Intuitive-Active-Visual-Sequential, Intuitive-Active-Visual-Global, etc.) (Felder \& L.K., 1988). Table 4.2 introduces the Felder-Silverman LSs. The characteristics associated to each dimension/pole are listed in Appendix A1. 
Table 4.2 The Felder-Silverman LSs

\begin{tabular}{|c|c|c|c|c|c|}
\hline & & \multicolumn{2}{|c|}{ Sensing } & \multicolumn{2}{|c|}{ Intuitive } \\
\hline & & "Visual & Verbal & 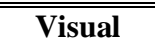 & Verbal \\
\hline & & $\mathrm{S}-\mathrm{Vi}$ & $\mathrm{S}-\mathrm{Vr}$ & $\bar{I}-\mathrm{Vi}$ & $\mathrm{I}-\mathrm{Vr}$ \\
\hline "Active - Sequential & $\mathrm{A}-\mathrm{Sq}$ & בA-S-Vi-Sq & בA-S-Vr-Sq & A-I-Vi-Sq & A-I-Vr-Sq \\
\hline Active - Global & $A-G$ & A-S-Vi-G & A-S-Vr-G & A-I-Vi-G & A-I-Vr-G \\
\hline Reflective - Sequential & $\mathrm{R}-\mathrm{Sq}$ & R-S-Vi-Sq & R-S-Vr-Sq & R-I-Vi-Sq & R-I-Vr-Sq \\
\hline Reflective - Global & $R-G$ & R-S-Vi-G & R-S-Vr-G & R-I-Vi-G & R-I-Vr-G \\
\hline
\end{tabular}

\subsubsection{H oney and M umford's Model}

In 1979, Alan Mumford was responsible for senior management development at the Chloride Organization and collaborated with Peter Honey, a chartered psychologist, in studying the then relatively neglected topic of how managers learn. They developed their LSM based upon the work of Kolb in Experiential Learning Theory.

Honey and Mumford adapted Kolb's learning cycle stages to accord with the managerial experiences and renamed it as follows: having an experience, reviewing the experience, concluding from experience, and planning the next steps (Mumford, 1997). Figure 4.6 shows the Honey and Mumford managerial experiences cycle.

Honey and Mumford (Honey \& Mumford, 1992) define a LS as being "a description of the attitudes and behavior which determine an individual's preferred way of learning". They aligned the learning cycle stages to four distinct LSs or preferences named: Activist, Reflector, Theorist and Pragmatist, see Figure 4.6. The characteristics associated to each learning style are listed in Appendix A2.

Activists learn best from short here-and-now tasks, and they tend to be more eager about new ideas. They prefer to work with others and like to tackle 
problems by brainstorming. Reflectors prefer to learn by collecting and observing information then thinking about it. They may avoid skipping in and like to observe from the sidelines. They like to generate analyses, reports and take the time to work towards an appropriate conclusion.

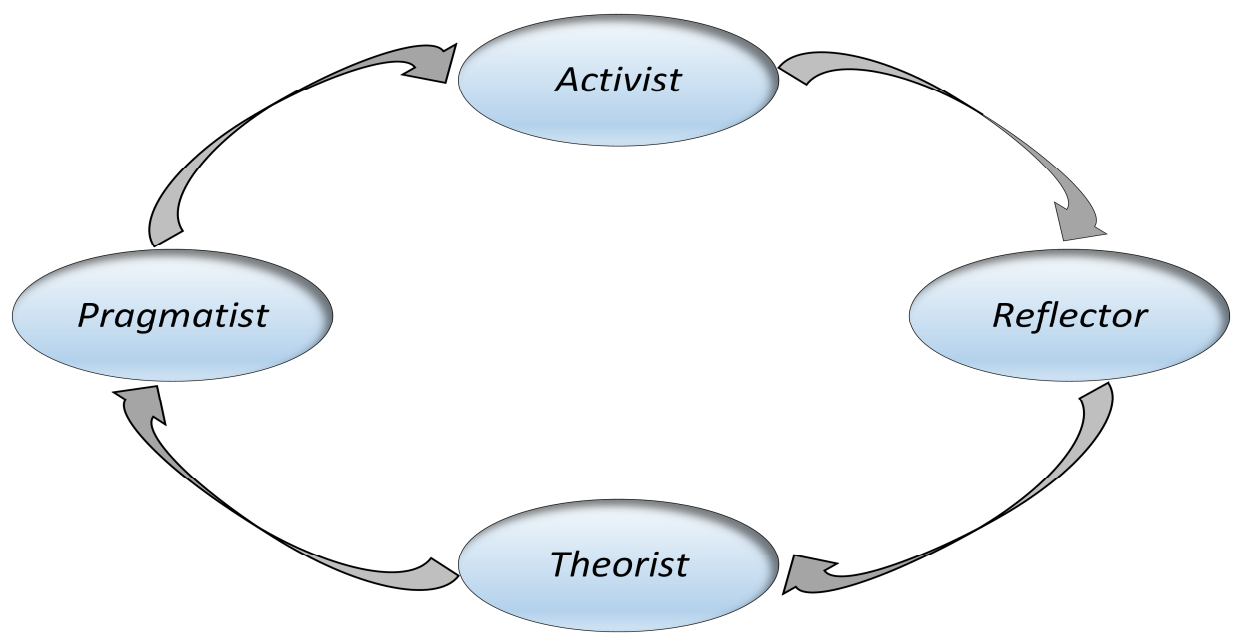

Figure 4.6 The H oney and Mumford's learning styles

Theorists learn best through complex tasks and from theories, models, concepts, and facts. They prefer to understand the theory behind the actions. They have the ability to visualize things by seeing the broad picture and drawing new ideas into a structured and logical manner. And finally, Pragmatists learn best through hands-on experiences and practical applications. They enjoy putting the acquired learning into practice in the real world. They also enjoy solving problems and decision making (Honey \& Mumford, 2000).

Honey and Mumford developed a LS Questionnaire (Honey \& Mumford, 2006) to help individuals to understand their learning preference or style. With this information, individuals will be in an excellent position to do three useful things (Honey \& Mumford, 2000):

- $\quad$ "Become smarter at getting a better fit between learning opportunities and the way you learn best. This makes your learning easier, more effective and more enjoyable. It saves you tackling your learning on a hit-and-miss basis. Equipped with information about your learning preferences, you'll have many more hits and fewer misses." 
- "Expand the 'band width' of experiences from which you derive benefit. Becoming an all-round learner, increases your versatility and helps you learn from a wide variety of different experiences - some formal, some informal, some planned and some spontaneous."

- $\quad$ Improve your learning skills and processes. Increased awareness of how you learn, opens up the whole process to self-scrutiny and improvement. Learning to learn is your most important capability since it provides the gateway to everything else you want to develop."

\subsubsection{Keirsey Temperaments}

Dr. David West Keirsey, American Psychologist, was the developer of the Keirsey Temperaments Theory and Keirsey Temperaments Sorter. Keirsey defined temperament as "a configuration of inclinations" (Keirsey, 1998). Based on the work of Myer-Briggs, Keirsey's Temperaments Theory relates an individual's behavior to four temperaments and sixteen personality types. He mainly categorized personality types into four temperaments according to three personality dichotomies: the Gathering information dichotomy, the Decision Making dichotomy, and the Lifestyle dichotomy.

In (Keirsey, 1998), Keirsey defined in detail the four temperaments: Artisan, Guardian, Idealist, and Rational. He also specified four personality types for each temperament (for example, Artisan is composed of ESTP, ISFP, ISTP, and ESFP). See Figure 4.7.

- Idealists: iNtuitive - Feeling (NF)

Idealists seek to discover how their learning is related to themselves and to their relationships with others. They search for the importance of things and want to comprehend their meanings. Reality for them is dependent on their personal impact, thus learning is personalized. Idealists think about possibilities in people, not facts. They are influenced by people's opinions and attitudes. Also, they tend to use feeling rather than principles. Finally, they enjoy communication with others (Keirsey, 1998; Montgomery, 2002). 


\begin{tabular}{ccccc}
\multicolumn{2}{c}{ Idealist } & & \multicolumn{2}{c}{ Rational } \\
ENFJ & INFJ & INTJ & ENTJ \\
ENFP & INFP & INTP & ENTP \\
ESFP & ISFP & ISFJ & ESFJ \\
ESTP & ISTP & ISTJ & ESTJ \\
& & & \\
& Artisan & & & Guardian \\
& & & &
\end{tabular}

Figure 4.7 The Keirsey's temperaments

- Rationals: iNtuitive - Thinking (NT)

Rationals learn by imaginative thinking. They want to be able to interpret, clarify, and control realities. They want to use principles and theories to describe facts. Rationals' life is full of serious research and creative thinking. They are very curious and are happy being serious. They like to collect information extensively and tend to be academic achievers. Following usual tasks and concrete information will lead to little interest for these people. They have some difficulties to show emotions and a tendency to loneliness (Keirsey, 1998; Montgomery, 2002).

- Guardian: Sensing - Judging (SJ)

Guardians learn best in a well-structured and orderly environment. They focus on responsibility, on developing good study habits, on developing proper social attitudes, and on completing well-structured assignments, which meet with instructor consent. They prefer to acquire knowledge and information through repetition and drill, through recognizing and remembering facts and procedures, and through structured materials. They consider that abstractions and theoretical principles have little value compared with any particular actuality. They need a clear and a systematic way to be able to accomplish a task 


\section{Chapter 4.}

and always want to receive approval and feedback from their instructors (Keirsey, 1998; Montgomery, 2002).

- Artisans: Sensing - Perceiving (SP)

Artisans prefer to learn through experience. People with this temperament have little interest in culture and intellectual matters. Also, they are not interested in abstractions, theoretical concepts, and plans. They prefer to deal with concrete realities. They feel restricted and subdued in structured and routine educational systems. They enjoy moving from personal activities or smallgroup activities to large-group activities. Artisans appreciate randomness and diversity (Keirsey, 1998; Montgomery, 2002).

\subsection{Ontology in e-Learning}

Without any doubt, ontology has become the future for the customization process in the e-Learning environment (Huang, Liu, Tang, \& Lu, 2011). There is a large amount of scientific research focused on the role of ontology in the personalized e-Learning environment. The ontology represents the learning experience (learning resources and process) in a new semantic way that enables machines to understand and process it semantically (Torre, 2009).

Sharing a knowledge process requires that several systems need to use different concepts for representing domains, these variations lead to a difficulty in knowledge sharing and reuse among the various systems, so this is one of the main drawbacks in knowledge sharing (Luna, et al., 2015). In this context, ontologies are used to explicitly and formally determine the different concepts, their properties, and relationships that relate to the e-Learning domain. Moreover, ontology is considered as the core component of several systems; it facilitates reuse of knowledge through sharing common concepts (Bürger \& Simperl, 2008; Vesin, Ivanovic, KlaLsNja-Milic Evic, \& Budimac, 2012).

Ontologies motivate customization and adaptation in the e-Learning environment by developing and improving several objectives, such as representing the learning objects taxonomies, labeling and indexing learning objects to improve reusability and personalization functions, describing the learner model 
to improve system interaction with the learner, and classifying several aspects like LSMs that also improve the personalization and customization issues (Labib, Canós, \& Penadés, 2017).

Learners have different preferences and needs, like LSs, background knowledge, cognitive abilities, and learning goals (Chrysafiadi \& Virvou, 2013; Dominic \& Francis, 2015; Kurilovas, Kubilinskiene, \& Dagiene, 2014). Educational organizations should therefore personalize their e-Learning environments based on the different characteristics of the learners (Kurilovas, Zilinskiene, \& Dagiene, 2014). Below we describe several studies that apply ontology to improve the customization issue within e-Learning environments.

\subsubsection{LOCO}

LOCO (Learning Object Context Ontology framework) is an ontology-based framework aimed at the explicit representation of context metadata obtained from the usage of learning objects. The learning object context is a unique set of interrelated information that characterizes a specific learning experience. The main part of the LOCO framework is the Learning Object Context Ontology that uses other ontologies (i.e. user model ontology, domain model ontology, etc.) to extract information about the usage of learning objects within the learning system. The LOCO framework introduces some information that enriches the personalization process. It enforces the reusability of learning objects by recommending the most suitable learning objects that have been used before in similar learning situations (Jovanovic, GaLsevic, Knight, \& Richards, 2007).

\subsubsection{O-DEST}

O-DEST is an Ontology-Driven E-learning system for the Thai learning environment and was developed by Snae and Brüeckner. It uses an ontology to help administrators, teachers, and students to set up and maintain the domain model of the learning materials. Also, O-DEST provides students with suitable learning objects based on their LS (Snae \& Brüeckner, 2007). 
Chapter 4.

\subsubsection{LORM}

LORM is a personalized Learning Object Recommendation Model that utilizes ontologies that help a tutoring system in recommending learning materials for students according to their needs, background, and helpfulness score. LORM adopts Java Learning Object Ontology (JLOO) that serves as a guideline in producing learning objects of introductory "Java Programming" course and in structuring these learning objects in an adaptive learning environment. JLOO covers only six subjects (defined in the area of introduction to Java programming). The JLOO's concept represents a learning unit in Java course, an instance is a learning object that belongs to a concept, and slot represents relations and attributes between two concepts. LORM proposes a personalized recommendation mechanism that uses the Preference-based algorithm and the Correlation-based algorithm to recommend the most suitable learning objects to learners. The former is used for recommending learning objects according to the learner's background knowledge and preferences. The latter is used for recommending learning objects according to the experience of similar learners when they search for learning objects that should be helpful for the learning experience (Wang, Tsai, Lee, \& Chiu, 2007).

\subsubsection{LT4el}

The LT4eL (Language Technology for eLearning) project aims to integrate the semantic web technology with language technology to improve e-Learning systems. Such integration will enhance "multilingual" learning content retrieval, management, and search for the purpose of the semi-automatic generation of descriptive metadata. Additionally, the ontology and languages technology integration will facilitate the creation of specific student courses, allow direct access to knowledge in several languages, improve the construction of personalized material, enhance the reuse and sharing of learning materials, and support decentralization and co-operation of content management. The LT4eL project uses a domain ontology that contains a corpus of keywords from eight languages (which have been translated into English). The primary purpose of this domain ontology is related to the indexing of the learning materials within a particular domain (Monachesi, Simov, Mossel, Osenova, \& Lemnitzer, 2008). 


\subsubsection{ORLM}

ORLM (Ontology for Recommended Learning Materials) is an ontology model that personalizes e-Learning systems and makes learning environments more effective and flexible. ORLM aims to recommend learning materials according to the student's LS. ORLM is based on three components: learning materials, LSs, and personal information. It also utilizes several standards such as FOAF (for personal information), Dublin Core (for learning materials) and fragments of ontology for the LSs found in a systematic revision (Valaski, Malucelli, \& Reinehr, 2011).

\subsubsection{Protus}

Protus, an adaptive and intelligent web-based PRogrammingTUtoring System, aims at automatically guiding the learner's activities and recommending appropriate actions during the learning process. Protus adopts three ontologies and SWRL rules. The first ontology is used to represent the learner model. The learner model ontology was developed using Protégé and presents a means for storing personal preferences and data about the learner's personal information, performance, and LS. Protus applies the Felder-Silverman LS model to describe and identify the learner's LS. The second ontology used by Protus is the learner observation ontology. This ontology is considered as a sub-ontology of the learner model ontology. It provides a structure of information about possible learner interactions. The third ontology represents the learning materials. The SWRL rules are used to infer and update the learner model. SWRL rules are also used to add new types of resources that support particular LSs. Protus is capable of updating the data model and represents knowledge in a more explicit specification for learner's preferences and needs. Protus is a personalized tutoring system for teaching different programming languages, and has been fully tested for an introductory Java programming course (Vesin, Ivanović, Klašnja-Milićević, \& Budimac, 2011). 


\subsubsection{SEALMS}

SEALMS is a Semantically Enhanced Adaptive Learning Management System. The SEALMS framework monitors the learners' profiles and performs several functionalities such as:

1. Extracting knowledge and results from learner's inputs, interactions, and actions,

2. Detecting the learner's LS from the extracted knowledge, and

3. Providing a personalized workflow according to the learner's requirements.

SEALMS constructs six ontologies from the learner input; Learner ontology, Domain ontology, Learner Style ontology, Pedagogical ontology, Adaptation ontology, and workflow ontology. The system automatically detects available learning objects and suggests the learner's workflow (Begam \& Ganapathy, 2012).

\subsubsection{Discussion}

The use of ontology technologies gives systems the ability to identify the context they are operating in and reasoning about those contexts. An ontology also enables the reuse of knowledge between humans and computer programs, so that it is helpful for the recommender systems that recommend several items to individuals concerning their preferences. One limitation found in the ontology frameworks studied is the inability to support the instructor with the appropriate contents (relevant to learner's preferences) during the creation process of learning materials. Overcoming this limitation would lead to improving the learning experience according to the learner's learning preferences. Moreover, recommending suitable learning materials may help students to optimize their learning path and progress.

Most ontology frameworks employ a Single-LS model to identify the learner's characteristics and preferences. It is assumed that the specification of learner characteristics and preferences provided by different LSMs leads to learning process improvement for both instructor and learner, and the use of an ontology provides an explicit way to connect Multi-LS models (connecting dimensions and LSs with the relevant learner characteristics, see Chapter 7). 
Based on the research studies reviewed above, we conducted a comparison of the different ontology frameworks, as shown in Table 4.3. 

CUSTOMIZATION ISSUESIN ELEARNING

\begin{tabular}{|c|c|c|c|c|c|c|c|}
\hline Criteria & LOCO & O-DEST & LORM & LT4eL & ORLM & Protus & SEALMS \\
\hline Goal & $\begin{array}{l}\text {-Extracting infor- } \\
\text { mation about the us- } \\
\text { age of learning mate- } \\
\text { rials. } \\
\text {-Personalization pro- } \\
\text { cess. }\end{array}$ & $\begin{array}{l}\text { - Providing learners } \\
\text { with suitable learn- } \\
\text { ing materials based } \\
\text { on their LS. }\end{array}$ & $\begin{array}{l}\text {-Recommending } \\
\text { learning materials } \\
\text { according learner's } \\
\text { needs, background } \\
\text { and helpfulness. }\end{array}$ & $\begin{array}{l}\text {-Enhancing of "mul- } \\
\text { tilingual" learning } \\
\text { content retrieval and } \\
\text { management. } \\
\text { - Content personali- } \\
\text { zation. }\end{array}$ & $\begin{array}{l}\text {-Recommending } \\
\text { learning materials } \\
\text { based on the } \\
\text { learner's LS. } \\
\text {-Personalization pro- } \\
\text { cess. }\end{array}$ & $\begin{array}{l}\text { - Recommending ap- } \\
\text { propriate actions. } \\
\text { - Guiding learner's } \\
\text { activities. }\end{array}$ & $\begin{array}{l}\text {-Extracting } \\
\text { knowledge. } \\
\text {-Personalizing } \\
\text { workflow }\end{array}$ \\
\hline Solution & $\begin{array}{l}\text { - Developing learn- } \\
\text { ing object context } \\
\text { ontology. }\end{array}$ & $\begin{array}{l}\text { - Developing an on- } \\
\text { tology for the e- } \\
\text { Learning process. }\end{array}$ & $\begin{array}{l}\text { - Developing a Java } \\
\text { Learning Object on- } \\
\text { tology. } \\
\text { - Developing a per- } \\
\text { sonalized recom- } \\
\text { mendation algo- } \\
\text { rithm. }\end{array}$ & $\begin{array}{l}\text { - Developing a do- } \\
\text { main ontology that } \\
\text { contains a corpus of } \\
\text { keywords from } \\
\text { eight different lan- } \\
\text { guages. }\end{array}$ & $\begin{array}{l}\text { - Developing ontol- } \\
\text { ogy using learning } \\
\text { materials, learner } \\
\text { personal infor- } \\
\text { mation, and LSs. }\end{array}$ & $\begin{array}{l}\text { - Developing learner } \\
\text { model ontology and } \\
\text { learner observation } \\
\text { ontology. }\end{array}$ & $\begin{array}{l}\text {-Constructing six } \\
\text { ontologies: learner, } \\
\text { domain, learner } \\
\text { style, pedagogical, } \\
\text { adaptation, and } \\
\text { workflow ontology. }\end{array}$ \\
\hline Learning Style & Yes & Yes & Yes & No & Yes & Yes & Yes \\
\hline Single-LS Model & Yes & Yes & Yes & No & Yes & Yes & Yes \\
\hline Multi-LS Model & No & No & No & No & No & No & No \\
\hline $\begin{array}{l}\text { Recommending } \\
\text { learning materials } \\
\text { upon various LS } \\
\text { models }\end{array}$ & No & No & No & No & No & No & No \\
\hline $\begin{array}{l}\text { Recommending } \\
\text { learner characteris- } \\
\text { tics upon his LS }\end{array}$ & No & No & No & No & No & No & No \\
\hline $\begin{array}{l}\text { Reusing learning } \\
\text { materials based on } \\
\text { different LS models }\end{array}$ & No & No & No & No & No & No & No \\
\hline $\begin{array}{l}\text { Unifying LS model } \\
\text { characteristics }\end{array}$ & No & No & No & No & No & No & No \\
\hline $\begin{array}{l}\text { LS models interop- } \\
\text { erability }\end{array}$ & No & No & No & No & No & No & No \\
\hline
\end{tabular}





\subsection{Conclusion}

In this chapter, the role of ontology in LO customization have been discussed with several examples of ontology frameworks used in research studies. Moreover, the AEHSs and the LSMs have also detailed. Finally, different ontology-based frameworks employed in e-Learning have been discussed. 



\section{PART THREE}

A CONCEPTUAL

FRAMEWORK FOR LO

DEVELOPMENT BASED ON

ONTOLOGY AND PRODUCT

LINE ENGINEERING 

This part proposes a conceptual framework to support the reuse and customization of LOs development in e-Learning systems. The framework is based on three models namely LO model, customization model and LO product line model. First, in chapter 5, a general description of the framework is presented and the combination of the three models is described. In chapter 6 we present the selected LO content model in details. In chapter 7 we introduce the customization model. This model is basically dependent on the Global Learning Style Model Ontology (GLSMO), that integrates seven LSMs using a strategy that mixes a hybrid ontology approach with the On-To-Knowledge method for ontology development. Chapter 8 introduces the LO Product Line (LOPL) approach for LO generation. Finally, chapter 9 aims at presenting an initial proposal for a $\mathrm{LO}$ authoring tool that enforce customization and reuse in the learning material authoring process. 



\section{Chapter 5}

\section{A Product Line Approach to LO D evelopment}

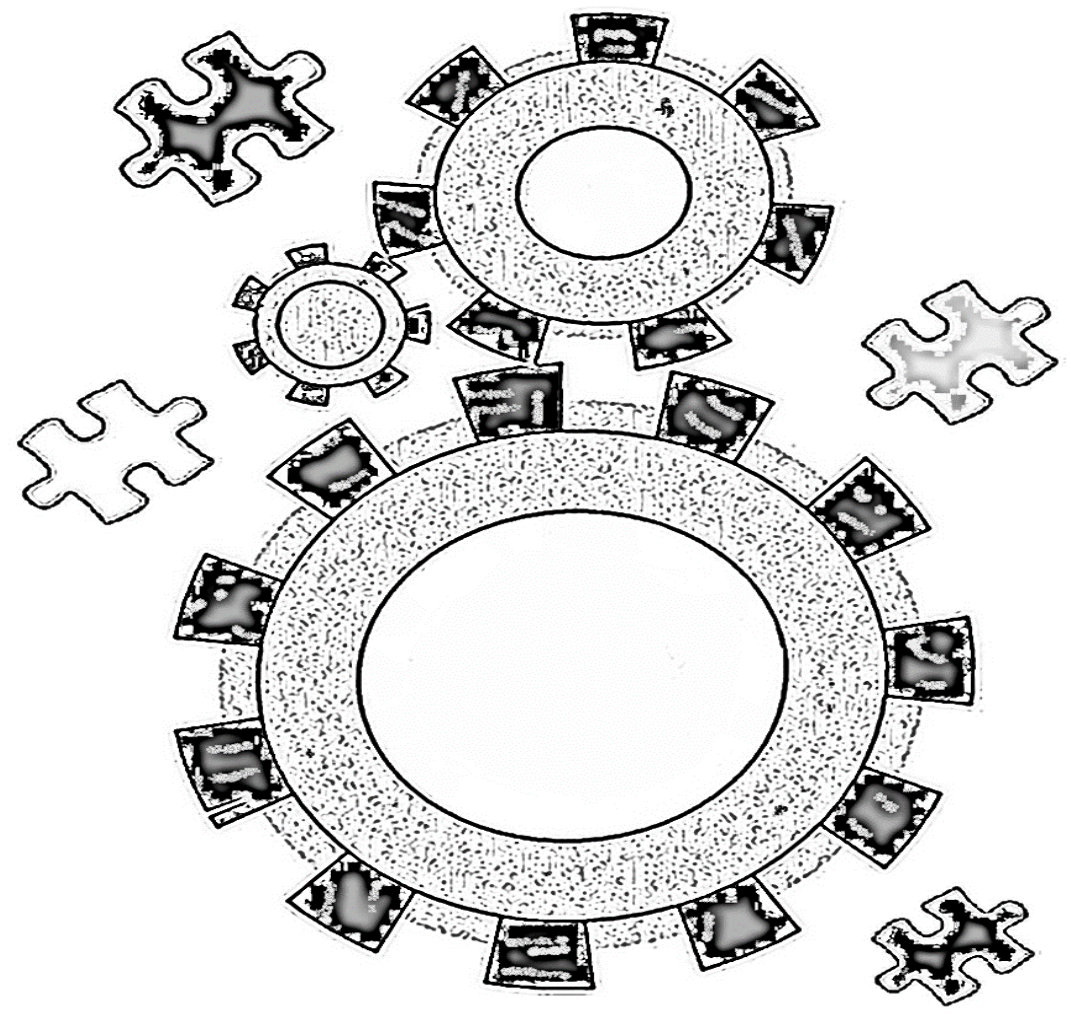




\section{Chapter 5.}

Despite the important advances that Information and Communication Technology (ICT) has brought to the e-Learning field in the last decade, many challenges remain open. Among these, customization (personalization) and reuse are of particular interest in order to provide flexibility to all the actors in the learning process. Firstly, instructors should design customized learning materials in terms of students' preferences and needs, and reuse content in the elaboration of such materials. Secondly, students should have access at all times to learning materials relevant to their preferences and needs, improving the effectiveness of the learning objects. Thus, the development of Customized Learning Materials in terms of content Reuse, Customization, and Ease of creation and efficiency of production is a very desirable task.

As described in Chapter 3, identifying the LO content model is a foundational decision for project organization based on individual goals. The incorrect choice or identification of these can thus lead to several problems in the reuse and instructional representation of learning materials. Also, the LO content model based on a scientific instructional method helps content authors to create flexible learning materials. An LO content model without an instructional method is therefore considered insufficient to produce good learning materials.

Another limitation that affects the LO development process is the negligence of learner's preferences and needs. As course authors create learning content for learners, they should be concerned about their LS. The use of a LS model in the LO development process provides authors with a catalog that describes everything about the learner's characteristics and preferred learning activities. Furthermore, recommending learning materials during the LO development process is considered as a new challenge to provide authors with various alternative resources that may be reused, especially if the recommended resource is relevant to the learner's LS and addresses his/her needs.

Finally, controlling the LO development process with a technical production strategy is also a challenge to manage all development aspects in an easy and flexible way.

We propose the combination of three models are the LO Content Model, the 
Customization Model, and the LO Product Line (LOPL) model, as will be described later.

\subsection{General description of the proposal}

Our proposal is mainly based on three models: firstly, the LO Content Model that specifies the LO structure, the granularity level, and the metadata application profile; and secondly the LO Customization Model that describes the personalization strategy that will be used during the LO development process and the criteria to be considered for identifying learner characteristics and preferences. Thirdly, the LO Product Line Model manages the LO creation process in a flexible way using the SPLE and Document Product Line (DPL) principles and techniques (see Figure 5.1).

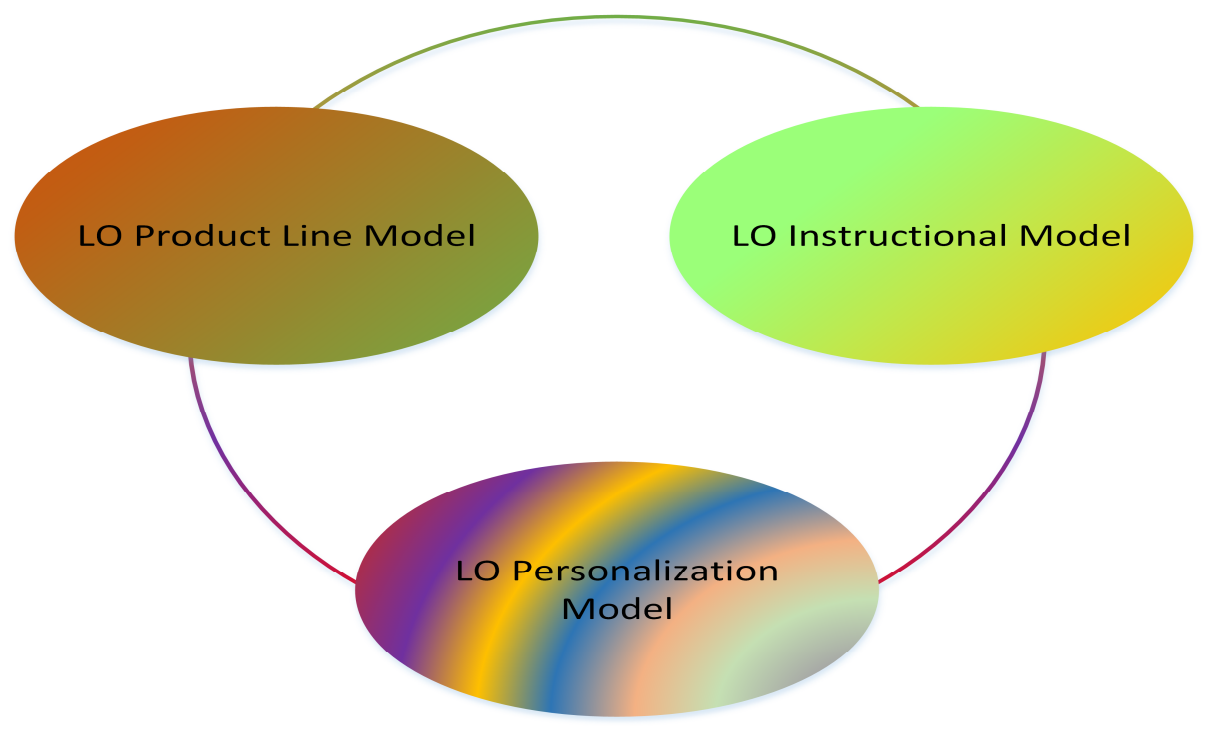

Figure 5.1 The proposed model for LO development

\subsubsection{The LO content model}

From our point of view, employing an LO content management strategy developed and structured on a scientific instructional method is a good starting point to develop flexibility of learning materials. The learning materials created can be customized or adapted as needed with great flexibility. 


\section{Chapter 5.}

In LO content model, the diversity of the LO granularity levels is an important issue to be considered. It gives authors the ability to form learning materials with different structures (from simple to complicated) and it is easier to reuse learning material for teaching a single concept in different learning contexts.

Employing suitable metadata elements with the LO content model is good way to tag the created learning materials with the necessary information needed to describe them and facilitate their discoverability for search and reuse purposes.

From the different LO content models available we selected the Reusable Information Object (RIO) model developed by CISCO (Cisco_Systems, 2003), an LO content model developed and structured on the basis of Component Display Theory (Merrill M. D., 1983) and Modified Information Mapping (Clark, 2009). The RIO model consists of building small learning content components that are aggregated into larger structure (LO) to address the needs of instructors/authors and learners. A detailed description of the RIO content model is given in Chapter 6.

\subsubsection{The LO Customization model}

The interest of instructors has focused on creating highly personalized learning material that meets learners' needs and preferences. The terms preferences and needs sometimes go with different parameters such as learner's knowledge level, preferred language, etc. But many educational organizations describe learners' preferences using the so-called LSMs; such preferences are captured by means of questionnaires, or automatically detected by dedicated modules in learning management systems, as in (Sabine \& Kinshuk, 2013). Using the LSM as one of the main sources of the learner's characteristics is a prominent point and incorporating the LO customization model in it will provide course authors with complete details about the learner's characteristics and preferences.

A major limitation when dealing with the LS domain is that there are numerous LSMs that have been proposed in the last decades (Özyurt \& Özyurt, 2015), in some cases with overlapping characteristics with the same or different names. 
A Product Line A pproach to LO Development

To solve this limitation, we have developed a GLSMO that integrates seven LSMs with their relevant characteristics and activities (Labib, Canós, \& Penadés, 2017). We aim at preserving the basic structure of each of the seven models while giving educational systems the choice of a specific model and the ability to interoperate with other models. The ontology can be used to perform semantic, multi-LSMs searches of LOs. The GLSMO also helps instructors to create multi-LSMs materials and facilitate interoperability between the seven models. The GLSMO can help instructors to improve and customize learning materials during the authoring process by recommending several contents which match a specific LS or learner's characteristics (Labib, Canós, \& Penadés, 2017). We apply an ontology construction methodology called On-To-Knowledge with a hybrid ontology approach for the integration of the seven models to clearly define their internal structure and to establish and implement the model mappings.

We introduce a conceptual model for LSM integration. This model is the basis of the global ontology construction (described in detail in Chapter 7).

Integrating the GLSMO into the LO development process will provide an opportunity for the semantic recommendation of learning contents according to the learner's LS or characteristics. This advantage will help authors to improve content customization in accordance with learner's LS and preferences.

\subsubsection{The LO Product Line (LOPL) model}

The LOPL aims to apply the SPLE and DPL principles, techniques and tools to the creation of customized LOs. SPLE is a software development technique that is used to build a family of products with common and variable features (Pohl, Bockle, \& van der Linden, 2005). Additionally, DPL approach provides a framework to variable content document generation (Gómez, Penadés, Canós, Borges, \& Llavador, 2014). In LOPL model, the basis is to identify and represent the commonality and variability points in the LOs and to model them as a set of features. These features can be managed using a variability management approach such as Feature Model (FM). We use FM as a domain independent high-level specification for LO. The Specification 


\section{Chapter 5.}

and representation of LOs by FM gives sufficient information to define the so called "LO family".

We use the term "LO family" to represent all the LO instances generated by combining the variability points. In this domain, a feature corresponds to a component according to the RIO strategy. A family of RIOs/RLOs can be defined by recalling the RIO strategy structure depicted in Chapter 6, which will guide the representation of RIO/RLOs in terms of features (RIO/RLO feature model).

Based on the LO family concept, an LOPL is defined to facilitate the LO creation process for non-expert users. Following the DPL approach, the LOPL separates two processes: Domain Engineering and Application Engineering. The Domain Engineering process is responsible for defining the LO commonality and variability, and construct the reusable components that accomplish the desired variability and the LO product line is defined. The Application Engineering process is responsible for the generation of personalized LOs; this process exploits the LO product line and each characterization of the variability in the LO product line generates a new personalized LO with high reuse of components.

In this thesis, we intend to bring flexibility to the learning materials creation process following Software Product Line Engineering (SPLE) principles and the learner's LS. Our main goal is the development of a product line-based framework to effectively represent and develop LOs together with the DPL framework (DPLfw), a document engineering framework for the reuse-based development of digital content in high variability environments. We have used the FM to define families of LOs, according to Cisco's RIO model, and will provide the means to develop LO components that can be reused during LO generation time. We have also considered the learner's LS in the learning object creation process to meet the learners' need and preferences. We have developed a GLSMO to provide instructors with extensive knowledge about the learner's characteristics and recommend materials that fit the Learners' LS to increase reuse of learning content. 
A Product Line A pproach to LO Development

\subsection{Conclusion}

This chapter has outlined the main contribution of our work. Our proposal is aimed to develop customized learning materials with three main folds are content Reuse, Customization, and Ease of creation. The approach is based on three models: the LO content model, the customization model, and LOPL model. Then, a brief description was introduced for each model.

Next, the following three chapters describe those three models in details. 



\section{Chapter 6}

\section{The LO Content Model}

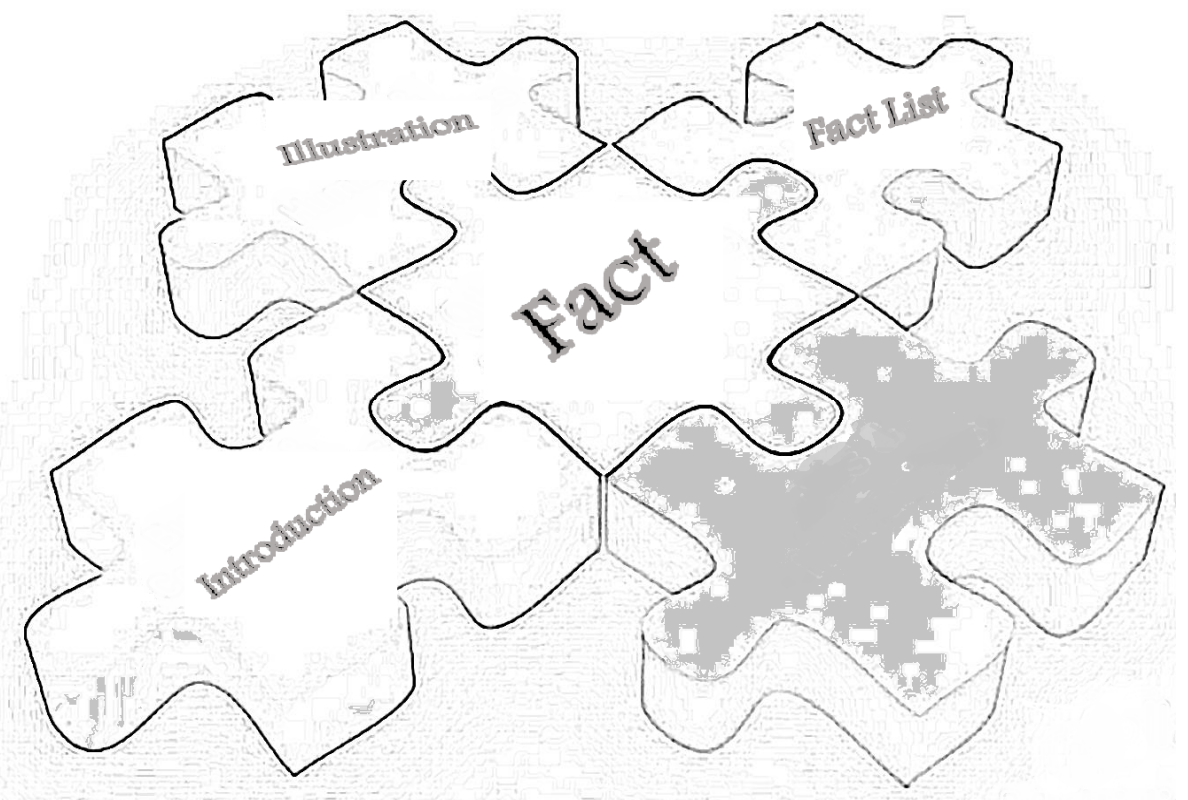




\section{Chapter 6.}

Several LO content models have been investigated in the literature in the last decade, such as the Learnativity content model (Wagner, 2002), NETg learning object model (L'Allier, 1997), SCORM content model (Paul, 2009), Navy Content Object Model (Navy-ILE, 2009), and Cisco RIO model (Cisco_Systems, 2003).

Most LO content models deal with the granularity issue (from the size view but not from the single concept view). They are also more concerned about how to package and aggregate learning materials into several levels, which is undoubtedly a good point to consider. However, they do not consider the instructional method by which the resulting LO will be strengthened. Incorporating an instructional method with an LO content model will help authors to create flexible learning materials. The Cisco RIO strategy has this advantage over other content models.

In our work, we propose to use the Cisco RIO content model as the LO content model and will be illustrated in the next section.

\subsection{The Cisco RIO content model}

The RIO content model, developed by CISCO (Cisco_Systems, 2003), is an LO content model grounded and structured on the basis of LO thinking and Component Display Theory of Merrill (Merrill M. D., 1983), and Modified Information Mapping (Clark, 2009). Moreover, RIO and Reusable Learning Object (RLO) classifications and guidelines for their construction are based on the structured writing methodology developed by Horn (Horn, 1998).

RIO content model consists of building small learning content pieces, called Components, that are assembled into LOs to address the needs of instructors/authors and learners. LOs are considered as both RIOs and RLOs.

The Component is the smallest piece of information defined in the RIO strategy. It may be a text, image, audio, video, or link. RIO is a granular and reusable piece of information. It can be created once and delivered in multiple formats (media independent). Each RIO relates to a single learning objective and can be formed from a collection of Components. RIOs can be combined to form a larger structure called an RLO. 
An RLO comprises four parts: Overview, Summary, Assessment, and RIOs. For instance, a RLO Overview is structured as follows: Introduction, Importance, Objectives, Prerequisites, Scenario, and Outline. The RLO Summary consists of three content items: Review, Next Step, and Additional Resources. An RLO is based on a single objective. The Cisco RIO strategy states that five to nine RIOs are needed to construct a new RLO, but we recommend eliminating this condition to guarantee flexibility to authors during RLO creation. The RIO content model is shown in Figure 6.1.

On the other hand, an RIO consists of three parts: content items, practice items, and assessment items (all considered as Components). All these items are grounded upon a single learning objective. As defined by information mapping (Clark, 2009), the content structure depends on the type of RIO being defined (Fact, Concept, Process, Procedure, and Principle). Table 6.1 contains the descriptions of RIO types.

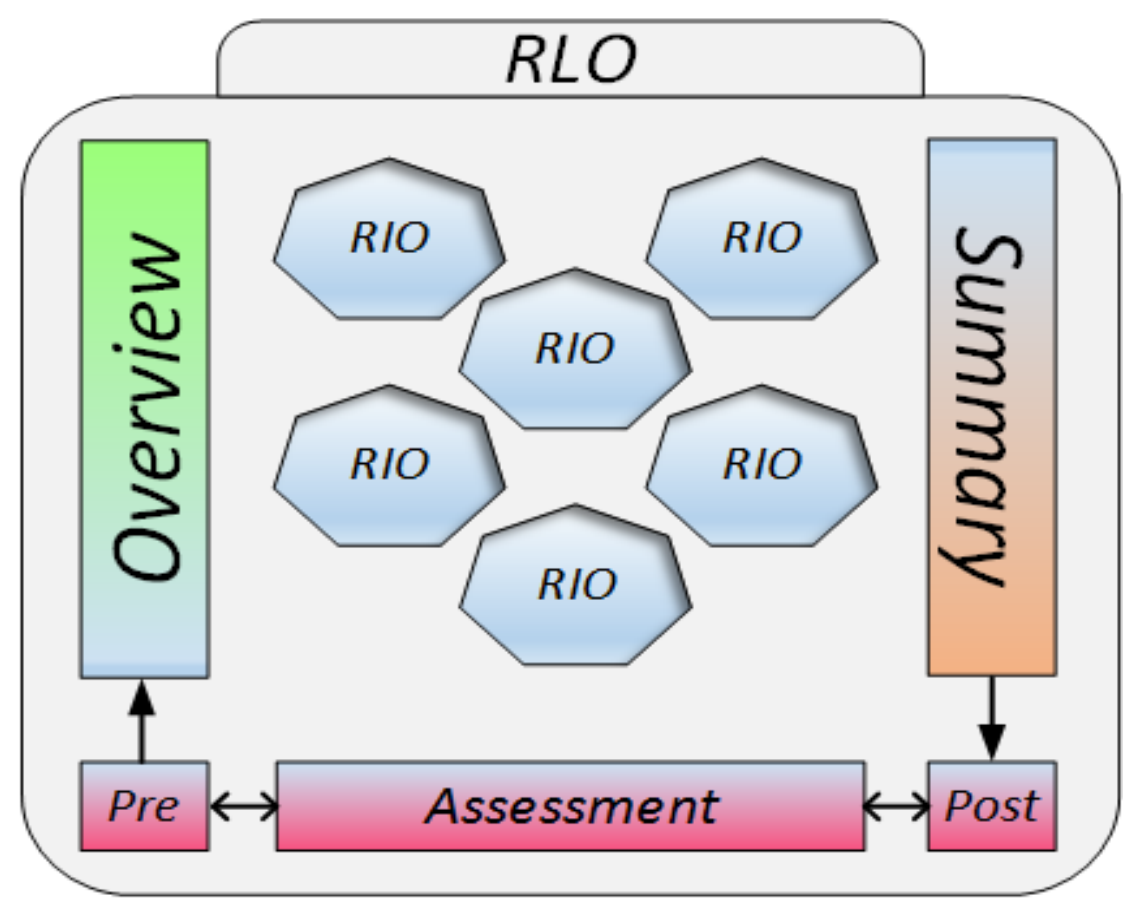

Figure 6.1 Cisco RIO content model 
Chapter 6.

Table6.1 RIO Types

\begin{tabular}{ll}
\hline RIO Type & Description \\
\hline \hline Fact & $\begin{array}{l}\text { Gives information based on real events; it explains an event or } \\
\text { something that holds without being a general rule }(1,2005) .\end{array}$ \\
\hline Concept & $\begin{array}{l}\text { Explains an abstract or generic idea generalized from specific } \\
\text { instances. A concept is employed for teaching a set of objects, } \\
\text { symbols, ideas, or events which are designated by a single } \\
\text { term, share a common feature and vary on irrelevant features } \\
(1,2005) .\end{array}$ \\
\hline Process & $\begin{array}{l}\text { Describes a sequence of events. A process gives information } \\
\text { on a flow of events that describes how a thing works and can } \\
\text { involve several actors (1, 2005). }\end{array}$ \\
\hline Procedure & $\begin{array}{l}\text { Comprises a specified sequence of steps or instructions to re- } \\
\text { alize an end (1, 2005). }\end{array}$ \\
\hline Principle & $\begin{array}{l}\text { A basic generalization that is accepted as true and that can be } \\
\text { used as a basis for reasoning or conduct }(1,2005) .\end{array}$ \\
\hline
\end{tabular}

For instance, a Principle RIO is structured as Introduction, Facts, Principle Statement, Guidelines, Example, Non-example, Analogy, and Instructor Notes. Some of these content items are mandatory and others optional. Table 6.2 shows the content items of RIO and RLO Overview and Summary.

Content and Practice items support the RIO's learning objective, and Assessment items are used by RIO and RLO to measure mastery. Content items are classified as a definition, example, review, next steps, analogy, topology illustration, block diagrams, introduction, outline, table, staged table, non-example, etc.

Practice items are activities that give the learners the chance to apply their skills and knowledge. Practice must have a direct relationship with the learning objective of the RIO. All types of practice can be applied in RIO (e.g. true and false test, Multiple Choice Questions, matching, fill in the blanks, etc.). The last component of an RIO is the assessment, used to determine gaps in knowledge and skills before taking the RLO and to ensure that the learner has 
mastered the objective of the RIO. There are two types of assessment, namely pre-assessment and post-assessment. Figure 6.2 shows a UML class diagram representation of the Cisco RIO content model.

Table 6.2 0 verview of content items to be used for RIO and RLO $((M)=$ Mandatory, $(0)=$ Optional)

\begin{tabular}{|c|c|}
\hline RLO-RIO type & Content items \\
\hline RLO overview & $\begin{array}{l}\text { Introduction }(M) \text {, importance }(M) \text {, objectives }(M) \text {, prerequi- } \\
\text { sites }(M) \text {, scenario }(\mathrm{O}) \text {, outline }(M)\end{array}$ \\
\hline RLO summary & Review $(\mathrm{M})$, next steps $(\mathrm{O})$, additional resources $(\mathrm{O})$ \\
\hline Concept RIO & $\begin{array}{l}\text { Introduction }(\mathrm{M}) \text {, facts }(\mathrm{O}) \text {, definition }(\mathrm{M}) \text {, example }(\mathrm{M}) \text {, } \\
\text { non-example }(\mathrm{O}) \text {, analogy }(\mathrm{O}) \text {, instructor notes }(\mathrm{O})\end{array}$ \\
\hline Fact RIO & Introduction $(\mathrm{M})$, facts $(\mathrm{M})$, instructor notes $(\mathrm{O})$ \\
\hline Procedure RIO & $\begin{array}{l}\text { Introduction }(\mathrm{M}) \text {, facts }(\mathrm{O}) \text {, procedure table }(\mathrm{M}) \text {, decision ta- } \\
\text { ble }(\mathrm{M}) \text {, combined table }(\mathrm{M}) \text {, demonstration }(\mathrm{O}) \text {, instructor } \\
\text { notes }(\mathrm{O})\end{array}$ \\
\hline Process RIO & $\begin{array}{l}\text { Introduction }(\mathrm{M}) \text {, facts }(\mathrm{O}) \text {, staged table }(\mathrm{M}) \text {, block diagrams } \\
(\mathrm{M}) \text {, cycle charts }(\mathrm{M}) \text {, instructor notes }(\mathrm{O})\end{array}$ \\
\hline Principle RIO & $\begin{array}{l}\text { Introduction }(\mathrm{M}) \text {, facts }(\mathrm{O}) \text {, principle statement }(\mathrm{O}) \text {, guide- } \\
\text { lines }(\mathrm{M}) \text {, example }(\mathrm{M}) \text {, non-example }(\mathrm{O}) \text {, analogy }(\mathrm{O}) \text {, in- } \\
\text { structor notes }(\mathrm{O})\end{array}$ \\
\hline
\end{tabular}

Each Component, RLO or RIO is annotated with metadata that describes its characteristics, purpose and relationships with other objects. We define a metadata profile that collects several elements from Dublin Core (to identify the general information of an LO) and LOM (to identify the technical and educational information of an LO) metadata standards. We also add several metadata elements that describe the LSM information associated with the LO. The proposed metadata profile is described in Table 6.3. 
Chapter 6.

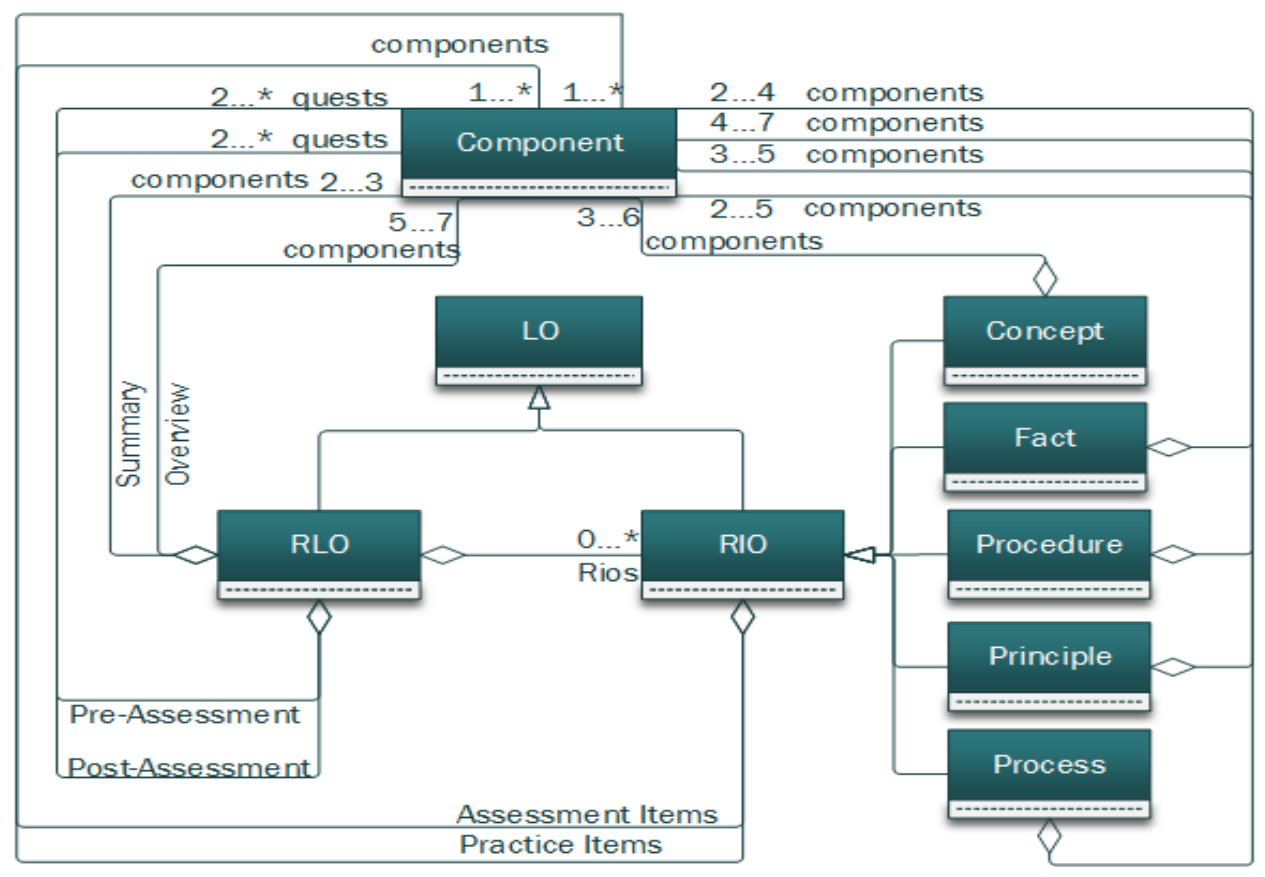

Figure 6.2 Cisco RIO content model UML dass diagram

Table 6.3 The Proposed Metadata Profile

\begin{tabular}{llll}
\hline Source & Category & Element & Mandatory \\
\hline \hline Dublin Core & General & Title & Yes \\
\cline { 3 - 3 } & Creator & Yes \\
\cline { 3 - 3 } & Subject & Yes \\
\cline { 2 - 3 } & Description & No \\
\cline { 2 - 3 } & Publisher & No \\
& Contributor & No \\
\cline { 2 - 3 } & Date & Yes \\
\cline { 2 - 3 } & Type & Yes \\
\cline { 2 - 3 } & Format & No \\
& &
\end{tabular}


The LO Content Model

\begin{tabular}{|c|c|c|c|}
\hline Source & Category & Element & Mandatory \\
\hline \multirow[t]{6}{*}{ Dublin Core } & \multirow[t]{6}{*}{ General } & Identifier & No \\
\hline & & Source & No \\
\hline & & Language & Yes \\
\hline & & Relation & No \\
\hline & & Coverage & No \\
\hline & & Rights & Yes \\
\hline \multirow[t]{11}{*}{$L O M$} & \multirow[t]{8}{*}{ Educational } & Interactivity Type & No \\
\hline & & Learning & No \\
\hline & & Resource Type & \\
\hline & & Intended End & No \\
\hline & & User Role & \\
\hline & & Context & No \\
\hline & & Typical Age & No \\
\hline & & Range & \\
\hline & \multirow[t]{3}{*}{ Classification } & $\begin{array}{l}\text { Purpose (Learning } \\
\text { Objective) }\end{array}$ & Yes \\
\hline & & Description & Yes \\
\hline & & Keywords & No \\
\hline \multirow{3}{*}{$\begin{array}{l}\text { Proposed Metadata } \\
\text { for learning style }\end{array}$} & \multirow[t]{3}{*}{ Learning Style } & Model & Yes \\
\hline & & Dimension & Yes \\
\hline & & Name & Yes \\
\hline
\end{tabular}


Chapter 6.

\subsection{Conclusion}

This chapter has introduced the Cisco RIO model, a LO content model. We have selected the Cisco RIO model to be our content model in the LO development process. Each LO is classified as RIO or RLO and it consists of several components. The component, RIO, and RLO are labeled with a special set of metadata that support our framework for generating customized LO.

Next chapter describes the second model in our framework, the Customization Model. The idea behind the Customization Model will be described in details and also its development methodology. 


\section{Chapter 7}

The Customization Model

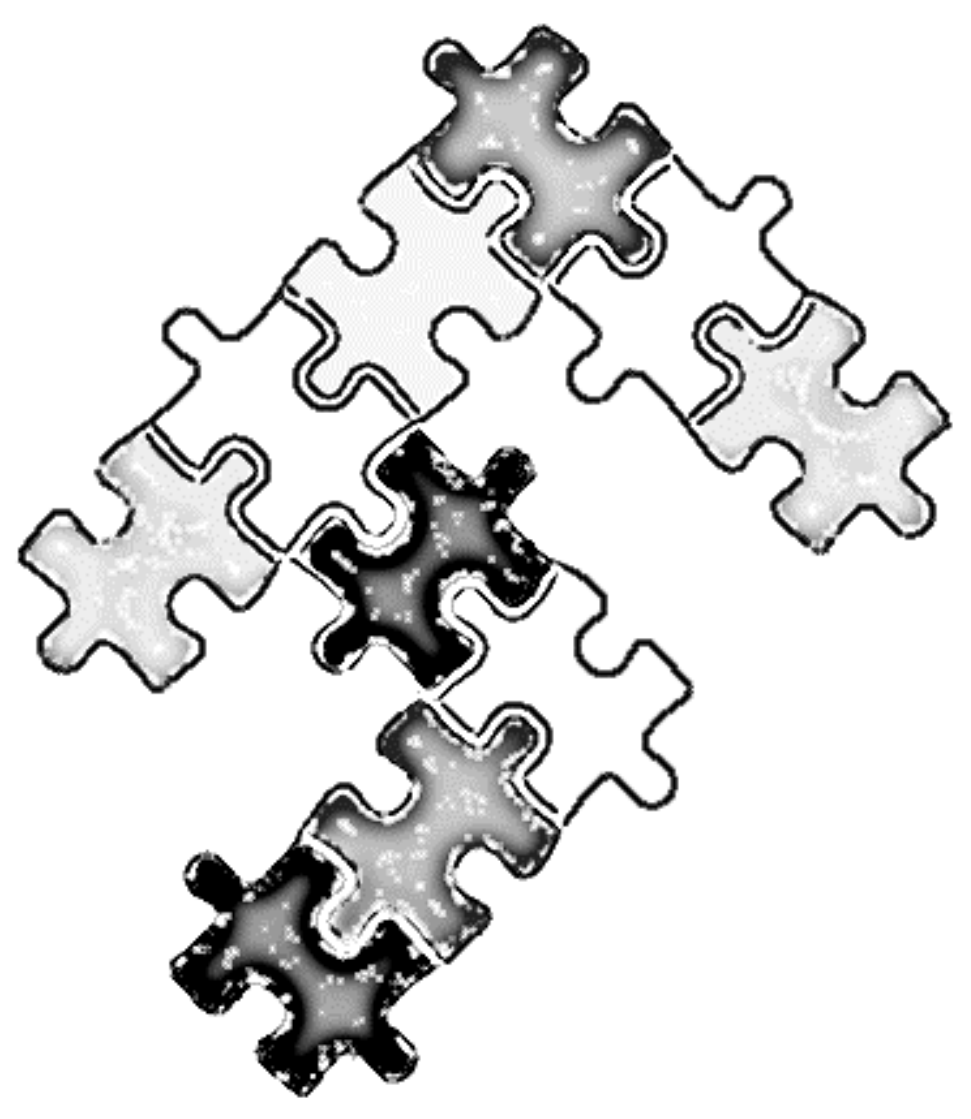




\section{Chapter 7.}

Most personalized e-Learning models and frameworks rely heavily on the learner model as the main source of variability. The learner model is considered a pivotal issue to enforce customization/personalization in e-Learning environments. It contains important information about the learner's personal data, cognitive traits, knowledge level, and LSs and preferences, which can be used to adapt the e-Learning environments to his needs. The possibility of creating learner-based content that varies with different learner characteristics is still being pursued by learning environment designers. These characteristics have been formalized through the concept of LS, which is part of the learner model.

LS is a dialectical issue in the personalization and customization of e-Learning environments because of the numerous factors (intellectual, background, learning environment, physical, social, teaching method, etc.) that affect it (Abante, Almendral, Manansala, \& Mañibo, 2014). It gives opportunities to provide and implement interventions suited to personal demands (Truong, 2016). Furthermore, learning preferences can provide many valuable pieces of advice for both learner and instructor. For learners, knowing their LS may help to build their self-confidence and self-efficacy, prevent misunderstanding with teachers, enhance study skills and increase the desire for participation in the learning process (Chen \& Chen, 2015; El-Hmoudova, 2015). For instructors, it will be able to introduce reports that enable them to develop their educational planning, understand the learner's learning process and create and customize learning contents with different personalized designs according to the learner's style (Graf, Kinshuk, \& Liu, 2009; Isik \& Kuzudisli, 2015).

Learning contents and related issues with LSs have been very popular in scientific research in recent years, for example, among others, (Vesin, Ivanović, Klašnja-Milićević, \& Budimac, 2011; Isik \& Kuzudisli, 2015; Kurilovas, Kubilinskiene, \& Dagiene, 2014; Valaski, Malucelli, \& Reinehr, 2011). Felder reported that learners with a dominant LS might have difficulties if the instructional materials are designed in a way not consistent with their style (Felder R. M., 1996). Therefore, incorporating LSMs in designing and constructing learning materials can help those learners to avoid their difficulties 
and increase their learning efficiency. A recent survey conducted by Thalmann for the purpose of determining the adaptation criteria for the personalized delivery of learning materials even concluded that the usefulness of the preparation of learning content according to the learner's LSs is highly considered. Hence, the integration of LSMs into learning content authoring systems seems valuable (Thalmann, 2014). Also, Kurilovas et al. (2014) analyzed the interconnections between the learners' LSs, suitable learning method, their favored learning activities, and the learning objects types. The research defined an ontology to create learners' personalized learning environments containing LOs, the preferred learning activities and methods according to their LSs (Kurilovas, Kubilinskiene, \& Dagiene, 2014). Truong gives some important recommendations and guidelines by reviewing 51 research studies related to integrating LSs and adaptive e-learning systems. One of his recommendations is to provide an opportunity to discover the integration of various LSMs or the combination of different LSMs into adaptive elearning systems (Truong, 2016).

Indeed, the term "LSM" was coined in 1970. The learning community has produced successive refinements that have resulted in a large list of proposals, many of them having some degree of overlapping concepts. As a matter of fact, in (Coffield, Moseley, Hall, \& Ecclestone, 2004) 53 different LSMs were classified into a hierarchal structure called Families of LSs, and 13 LSMs were evaluated regarding the theory behind each model. Such diversity makes the development of a general purpose, multi-model learning tool very difficult.

As a consequence, to the best of our knowledge, all the research studies in the personalized learning environments frameworks tend to adapt a Single-model of LS, leaving others uncovered. Single-model means applying only one LSM for the purpose of the personalization process. For instance, personalized frameworks based on the Felder-Silverman LSM such as (Begam \& Ganapathy, 2012; Jovanovic, GaLsevic, Knight, \& Richards, 2007), personalized frameworks based on Kolb LSM such as (Wang \& Chen, 2008; Yang $\& \mathrm{Wu}, 2009$ ), and several frameworks based on anonymous LSM such as (Wang, Tsai, Lee, \& Chiu, 2007; Vesin, Ivanović, Klašnja-Milićević, \& 


\section{Chapter 7.}

Budimac, 2011; Valaski, Malucelli, \& Reinehr, 2011). Using a Single-LSM in the e-Learning environments has limitations, such as the lack of interoperability between systems, the lack of reusability of the learning materials, creating learning materials limited to one LSM, and limiting learning activities with one LSM.

This dramatic growth in the use of LSMs led to similar growth in the learning materials that had been developed to meet the needs of educational communities and the learners' LS. Consequently, the need for the integration of LSMs is a crucial issue to:

1) support the semantic LSMs interoperability,

2) facilitate mapping between different LSMs,

3) increase the reusability of learning materials with various e-learning systems that use different LSMs,

4) decrease the concept overlapping between the various LSMs,

5) develop a customized e-Learning frameworks and applications based on a Multi-LS model,

6) preserve the basic modularization of the original LSMs,

7) unify learners' characteristics, and preferences with the usage of the original psychometric instrument associated with each LSM.

8) support customized/adaptive learning material design and development,

9) define criteria to be used by recommender systems to suggest materials according to several LSMs,

10) assist learners to search for learning materials (with different LSMs) semantically, and

11) enable knowledge reusability for both humans and systems.

As a result, developing a GLSMO that represents a generalization of several models is necessarily a complex task. Sometimes the knowledge implicitly makes the ontology formalization process difficult. We will use an ontological engineering methodology, On-To-Knowledge method, for the construction of the GLSMO. In parallel with the On-To-Knowledge method, we adapt a hybrid-ontology approach for the integration process of the LSMs, as defined by Buccella in (Buccella, Cechich, \& Brisaboa, 2003). 
First of all, the criteria behind the selection of the seven LSMs are discussed, followed by an explanation of the selected LSMs, a brief description of the On-To-Knowledge method and the GLSMO.

\subsection{The selection criteria of the LSMs}

To develop the GLSMO, the following seven LSMs were selected: Kolb's Experiential Learning LSM, The Myer-Briggs Type Indicator Theory (MBTI), Riding's Cognitive Style Model, Gregorc's Mind Styles Model, the Felder-Silverman Model, Honey and Mumford's Model, and the Keirsey Temperaments.

A report by Coffield identified the existence of 71 LSMs and defined a family of LSs that contains approximately 53 models, 13 of which were evaluated in (Coffield, Moseley, Hall, \& Ecclestone, 2004). We chose the seven models, which will be described later according to two criteria:

\section{1- The extensive usage in scientific research}

As pointed by Özyurt et. al. (2015), There are 69 articles published from 2005 to 2014 dealing with the employment of the LSMs in the Adaptive Hypermedia Educational Systems (Felder-Silverman 29 articles, Kolb 10 articles, Riding's Cognitive style 6 articles, MyersBriggs Type Indicator 4 articles, and Honey \& Mumford and Gregorc 3 articles). Also, Truong (2016) investigated the integration of LSMs and the adaptive e-Learning systems. His study includes 51 articles (Felder-Silverman, Kolb, and Honey \& Mumford).

\section{2- Curry's classification of LSS}

Curry suggested a classification model in (Curry, 1983) which is known as the Curry Onion Model. The model was organized into three strata, from inner to outer: Cognitive Personality, Information Processing, and Instructional Preferences. The Instructional Preferences stratum describes the preferred way the individual interacts with the learning environment. The Felder-Silverman model is an instance of this stratum. The Information Processing stratum focuses on the indi- 
vidual's approach to processing information. Two models representing this stratum are Kolb and Honey \& Mumford. Finally, the Cognitive Personality stratum describes the learning behavior associated with the individual's personality style, not with the learning environment. The Riding, Myer-Briggs, and Gregorc models represent the inner stratum.

\subsection{The On-To Knowledge - Ontology Development Methodology}

The On-To-Knowledge approach focuses on the application-driven development of ontologies. It covers aspects from the Knowledge Management project and the Ontology-based Knowledge Management application (Sure \& Studer, 2002). The On-To-Knowledge methodology conforms to the IEEE 1074-1997 Standard for Developing Software Life Cycle Processes (IEEE, 1997) which helps to ultimately achieve quality ontologies.

The design of the On-To-Knowledge methodology focuses on the creation of ontologies to improve Knowledge Management in large and distributed organizations (Staab \& Studer, 2009). The On-To-Knowledge methodology is based on two distinct processes: the Knowledge Meta Process, focusing on the development of ontologies, and the Knowledge Process relating to the post-implementation process of the ontology. Our work focuses on the Knowledge Meta Process. The Knowledge Meta Process consists of five main phases (Staab \& Studer, 2009): Feasibility Study, Kick-off, Refinement, Evaluation, and Maintenance (see Figure 7.1).

\subsubsection{Feasibility Study phase}

Such a knowledge management system may only function well if it is properly integrated into a wider organizational perspective. There are several factors, other than technology, that determine the success or failure of any knowledge management system. To interpret and analyze these factors, we must perform a feasibility study (scoping and problem analysis study). The feasibility study is used, firstly, to identify problems and opportunity areas (all resources) and potential solutions, and secondly, to put them into a wider organizational perspective. The feasibility study helps decision makers to 
clarify the economic and technical project issues, to pick the most promising focus area and target a solution. An impact and improvements study can also be carried out for the selected solution. At the end of this phase, the decision maker or the ontology engineer must decide whether or not it is possible to continue with the ontology development process. The feasibility study phase serves as the basis for the Kick-off phase.

\subsubsection{Kick-off phase}

The actual development of the ontology starts in this phase. The kick-off phase is devoted to identifying the ontology requirements. Several information should be identified such as the goal and the domain of the ontology, the available knowledge sources (e.g. domain experts, organization charts, business plans, dictionaries, index lists, DB-schemas etc.), the design guidelines, the potential users, the use cases, the application support by the ontology, the competency questionnaire (i.e. an overview of possible queries to the system, indicating the scope and content of the domain ontology), and the potentially reusable ontologies. These requirements should guide an ontology engineer in deciding on the acceptance or rejection of concepts and relationships and the preliminary hierarchical structure of the ontology.

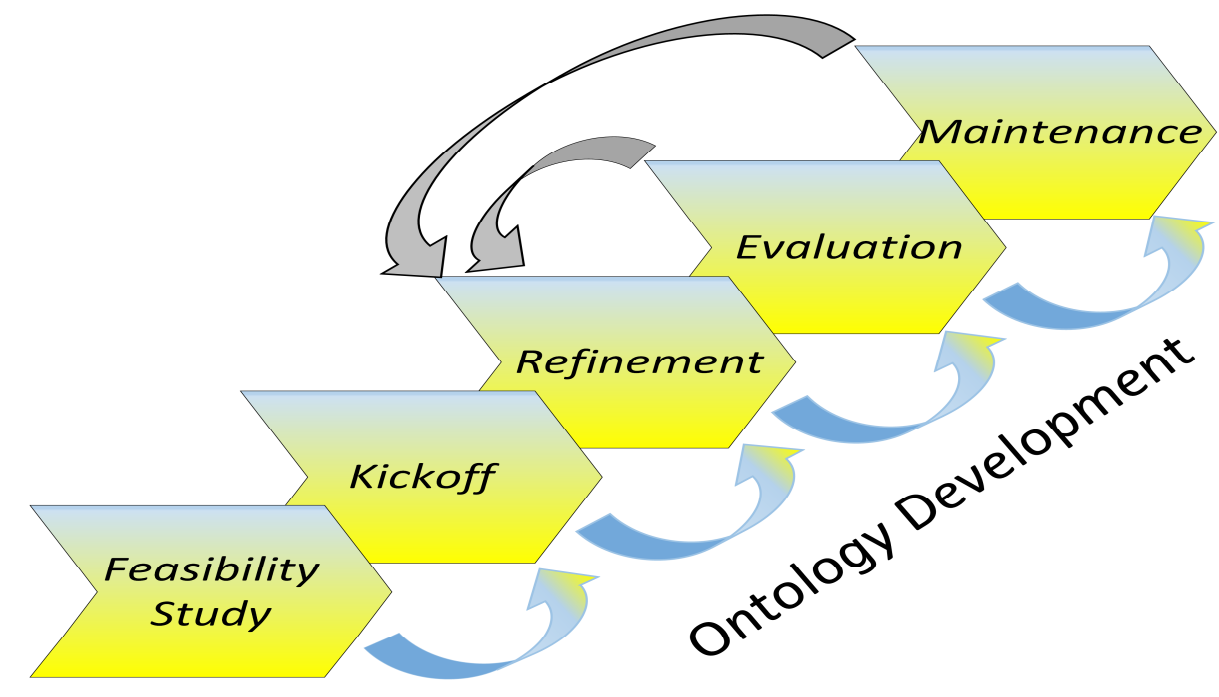

Figure 7.1 The On-To-Knowledge five phases 


\section{Chapter 7.}

The outcome of this phase is a semi-formal description of the contents of the ontology, for example, using conceptual maps and descriptive text. Once the requirements are adequately captured, we may proceed with the next phase. At the end of this phase, the decision maker or the ontology engineer in collaboration with domain experts must decide whether to move forward with the next phase or to collect further information.

\subsubsection{Refinement phase}

The goal of the refinement phase is to create an application-oriented target ontology according to the requirement specification produced in the kick-off phase, in three steps:

- Baseline taxonomy

In this step, the ontology engineer gathers all semi-formal descriptions (collected from the kick-off phase) which he uses to form the taxonomical structure that contains knowledge entities (concepts) and relationships.

- Knowledge Elicitation

With the participation of domain experts, the knowledge elicitation step is based on the information provided from the kick-off phase and the baseline taxonomy to develop a "Seed Ontology" containing the relevant concepts, their relationships, and axioms. The "Seed Ontology" is usually expressed at an epistemological level. The ontology engineer can extract the knowledge entities from relevant knowledge sources using any concurrent approach such as a top-down, bottomup, or middle-out approach, or mixed approaches. However, the Baseline taxonomy and the Knowledge Elicitation steps are cyclic in themselves, which means that the ontology engineer may start to interview domain experts again and use the already formalized ontology as a base for discussions. It might be helpful to visualize the taxonomic hierarchy and give the domain experts the task to add attributes to concepts and to draw relations between concepts. For example, the ontology engineer presents the domain experts with the taxonomy in the form of a mind map. 
- Formalization

The formalization step is responsible for converting the "Seed Ontology" into the "Target Ontology" using any formal ontology representation language, like XOL, RDF, or OWL.

The usage of potentially reusable ontologies (identified during the kickoff phase) may improve the speed and quality of development during the whole refinement phase. The major decision that needs to be taken to complete this step is whether the ontology fulfills the requirements captured in the previous kick-off phase. For this, the ontology engineer compares the initial requirements with the current status of the ontology.

The outcome of this phase is the "target ontology" that needs to be evaluated in the next step.

\subsubsection{Evaluation phase}

A systematic evaluation of the ontologies might lead to a consistent level of quality, which is crucial for its acceptance in a real-world application. This stage is devoted to proving the correctness and usefulness of the ontology. We distinguish between three different types of evaluation:

i) Technology-focused evaluation

There are two important aspects: (1) the evaluation of properties of ontologies generated by development tools (e.g. language conformity (Syntax) and consistency (Semantics)), and (2) the evaluation of the technology properties (e.g. interoperability, scalability, etc.).

ii) User-focused evaluation

Evaluates whether users are satisfied by the Knowledge Management application. Feedback from beta users may be a valuable input for further refinement of the ontology.

iii) Ontology-focused evaluation.

The ontology engineer checks the "Target Ontology" is sufficient with the Ontology Requirements Specification Document and answers the competency questions investigated in the kickoff phase.

The result of this phase is an evaluated ontology, ready for incorporating into a system. In most cases, it is expected that an ontology engineer will perform 


\section{Chapter 7.}

several iterations of "Evaluation - Refinement - Evaluation" until the resulting ontology supports the decision of incorporating it into a system.

\subsubsection{Maintenance}

On-To-Knowledge includes ontology maintenance as part of the system software engineering process. Maintenance is normally devoted to clarifying who is responsible for maintenance, how it is performed and the time intervals between two successive maintenance processes. There have to be strict rules about the update/insert/delete processes within the ontology and valuable user feedback may be used as guidance for identifying new changes to it (as in the refinement phase), e.g. expansion and tailoring procedures can be defined.

\subsection{Developing the Global Learning Style Model Ontology (GLSMO)}

From the perspective of e-learning, where there is no single model for either the learner's personality or content structure, the formal description of knowledge is important for integration and interoperability between models. The explicit description of knowledge weakens the assumptions on the implicit nature of information (Rani, Nayak, \& Vyas, 2015). In particular, using ontologies as tools for specifying the semantic interoperability of different LSMs could improve communication and interaction between computers and humans by specifying the semantics of LSMs used in the human-computer communication process.

To develop the GLSMO, we used a strategy that mixes Buccella's hybridontology approach (Buccella, Cechich, \& Brisaboa, 2003) for the integration process inside the On-To-Knowledge methodology phases (as described in the previous section), see Figure 7.2.

The GLSMO development methodology consists of five phases. The feasibility study phase consists of identifying the resources. A complete analysis of information resources and a comparative analysis for the LSMs will be introduced. At the end of this phase, the developer must decide whether it is possible to continue the development process or not. The kick-off phase is concerned with the establishment of the ontology requirements specification. It 
provides a semi-formal description of the ontology (tables, conceptual maps, and text). Additionally, the primitive terms will be identified and the initial view of the ontology will be defined. The refinement phase goal is to create an application-oriented target ontology according to the requirements specification. All the local ontologies (the LSMs) will be established for each LSM. At the end of this phase, the mapping (and all relations) between the global ontology and the local ontologies will be defined. Finally, the evaluation and maintenance phases serve as a proof for the correctness and usefulness of the ontology. The ontology is then deployed and can be improved over time.

In the rest of this section, we describe the steps followed to create the GLSMO.

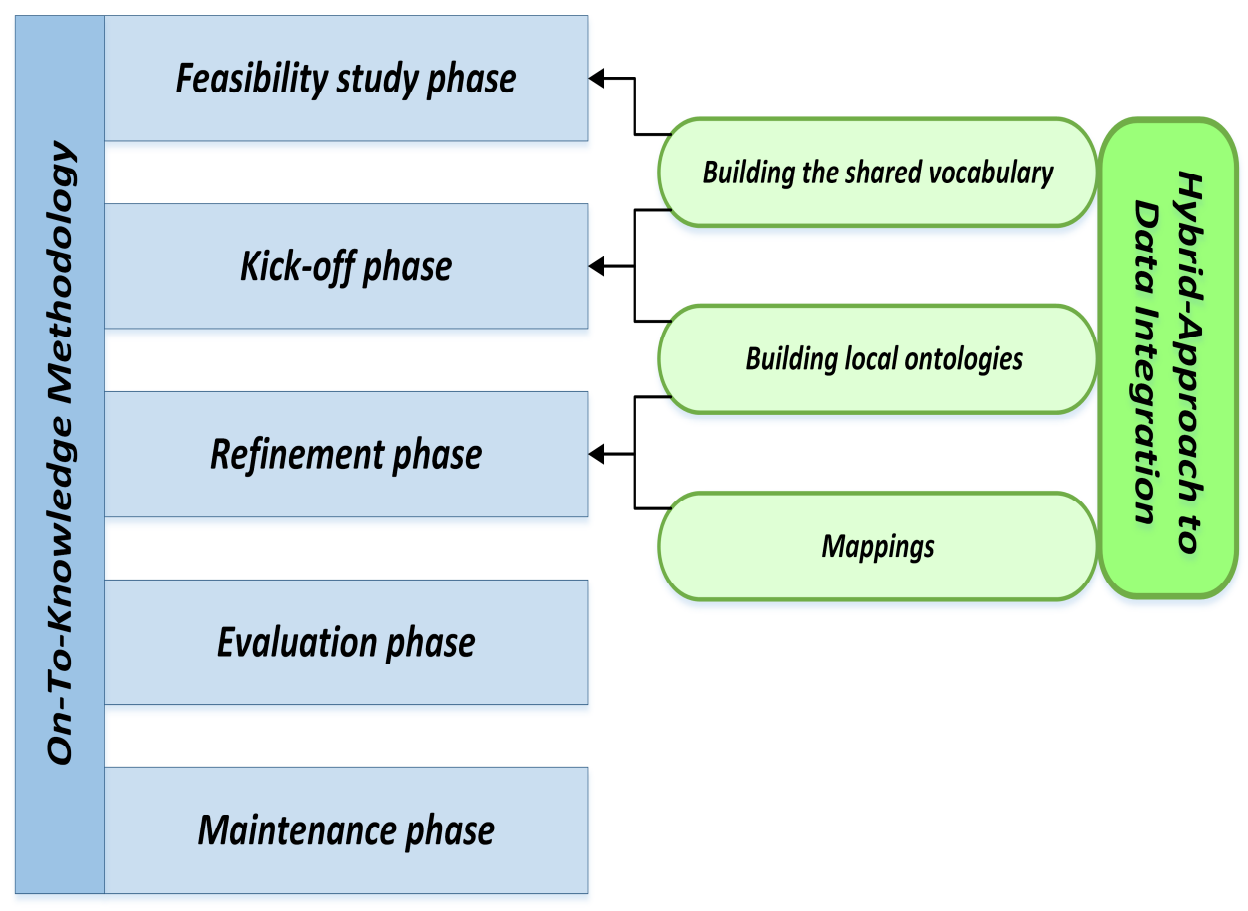

Figure 7.2 The development strategy of GLSMO 
Chapter 7.

\subsubsection{Feasibility study phase}

In this first phase, we will identify the problem, the opportunity area and the selection criteria behind our GLSMO.

\subsubsection{Problem identification}

To enforce customization and personalization in e-learning environments, the learner's needs and preferences appear to be the main sources of variability. As a consequence, we need to explore -and exploit- the learner's LSM. In general, a learner's learning needs, characteristics, and activities can be linked to the so-called learner's LS to provide the instructor with extensive knowledge about the learner's characterization in perceiving and processing information. Several research studies use a Single-LS model. The major disadvantage appears when using a Single-LS model in the e-Learning environments is creating learning materials limited to only one LSM which minimize the ability of customization during the learning materials development process. Consequently, the possibility of (re)-using learning materials from different LSMs will decrease.

As a vast number of learning materials have been created to meet various learner's LSs, the need to develop a GLSMO that represents a generalization of several models is necessary to cope with the foregoing disadvantages and to increase the reusability of the different learning materials with different LSs.

\subsubsection{Selection criteria}

Here, we identified several information resources related to LSMs, many of which are available on the Internet. To create the ontology, we collected information from studies available in scientific databases (ScienceDirect $^{6}$, IEEE Xplore ${ }^{7}$, CiteSeerx ${ }^{8}$, and Google Scholar ${ }^{9}$ ), Elsevier journals, and Springer journals.

\footnotetext{
${ }^{6}$ www.sciencedirect.com

${ }^{7}$ www.ieeexplore.ieee.org

${ }^{8}$ www.citeseerx.ist.psu.edu

${ }^{9}$ www.scholar.google.com
} 
The selection criteria is described in detail in Section 7.1.

\subsubsection{Kick-off phase}

In this phase, we executed the primitive terms extraction process. The information to be used in the ontology was collected, consisting of a corpus of primitive concepts, relations, and characteristics selected from the seven LSMs. We conducted a comparative analysis of the LSMs to extract all this information.

\subsubsection{Comparative analysis}

From our study on the seven LSMs, described in Section 4.2 (chapter 4), some similarities were detected in the structure, scientific basis, and characteristics of the LSMs.

\section{1- The LSMs Structure}

The overall model structure is a two or four-dimensional model that represents different individual's information treatment modalities (grasping or organizing etc.). Subsequently, each dimension is made up of two uncorrelated aspects or poles (e.g. Sensing/Intuitive in MBTI theory). LS is the result of the combination of the poles. For instance, The Kolb, Riding, and Gregorc are two-dimensional models, while MBTI, Felder-Silverman, and Keirsey are four-dimensional models. Table 7.1 shows the classification of the proposed concepts in the seven models.

\section{2- The LSMs' Scientific Base}

Some LSMs have a shared scientific basis (See Table 7.2). The MBTI, Keirsey, and Felder-Silverman models define an individual's grasping information (Sensing/Intuitive) based on Jung's personality type theory. The Kolb and Gregorc models describe the individual's grasping information as a Concrete or Abstract mode. Based on Kolb's theory, the Felder-Silverman model uses the Active/Reflective mode for an 
Chapter 7.

individual's information processing. Riding and Felder-Silverman define the individual's information input modality according to the work of Paivio in Dual Coding Theory (Paivio, 2006) and the Piaget Theory

Table 7.1 The proposed classification of LSM s' concepts

\begin{tabular}{llll}
\hline \multicolumn{1}{c}{ Model } & \multicolumn{1}{c}{ Dimension } & Pole & Learning Style \\
\hline \hline Kolb & Learning Mode & Stage & Learning Style \\
\hline MBTI & Personality Dichotomy & Pole & Personality Type \\
\hline Riding & Cognitive Dimension & Habitual Way & Cognitive Style \\
\hline Gregorc & Mind Ability Dimension & Mind Preference & Mind Style \\
\hline Felder-Silverman & Dimension & Pole & Learning Style \\
\hline $\begin{array}{l}\text { Honey } \text { and } \text { Mum- } \\
\text { ford }\end{array}$ & - & & Learning Style \\
\hline Keirsey & Personality Dichotomy & Pole & Temperament
\end{tabular}

Table 7.2 The LSM s' scientific bases

\begin{tabular}{ll}
\hline \multicolumn{1}{c}{ The Scientific Base } & \multicolumn{1}{c}{ The Learning Style Model } \\
\hline \hline Dewey, Lewin Experiential Learning (1933) & Kolb \\
\hline Piaget Theory of Cognition (1957) & Kolb - Riding - Felder-Silverman \\
\hline Jung Theory (1971) & MBTI - Keirsey - Felder-Silverman \\
\hline Paivio Dual Coding Theory (1971) & Riding - Felder-Silverman \\
& \\
\hline Witkin Field Independent/Dependent (1977) & Riding \\
\hline Kolb Experiential Learning Theory (1984) & Kolb - Felder-Silverman - Honey \& \\
& Mumford \\
\hline Pask Model (1988) & Felder-Silverman \\
\hline
\end{tabular}


of Cognition (Piaget, 1999). We can also consider Keirsey Temperaments as another classification for MBTI personality types. The Sequential/Random (Sequential/Global) mode of individual's organizing information is used in the Gregorc and Felder-Silverman models. A correlation was found between Active/Reflective poles on the Felder-Silverman model and Extravert/Introvert poles on MBTI (Sottilare, 2006; Felder \& L.K., 1988). There is also a correlation between Extravert/Introvert poles in MBTI and Kolb's Active/Reflective stages (Lawrence, 2015).

\section{3- The LSMs Characteristics}

From our study on the seven LSMs, we concluded that several common characteristics are shared among several dimensions in different models. Table 7.3 shows the link between the dimensions of several LSMs, described in Section 4.2, and the common characteristics identified. Due to space limitations, only 25 of the shared characteristics are shown in Table 7.3. Here we list only three of the relationships found:

1. A learner related to Kolb's Concrete Experience (Kolb-CE), FelderSilverman's Sensing (FS-S), MBTI's Sensing (MB-S), and Gregorc's Concrete (Gre-C) dimensions has several common characteristics, such as: Literal Manner, Tangible Facts, Direct and Hands-on Experience, Practical, and Concrete Thinking, among others.

2. The Felder-Silverman's Intuitive (FS-IN), Kolb's Abstract Conceptualization (Kolb-AC), MBTI's Intuitive (MB-IN), and Gregorc's Abstract (Gre-A) dimensions have various common characteristics, such as: Look at The Big Picture, Imagination, Endless Possibilities, Analyzing and Interpreting, Theoretical Connections, Logical Thinking, etc.

3. A learner related to both Felder-Silverman's Global (FS-Gl) and Riding's Wholist (Rdi-W) dimensions has several common characteristics, such as: Holistic Thinking, Divergent Thinking, and Content Map. 
Chapter 7.

Several common characteristics are related to several LSs in different models. For instance, Gregorc's Concrete-Sequential, Honey and Mumford's Theorist, MBTI's ISTJ (Introvert-Sensing-Thinking-Judging), and Felder-Silverman's Sensing-Active-Visual-Global LSs share a single characteristic named "Tangible Facts." Several characteristics are also associated with both dimensions and LSs at the same time. Honey and Mumford's Theorist LS is also characterized by the "Theoretical Connection" characteristic in Table 7.4, and related to MBTI's Intuitive (MB-IN), Kolb's Abstract Conceptualization (KolbAC) and Gregorc's Abstract dimensions (Gre-A), see Table 7.3. 
The Customization Model

\section{Table 7.3 Some Characteristics related to Dimensions of Learning Style M odels}

\begin{tabular}{|c|c|c|c|c|c|c|c|c|c|c|c|c|c|c|c|c|c|c|c|c|c|c|c|c|c|c|c|c|}
\hline \multirow[t]{3}{*}{ Characteristics } & \multicolumn{28}{|c|}{ Learning Style Models } \\
\hline & \multicolumn{4}{|c|}{ Kolb's Dimensions } & \multicolumn{7}{|c|}{ "Felder-Silverman's Dimensions } & \multicolumn{5}{|c|}{$\begin{array}{c}\text { Riding's Dimen- } \\
\text { sions }\end{array}$} & \multicolumn{8}{|c|}{ "Myer-Briggs's Dimensions } & \multicolumn{4}{|c|}{$\begin{array}{l}\text { Gregorc's Dimen- } \\
\text { sions }\end{array}$} \\
\hline & $\begin{array}{l}\text { Kolb } \\
-C E\end{array}$ & $\begin{array}{l}\text { Kolb } \\
- \text { AC }\end{array}$ & $\begin{array}{l}\text { Kolb } \\
- \text { RO }\end{array}$ & $\begin{array}{l}\text { Kolb } \\
-\mathrm{AE}\end{array}$ & $\begin{array}{l}\mathrm{FS} \\
-\mathrm{S}\end{array}$ & $\begin{array}{c}\text { FS- } \\
\text { IN }\end{array}$ & $\begin{array}{l}\text { FS } \\
-A\end{array}$ & $\begin{array}{l}\mathrm{FS} \\
-\mathrm{R}\end{array}$ & $\begin{array}{l}\mathrm{FS} \\
-\mathrm{Vi}\end{array}$ & $\begin{array}{c}\text { FS- } \\
\mathrm{Vr}\end{array}$ & $\begin{array}{l}\text { FS- } \\
\text { Sq }\end{array}$ & $\begin{array}{l}\text { FS- } \\
\text { Gl }\end{array}$ & $\begin{array}{l}\text { Rid } \\
-W\end{array}$ & $\begin{array}{c}\text { Rid } \\
-A\end{array}$ & $\begin{array}{l}\operatorname{Rid} \\
-\mathrm{Vr}\end{array}$ & $\underset{-I}{\operatorname{Rid}}$ & $\begin{array}{c}\text { MB } \\
-S\end{array}$ & $\begin{array}{l}\text { MB } \\
- \text { IN }\end{array}$ & $\begin{array}{l}\text { MB } \\
\text {-Th }\end{array}$ & $\begin{array}{l}\mathrm{MB} \\
-\mathrm{Fe}\end{array}$ & $\begin{array}{l}\text { MB } \\
\text {-Ext }\end{array}$ & $\begin{array}{l}\text { MB } \\
\text {-Intr }\end{array}$ & $\begin{array}{l}\text { MB } \\
-\mathrm{Pr}\end{array}$ & $\begin{array}{c}\mathrm{MB} \\
-\mathrm{Jd}\end{array}$ & $\begin{array}{l}\text { Gre } \\
-C\end{array}$ & $\begin{array}{l}\text { Gre } \\
-A\end{array}$ & $\underset{-S}{\text { Gre }}$ & $\underset{\mathrm{R}}{\mathrm{Gre}-}$ \\
\hline Literal Manner & $x$ & & & & $x$ & & & & & & & & & & & & $x$ & & & & & & & & $x$ & & & \\
\hline Tangible Facts & $x$ & & & & $x$ & & & & & & & & & & & & $x$ & & & & & & & & $x$ & & & \\
\hline $\begin{array}{l}\text { Direct, Hands-on } \\
\text { Experience }\end{array}$ & $x$ & & & & $x$ & & & & & & & & & & & & $x$ & & & & & & & & $x$ & & & \\
\hline Practical & $x$ & & & & $x$ & & & & & & & & & & & & $x$ & & & & & & & & $x$ & & & \\
\hline $\begin{array}{l}\text { Concrete Think- } \\
\text { ing }\end{array}$ & $x$ & & & & $x$ & & & & & & & & & & & & $x$ & & & & & & & & $x$ & & & \\
\hline $\begin{array}{l}\text { Look at The Big } \\
\text { Picture }\end{array}$ & & $x$ & & & & $x$ & & & & & & & & & & & & $x$ & & & & & & & & $x$ & & \\
\hline Imagination & & $x$ & & & & $x$ & & & & & & & & & & & & $x$ & & & & & & & & $x$ & & \\
\hline $\begin{array}{l}\text { Analyzing and In- } \\
\text { terpreting }\end{array}$ & & $x$ & & & & $x$ & & & & & & & & & & & & $x$ & & & & & & & & $x$ & & \\
\hline $\begin{array}{l}\text { Theoretical Con- } \\
\text { nections }\end{array}$ & & $x$ & & & & $x$ & & & & & & & & & & & & $x$ & & & & & & & & $x$ & & \\
\hline Logical Thinking & & $x$ & & & & $x$ & & & & & & & & & & & & $x$ & & & & & & & & $x$ & & \\
\hline Linear Thinking & & & & & & & & & & & $x$ & & & $x$ & & & & & & & & & & & & & $x$ & \\
\hline Pictorial & & & & & & & & & $x$ & & & & & & & $x$ & & & & & & & & & & & & \\
\hline $\begin{array}{l}\text { Written Demon- } \\
\text { stration }\end{array}$ & & & & & & & & & & $x$ & & & & & $x$ & & & & & & & & & & & & & \\
\hline
\end{tabular}


Chapter 7.

Table 7.3 Some Characteristics related to Dimensions of Learning Style M odels (Continue)

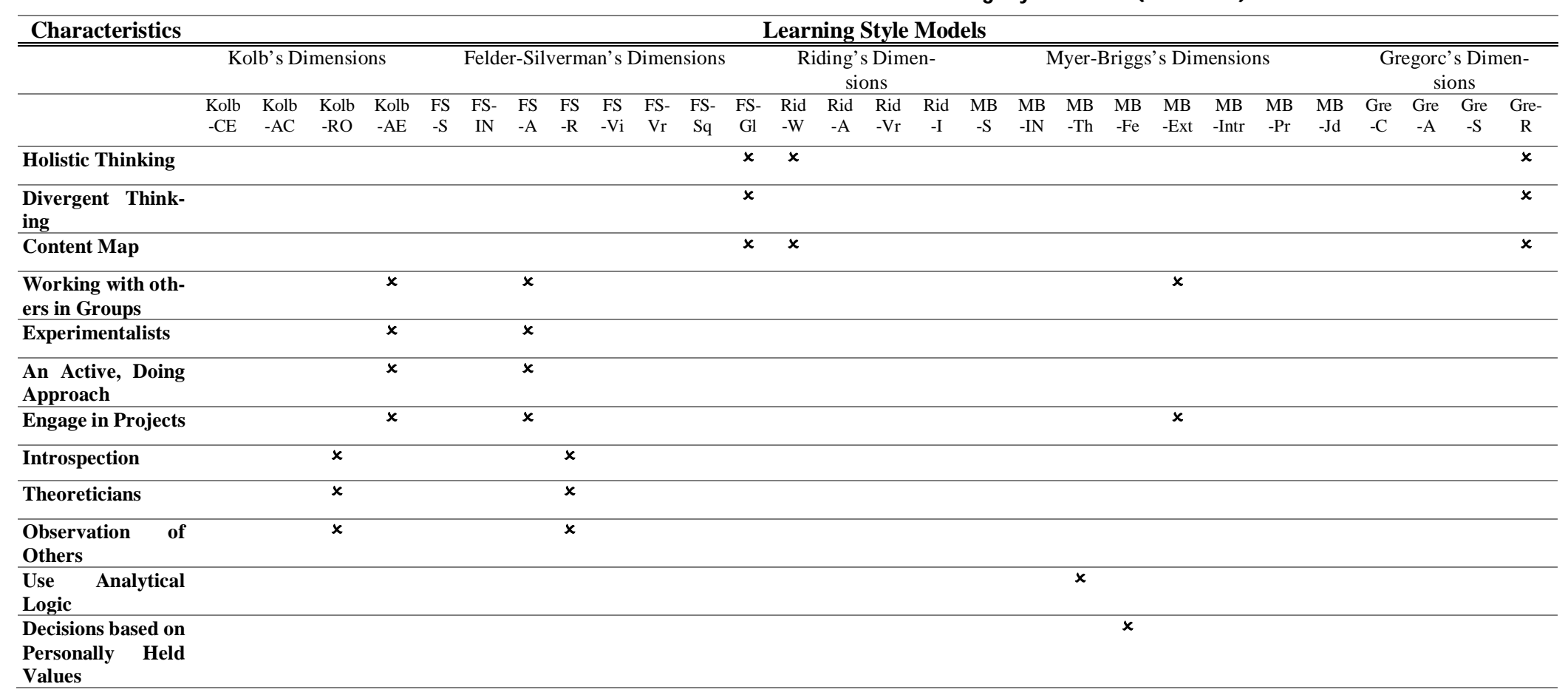


The Customization Model

Table 7.4 Characteristics of Honey and Mumford's learning styles

\begin{tabular}{|c|c|c|c|c|}
\hline \multirow[t]{2}{*}{ Characteristics } & \multicolumn{4}{|c|}{ Honey and Mumford's learning styles } \\
\hline & Activist & Reflector & Theorist & Pragmatist \\
\hline Here-and-Now Tasks & $x$ & & & \\
\hline Brainstorming & $x$ & & & \\
\hline Action Learning & $x$ & & & \\
\hline Working in Small Groups & $x$ & & & \\
\hline Collects data \& Analyses & & $x$ & & \\
\hline Observing and Thinking & & $x$ & & \\
\hline Self-directed Learning & & $x$ & & \\
\hline Cautious and Thoughtful & & $x$ & & \\
\hline Theories \& Facts & & & $x$ & \\
\hline Theoretical Connections & & & $x$ & \\
\hline $\begin{array}{l}\text { Drawing information into a } \\
\text { systematic and logical Theory }\end{array}$ & & & $x$ & \\
\hline Complex Tasks & & & $x$ & \\
\hline $\begin{array}{l}\text { Trying out new Ideas and The- } \\
\text { ories }\end{array}$ & & & & $x$ \\
\hline Practical Applications & & & & $x$ \\
\hline Action Learning & & & & $x$ \\
\hline Problem-Solving & & & & $x$ \\
\hline
\end{tabular}

Peter Honey and Alan Mumford developed four LSs based on Kolb, with no clear dependence on basic dimensions, as do almost all the other LSMs. Honey and Mumford's LSM and its' characteristics are interconnected. Table 7.4 gives the characteristics of various LSs related to Honey and Mumford's LSM. For example, the Pragmatist student prefers to be Practical and enjoys Problem-Solving. Similar mappings have been made for the other LSMs. In this way we established the interconnections between the LSMs dimensions, LSs, and related characteristics.

As a result of the similarities in the structure, scientific bases, and characteristics of the reviewed models, we conduct a new classification (or shared vocabulary) associated with the dimensions of the reviewed models (See Table 7.5). Several models have shared dimensions that are similar in name, definition or characteristics. To describe the global model's dimensions, we applied a top-down approach. 


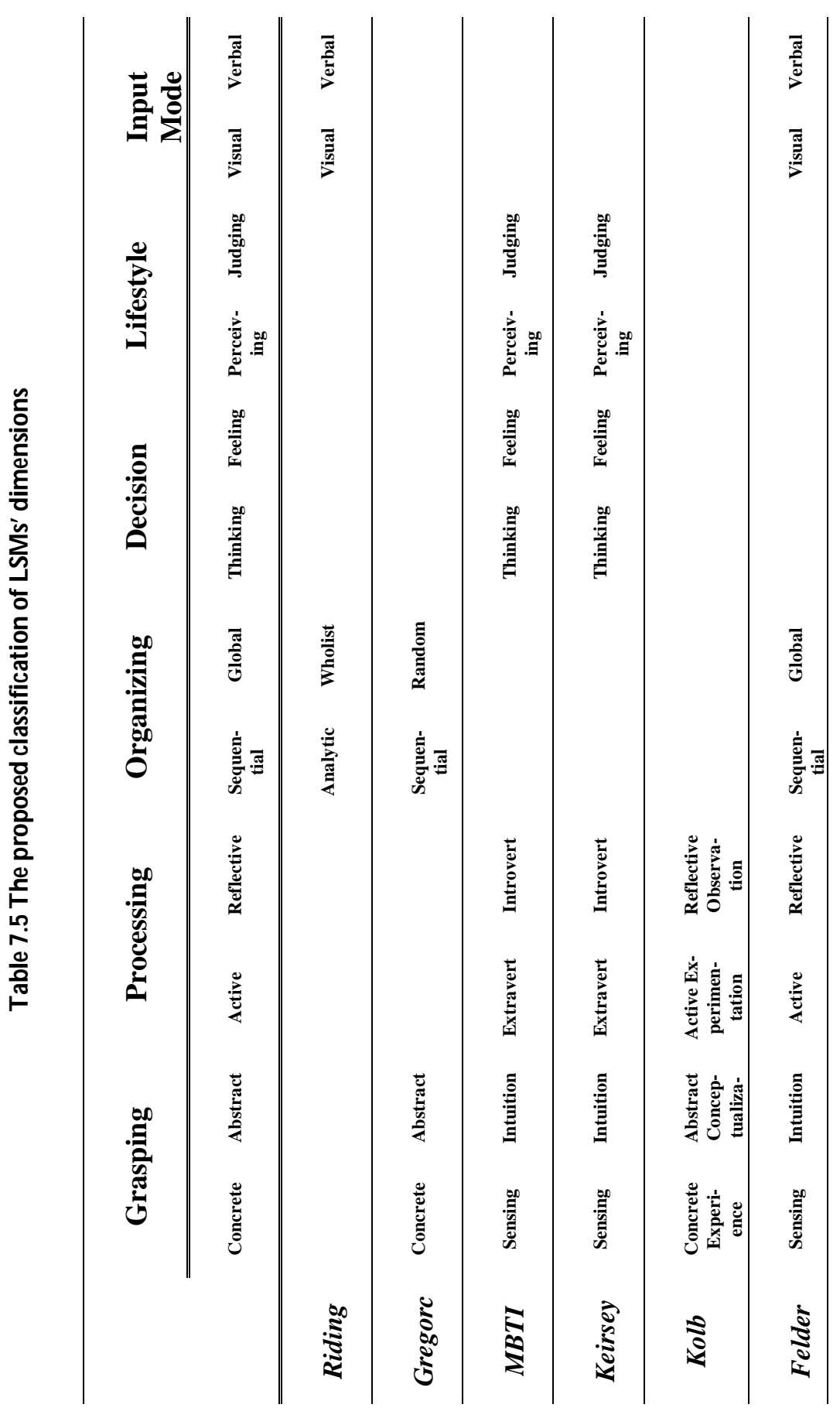

$\overline{130}$ 
Starting from the classification of LSMs' dimensions presented in Table 7.5, the global classification is composed of five main dimensions that represent different modalities of individual information treatment:

\section{1- Grasping}

The Grasping information dimension defines the personal way of grasping and gathering information. It contains a Concrete and an Abstract pole. The Concrete pole articulates the individual preference to use 'here-and-now' experience to test situation and to observe facts and basic information using one or more of the five senses. The Abstract pole articulates the individual preference to use "intuition" and "interpretation" to discover things and conceive ideas. As shown in Table 7.5, Gregorc's, the MBTI, Keirsey's, Kolb's and Felder-Silverman's perception dimensions include the Grasping information dimension.

2- Processing

The Processing dimension describes how the individual prefers to process information. The Processing dimension contains two poles Active and Reflective. The Active pole shows the individual preference to react to circumstances and to process information through engagement in activities. In contrast, the Reflective pole shows the individual preference to process information through introspection and seeing things from different perspectives. As seen in Table 7.5, Kolb's, Felder-Silverman's processing dimensions and the MBTI's Extravert/Introvert dimension include the Processing information dimension.

3- Organizing

The Organizing dimension provides the type of perspective on the information presented. The organizing dimension contains two poles Sequential and Global. The Sequential pole explains the individual preference to learn, understand, and deal with information in small steps in an organized way. On the other hand, the Global pole explains the individual preference to learn, understand, and deal with infor- 


\section{Chapter 7.}

mation in a global view and then explore areas in a less random manner. As shown in Table 7.5, Riding's organizing dimension, Gregorc's ordering dimension, and Felder-Silverman's understanding dimension include the Organizing information dimension.

4- Decision

The Decision dimension describes how persons come to decisions. The Decision dimension has two poles: Thinking and Feeling. The Thinking pole describes the individual preference to decide things independently using logical and reasonable rules. Conversely, the Feeling dimension describes the individual preference to come to decisions based upon the situation and personal impact. As seen in Table 7.5, MBTI and Keirsey's Thinking/Feeling dimension include the Decision dimension.

\section{5- Lifestyle}

The Lifestyle dimension specifies personal attitude when dealing with the outside world. The Lifestyle dimension has two poles: firstly, the Perceiving pole describes the individual preference to continue to collect information and keep decisions open. Secondly, the Judging pole describes the individual preference to get things decided. As shown in Table 7.5, MBTI and Keirsey's Perceiving/judging dimension include the Lifestyle dimension.

\section{6- Input Mode.}

The Input Mode dimension determines the preferred personal way to represent or retain information. The Input Mode dimension contains two poles: Visual and Verbal. The Visual pole describes the individual preference to represent information through pictures and diagrams. The Verbal pole describes the individual preference to retain and represent information through words and discussions. As seen in Table 7.5, Riding's and Felder-Silverman's Visual/Verbal dimension include the Input Mode dimension.

Figure 7.3 shows a concept map for the GLSMO Dimensions as defined above. 


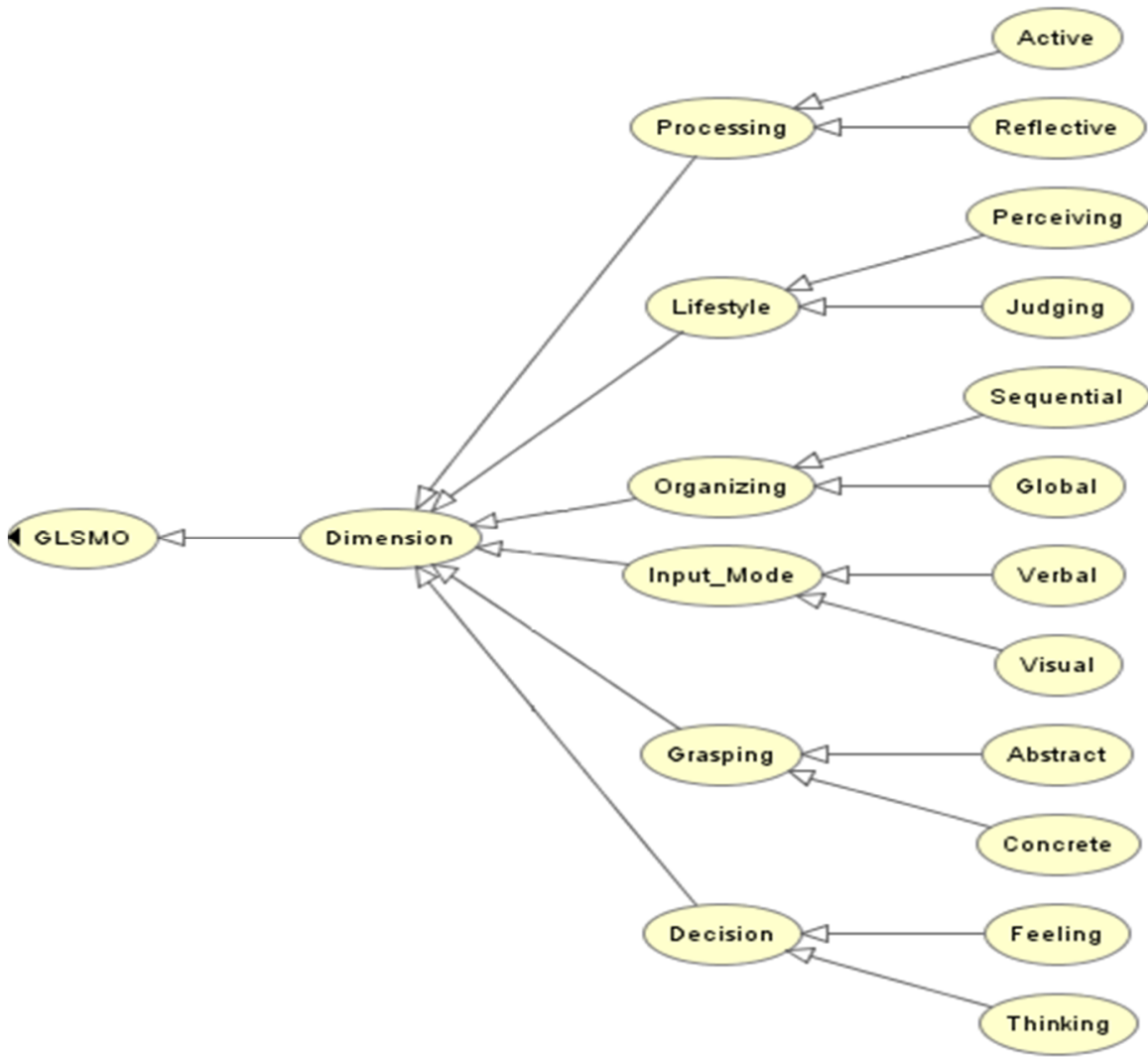

Figure 7.3 The GLSMO dimensions

Finally, the representation of the several concepts, characteristics, and relationships extracted in this phase will be used to build the shared vocabulary, form the local ontologies and define the mapping in the next phase.

\subsubsection{Refinement phase}

The third phase of the Knowledge Meta process is Refinement, composed of three sub-phases:

\subsubsection{Baselinetaxonomy}

According to the initial specifications obtained in previous phases, the baseline taxonomy is required to formulate the initial application-oriented ontology. Figure 7.4 shows a partial view of the GLSMO. 
Chapter 7.

\subsubsection{Elicitation}

Several knowledge entities (Concepts) were obtained from the Kick-off phase as follows:

1. The LSM (Learning_Style_Model) representing the seven LSMs.

2. The Model Dimension (Dimensions) specifying all dimensions related to each model.

3. The LS (Learning-Style) specifying all LSs related to each model.

4. The Pole (Pole) specifying all poles related to each dimension.

5. Characteristics (Characteristics) containing all characteristics related to LSs and dimensions.

A shared Characteristic may be related to several Dimensions and/or several LSs at the same time.

\subsection{Developing a Conceptual Framework for GLSMO}

To summarize the above descriptions, as well as to make their interrelationships explicit, we have defined a metamodel that represents the domain of LSMs. This metamodel is the conceptual base for the construction of the GLSMO that facilitates the integration of the different LSMs. Figure 7.5 shows the metamodel defined using the Unified Modeling Language (UML) class diagram notation. For us, a LSM (represented by the Learning_Style_Model class) is composed of a number of dimensions (Dimension class) representing individual ways of dealing with information (e.g. Perception, Ordering, Decision, etc.). Subsequently, each dimension is made up of a discrete spectrum or two opposite poles (e.g. a Perception dimension can be defined by two poles: Intuitive and Sensing; similarly, an Ordering dimension can be defined by Sequential and Random poles).

Each pole (Pole class) is described by several learner's characteristics (Characteristic class). We introduce this class to ease the management of the semantic searches of learning materials because a learner's characteristic represents a preference or feature of a pole. Finally, a LS (Learning_Style class) is typically built from two or four poles. For instance, an Assimilating LS (in the Kolb model) is formulated by combining the Abstract Conceptualization and Reflective Observation poles. 


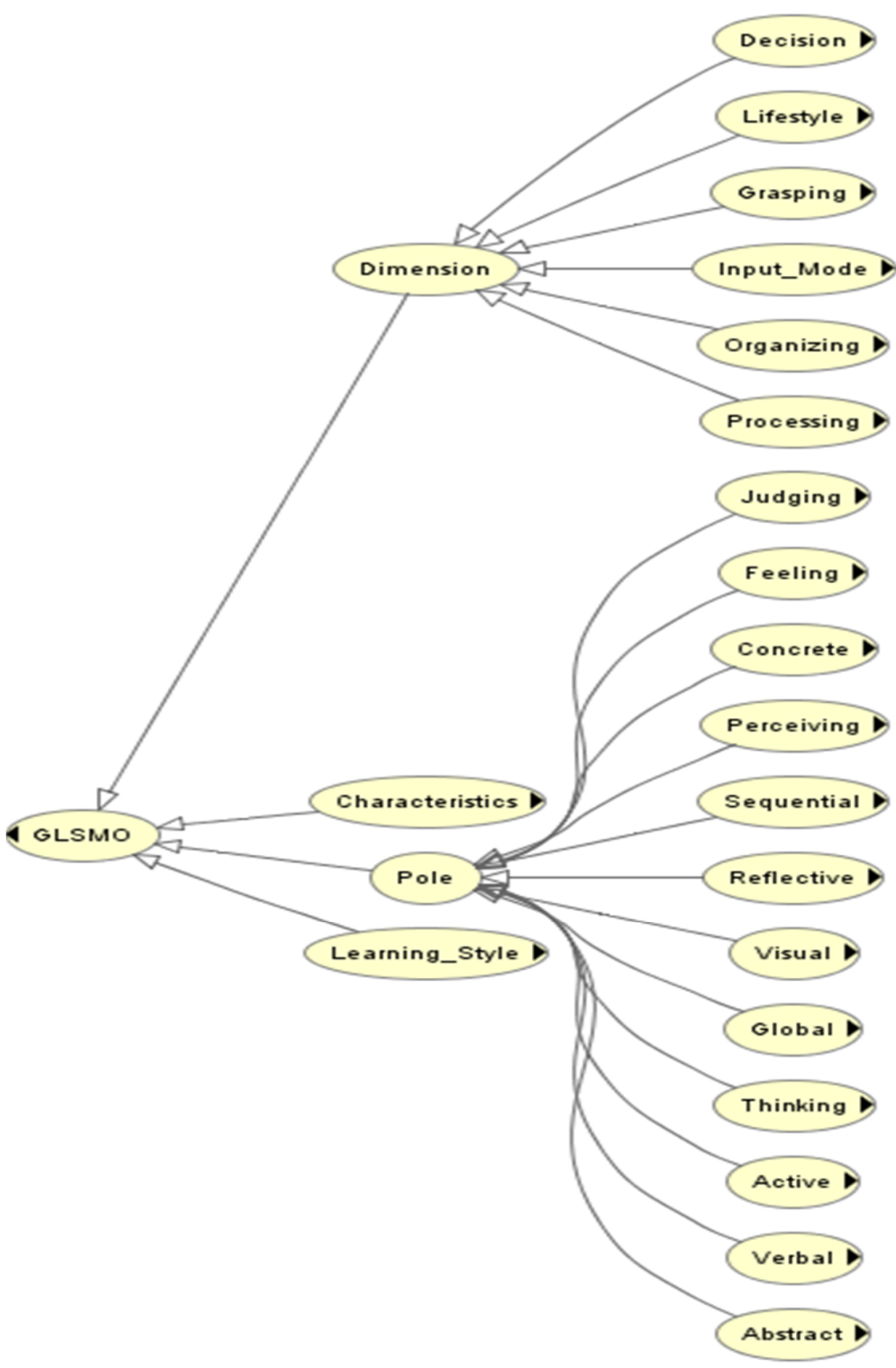

Figure 7.4 A partial view of the GLSMO 
Chapter 7.

On the other hand, LSs are also associated with characteristics to facilitate the semantic searches. The cardinalities of the relationships in the conceptual model come from the study of different LSs, as we describe in the local ontologies in the next Section.

\section{- Building Local Ontologies}

In the second stage of the method, local ontologies are defined for each content model, representing concepts and relationships defined by the model.

Here, local ontologies are defined for each LSM, representing concepts and relationships defined by the model. The local ontologies are explained according to a Conceptual Framework for the GLSMO and the LSMs description in Section 4.2.

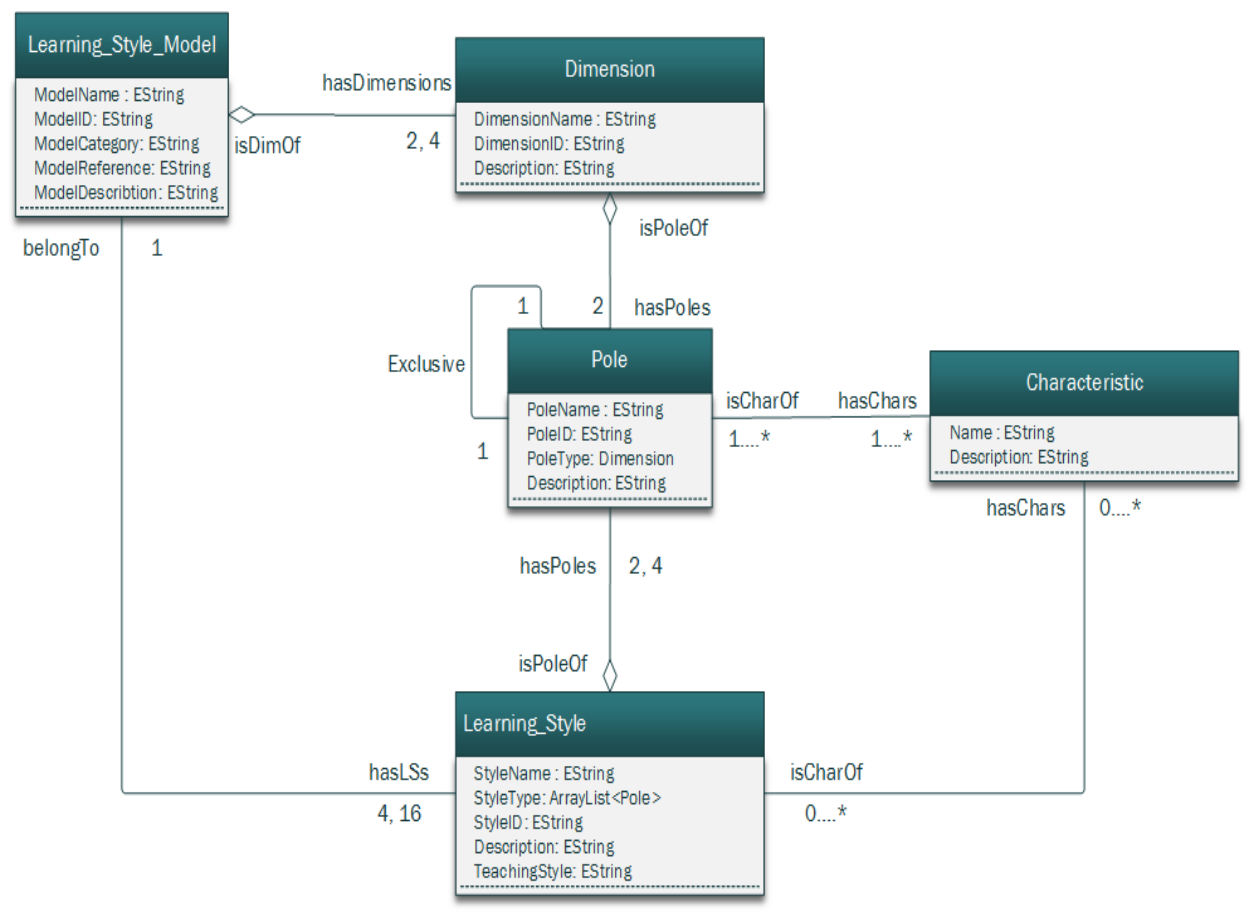

Figure 7.5 A conceptual framework of the GLSMO 
1- The Felder-Silverman local ontology

The Felder-Silverman ontology defines Felder-Silverman's concepts (LS dimensions, poles, and LSs) and their relationships. In Figure 7.6, the UML class diagram representation of the Felder-Silverman ontology, concepts, and aggregation relationships are presented.

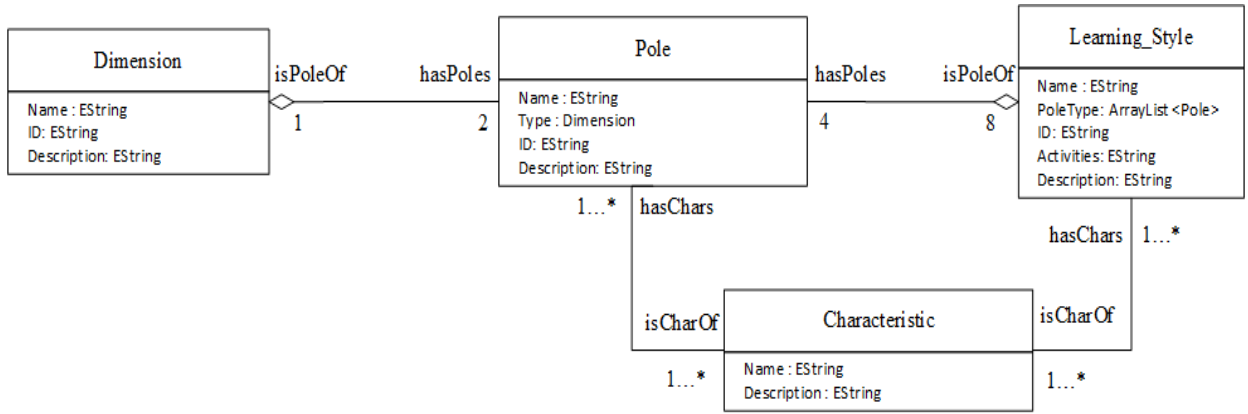

Figure 7.6 The UML class diagram for Felder-Silverman local ontology

Constraints imposed on The Felder-Slverman's concepts are introduced in the axiom set below. The constraints are expressed in Object Constraint Language (OCL). For instance, the constraints indicate that every Felder-Silverman's dimension (Dimension) must have two poles (Pole). These two poles must be related to only one dimension. Furthermore, every LS (Learning_Style) has four poles (Pole). These four poles must be selected as one pole per dimension.

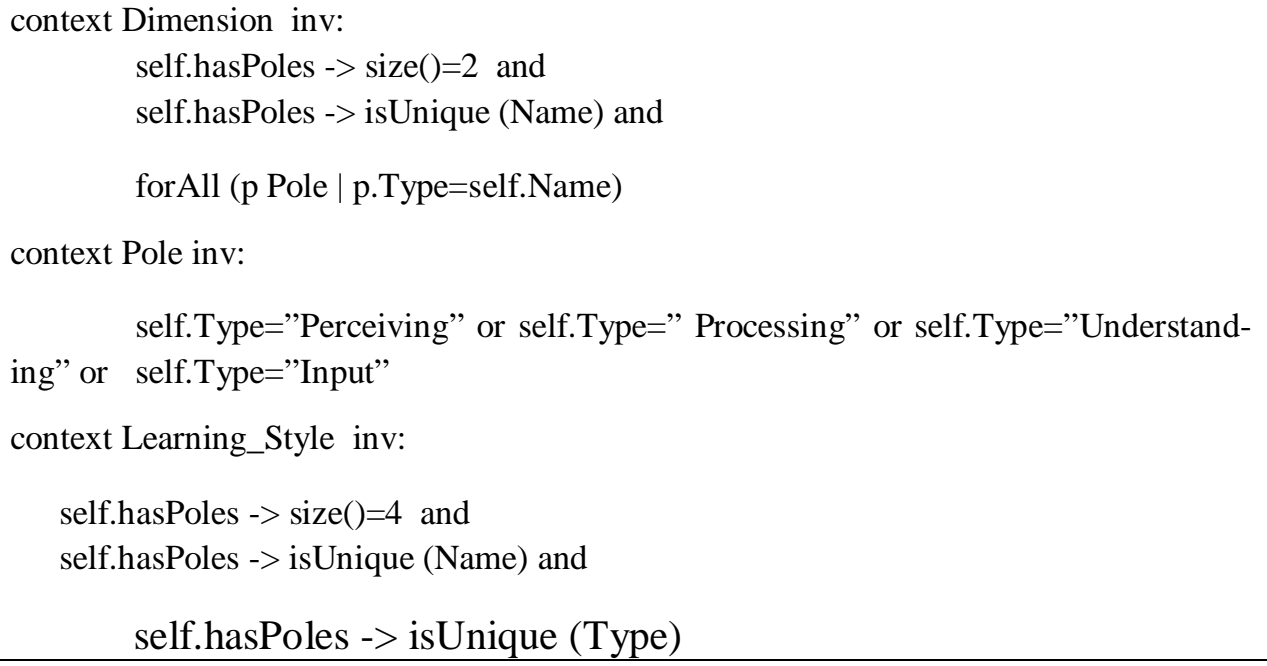


Chapter 7.

Additionally, the Sensitive-Active-Visual-Sequential (S-A-Vi-Sq) LS is represented as an instance of Felder-Silverman LSM in the UML object diagram, see Figure 7.7.

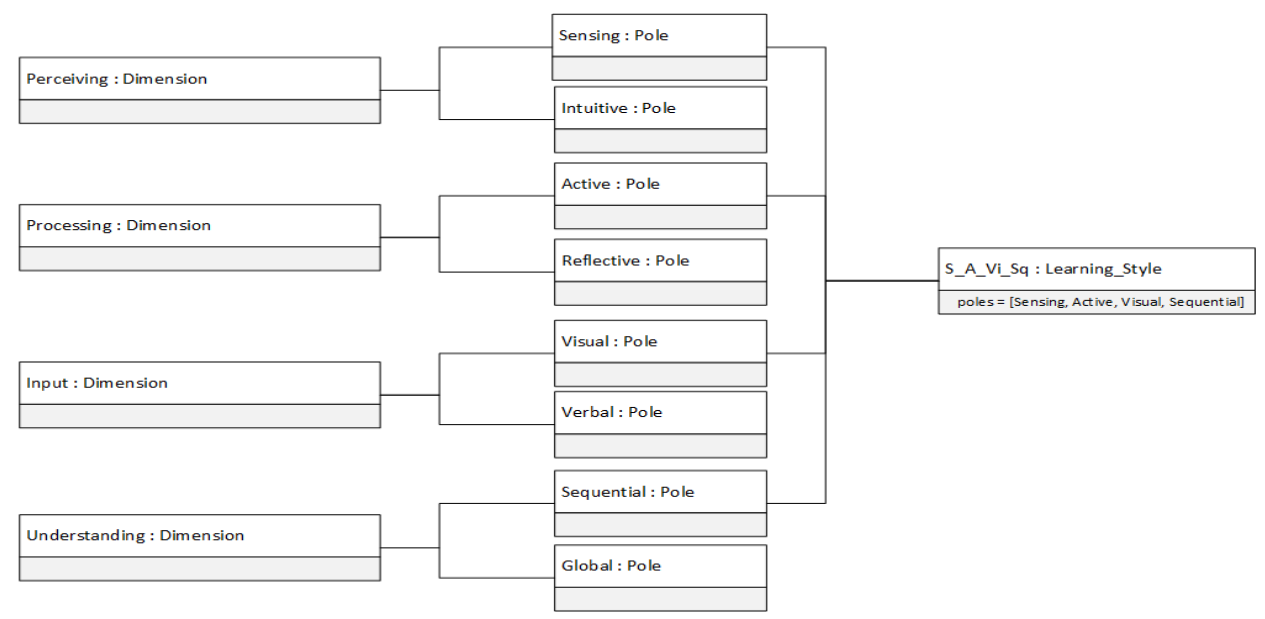

Figure 7.7 UML object diagram represents the S_A_Vi_Sq learning style

2- The Kolb local ontology

The Kolb ontology defines Kolb's concepts (learning dimensions, stages, and LSs) and their relationships. In Figure 7.8, an excerpt of the UML class diagram representation of the Kolb LSM, concepts, concepts hierarchy, and aggregation relationships are presented.

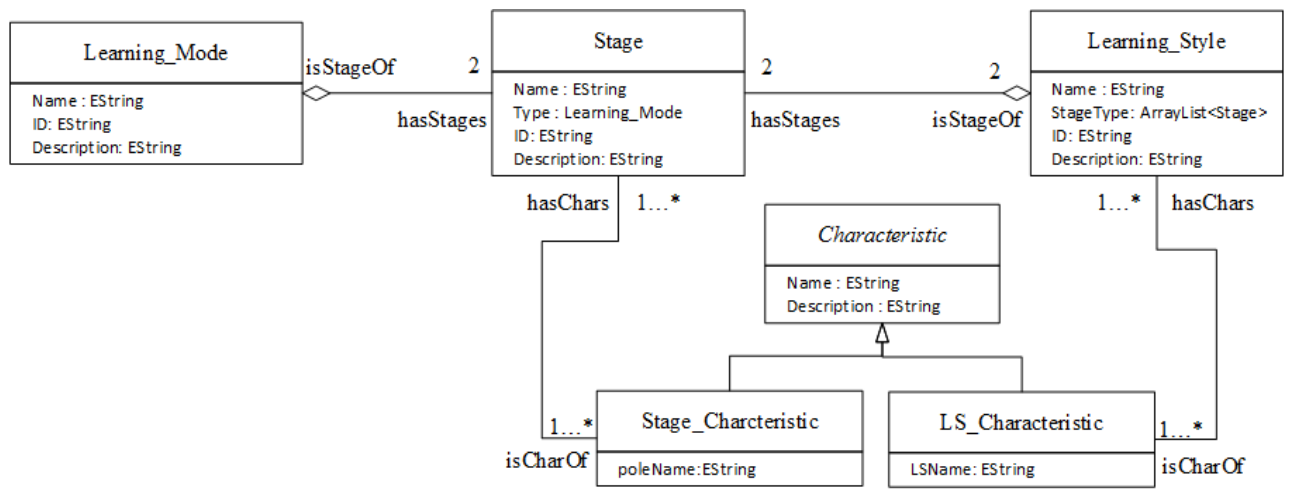

Figure 7.8 The U ML class diagram for Kolb local ontology 
Several OCL constraints appointed to The Kolb's concepts are introduced in the axiom set below. For instance, the constraints indicate that every Kolb learning mode (Learning_Mode) must have two stages (Stage). These two stages must be related to only one learning mode (e.g. Reflective Observation and Active Experimentation stages are related to the Transforming Experience learning mode). Moreover, every LS (Learning_Style) has two stages (Stage). These two Stages must be selected as one stage per learning mode.

context Learning_Mode inv:

self.hasStages $->\operatorname{size}()=2$ and

self.hasStages -> isUnique (Name) and

forAll (s Stage | s. Type=self.Name)

context Stage inv:

self.Type="Grasping Experience" or self.Type="Transforming Experience"

context Learning_Style inv:

self.hasStages $->\operatorname{size}()=2$ and

self.hasStages -> isUnique (Name) and

self.hasStages -> isUnique (Type)

Additionally, the Kolb's Diverging LS is represented as an instance of the Kolb LSM in the UML object diagram (see Figure 7.9).

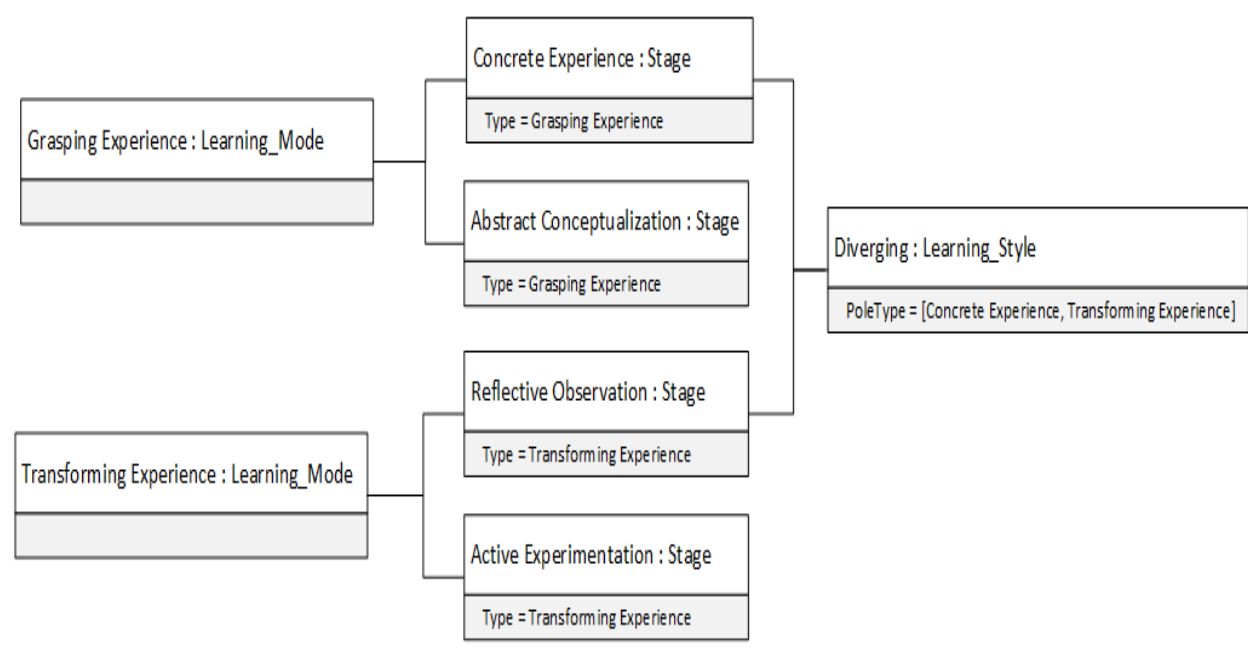

Figure 7.9 UML object diagram represents the Diverging learning style 
Chapter 7.

3- The MBTI local ontology

The MBTI ontology represents MBTI's concepts (personality dichotomies, poles, and personality types) and their interrelationships. An excerpt of the UML class diagram representation of the MBTI LSM, concepts, concepts hierarchy, and aggregation relationships are presented in Figure 7.10.

The OCL constraints imposed on The MBTI's concepts are presented in the axiom set below. For example, the constraints point out that each MBTI personality dichotomy (Personality_Dichotomy) must have two poles (Pole). These two Poles must be related to only one personality dichotomy. Moreover, each personality type (Personality_Type) has four poles (Pole). These four Poles must be selected as one pole per personality dichotomy (e.g. ESTJ personality type has four poles: Extraversion from Acquiring Energy dichotomy, Sensing from Gathering dichotomy, Thinking from Decision dichotomy, and Judging from Lifestyle dichotomy).

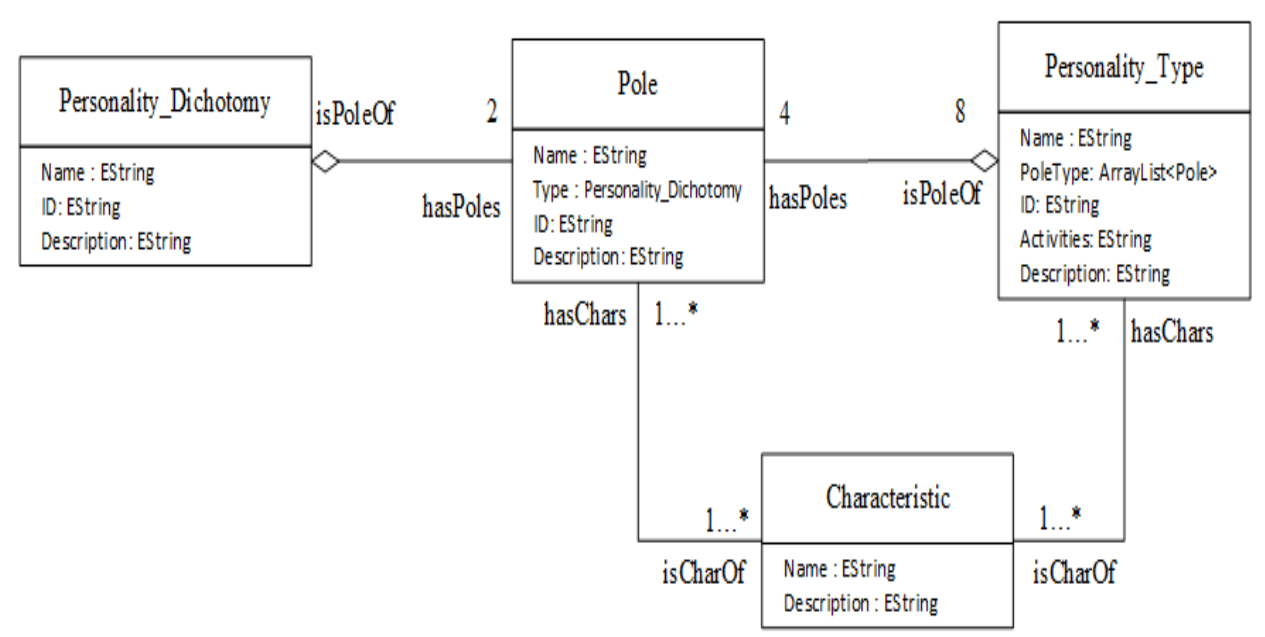

Figure 7.10 The UML class diagram for M BTI local ontology 
context Personality_Dichotomy inv:

self.hasPoles $->$ size ()$=2$ and

self.hasPoles $->$ isUnique (Name) and

forAll ( $p$ Pole | p.Type=self.Name)

context Pole inv:

self.Type="Gathering" or self.Type="Acquiring Energy" or self.Type="Decision" or self.Type="Lifestyle"

context Personality_Type inv:

self.hasPoles $\rightarrow$ size ()$=4$ and

self.hasPoles -> isUnique (Name) and

self.hasPoles -> isUnique (Type)

Figure 7.11 shows the UML object diagram that represents the ESTJ personality type as an instance of the MBTI LSM.

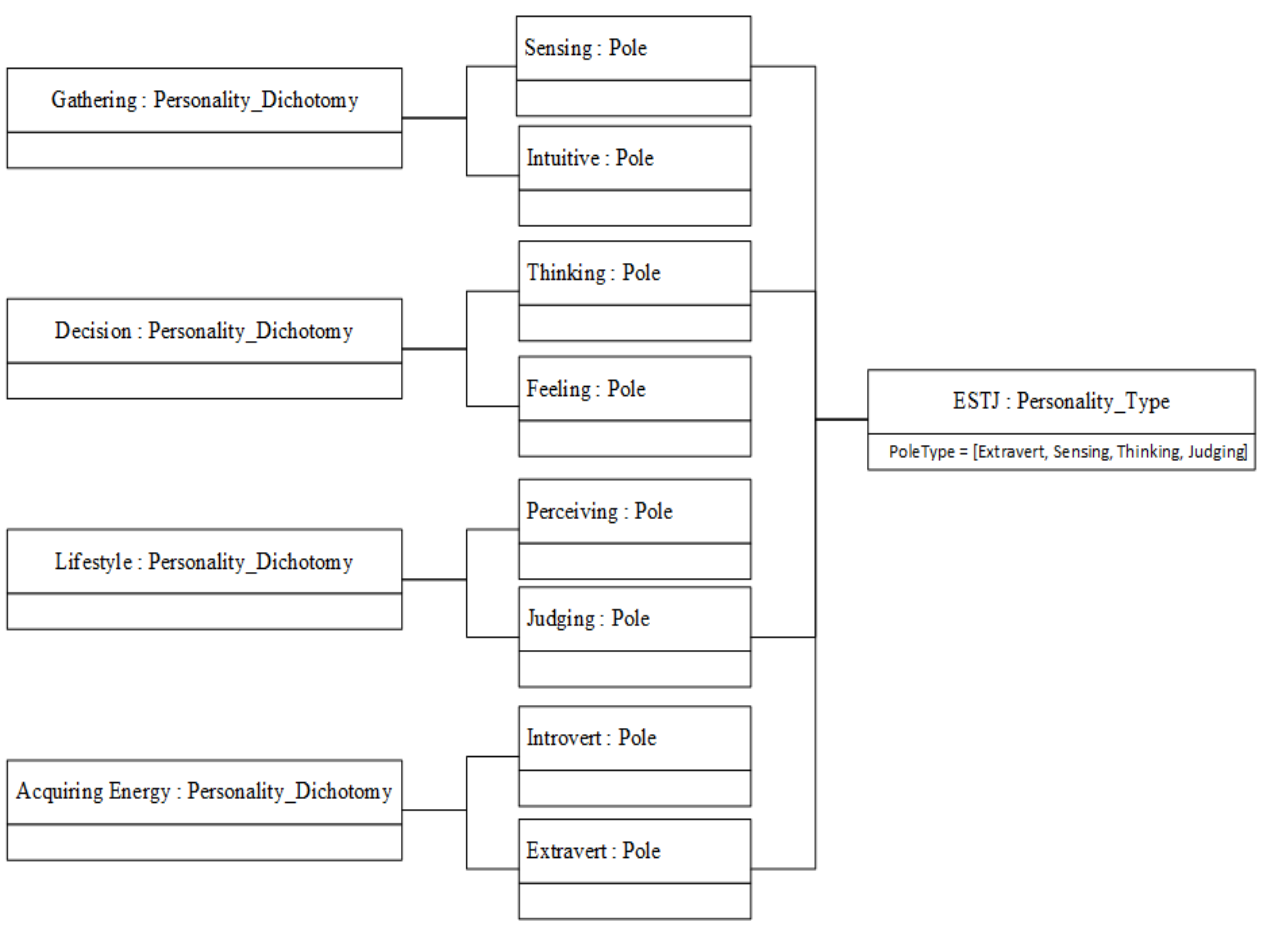

Figure 7.11 UML object diagram represents the ESTJ personality type 
Chapter 7.

4- The Keirsey local ontology

The Keirsey model is considered as another classification of The MBTI model. The Keirsey ontology defines Keirsey's concepts (personality dichotomies, poles, personality types, and temperaments) and their relationships. Figure 7.12, gives the UML class diagram representation of the Keirsey ontology, concepts, concepts hierarchy, and aggregation relationships.

The OCL constraints imposed on Keirsey's concepts are shown in the axiom set below. For instance, the constraints indicate that every Keirsey personality dichotomy (Personality_Dichotomy) must have two poles (Pole). These two Poles must be related to only one personality dichotomy. Each personality type (Personality_Type) has four poles (Pole). These four Poles must be selected as one pole per personality dichotomy. Moreover, every temperament (Temperament) is defined by four personality types, as shows in the axioms below (e.g. Idealist temperament contains four personality types: ENFJ, ENFP, INFJ, and INFP).

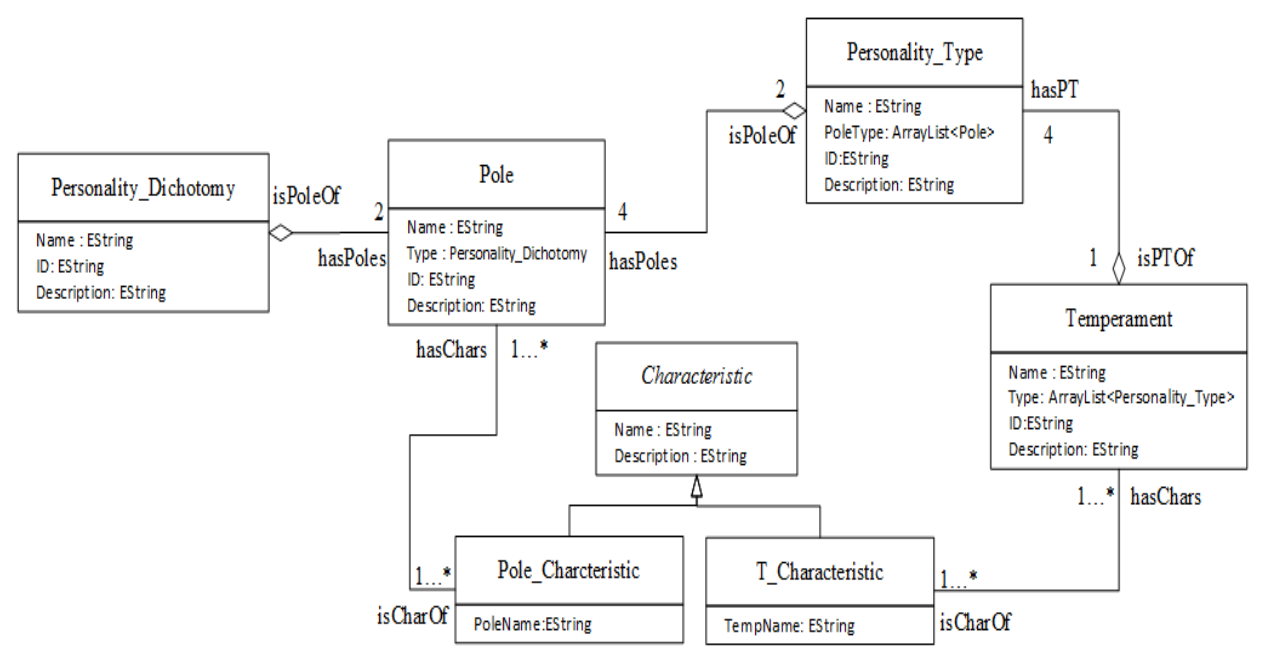

Figure 7.12 The UML class diagram for Keirsey local ontology 


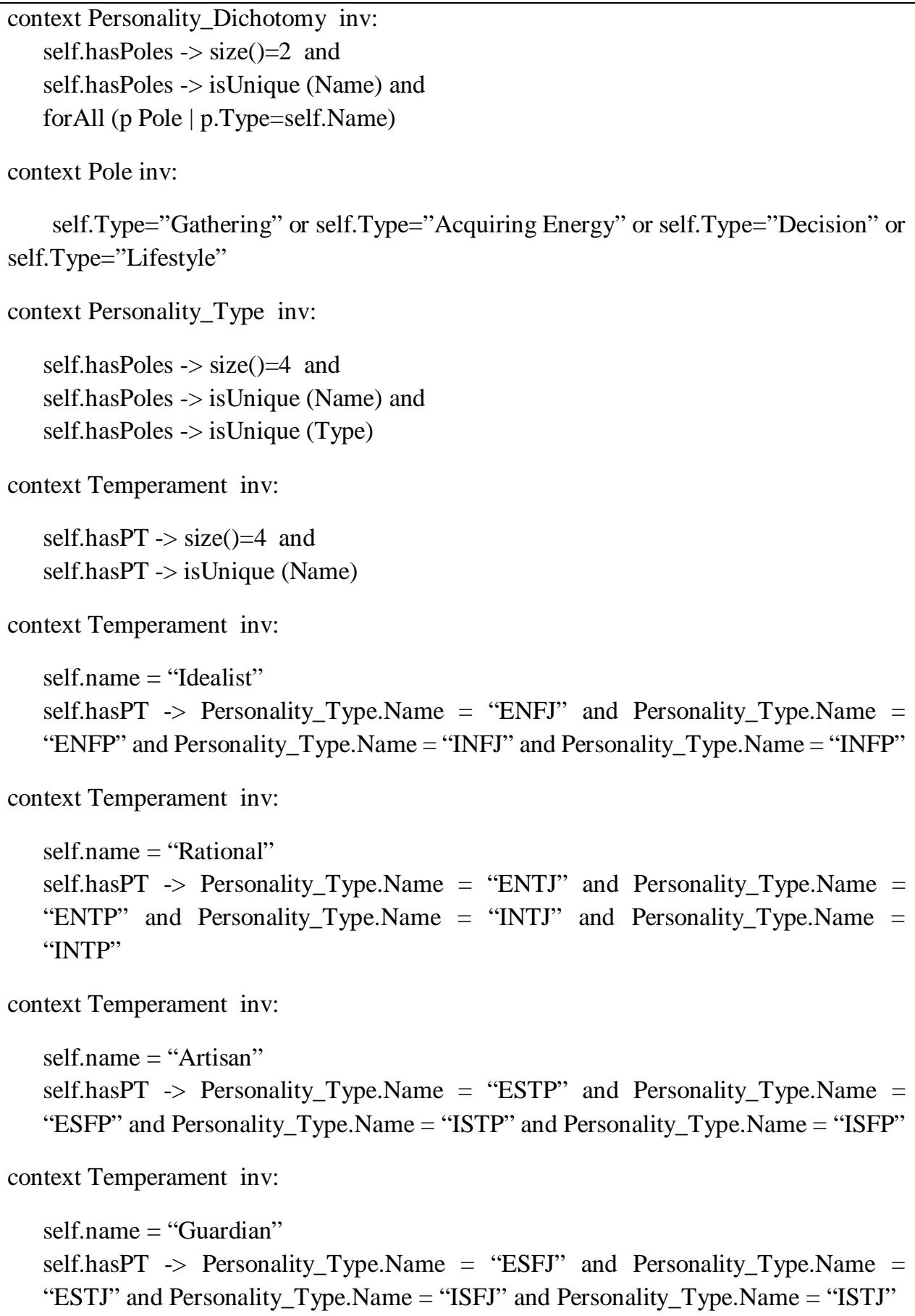


Chapter 7.

Additionally, Keirsey's Idealist temperament is represented as an instance of the Keirsey Temperaments model in the UML object diagram (see Figure 7.13).

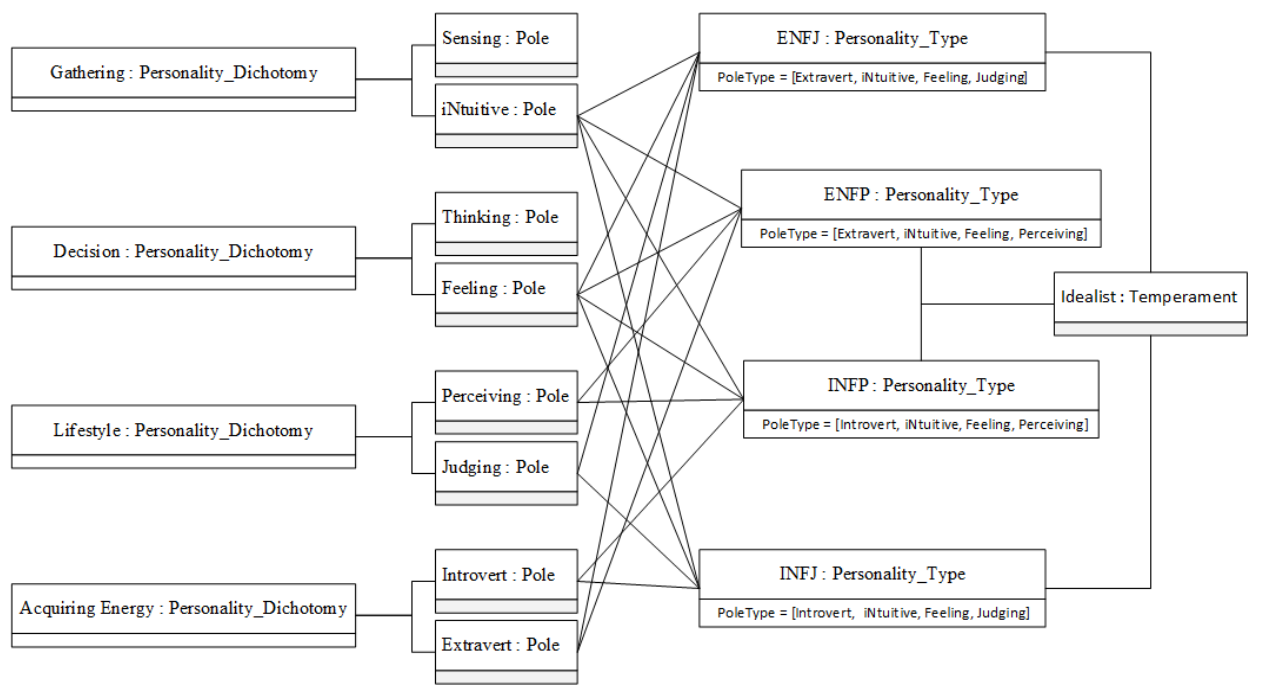

Figure 7.13 UML object diagram represents the I dealist temperament

5- The Riding local ontology

The Riding ontology defines Riding's concepts (cognitive dimensions, habitual ways, and cognitive styles) and their relationships. Figure 7.14 gives the UML class diagram representation of the Riding cognitive style model, concepts, concepts hierarchy, and aggregation relationships.

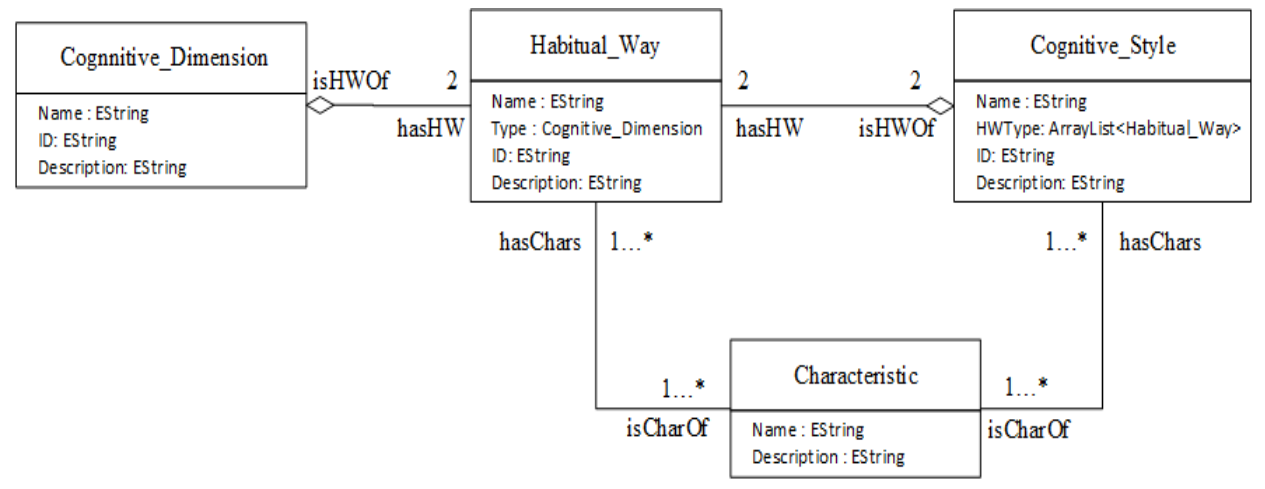

Figure 7.14 The UML class diagram for Riding local ontology 
The OCL constraints appointed to Riding's concepts are shown in the axiom set below. For instance, the constraints indicate that every Riding's cognitive dimension (Cognitive_Dimension) must have two habitual ways (Habitual_Way). These two habitual ways must be related to only one cognitive dimension (e.g. Wholist and Analytical habitual ways are related to the Cognitive Organization cognitive dimension). Moreover, every cognitive style (Cognitive_Style) has two habitual ways, which must be selected as one per cognitive dimension.

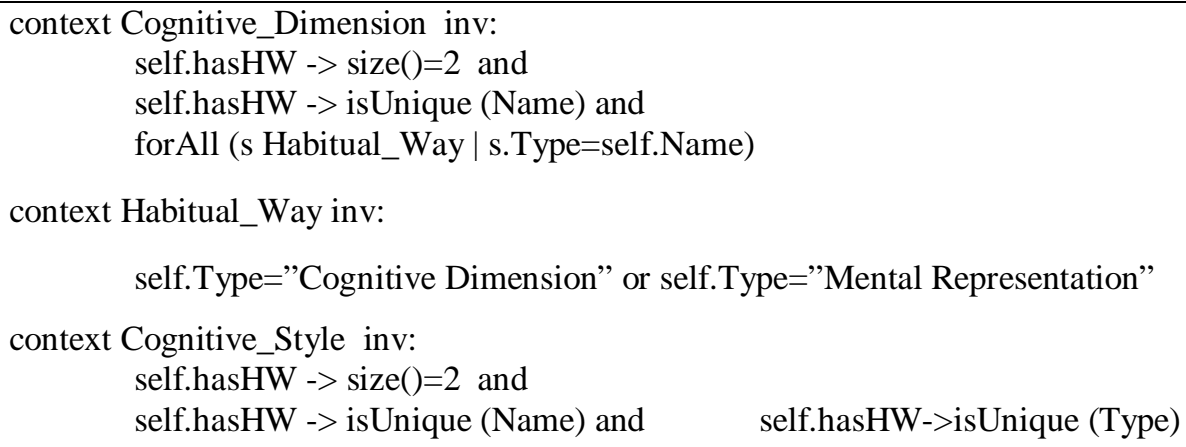

Riding's Wholist-Imagery cognitive style is described as an instance of The Riding cognitive style model in the UML object diagram (see Figure 7.15).

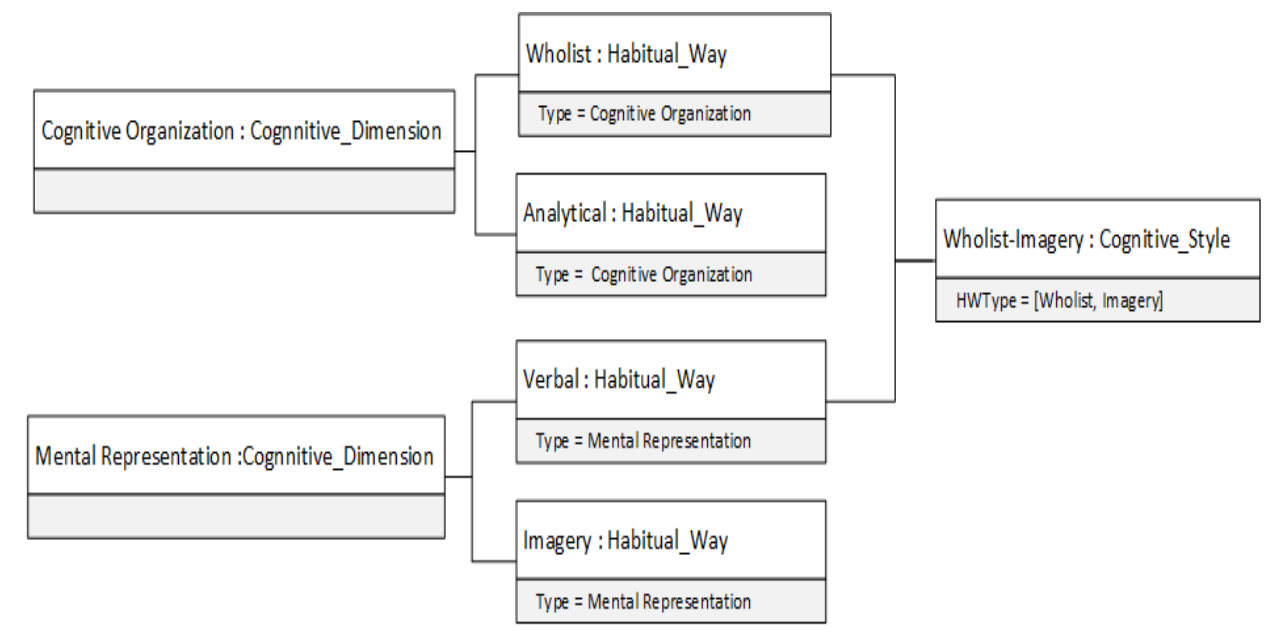

Figure 7.15 UML object diagram represents the Wholist-I magery cognitive style 
Chapter 7.

6- The Gregorc local ontology

The Gregorc ontology illustrates Gregorc's concepts (mind ability dimensions, mind preferences, and mind styles) and their relationships. The representation of concepts, concepts hierarchy, and aggregation relationships related to the Gregorc mind style model are shown in the UML class diagram notion (see Figure 7.16).

The OCL constraints imposed on Gregorc's concepts are introduced below. For example, the constraints show that every Gregorc's mind ability dimension (Mind_Ability_Dimension) must have two mind preferences (Mind_Preferences). These two mind preferences must be related to only one mind ability dimension. Moreover, every mind style (Mind_Style) has two mind preferences, which must be selected as one per mind ability dimension (e.g. Concrete-Sequential mind style has two mind preferences: Concrete from Perception mind ability dimension and Sequential from Ordering mind ability dimension).

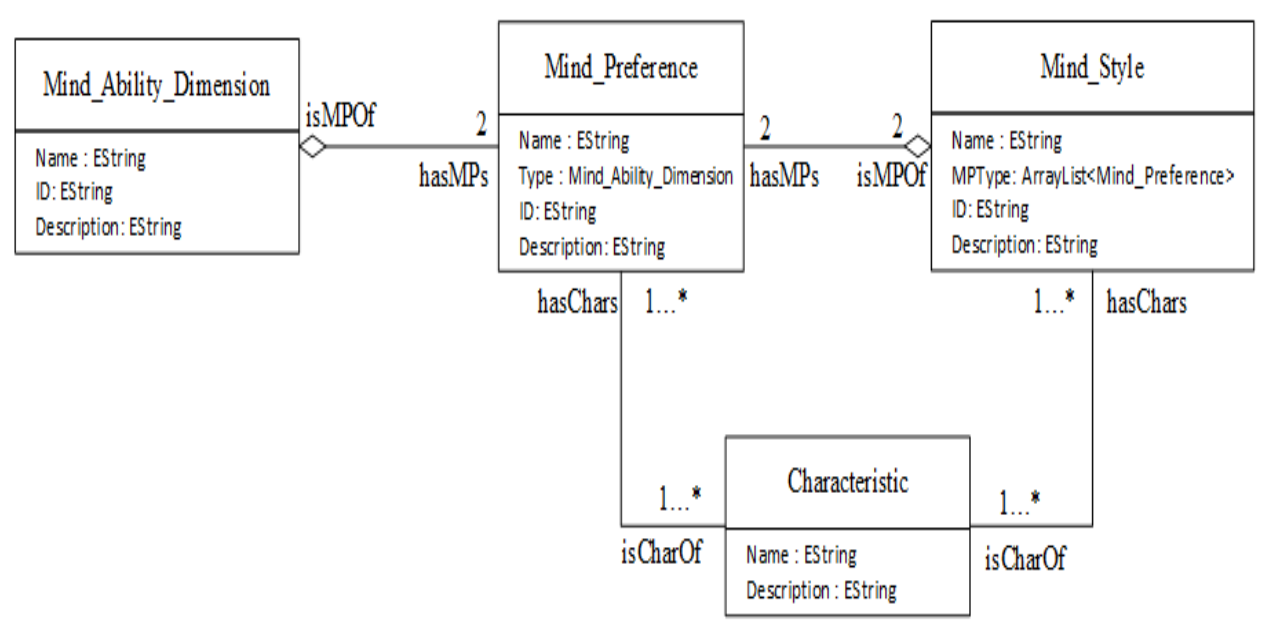

Figure 7.16 The UML dass diagram for Gregorc local ontology 
context Cognitive_Dimension inv:

self.hasHW $\rightarrow$ size ()$=2$ and

self.hasHW -> isUnique (Name) and

forAll (s Habitual_Way | s.Type=self.Name)

context Habitual_Way inv:

self.Type="Cognitive Dimension" or self.Type="Mental Representation"

context Cognitive_Style inv:

self.hasHW $->$ size ()$=2$ and

self.hasHW -> isUnique (Name) and

self.hasHW -> isUnique (Type)

Figure 7.17 represents the Gregorc's Concrete-Sequential mind style as an instance of The Gregorc mind style model in the UML object diagram.

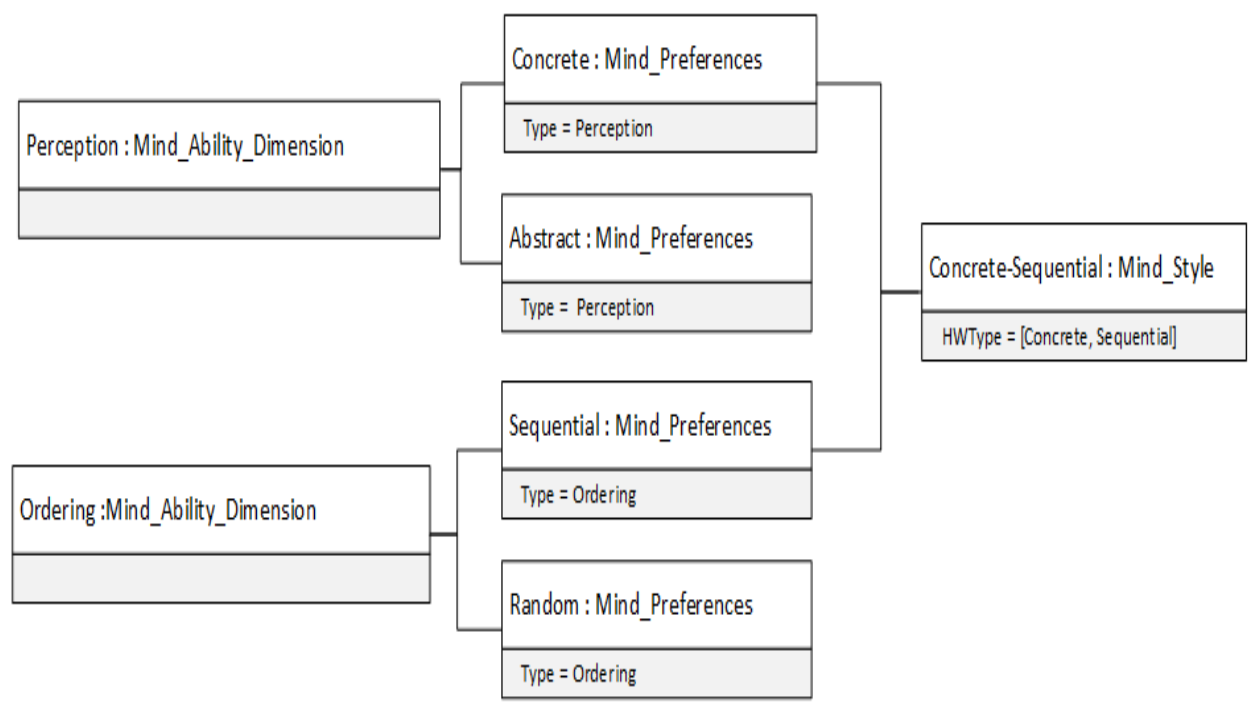

Figure 7.17 UML object diagram represents the Concrete-Sequential mind style

7- The Honey and Mumford local ontology

The Honey and Mumford ontology defines Honey and Mumford's LS concept (Learning_Style) and its associated characteristics (Characteristic). Figure 7.18 gives the UML class diagram representation of the Honey and Mumford LSM. 
Chapter 7.

\begin{tabular}{|c|c|}
\hline Learning_Style & Characteristic \\
\hline $\begin{array}{l}\text { Name : EString } \\
\text { ID: EString } \\
\text { Description: EString }\end{array}$ & $\begin{array}{l}\text { Name : EString } \\
\text { Description : EString }\end{array}$ \\
\hline
\end{tabular}

Figure 7.18 The UML dass diagram for H oney and M umford local ontology

\section{- Mapping}

Ontology mappings are determined between the GLSMO and the LSMs' local ontologies. Mapping is one of the fundamental steps of the ontology integration process. Mapping from ontology $\mathcal{O}_{A}$ to another ontology $\mathcal{O}_{B}$ is performed by establishing correspondences (or Similarities) between concepts (and relations), which have the same or similar semantics in both ontologies.

Based on the description of LSMs in Section 4.2 and the extensive comparative analysis of the models, mapping is defined upon the similarity between concept definitions, attributes, and shared characteristics. Mappings defined between the GLSMO and local LSMs ontologies are bi-directional.

As a result, we identify the sets of related concepts in the GLSMO and local ontologies, as shown in Table 7.6. Four sets of concepts are formed: Dimension Set $\left(S_{1}\right)$, Pole Set $\left(S_{2}\right)$, Learning Style Set $\left(S_{3}\right)$, and Characteristic $\left(S_{4}\right)$.

Table 7.6 The related concepts in GLSMO and LSM s local ontologies

\begin{tabular}{ll}
\hline Set & Concept \\
\hline$S_{1}$ & $\begin{array}{l}\text { Dimension }\left(\mathcal{O}_{0}\right), \text { Learning_Dimension }\left(\mathcal{O}_{1}\right), \text { Personality_Dichotomy }\left(\mathcal{O}_{2}\right), \\
\text { Cognitive_Dimension }\left(\mathcal{O}_{3}\right), \text { Mind_Ability_Dimension }\left(\mathcal{O}_{4}\right), \text { Dimension }\left(\mathcal{O}_{5}\right), \\
\text { Personality_Dichotomy }\left(\mathcal{O}_{7}\right)\end{array}$ \\
\hline$S_{2}$ & $\begin{array}{l}\text { Pole }\left(\mathcal{O}_{0}\right), \text { Stage }\left(\mathcal{O}_{1}\right), \text { Pole }\left(\mathcal{O}_{2}\right), \text { Habitual_Way }\left(\mathcal{O}_{3}\right), \text { Mind_Preference }\left(\mathcal{O}_{4}\right), \\
\text { Pole }\left(\mathcal{O}_{5}\right), \text { Pole }\left(\mathcal{O}_{7}\right)\end{array}$ \\
\hline$S_{3}$ & $\begin{array}{l}\text { Learning_Style }\left(\mathcal{O}_{0}\right), \text { Learning_Style }\left(\mathcal{O}_{1}\right), \text { Personality_Type }\left(\mathcal{O}_{2}\right), \text { Cogni- } \\
\text { tive_Style }\left(\mathcal{O}_{3}\right), \text { Mind_Style }\left(\mathcal{O}_{4}\right), \text { Learning_Style }\left(\mathcal{O}_{5}\right), \text { Learning_Style }\left(\mathcal{O}_{6}\right), \\
\text { Temperament }\left(\mathcal{O}_{7}\right)\end{array}$ \\
\hline$S_{4}$ & Characteristic $\left(\mathcal{O}_{0}, \mathcal{O}_{1}, \mathcal{O}_{2}, \mathcal{O}_{3}, \mathcal{O}_{4}, \mathcal{O}_{5}, \mathcal{O}_{6}, \mathcal{O}_{7}\right)$ \\
\hline
\end{tabular}


Where: $\mathcal{O}_{0}$ is the GLSMO

$\mathcal{O}_{1}$ is the Kolb LSM local ontology

$\mathrm{O}_{2}$ is the MBTI model local ontology

$\mathrm{O}_{3}$ is the Riding cognitive style model local ontology

$\mathcal{O}_{4}$ is the Gregorc mind style model local ontology

$\mathcal{O}_{5}$ is the Felder-Silverman LSM local ontology

$\mathcal{O}_{6}$ is the Honey and Mumford LSM local ontology

$\mathcal{O}_{7}$ is the Keirsey Temperaments model local ontology

In each set of concepts there exists one concept from the global ontology $\left(\mathcal{O}_{0}\right)$ :

Dimension $\left(\mathcal{O}_{0}\right)$ in $S_{1}$, Pole $\left(\mathcal{O}_{0}\right)$ in $S_{2}$, Learning_Style $\left(\mathcal{O}_{0}\right)$ in $S_{3}$, and Characteristic $\left(\mathcal{O}_{0}\right)$ in $S_{4}$. For each set, we need to create a mapping (equivalences) from the concept in the global ontology to the concepts in other local ontologies. Figure 7.19 shows a general view of the LSMs ontology integration.

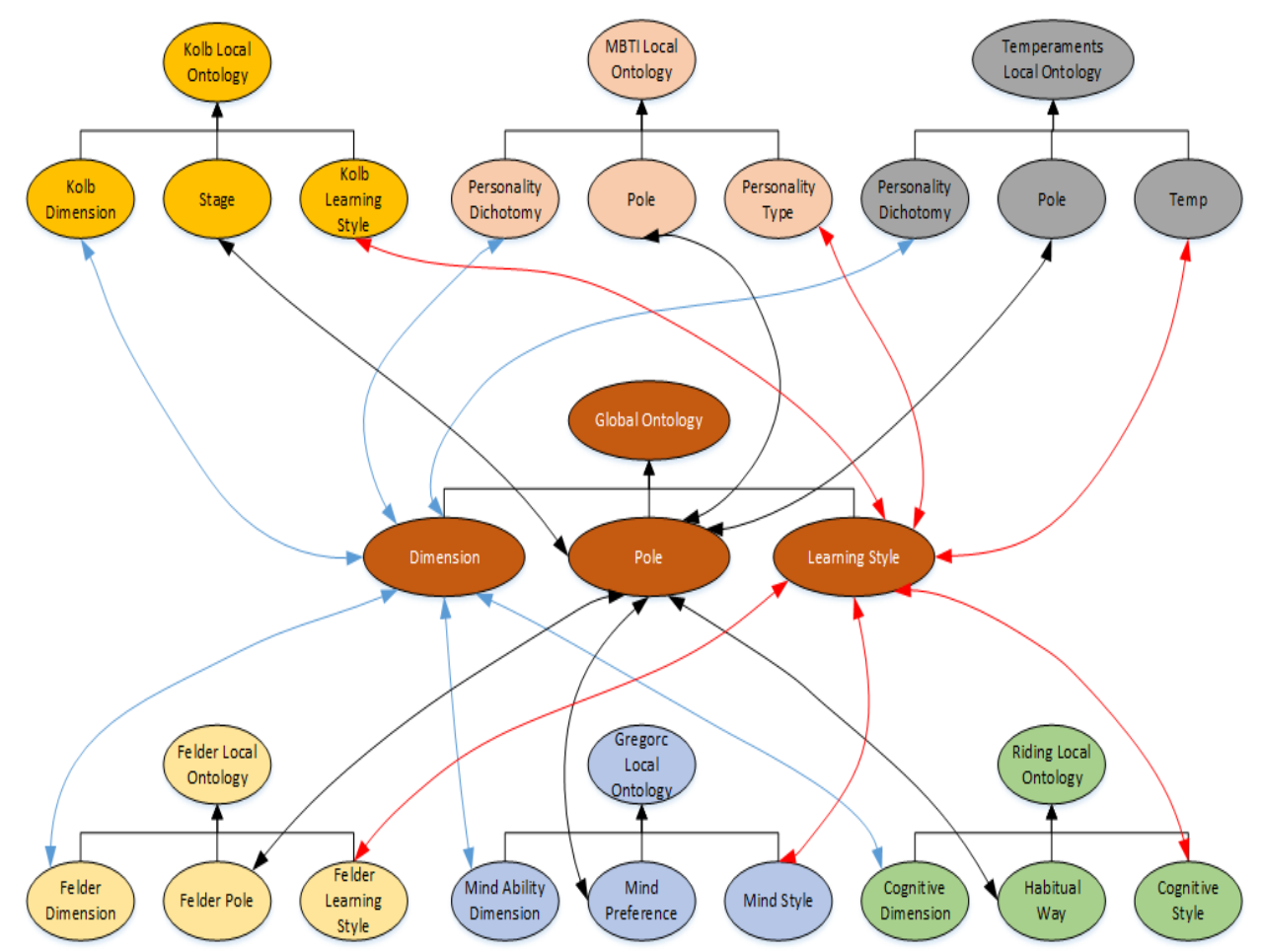

Figure 7.19 An integrated view of GLSMO 
Chapter 7.

1- Dimension Mappings

The Kolb's Learning Mode, MBTI's and Keirsey's Personality Dichotomy, Riding's Cognitive Dimension, Gregorc's Mind Ability Dimension, and Felder-Silverman's Dimension are equivalent to the global LS model's Dimension.

Also, the Kolb's Grasping Experience, MBTI's and Keirsey's Gathering, Gregorc's Perception, and Felder-Silverman Perceiving dimensions are mapped to the global model Grasping class. Felder-Silverman's Understanding, Riding's Cognitive Organization and Gregorc's Ordering dimensions are mapped to the global model Organizing class. Table 7.7 shows several mappings between the GLSMO and local ontology dimensions.

Table 7.7 Dimensions mapping between GLSMO and LSM s local ontologies

\begin{tabular}{|c|c|c|c|c|c|c|c|}
\hline & \multicolumn{6}{|c|}{ Learning Style Model } \\
\hline & & Kolb & MBTI & Riding & Gregorc & $\begin{array}{c}\text { Felder- } \\
\text { Silverman }\end{array}$ & Keirsey \\
\hline$\theta$ & Grasping & $\begin{array}{c}\text { Grasping } \\
\text { Experience }\end{array}$ & $\begin{array}{l}\text { Gather- } \\
\text { ing }\end{array}$ & & Perception & Perceiving & Gathering \\
\hline •气̄ & Processing & $\begin{array}{l}\text { Transform- } \\
\text { ing Experi- } \\
\text { ence }\end{array}$ & $\begin{array}{l}\text { Acquir- } \\
\text { ing En- } \\
\text { ergy }\end{array}$ & & & Processing & $\begin{array}{c}\text { Acquiring } \\
\text { Energy }\end{array}$ \\
\hline$\underline{\underline{a}}$ & $\begin{array}{l}\text { Organiz- } \\
\text { ing }\end{array}$ & & & $\begin{array}{c}\text { Cognitive } \\
\text { Organization }\end{array}$ & Ordering & $\begin{array}{l}\text { Understand- } \\
\quad \text { ing }\end{array}$ & \\
\hline ల్ర & Decision & & Decision & & & & Decision \\
\hline 之 & Lifestyle & & Lifestyle & & & & Lifestyle \\
\hline$\frac{0}{0}$ & $\begin{array}{l}\text { Input } \\
\text { Mode }\end{array}$ & & & $\begin{array}{l}\text { Mental Rep- } \\
\text { resentation }\end{array}$ & & Input & \\
\hline
\end{tabular}

Dimension subclasses are often represented by the same name (see Figure 7.20). Semantically related concepts are, amongst others:

- Global: Processing $\rightarrow$ Felder-Silverman: Processing

- Global: Decision $\rightarrow$ MBTI: Decision

- Global: Decision $\rightarrow$ Keirsey: Decision

- Global: Lifestyle $\rightarrow$ MBTI: Lifestyle 
2- Pole Mappings

The Kolb's Stage, MBTI's and Keirsey's Pole, Riding's Habitual Way, Gregorc's Mind Preference, and Felder-Silverman's Pole are equivalent to the global LS model's Pole.

Furthermore, Kolb's Concrete Experience, MBTI's and Keirsey's Sensing, Gregorc's Concrete, and Felder-Silverman's Sensing poles are mapped to the global model Concrete class. Additionally, Riding's Wholist, Felder-Silverman's Global, and Gregorc's Random poles are mapped to the global model Global class. Table 7.8 shows several mappings between GLSMO and LSMs local ontologies poles.

Table 7.8 Poles mapping between GLSMO and LSM s local ontologies

\begin{tabular}{|c|c|c|c|c|c|c|c|}
\hline & & \multicolumn{6}{|c|}{ Learning Style Model } \\
\hline & & Kolb & MBTI & Riding & Gregorc & $\begin{array}{c}\text { Felder- } \\
\text { Silverman }\end{array}$ & Keirsey \\
\hline \multirow{12}{*}{$\begin{array}{l}\frac{\mathscr{\theta}}{0} \\
\frac{0}{0} \\
\frac{0}{0} \\
\frac{0}{0} \\
\frac{0}{0} \\
\frac{0}{0}\end{array}$} & Concrete & $\begin{array}{l}\text { Concrete Ex- } \\
\text { perience }\end{array}$ & Sensing & & Concrete & Sensing & Sensing \\
\hline & Abstract & $\begin{array}{l}\text { Abstract Con- } \\
\text { ceptualization }\end{array}$ & iNtuitive & & Abstract & Intuitive & iNtuitive \\
\hline & Active & $\begin{array}{l}\text { Active Experi- } \\
\text { mentation }\end{array}$ & Extravert & & & Active & Extravert \\
\hline & Reflective & $\begin{array}{l}\text { Reflective } O b- \\
\text { servation }\end{array}$ & Introvert & & & Reflective & Introvert \\
\hline & Sequential & & & Analytical & Sequential & Sequential & \\
\hline & Global & & & Wholist & Random & Global & \\
\hline & Thinking & & Thinking & & & & Thinking \\
\hline & Feeling & & Feeling & & & & Feeling \\
\hline & Perceiving & & Perceiving & & & & $\begin{array}{l}\text { Perceiv- } \\
\quad \text { ing }\end{array}$ \\
\hline & Judging & & Judging & & & & Judging \\
\hline & Verbal & & & Verbal & & Verbal & \\
\hline & Visual & & & Imagery & & Visual & \\
\hline
\end{tabular}


Chapter 7.

Pole subclasses are often represented by the same name (see Figure 7.20). Semantically related concepts are, amongst others:

- Global: Sequential $\rightarrow$ Felder-Silverman: Sequential

- Global: Sequential $\rightarrow$ Gregorc: Sequential

- Global: Verbal $\rightarrow$ Riding: Verbal

- Global: Verbal $\rightarrow$ Felder-Silverman: Verbal

3- LS Mappings

Kolb's, Felder-Silverman's and Honey \& Mumford's LS, MBTI's Personality Type, Keirsey's Temperament, Riding's Cognitive Style, and Gregorc's Mind Style are equivalent to the global learning style model's $L S$. 
The Customization Model

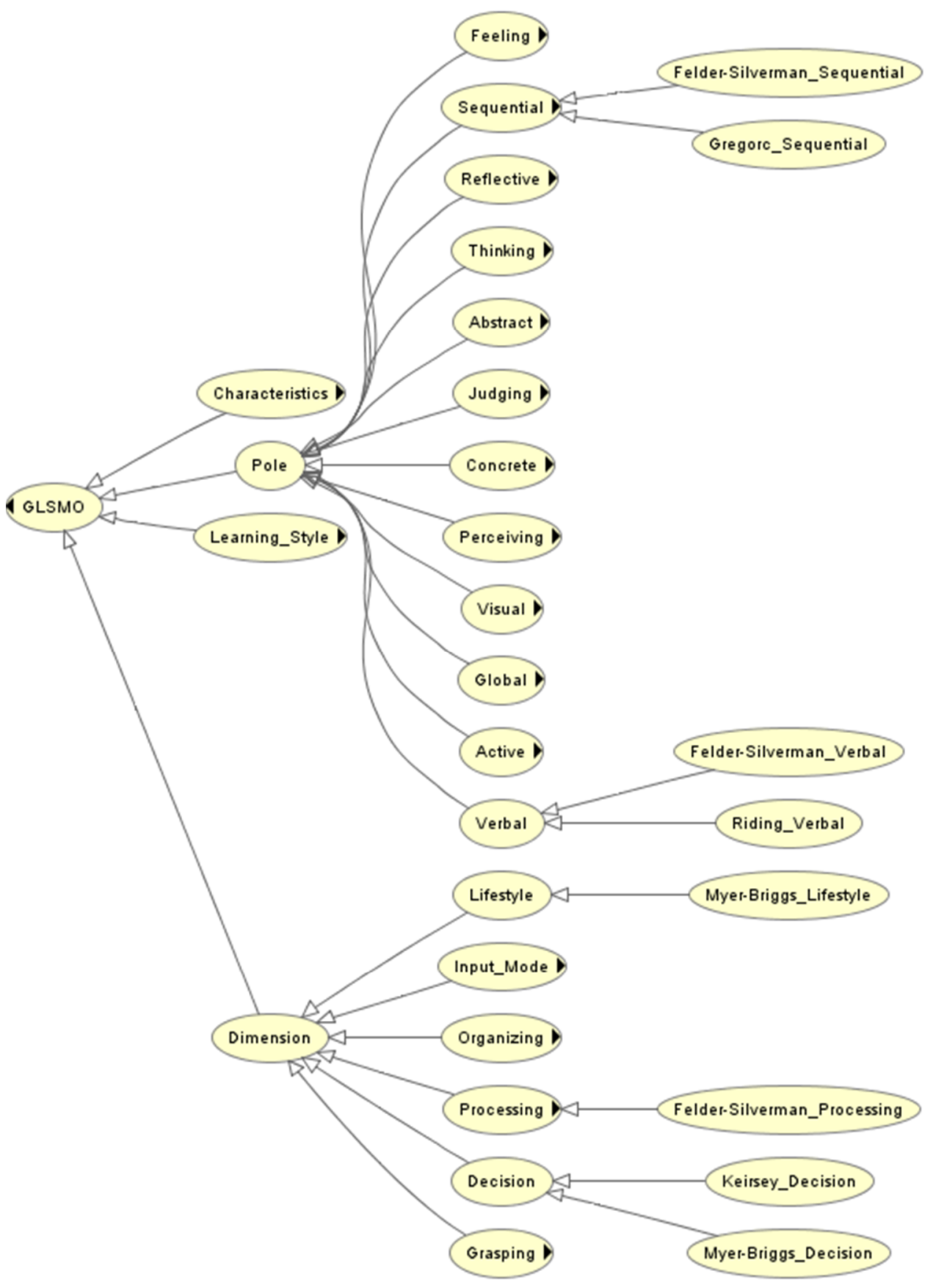

Figure 7.20 An excerpt of GLSMO 
Chapter 7.

\subsubsection{Formalization}

According to the specifications and the knowledge entities obtained (represented above), ontological entities (Concepts/Classes) were organized in hierarchies. Figure 7.21 shows the topmost level Concepts of the GLSMO.

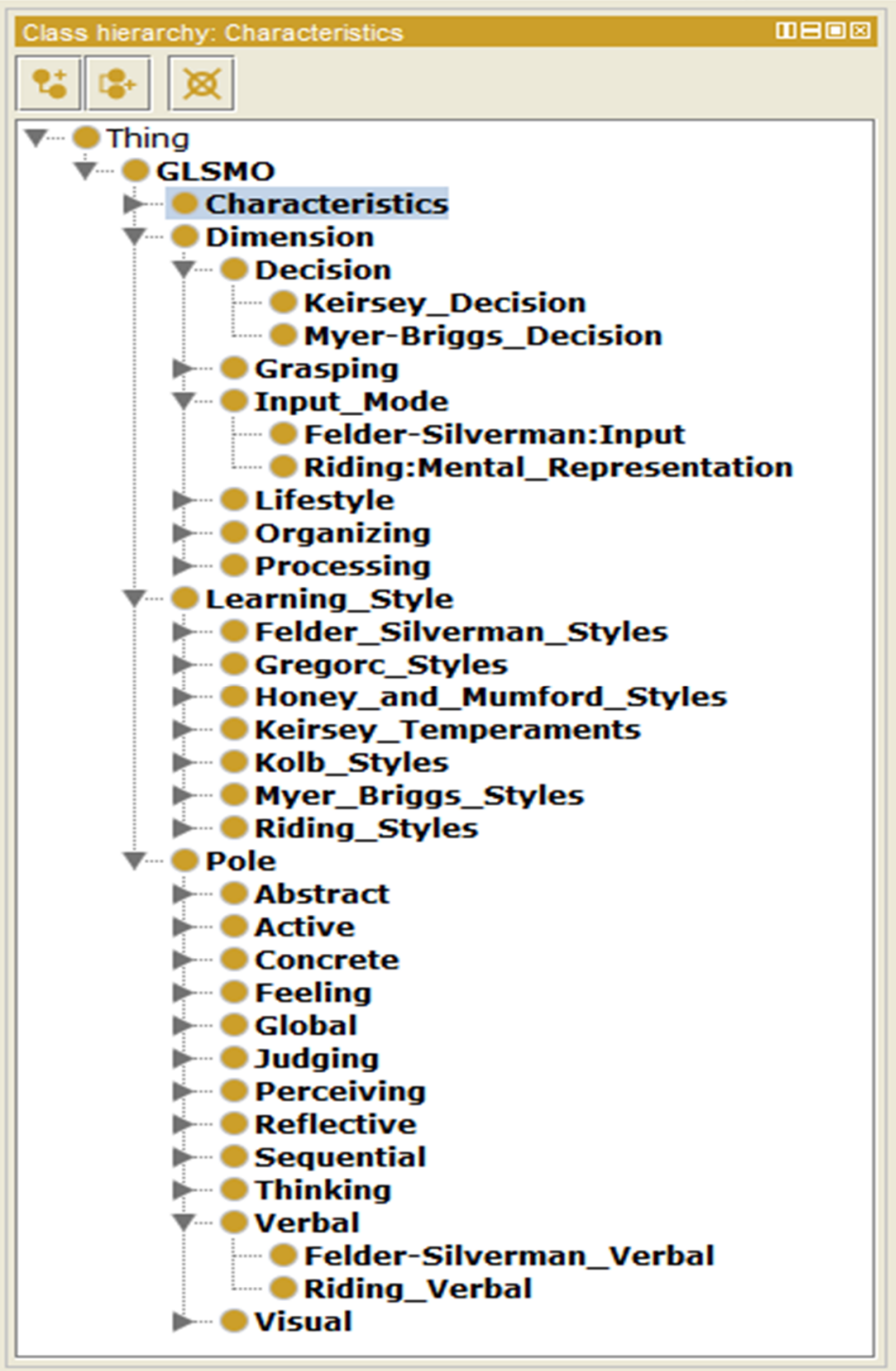

Figure 7.21 The upper-level concepts of GLSMO 
At the end of the Refinement phase, the main classes/concepts and relationships/properties were defined in the GLSMO, so that the ontology obtained after this phase had to be encoded in a suitable ontology language.

We used the World Wide Web Consortium's (W3C) Web Ontology Language (OWL) (Hitzler, M., Parsia, Patel-Schneide, \& Rudolph, 2012) for ontology encoding and the Protégé framework (http://protege.stanford.edu) for developing and maintaining ontologies. In OWL, the user can specify taxonomies for classes and properties. A class is interpreted as a set that contains individuals. The OWL Relationship/Property is a binary relation between two individuals. For example, the property is CharOf links the individual Characteristics to the individual Dimension and Learning_Style. Also, the property isPoleOf links the class Pole (Domain) to the classes Dimension and Learning_Style (Range) (see Figure 7.22).

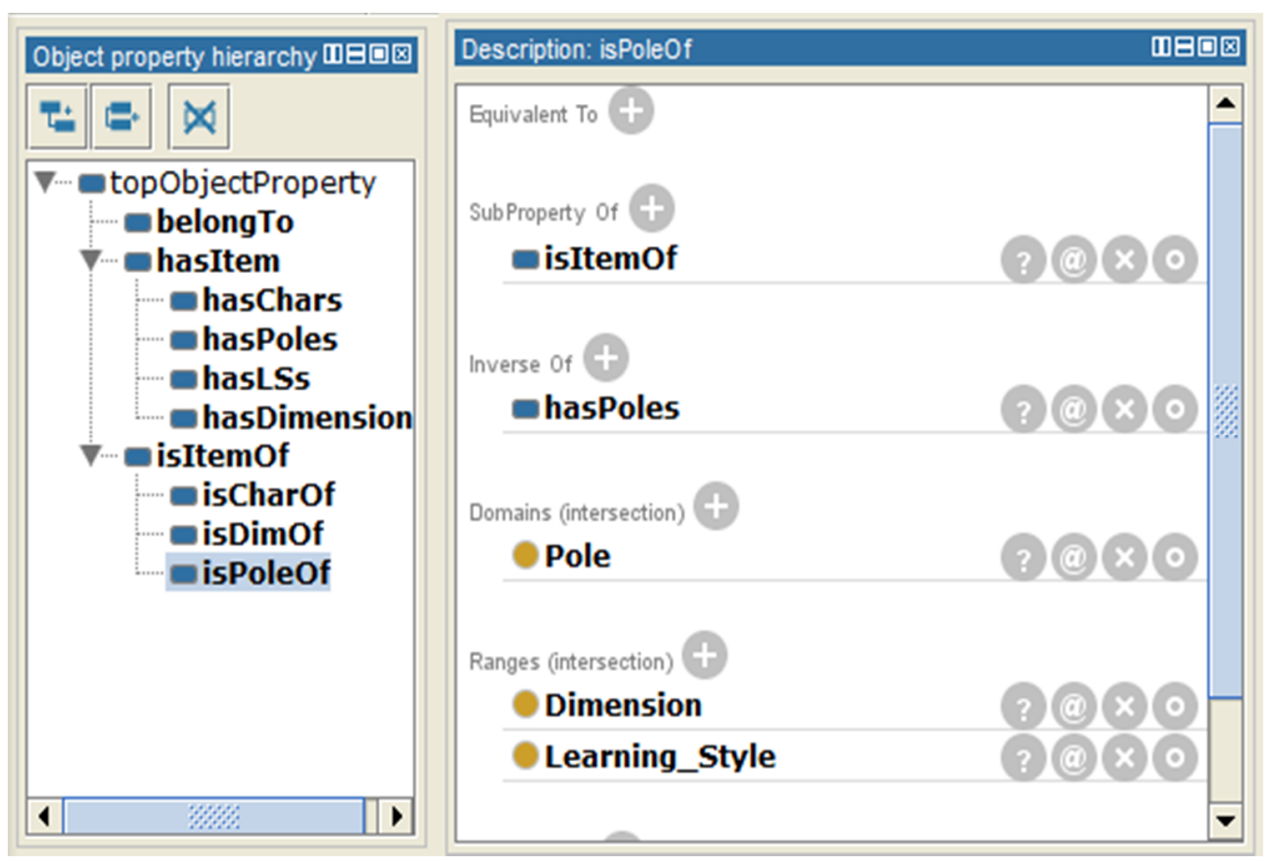

Figure 7.22 Relationships between concepts 


\subsubsection{Evaluation and Maintenance phase}

Once the GLSMO had been built using OWL and checked via the standard Protégé reasoner, the Evaluation phase started. We applied several query examples to test the consistency and verify the usefulness of the proposed ontology. We used the DL Query ${ }^{10}$ (a standard Protégé plug-in), which provides an easy-to-use feature for querying and searching in an ontology. Figure 5.30 presents two query examples of the learner's characteristics related to the Kolb LS. The first one shows characteristics related to a learner that has a Diverging LS as a dominant learning preference (see Figure 7.23 (a)). Several learners have a multi-LS (bi- or tri-LS). In the second query example, the learner's characteristics related to the Kolb Converging and Diverging LSs are displayed (see Figure 7.23 (b)).

On the way to the development of a LSM-independent authoring tool, we aim at bridging the gap between the different LSMs. Thus, we will give a more exhaustive usage of GLSMO in Chapter 9, when a prototype of the Learning Object Authoring Tool (LOAT) (Labib, Penadés, Canós, \& Abel, 2015) will be described.

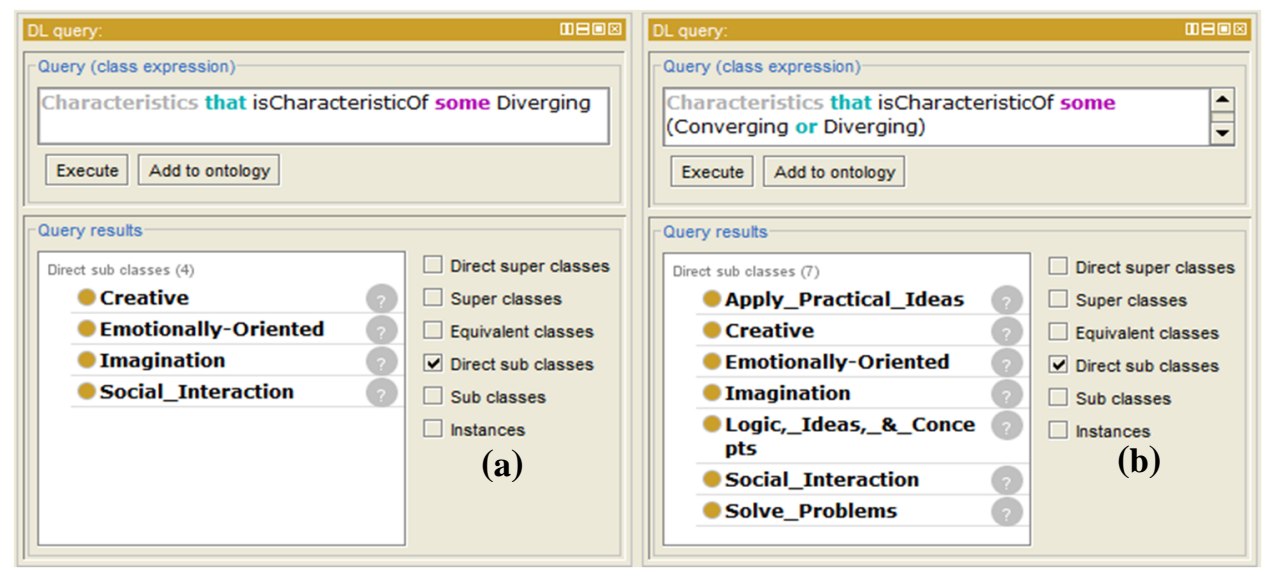

Figure 7.23 Q uery examples. (a) For finding Learner's C haracteristics of Diverging learning style. (b) For bi-learning styles (C onverging and Diverging).

\footnotetext{
${ }^{10}$ www.protegewiki.stanford.edu/wiki/DLQueryTab
} 


\subsection{Comparison}

In Section 4.3, we have introduced several studies that apply ontology to improve the customization issue within e-Learning environments. We have suggested different criteria to compare GLSMO with these studies. Table 7.9 contains a comparison of the GLSMO with the different ontology frameworks.

\begin{tabular}{|c|c|c|c|c|c|c|c|c|}
\hline Criteria & LOCO & O-DEST & LORM & LT4eL & ORLM & Protus & SEALMS & GLSMO \\
\hline Goal & $\begin{array}{l}\text { - Extracting infor- } \\
\text { mation about the } \\
\text { usage of learning } \\
\text { materials. } \\
-\quad \text { Personalization } \\
\text { process. }\end{array}$ & $\begin{array}{l}\text { - Providing learners } \\
\text { with suitable learn- } \\
\text { ing materials based } \\
\text { on their LS. }\end{array}$ & $\begin{array}{l}\text { - Recommending } \\
\text { learning materials ac- } \\
\text { cording learner's } \\
\text { needs, background } \\
\text { and helpfulness. }\end{array}$ & $\begin{array}{l}\text { - Enhancing of "multi- } \\
\text { lingual" learning con- } \\
\text { tent retrieval and man- } \\
\text { agement. } \\
\text { - Content personaliza- } \\
\text { tion. }\end{array}$ & $\begin{array}{l}\text { - Recommending } \\
\text { learning materials } \\
\text { based on the learner's } \\
\text { LS. } \\
\text { - Personalization pro- } \\
\text { cess. }\end{array}$ & $\begin{array}{l}\text { - Recommending ap- } \\
\text { propriate actions. } \\
\text { - Guiding learner's ac- } \\
\text { tivities. }\end{array}$ & $\begin{array}{l}\text { Extracting } \\
\text { knowledge. } \\
\text { - Personalizing work- } \\
\text { flow }\end{array}$ & $\begin{array}{l}\text { - Providing instructor } \\
\text { with extensive } \\
\text { knowledge about } \\
\text { learner characteris- } \\
\text { tics. Recommending } \\
\text { learning materials } \\
\text { suitable to learner LS. } \\
\text { - Global LS models. } \\
\text { - Customizing and } \\
\text { personalizing the e- } \\
\text { Learning process. }\end{array}$ \\
\hline Solution & $\begin{array}{l}\text { - Developing learn- } \\
\text { ing object context } \\
\text { ontology. }\end{array}$ & $\begin{array}{l}\text { - Developing an } \\
\text { ontology for the e- } \\
\text { Learning process. }\end{array}$ & $\begin{array}{l}\text { - Developing a Java } \\
\text { Learning Object ontol- } \\
\text { ogy. } \\
\text { - Developing a per- } \\
\text { sonalized recommen- } \\
\text { dation algorithm. }\end{array}$ & $\begin{array}{l}\text { - Developing a do- } \\
\text { main ontology that } \\
\text { contains a corpus of } \\
\text { keywords from eight } \\
\text { different languages. }\end{array}$ & $\begin{array}{l}\text { - Developing ontology } \\
\text { using learning materi- } \\
\text { als, learner personal } \\
\text { information, and LSs. }\end{array}$ & $\begin{array}{l}\text { - Developing learner } \\
\text { model ontology and } \\
\text { learner observation } \\
\text { ontology. }\end{array}$ & $\begin{array}{l}\text {-Constructing six on- } \\
\text { tologies: learner, do- } \\
\text { main, learner style, } \\
\text { pedagogical, adapta- } \\
\text { tion, and workflow } \\
\text { ontology. }\end{array}$ & $\begin{array}{l}\text { - Developing a global } \\
\text { learning style model } \\
\text { ontology composed of } \\
\text { several LS models. }\end{array}$ \\
\hline Learning Style & Yes & Yes & Yes & No & Yes & Yes & Yes & Yes \\
\hline Single-LS Model & Yes & Yes & Yes & No & Yes & Yes & Yes & Yes \\
\hline Multi-LS Model & No & No & No & No & No & No & No & Yes \\
\hline $\begin{array}{l}\text { Recommending } \\
\text { learning materials } \\
\text { upon various LS } \\
\text { models }\end{array}$ & No & No & No & No & No & No & No & Yes \\
\hline $\begin{array}{l}\text { Recommending } \\
\text { learner characteris- } \\
\text { tics upon his } L S\end{array}$ & No & No & No & No & No & No & No & Yes \\
\hline $\begin{array}{l}\text { Reusing learning } \\
\text { materials based on } \\
\text { different LS models }\end{array}$ & No & No & No & No & No & No & No & Yes \\
\hline $\begin{array}{l}\text { Unifying LS model } \\
\text { characteristics }\end{array}$ & No & No & No & No & No & No & No & Yes \\
\hline $\begin{array}{l}\text { LS models interop- } \\
\text { erability }\end{array}$ & No & No & No & No & No & No & No & Yes \\
\hline
\end{tabular}





\subsection{Conclusion}

This chapter has presented the GLSMO, a global ontology model that integrates seven LSMs. The GLSMO development methodology started by identifying the criteria behind the selection of LSMs. A detailed description of the selected LSMs have presented. Consequently, the GLSMO development steps have described. Finally, comparison between GLSMO and several personalized e-Learning ontology-based studies has conducted.

Next chapter describes the third model in our framework, the LOPL Model. 



\section{Chapter 8}

\section{Product Line-based}

D evelopment of LOs

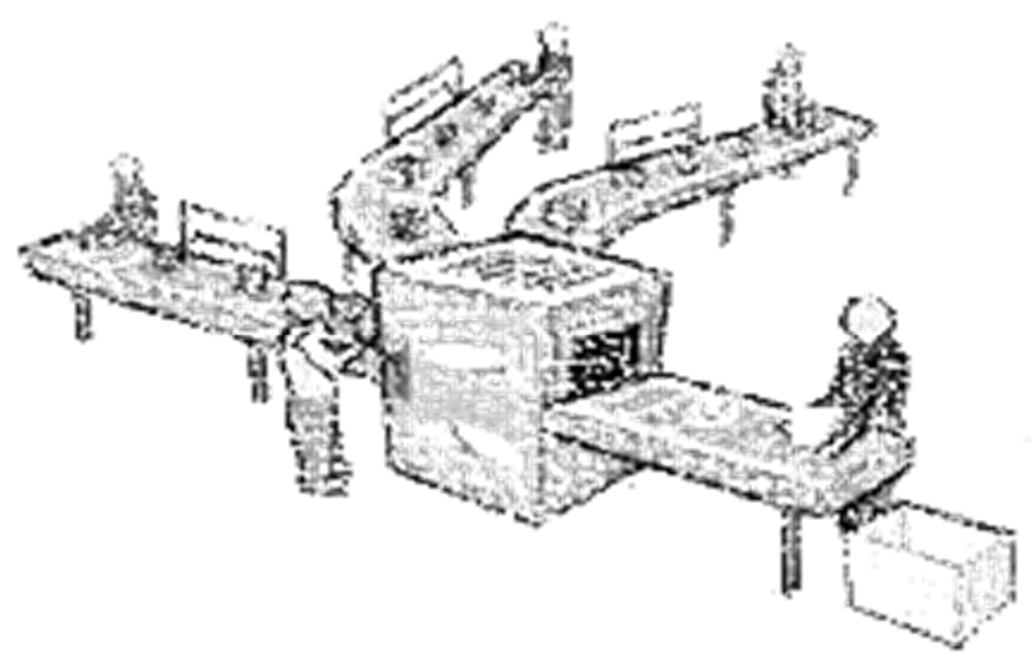




\section{Chapter 8.}

The LO product line aims to apply the SPLE and the DPL principles, techniques and tools for the creation of customized LOs. In this Chapter we give an overview of the SPLE with its associated Domain and Application Engineering processes, and a short description of the SPLE variability management. We then briefly describe the DPL framework and introduce the LO Product Line (LOPL) approach in the last section.

\subsection{Software Product Line Engineering and V ariability Management}

As the time and effort needed to develop software applications have now been greatly reduced, there is increasing pressure for organizations to explore new ways to expand and deliver their products in a timely and efficient manner.

SPLE has appeared as a promising software development model for increasing the production of IT-applications, giving them control of the diversity of products and reducing time to delivery.

For organizations, the basic concept of the SPLE approach is to develop a "product family" from reusable artifacts rather than from scratch. The SPLE approach allows software developers to develop customizable applications quickly and economically.

Pohl et. al. (2005) developed an SPLE framework that incorporates the concepts of the use of Platforms and the ability to provide Mass Customization. In the software context, a platform is a collection of reusable assets or artifacts. These assets may be reused in a systematic and consistent way to construct an application. To enable mass customization, the platform must provide the facilities to meet different user requirements, so that the variability concept is a key issue in the platform.

The SPLE framework consists of two development processes: Domain engineering and Application engineering (See Figure 8.1).

\subsubsection{Domain engineering}

The Domain engineering process is responsible for capturing information and knowledge about a specific domain to create the reusable artifacts. The "product family" is analyzed in order to define and realize the commonalities (features that are part of each application) and variabilities (features that are part 


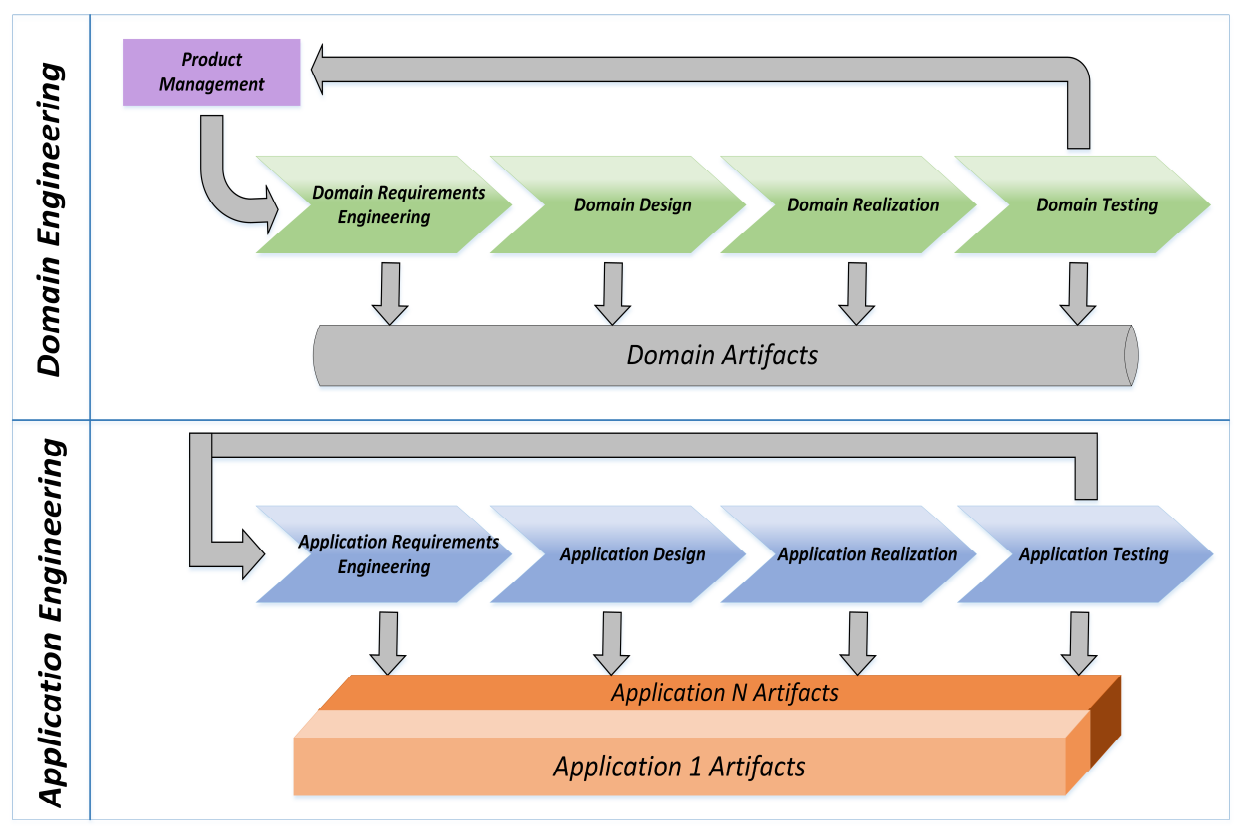

Figure8.1 SPLE framework

of a specific application). The Domain engineering process is comprised of five sub-processes: Product Management, Domain Requirements Engineering, Domain Design, Domain Realization, and Domain Testing.

\subsubsection{Application engineering}

The Application engineering process is responsible for producing product line applications from the platform established in the Domain engineering process. It reuses the domain artifacts (resulting from Domain engineering), exploits the variability and guarantees the correct linking of the variability according to the application's specifications. The Application engineering process is composed of four sub-processes: Application Requirements Engineering, Application Design, Application Realization, and Application Testing.

\subsubsection{Variability Management}

The realization of mass customization relies heavily on the variability. The Variability Management concept supports the definition and exploitation of variability throughout the various processes in SPLE. The reusability strength 


\section{Chapter 8.}

point of SPLE over other techniques is that software reuse is planned, since the development process is designed (Llana, 2012). So, the variability of the domain is firstly determined in the Product Management and Domain Requirements Engineering sub-processes in the Domain Engineering process. It is then exploited during the Application Engineering process by connecting the appropriate variants. The other sub-processes of the Domain and Application Engineering deal with models that describe the variability at various levels of abstraction. These levels may be refined after the completion of each sub-process and additional variability may be introduced.

To manage the variability in an easy, organized, and consistent way, a method or model for discovering and representing it is needed. Several variability management approaches are introduced into SPLE, such as the Feature-Oriented approach (FODA (Kang, Cohen, Hess, Nowak, \& Peterson, 1990)), architecture-centric approach (Thiel \& Hein, 2002), configuration-based approach (Sinnema, Deelstra, Nijhuis, \& Bosch, 2004), and UML-based approach (orthogonal variability model (Pohl, Bockle, \& van der Linden, 2005; Chen, Ali Babar, \& Ali, 2009). In 1990, the Feature-Oriented Domain Analysis (FODA) was proposed by Kang et al. (1990) and features began to be used to represent variability.

\subsubsection{Feature model}

According to The American Heritage Dictionary (https://ahdictionary.com), a feature is defined as "a prominent or distinctive part, quality, or characteristic". Kang et al. (1990) refined the previous definition as "A prominent or distinctive user-visible aspect, quality, or characteristic of a software system or systems."

A feature model describes the principle (or the interesting) features of a family of systems or applications in a particular domain and represents the relationships between them (Kang, Cohen, Hess, Nowak, \& Peterson, 1990). The relationships are classified according to the nature of the feature in the family (Common or Variable).

The feature model works as a communication layer between end-users and 
developers. To the end-users, the feature model presents the principle features, the optional features that can be chosen, and when they can choose them. To the developers, the feature model states the requirements to be parameterized in the other models and the application architecture, and describes the parameterization process.

\section{Feature-Oriented Domain Analysis (FODA)}

Features are the attributes of a system that directly affect end-users (Kang, Cohen, Hess, Nowak, \& Peterson, 1990). The main goal of feature analysis is to catch the end-user's understanding of the general capabilities of applications in a domain and represent them in a model. Several relationships are identified between features. FODA defines a structural relationship that represents the logical grouping of features. The structural relationship consists of three types: Mandatory, Optional, and Alternative; see Table 8.1 .

\section{Table8.1 Structural Relationships in FODA}

\begin{tabular}{ll}
\hline Relationship & Description \\
\hline \hline Mandatory & $\begin{array}{l}\text { Mandatory feature is the common feature or aspect be- } \\
\text { tween all the members of the family. In FODA, mandatory } \\
\text { relation is represented as a line between two features. See } \\
\text { Figure } 8.2 .\end{array}$ \\
\hline Optional & $\begin{array}{l}\text { Optional feature is the feature that may or may not be in- } \\
\text { cluded in a specific application of the family. In FODA, an } \\
\text { optional relation is represented as a line ending in a circle } \\
\text { that indicates the optional feature. See Figure } 8.2 .\end{array}$ \\
\hline Alternative & $\begin{array}{l}\text { Alternative relationship defines the relation between one } \\
\text { feature and a group of features. Alternative indicates that } \\
\text { no more than one feature will selected from the group of } \\
\text { features to represent in a specific application of the family. } \\
\text { Figure } 8.2 \text { shows the representation of the alternative rela- } \\
\text { tionship. }\end{array}$ \\
\end{tabular}




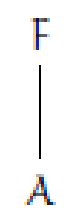

(a)

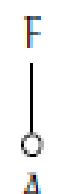

(b)

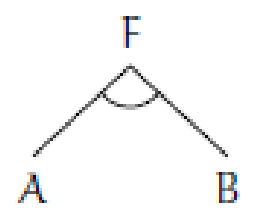

(c)

Figure 8.2 FODA relationships

FODA also defines two "composition rules" that define the semantics existing between two optional or alternative features. See Table 8.2.

Table8.2 FODA compositional rules

\begin{tabular}{ll}
\hline Rule & Description \\
\hline "requires" & $\begin{array}{l}\text { The selection of a specific feature requires the se- } \\
\text { lection of another feature. }\end{array}$ \\
\hline "mutually exclusive with" & $\begin{array}{l}\text { The selection of a specific feature is mutually ex- } \\
\text { clusive with the selection of another feature. }\end{array}$
\end{tabular}

The FODA proposal provides a textual representation of the composition rules as follows:

$\varangle$ feature1 $>$ (' requires ') $\varangle$ feature $2>$

feature1 >('mutex-with ') \&eature2 >

\subsection{Document Product Line (DPL)}

The DPL applies product line engineering principles to the semiautomatic generation of documents in domains with high content variability and reuse (Gómez, Penadés, Canós, Borges, \& Llavador, 2014). Central to DPL is the notion of family of documents. By family we mean a set of documents that share some common, mandatory parts while they differ in other, optional 
parts. Every member of the family is built by assembling a set of content components.

The DPL process is composed of two main activities, namely Domain Engineering and Application Engineering. The Domain Engineering starts with the specification of a family of documents in terms of content features, which represent document fragments that either must or can be included in a specific document (a member of the family). Every content feature must be linked to one or more technology features, which are associated to the way in which a particular content feature is represented; there may be more than one way of representing a given content feature since different disseminations of the same content can be requested. For instance, a given text may be rendered into pdf or html depending on different factors.

Every content feature is associated with actual content by linking to some content component. Reusable content assets, called InfoElements, are organized and stored in the DPL Repository. Each InfoElement has a specific content plus some descriptive metadata, and can be reused just by attaching it to a particular document feature. There is no prescription about the granularity of InfoElements; rather, how complex an InfoElement is depends on the specific domain it is intended for. In some cases, an InfoElement can be a simple form with a text label plus a text input field where a user puts some data, whereas in other cases an InfoElement can be a complex workflow model describing an emergency response plan.

Given a document family specification (i.e. a document feature model), a specific member of the family is defined by means of a configuration in the Application Engineering stage of the DPL process. There, the user (typically a document engineer) selects the optional features that are to be included in the document along with the mandatory ones, which are common to all the members of the family. After the configuration, an automatic process assembles the document by taking the InfoElements from the Repository, as described in (Gómez, Penadés, Canós, Borges, \& Llavador, 2014).

Figure 8.3 shows the main parts of the DPL framework supporting a completed DPL process. 
Chapter 8.

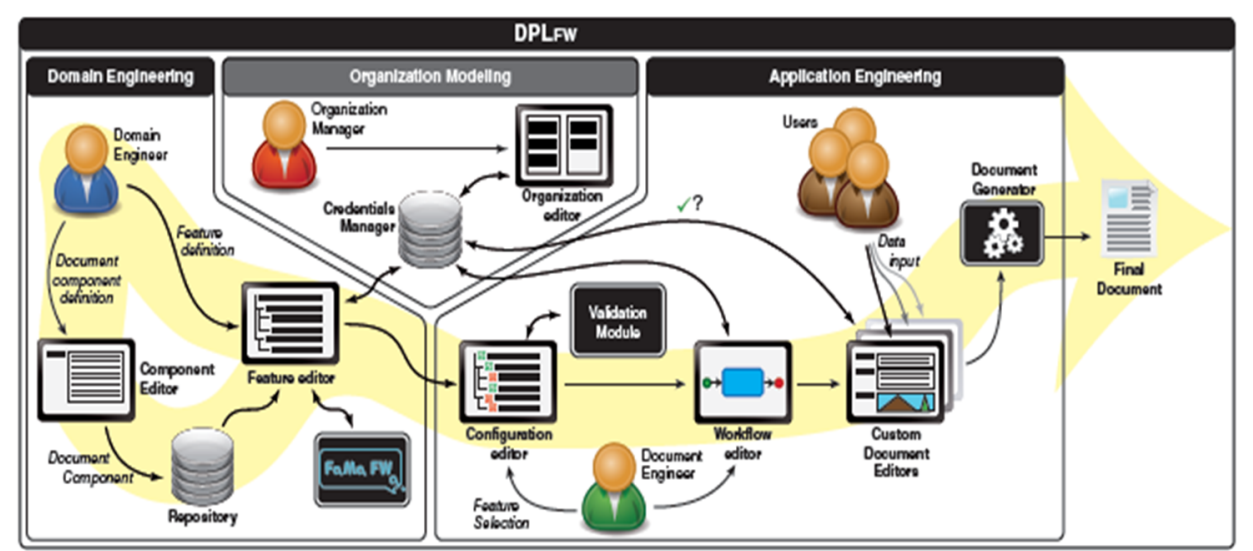

Figure 8.3 D PL framework (Gómez, Penadés, Canós, Borges, \& Llavador, 2014) 


\subsection{LO product line (LOPL) approach}

The LO product line aims to apply the SPLE and the DPL principle, techniques and tools for the creation of customized LOs. The LOPL model provides a methodology to model the commonality and variability in the LO family as a group of features (similar to DPL). We use the term "LO family" to represent all the LO instances generated by combining the alternative and optional features. The model was developed with key goals: firstly, to facilitate the LO creation process to non-expert users by employing the domain engineering process and secondly to enforce Component reusability following SPLE principles.

In this domain, a feature corresponds to a component according to the RIO/RLO Cisco strategy (introduced in Chapter 6). A family of RIOs/RLOs can be defined by recalling the RIO strategy structure depicted in Figure 6.2 (in Chapter 6), which will guide the representation of RIOs and RLOs in terms of features (RIO/RLO feature model).

Following DPL, the LO product line paradigm separates two processes, called Domain Engineering and Application Engineering. The Domain Engineering process is responsible for defining the LO commonality and variability, and construct the reusable components that accomplish the desired variability; the LO product line is defined. The Application Engineering process is responsible for the generation of personalized LOs; this process exploits the LO product line and each characterization of the variability in the LO product line generates a new personalized LO with high reuse of components. Figure 8.4 describes the LO product line process using the Business Process Modelling Notation (BPMN) (OMG, 2011).

\subsubsection{LO Domain Engineering}

As deduced from the SPLE, the input of the Domain Engineering process is the "LO roadmap", which specifies the main common and variable features of the LOs and the organizational view of the future of their production. The Domain Engineering process comprises four sub-processes; the LO Family 


\section{Chapter 8.}

Analysis, LO Family Design, Develop Components, and LO Production Plane sub-process.

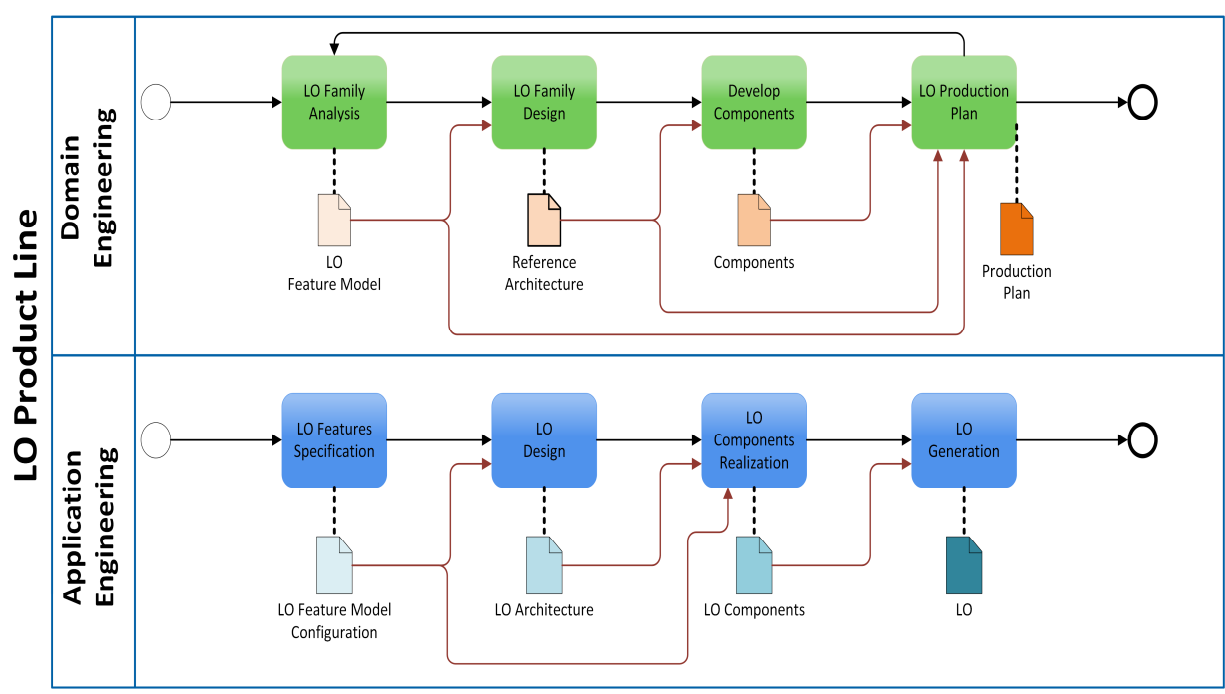

Figure 8.4 The LO product line process using BPMN

\subsubsection{The LO Family Analysis}

In the LO Family Analysis sub-process, the main activities are to elicit and analyze the common and variable requirements or features for the LO product line. The domain engineer describes LOs (RIO or RLO) in terms of content and technology features, similar to the DPL methodology. The domain engineer identifies the features that are common to all LOs of the LO product line. The domain engineer identifies the different features among the LOs. To model the commonalities and variabilities of the LO family, we use the cardinality-based feature model. The result of the analysis is an LO feature model including mandatory, optional and alternative features. Mandatory features represent parts that must be included in all the LOs of the family, whereas the optional and alternative ones, which represent the variability parts in the LO, will only be included in some members of the family. An example of an excerpt of the LO feature model is shown in Figure 8.5. 


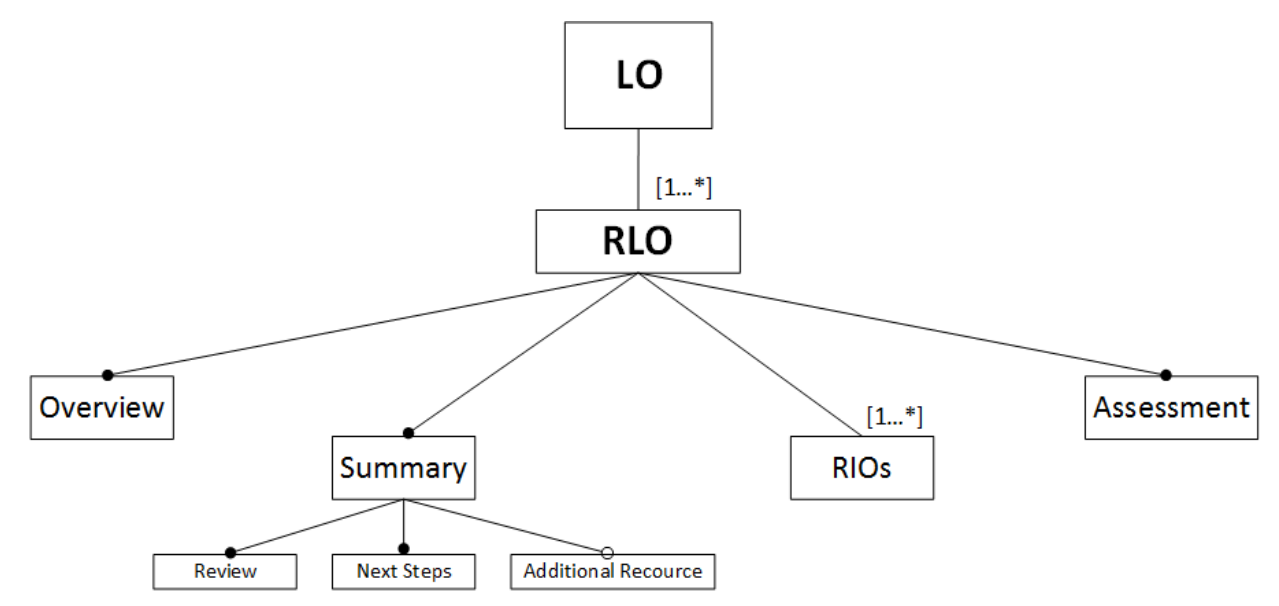

Figure 8.5 An excerpt of the LO feature model

\subsubsection{The LO Family Design}

In the LO Family Design sub-process, the LO reference architecture is defined by determining the required LO components according to the feature model (common and variable based on the variability model). The LO components must exist in the repository. Thus, all the features specified in the LO feature model must be fulfilled by a corresponding component in the repository. The output includes the LO reference architecture and the variability model. Later, in Application Engineering process, a specific instance of the reference architecture, called the $L O$ architecture, will be created after fixing the variability points for a specific LO.

\subsubsection{The Develop Components}

The Develop Components sub-process is responsible for the creation or retrieval of components to fulfil the required features in the LO feature model. Each component is attached with metadata to support the retrieval process. The current versions of the LO metadata specifications (IEEE LTSC, IMS Global Learning Consortium, etc.) do not support customized or personalized learning. In our approach, LOs are represented and managed using a specific application metadata profile. The proposed application profile takes advantage of the IEEE LOM in educational perspective plus several metadata 


\section{Chapter 8.}

related to the LSM, the LS, and the learner characteristics. The input for the Develop Components sub-process is the LO reference architecture, including a list of reusable components to be developed. The output of this sub-process contains the complete design and implementation of reusable LO components.

\subsubsection{The LO Production Plane}

Finally, a production plan is generated in the LO Production Plane sub-process. The production plan describes how components are joined according to the relationships between the LO features.

\subsubsection{LO Application Engineering}

The Application Engineering process is responsible for deriving the LOs from the platform established in the Domain Engineering process. It comprises four sub-processes; the LO Features Specification, LO Design, LO Components Realization, and LO Generation sub-process.

\subsubsection{The LO Features Specification}

In the LO Features Specification sub-process, the application (LO) engineer (the person responsible for systemizing the creation of a particular LO) specifies the variability points included in a specific LO. The main activity is to determine which features will be included in a specific LO that will be generated later. The specified features are ready to be configured and will be used as an input for the next sub-process.

\subsubsection{The LO Design}

In the $L O$ Design sub-process, to present a specific LO regarding the $L O R e$ quirements Specification, all the selected LO features must be linked and the $L O$ architecture must be introduced. The $L O$ architecture is a specialization of the LO reference architecture implemented in the LO Family Design subprocess. Only the desired elements of the LO reference architecture for a specific LO are therefore selected and configured. At the end of this sub-process, the $L O$ architecture is presented to the next sub-process; LO Components Realization. 


\subsubsection{The LO Components Realization}

The LO Components Realization sub-process is responsible for assembling the reusable components of a specific LO. The components are requested according to the selected variability points and elements in The $L O$ architecture. Sometimes, in this sub-process, the application engineer may need to modify or complete the content of several LO components before the generation process has begun. The output of the LO Components Realization sub-process consists of the specific $L O$ components, the selected variants of the reusable $L O$ components, and the configurations.

\subsubsection{LO Generation}

Finally, after fixing and configuring all the variability points for a specific LO, the LO Generation sub-process produces the final LO.

\subsection{Conclusion}

This chapter has introduced the LOPL model that used to develop LOs in terms of industrial manufacturing. We have briefly mentioned SPLE, variability management, and DPL. Then, we have described the LOPL process into two processes are Domain Engineering and Application Engineering. Describing the usage of FM to manage the LO variability.

Next chapter introduces our efforts in designing and implementing a tool that supports the combination of the LO content model, the customization model, and the LOPL model for the development of LOs. 



\section{Chapter 9}

\section{Towards a Tool Supporting LO Product Lines}

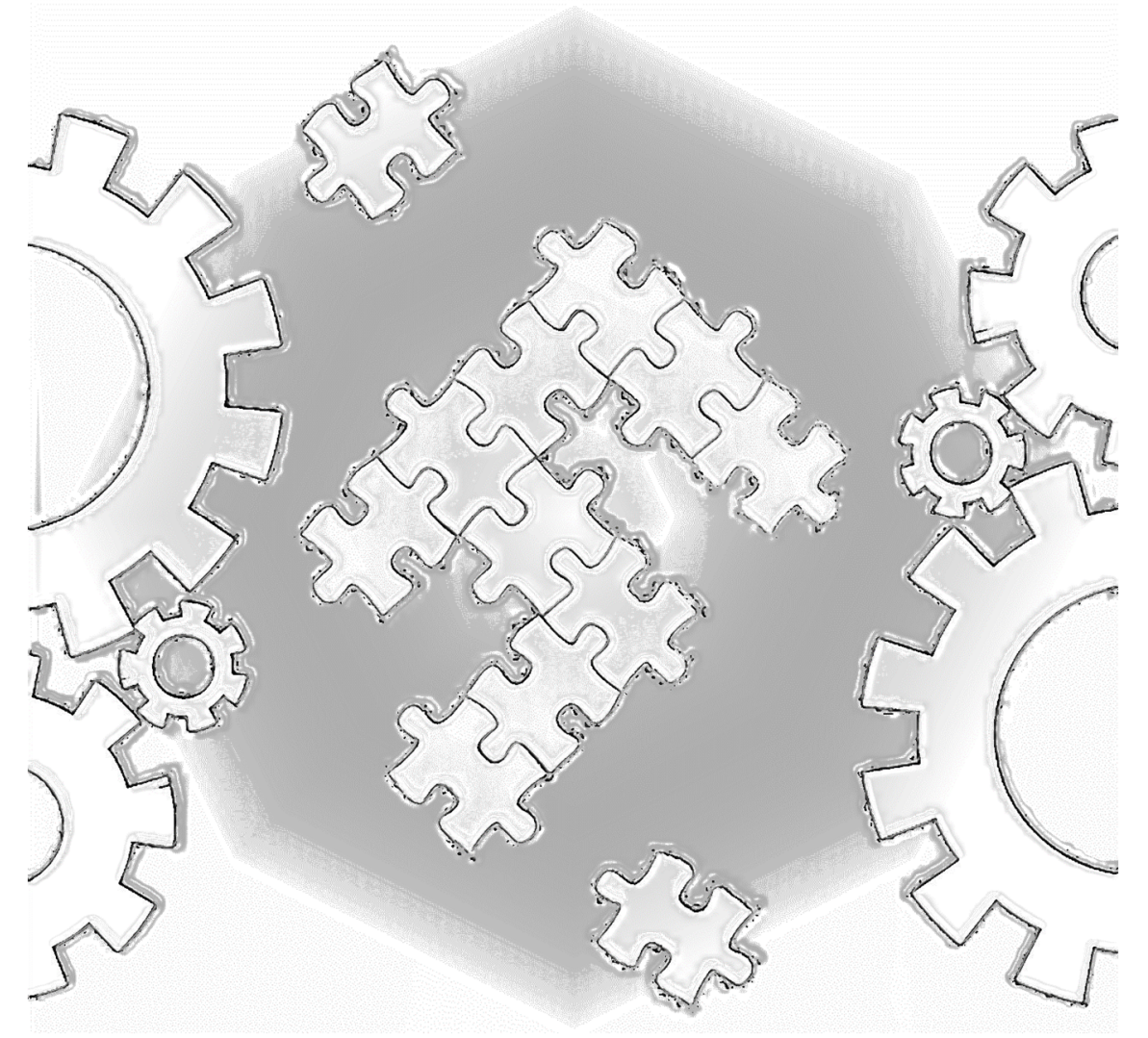




\section{Chapter 9.}

Learning Object Authoring Tool (LOAT) is tool that enforces customization and reuse to increase the efficacy of learning materials authoring process. We are designing and implementing LOAT on the basis of three models: the LO content model, the customization model, and the LOPL model. Firstly, a LO content model able to address the domain requirements. Secondly, a personalization strategy that helps instructors to design learning materials addressing the learners' preferences and needs. Finally, an LO generation process supported by the appropriate technologies. Such a process should be reuseaware and grant a high degree of customization. To do this, most learning management systems offer a metadata-based catalog of LOs and retrieval tools as the main support for content reuse.

The chapter is organized as follows. The LOAT Architecture is introduced in Section 9.2. The whole LOAT framework is described in Section 9.3 (Labib, Penadés, Canós, \& Abel, 2015; Labib, Canós, \& Penadés, 2017) which we are developing to provide a domain oriented layer to the system. Finally, a case study is described of a test on the generation process of an "If Statement" RIO as part of a "Java Programming" course.

\subsection{LOAT Architecture}

Building an LO requires a model able to address the domain requirements. The LOAT architecture comprises three layers; the Repository layer, Services layer, and Presentation layer (see Figure 9.1).

The first is the Repository layer, which provides the persistence of the generated LOs (RIO and RLO) and the LO's Components. The second layer is the Services layer, which comprises three modules: the LO Product Line model, $L O$ Content model and LO Customization model. The Presentation layer is responsible for providing the application portal to the end user. The LOAT layers interact with the DPL framework because the LO product line functionalities are supported by the DPL.

\subsubsection{The Repository layer}

LO product line processes depend on the availability of the Components that will be reused to create various LOs of the LO family. The Repository is responsible for granting the component availability to create LOs. It provides 
several services for managing and retrieving Components, for instance creating or deleting components and searching for components using keywords and knowledge-based ontology. The Repository layer uses the DPL Repository for saving LO Components and the LOAT Repository for the created RIOs and RLOs.

In LOAT, the LOs of the Repository are called RIOs and RLOs. Each one is composed of two main parts: data and metadata. The former is the LO content, which is represented as a Dita-map. The metadata is responsible for describing and managing the LO content by providing information about it. To be able to perform the structure combination of a specific LO, as stated in the LO content model in the next layer, the Component must be tagged with metadata to be able to discover and interoperate during technology supported learning. In our approach, LOs are represented and managed using a specific application metadata profile. The proposed application profile takes advantage of the IEEE LOM in the educational perspective, plus several other metadata related to the LSM, LS, and learner characteristics.

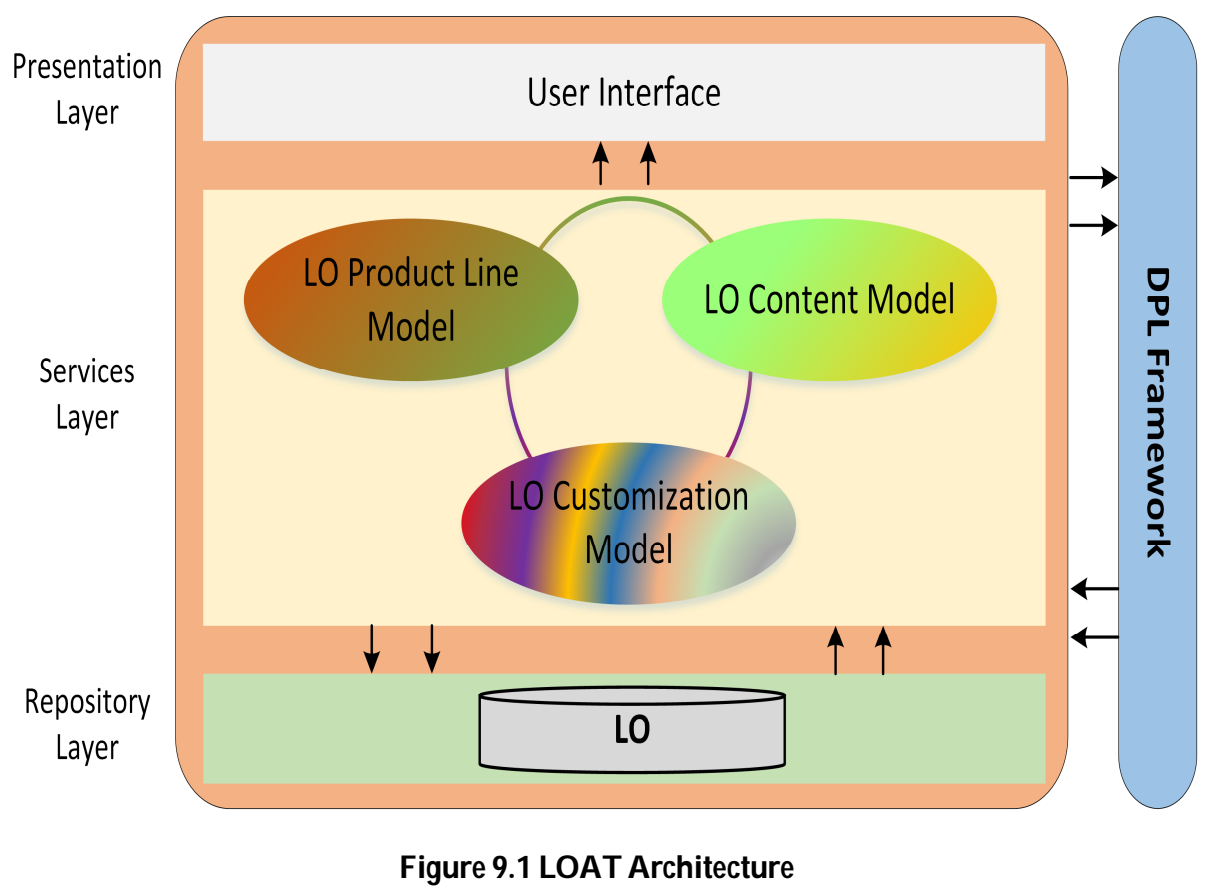


Chapter 9.

\subsubsection{Service layer}

The Service layer is responsible for managing the business rules of transforming and translating data between the two layers. The Service layer contains an content model that helps instructors and course-designers to create meaningful learning activities and effective assessment. It also contains a personalization strategy that helps instructors to use semantic techniques to adapt learning materials to meet the learners' needs. And, finally, there is a production technique that brings high flexibility and reuse in the LO creation process. The Services layer comprises three modules: the LOPL model, LO Content model, and LO Customization model, as shown in Figure 7.1.

\subsubsection{Presentation layer}

The presentation layer comprises the elements that implement and display the User Interface (UI) and control user behavior and interactions with the application. For instance, it manages the process of user input and displays contents related to a specific user.

\subsection{LOAT Framework}

The LOAT framework provides the technical and methodological structure to create LOs following the LO product line and DPL approaches. We developed the LOAT framework following the Model-Driven Web Engineering (MDWE) paradigm (Londoño \& Duitama, 2012), which enabled us to take advantage of the construction of meta-models and models in the Web application domain and code generation/reusability for the implementation of the application.

The LOAT framework was developed within the DPL framework, which allowed us to take advantage of its generation process. The LOAT framework was developed using the well-known Eclipse environment (Overview, Eclipse Platform Technical, 2006). Several key technologies were selected for the LOAT implementation: the Apache Maven framework (Apache Maven 3.x documentation, version 3.5.0, 2017), the Hibernate Object Relational Mapping (ORM) framework (Hibernate ORM documentation 5.2, 
2017), and the Eclipse Modeling Framework (EMF) (Eclipse Modeling Framework Project (EMF), 2012). The Apache Maven is a build automation tool; based on the concept of a project object model (POM), Maven can describe how software is built, describe its dependencies, reporting and documenting from a central piece of information. Hibernate ORM is an ObjectRelational Mapping (ORM) framework for Java environments that facilitates mapping data between an object model and a relational database. It also provides data query and means for data retrieval. EMF is an Eclipse-based framework and code generation facility to build applications using Model-Driven Engineering (MDE) techniques.

Figure 9.2 shows the main elements of the LOAT framework. The LO Feature Model is used in the Domain Engineering process to identify the variability of the LO (RIO or RLO). The LO Feature Model is determined according to the specification of the LO type. The LO Feature Model is linked with four elements: the Administration Model, Repository, Feature Model Validation, and Recommend Relative Components. The Administration Model has a Certificates \& Privileges element responsible for storing information on the application users. All administrative issues and information can be edited by the Administrator in the Administration Portal. The Repository contains the artifacts that will be reused in the LO creation process. The LOAT framework deals with two repositories: one responsible for storing the RIOs and RLOs and the other belongs to the DPL framework, which stores the core Components that are also used in the LO creation process. Thirdly, the LO Feature Model must be validated and verified by the Feature Model Validation element. The Feature Model Validation is a core element in the DPL framework and ensures that the LO Feature Model has no errors. The Recommend Relative Components element recommends RIOs, RLOs or Components (stored in the Repository) to be used in the LO creation process. This recommendation is based on the LO's LS specified in the LO Metadata element. The GLSMO is employed for this purpose. All the previously described elements belong to the Domain Engineering process of the LO product line. 
Chapter 9.

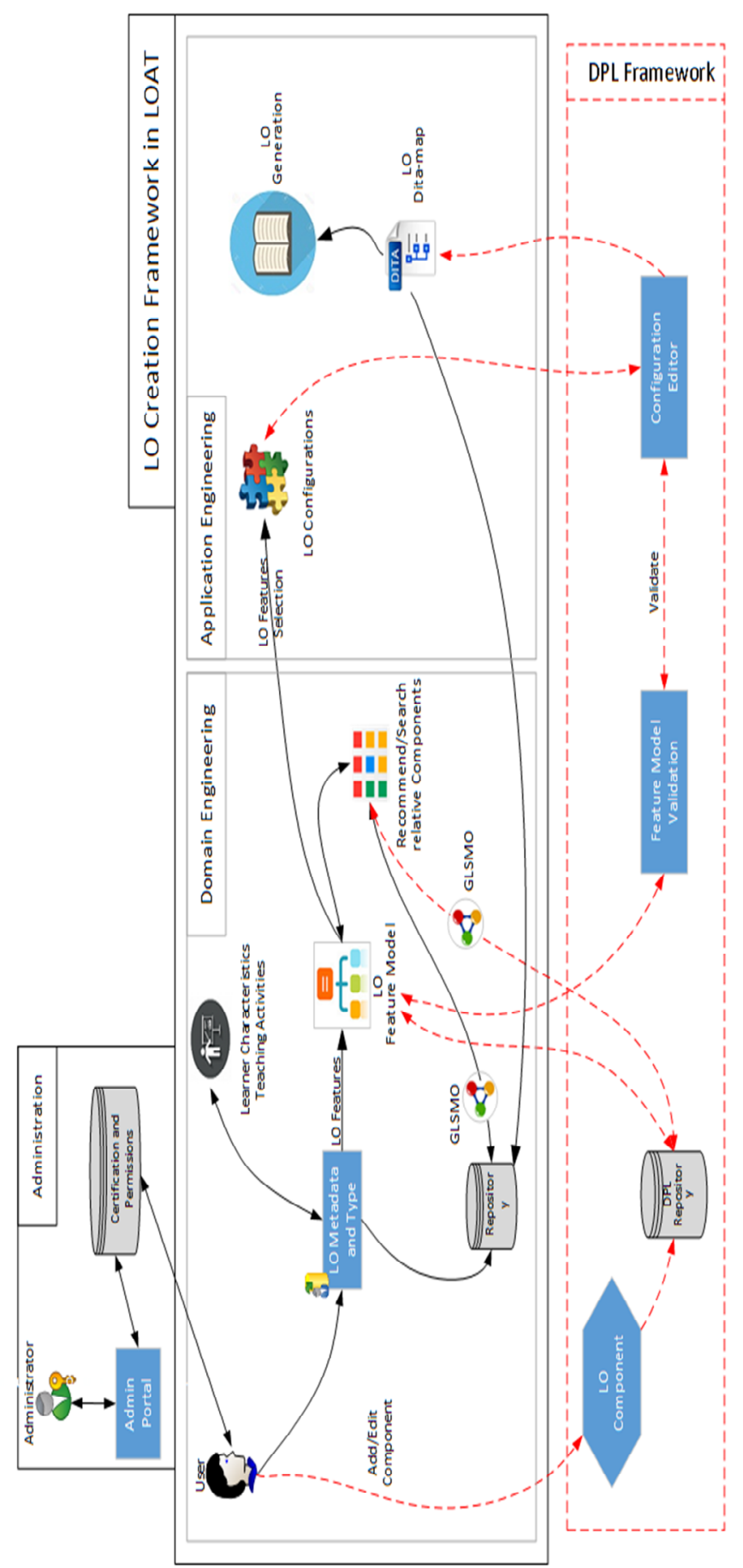

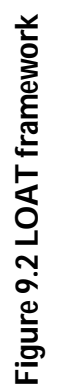


The second process in the LO product line is the Application Engineering process, to which the remaining elements belong. The LO Configuration element provides the selection of variability points in the LO. This element is connected with the Configuration Editor in the DPL framework. By means of the Feature Model Validation element in the Domain Engineering process, the user can avoid any configuration errors in this step.

When a configuration is defined, the LO DITA-map is created. The LO DITAmap is an LO architecture that contains the Component hierarchies and references of a specific LO. Finally, the LO is generated by the DITA Open Tool Kit Engine, which integrates the different components in the LO DITA-map to produce the LO in a specific format (printed, hypermedia, etc.).

In the rest of this chapter the main elements of the LOAT framework are described in detail and an example is given of the LO generation steps.

\subsubsection{Administration}

Following the role-based access control, the Administration can restrict system access to authorized users. The LOAT framework must have administrator/s with unlimited privileges. The administrator/s has/have responsibilities, such as the definition of user type and user privileges.

In the LOAT, Administration model is represented according to the UML class diagram shown in Figure 9.3. The model characterizes an administration as a collection of Administrators and Roles. Administrators and users are inherited from a parent class, named Actors. Actors are identified using both an ID and a UUID (universally unique identifier) for extra fields, like viewing/editing a profile of an actor to avoid security risks. Also, actors must have a name, password, email address, and phone number. Administrators may manage users. Each user is managed by one administrator. Actors are assigned with Roles. Roles specify the actor functionalities with the LOAT framework. Roles must have an ID, role name, parent role, child role, and description. Roles may be combined in a hierarchy where the parent role subsumes functions and permissions owned by child roles. 


\section{Chapter 9.}

The LOAT framework supports administrators by means of an Administration Portal, which is used to manage users and all administrative issues. Figure 9.4 describes a global use case diagram for different actor concepts.

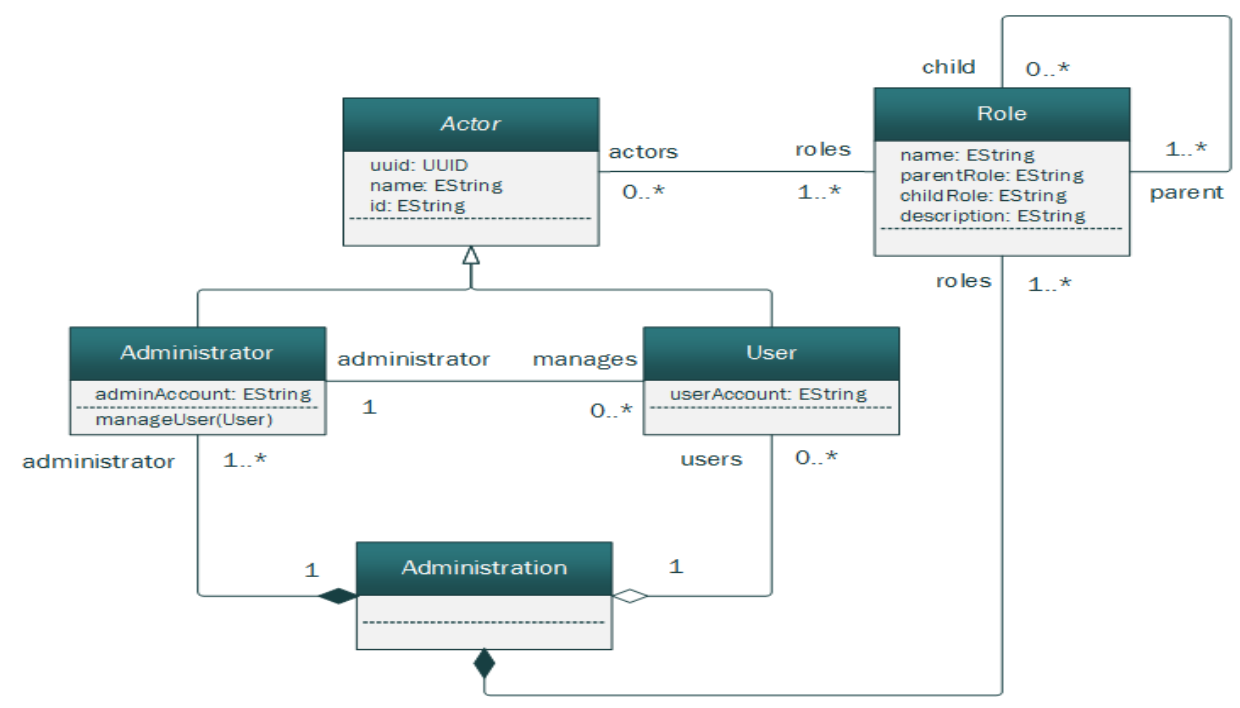

Figure 9.3 The Administration model

\subsubsection{LO Metadata}

In the LOAT framework, the LO creation process is supported by the knowledge of the LS associated with a specific LO. As far as we know, no LO metadata standards support the specification of LSs. Moreover, since DPL is a key partner in the LOAT framework, DPL uses the Dublin Core Metadata set to describe the Components (Infoelements in DPL). To solve these diversities, we propose the use of an Application Profile ${ }^{11}$ to indicate the mandatory and optional metadata needed to meet our functional requirements in LOAT. The purpose of an Application Profile is to combine existing metadata schemas and add several aspects (LSM information) in a package tailored to the

\footnotetext{
${ }^{11}$ Application Profile is "an assemblage of metadata elements selected from one or more metadata schemas and combined in a compound schema." (Duval, Wayne, Sutton, \& Weibel, 2002)
} 


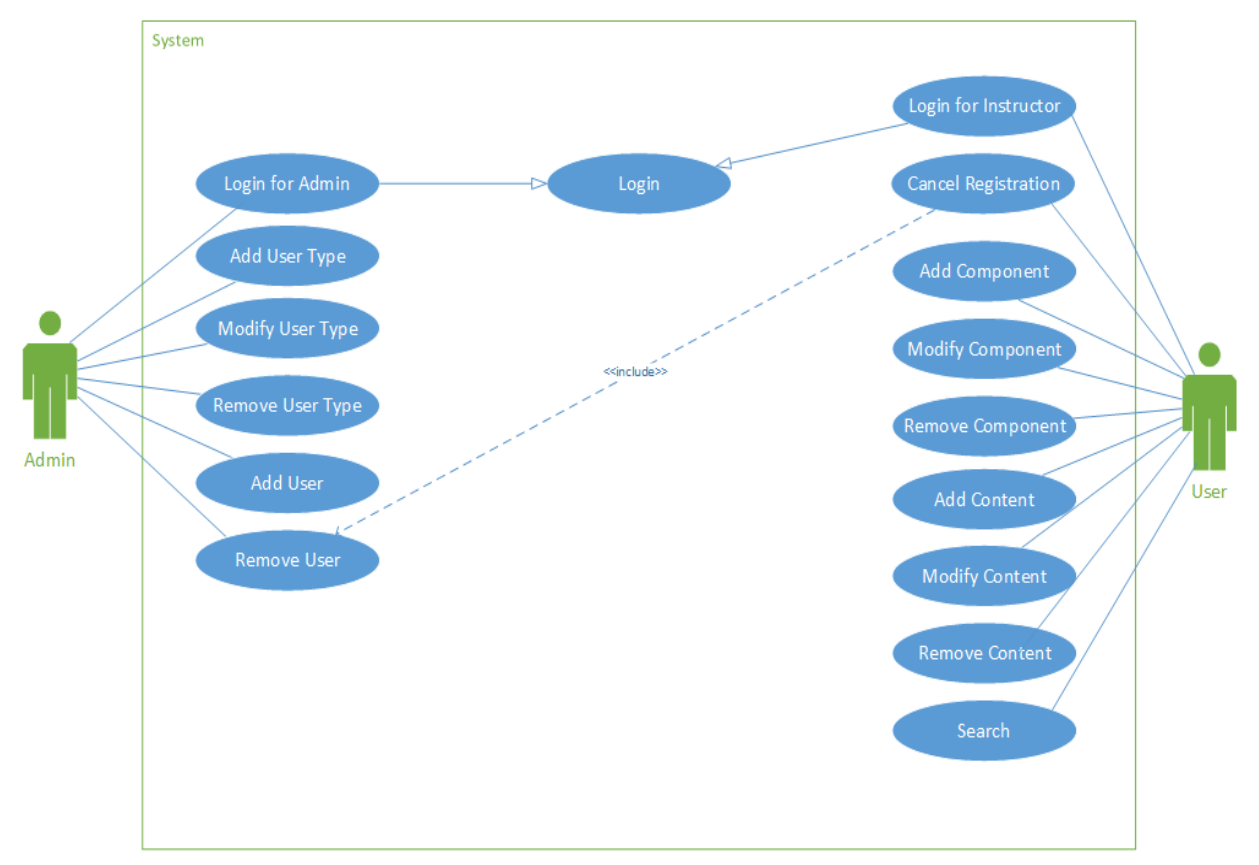

Figure 9.4 The use case diagram for different actor concepts

functional requirements of our tool while retaining interoperability with the original base schemas (Duval, Wayne, Sutton, \& Weibel, 2002).

In the LOAT framework, LOM and Dublin Core metadata specifications are attached to LOs, plus the LS metadata that describe and identify the LS associated to the LOs. Only the useful metadata for our tool is filtered by the Application Profile. All metadata elements used in the LOAT Application Profile are shown in Table 6.3 in Chapter 6.

\subsubsection{LO Feature Model}

As in DPL, we use a feature model to model and manage the commonality and variability in the LO domain. It is employed to define families of LOs, according to Cisco's RIO model, and provides the means to develop LO components that will be reused during the LO creation process.

The commonality and variability of the LOs enable them to be modeled as a set of mandatory, optional or alternative features. We use the term " $L O$ family" to represent all the LO instances generated by combining the alternative 


\section{Chapter 9.}

and optional features. In this domain, a feature corresponds to a Component according to the RIO strategy. A family of RIOs/RLOs can be defined by recalling the RIO content model structure depicted in Figure 6.2 (in Chapter 6 ), which will guide the representation of RIO/RLOs in terms of features (RIO/RLO feature model).

The LO Feature Model shown in Figure 9.5 specifies the family of LOs to be created as a group of features. The line with solid circles denotes mandatory features, while the line with blank circles indicates optional features. The lines grouped by arcs denote an Alternative relationship (no more than one feature will selected from the group of features), sometimes called an xorgroup. The first feature, LO feature, is composed of two optional features; RLO and RIO. The RLO feature must contain four mandatory sub-features; Overview, Summery, RIOs, and Assessment. The RIO feature is composed of a group of five alternative features; Concept, Fact, Procedure, Principle, and Process (only two features are shown in Figure 9.5). Only one feature will be selected for each instance of LO. This type of feature mainly changes the LO structure in the configuration process. All the LO contents are modeled as hierarchically organized features and are represented as mandatory, optional and alternative.

The Overview feature is composed of five mandatory features (Introduction, Importance, Objectives, Prerequisites, and Outline) and two optional features (Job-Based Scenario and Topology Illustration). In a specific RLO configuration, the existence of the Topology Illustration feature is related to the existence of the Job-Based Scenario feature. This dependency is modeled using the "requires" constraint. The dotted arrow from the Topology Illustration feature to the Job-Based Scenario feature represents the "requires" constraint, see Figure 9.6. 


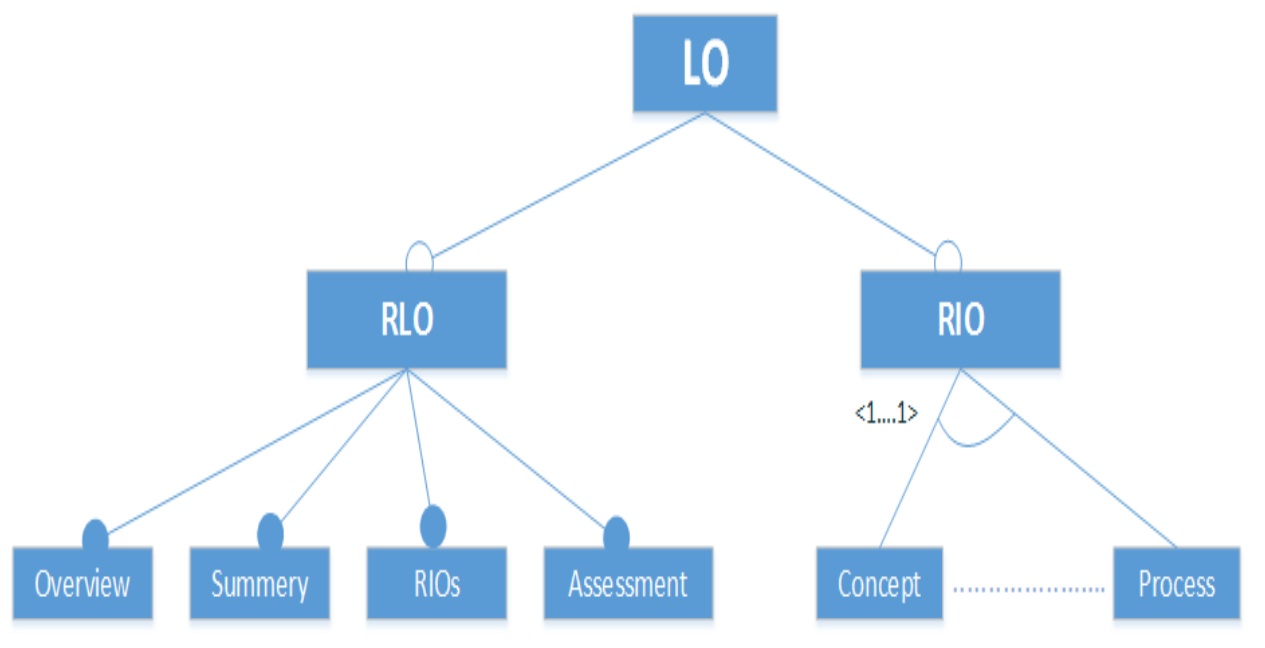

Figure 9.5 LO Feature Model according to RIO content model

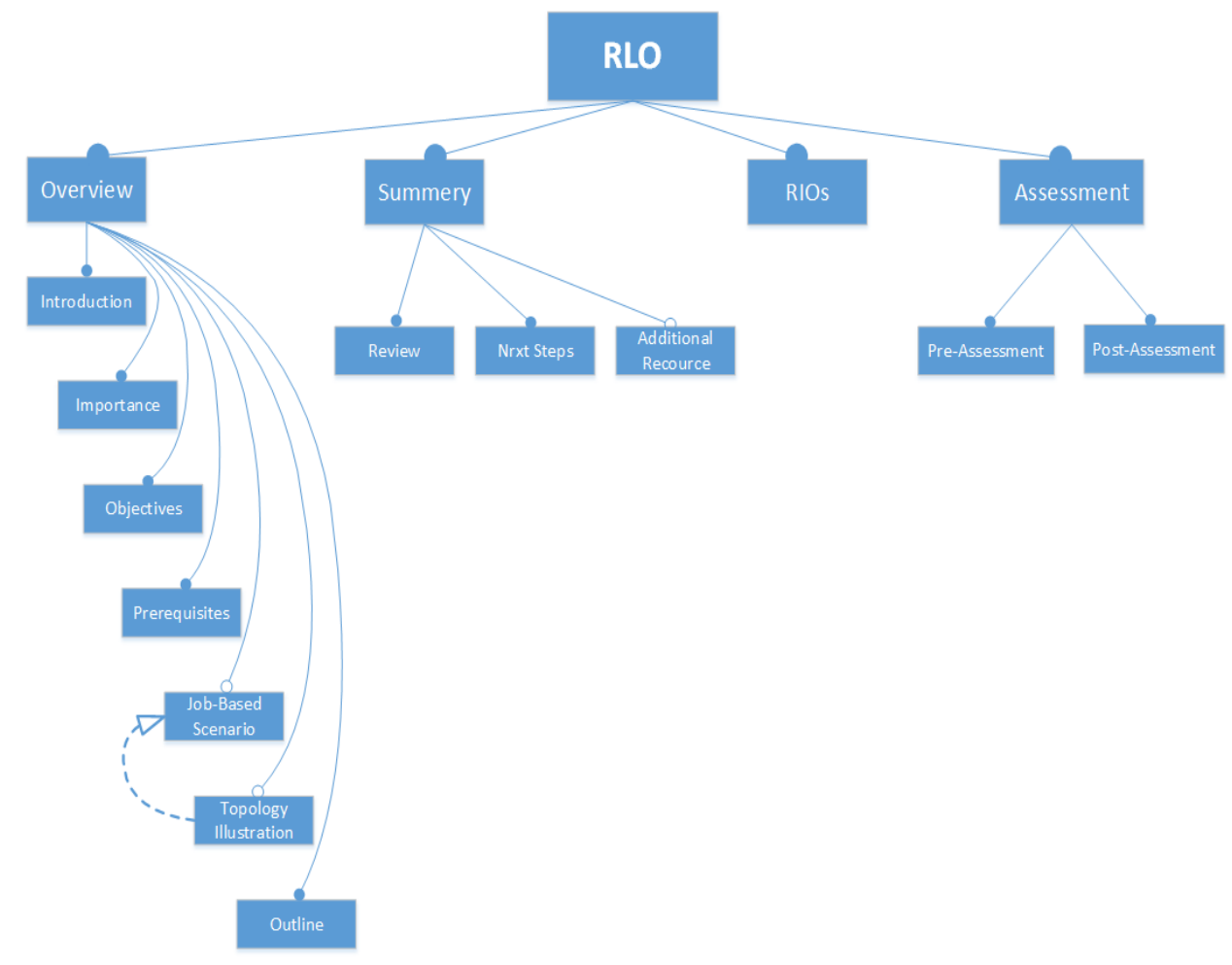

Figure 9.6 RLO Feature Model 
Chapter 9.

The RIO Feature Model shown in Figure 9.7 specifies the representation of RIO features in detail. For instance the Content Items feature related to the Procedure feature is composed of two mandatory features (Introduction and Demonstration), two optional features (Facts and Instructor Notes), and a group of three alternative features (Procedure Table, Decision Table, and Combined Table), although only one feature will be selected for each RIO instance.

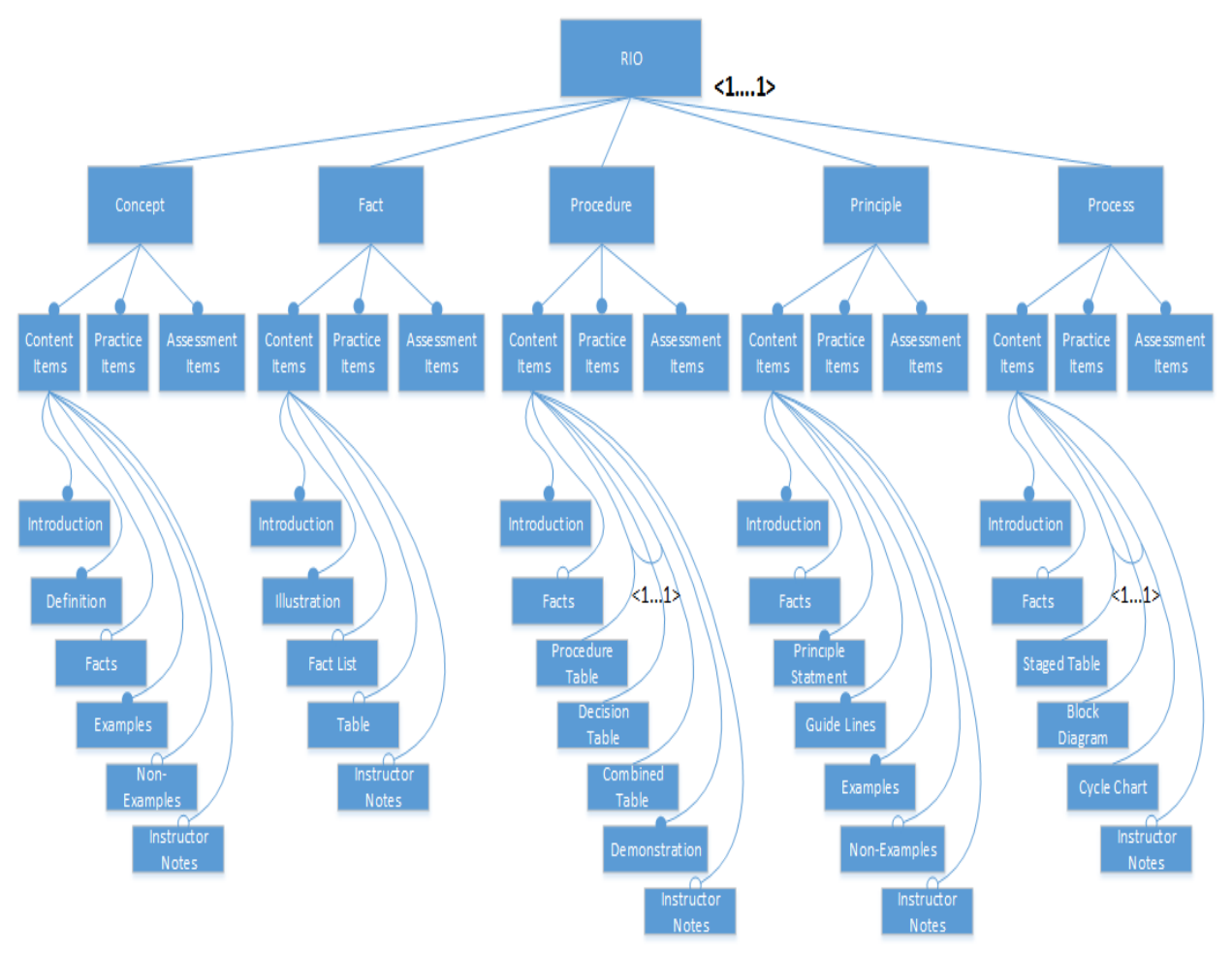

Figure9.7 RIO Feature Model

\subsubsection{Recommend/Search Relative Components and RIOs}

Upon the specification of LO metadata, the LO's LS is identified and the Recommend/Search Relative Components and RIO process automatically begins to recommend several Components and RIOs, depending on the type of LO to be created (RIO or RLO). The recommended Components or RIOs, which 
may be used in the LO creation process, have a LS similar to the one identified in the LO metadata. The suggestion of these Components relies on the GLSMO. Figure 9.8 shows a UML representation of the GLSMO and its association with LO.

Users can search for Components, RIOs and RLOs by specifying the LS and the GLSMO will suggest several results related to the specified LS.

\subsubsection{Recommend Characteristics}

The Recommend Characteristics and Activities process provides users (especially Instructors and Authors) with an authoring guide that provide them with a catalog of Learner's Characteristics and Learning Activities that should be taken into consideration during the LO creation process. Indeed, the Learner's Characteristics are recommended using the GLSMO. The Recommend Characteristics process plays a great role in enabling users to take the learner's preferences and needs into consideration.

All the previously described elements belong to the Domain Engineering process of the LO product line.

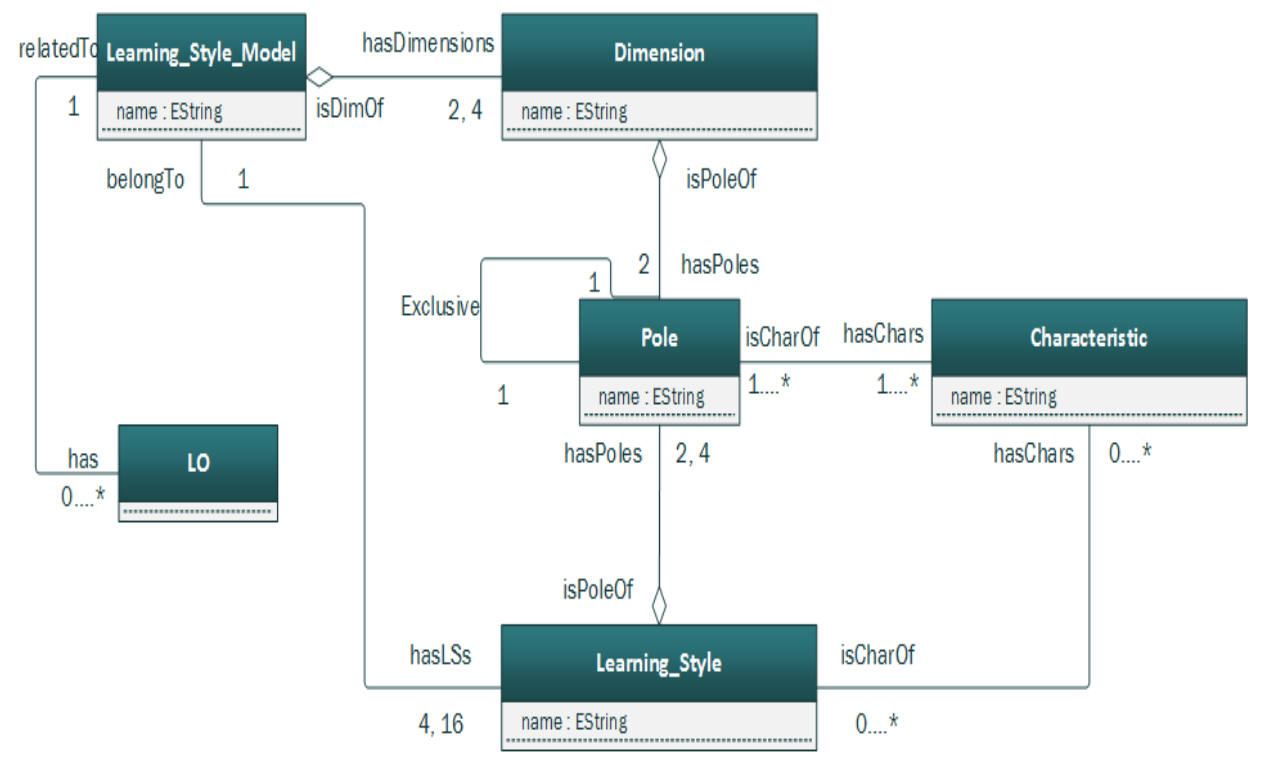

Figure 9.8 The GLSMO and LO 
Chapter 9.

\subsubsection{LO Configuration}

After every LO feature in the model has been linked to one component or RIO in the Repository, the LO generation can start. To do this, a specific LO has to be selected by means of an $L O$ Configuration process. Configurations are defined using the DPL Configuration Editor. A configuration consists of the features that have been selected according to the variability constraints defined by the LO feature model. The configuration process relies on the Feature Model Validation, which examines the LO feature model on every user selection. For instance, when a feature is selected, all its descending features are selected automatically, while optional and alternative features will be selected manually.

After the LO configuration process is complete, a DITA specification or $L O$ Architecture, known as the "LO Dita-map" is generated according to the features selected.

\subsubsection{LO Generation}

When the LO Configuration process concludes, a "LO Dita-map" is obtained and stored in the LOAT repository for reuse in other situations. Adding or removing Components or RIOs to a given LO is as simple as going to the $\mathrm{LO}$ Configuration step, modifying the selection, and re-generating the configuration files and the "LO Dita-map".

The DPL integrated DITA Open Tool Kit engine uses the "LO Dita-map" to generate the final LO in a specific format (PDF file or HTML).

\subsection{A Case Study: Generating "If Statement" RIO}

In this section we show the main steps in the creation of an RIO using LOAT and DPL framework. To illustrate the process we use as example a learning material entitled "If Statement" which is part of "Introduction to the Java Programming" course. 


\subsubsection{The "IF Statement" RIO Metadata}

Initially, the user needs to fill in the RIO metadata form according to the LOAT Application Profile defined in Section 6.1. The RIO metadata is a key element in specifying various aspects (e.g. RIO type, learning style model, learner characteristics, learning objective, etc.), see Figure 9.9.

\subsubsection{The "IF Statement" RIO Feature Model}

To create the RIO, the system will recall the suitable RIO feature model according to the specification of RIO type. An RIO includes three components: Content, Practices and Assessment elements. Figure 9.10 shows the "If Statement" RIO feature model. At this stage, we use DPL's feature model editor to model and manage the variability in RIO. Several optional features are available to be included in RIO. At this point, we are just modeling the elements that compose the RIO, without any mention of actual content. To link RIO features with content, we have to search for the right content components at the LOAT and DPL Repositories, as shown in the next step.

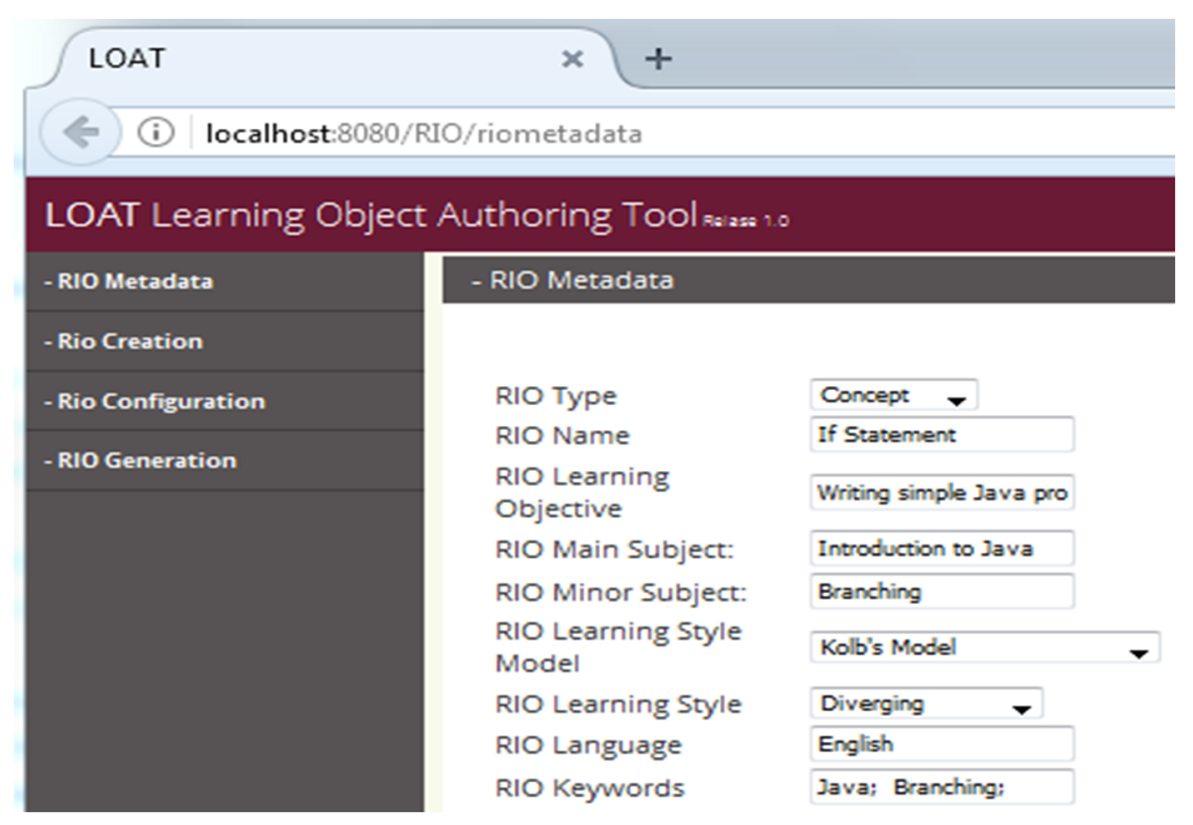

Figure 9.9 The "If Statement" RIO metadata form 
Chapter 9.

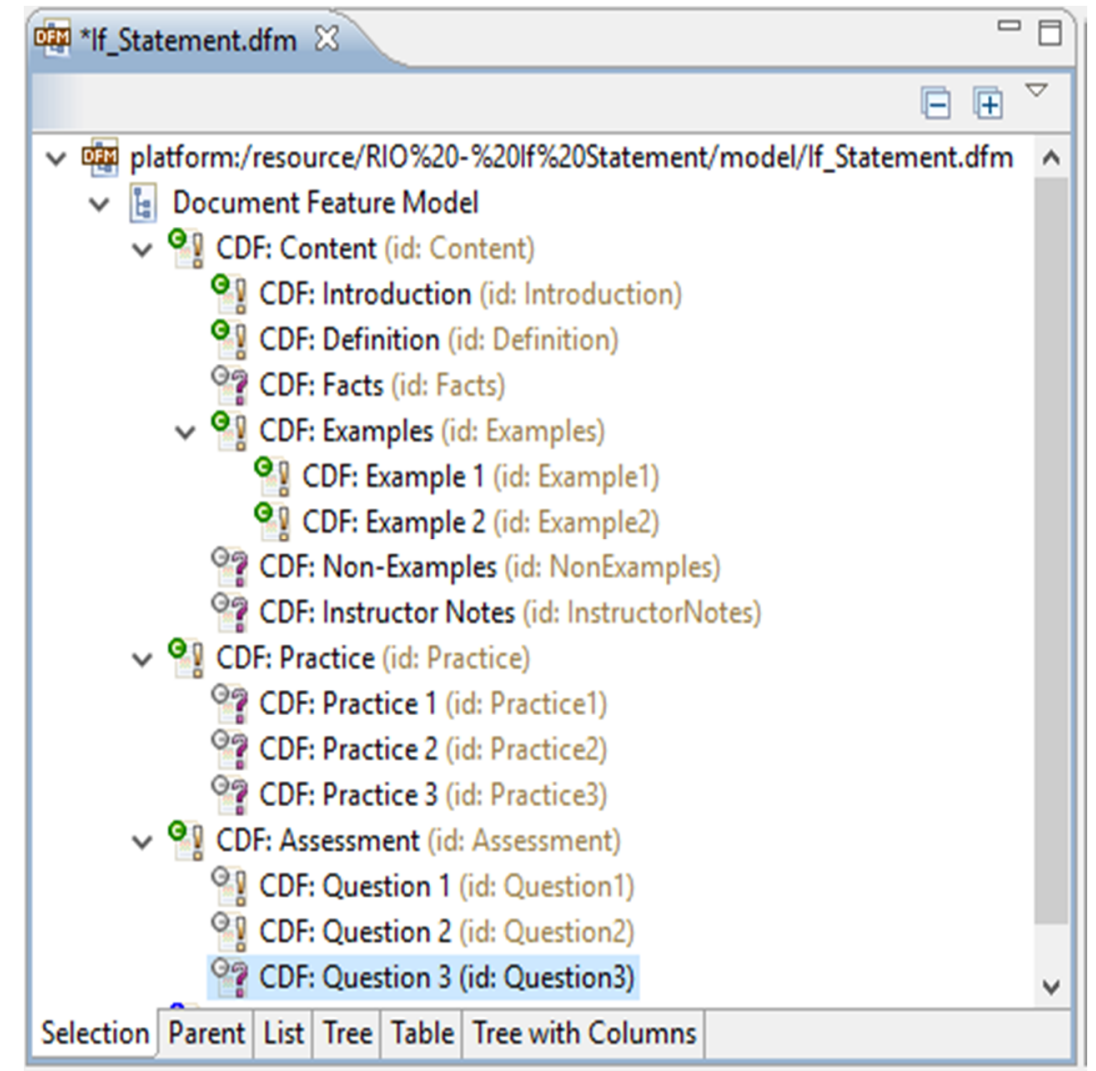

Figure 9.10 The "If Statement" RIO feature model

\subsubsection{Customizing \& Personalizing the "IF Statement" RIO}

Building an RIO depends on the presence of its components in the Repository. As mentioned above, the components contain two types of properties: data (i.e. the actual content) and metadata (data used to describe the components that serve as criteria to retrieve them from the Repository). The GLSMO provides the user with an authoring guide that provides him/her with a catalog of learner's characteristics and learning activities that should be taken into consideration during the authoring process. The GLSMO recommends several components related to the RIO's LS. Figure 9.11 shows the learner characteristics and the recommended components. Notice that two components are recommended, one related to Kolb's Diverging and the other to Felder's Sensing-Reflective style, which has similar characteristics to the Diverging style. 


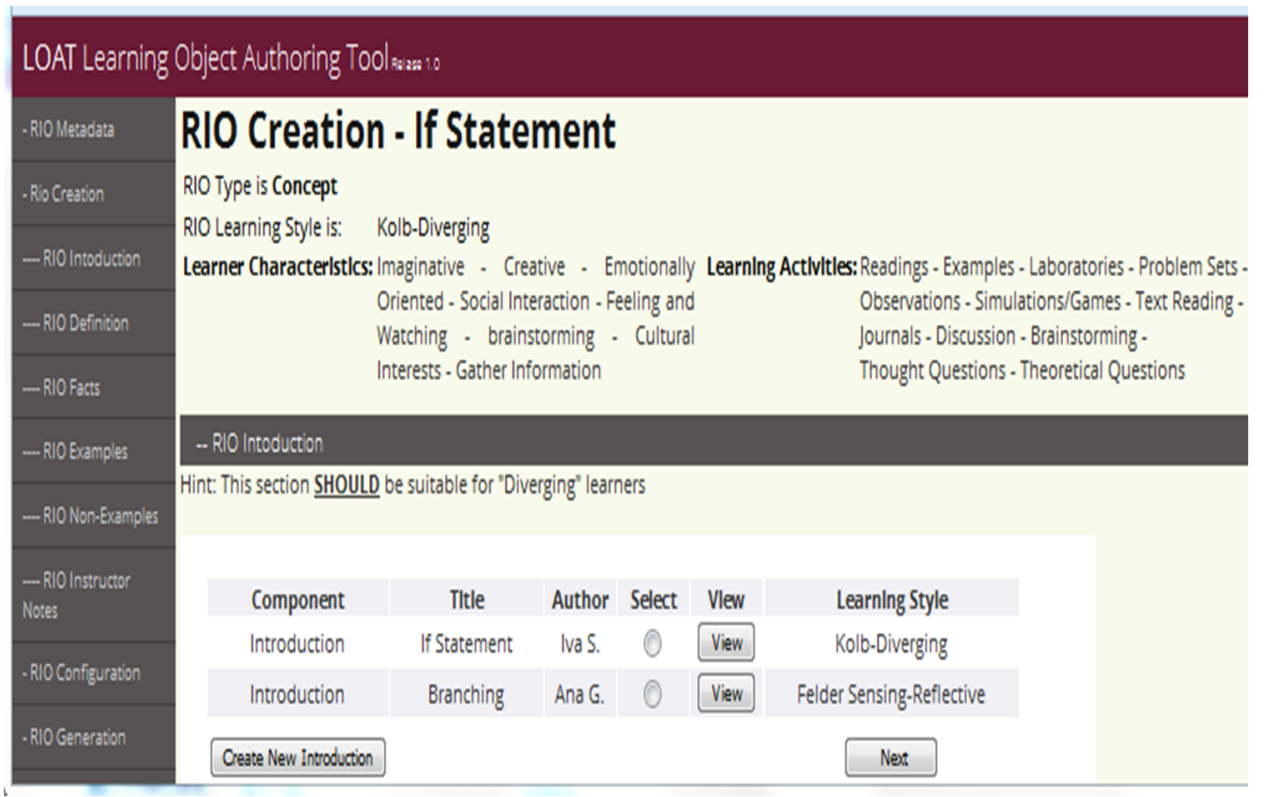

Figure 9.11 Customizing "If Statement" RIO

\subsubsection{The "IF Statement" RIO Configuration}

After every RIO feature in the model has been linked to a component in the Repository, the RIO generation can start. To do this, a specific RIO is selected by means of an RIO configuration model. A configuration consists of the features that have been selected according to the variability constraints defined by the feature diagram, as shown in Figure 9.12. There, a particular configuration of our "If Statement" is set. Each configuration represents a member of the RIO family that has been defined in the RIO feature model. Notice that adding or removing components to a given LO is a matter of clicking on a checkbox, since all the engineering work has been done in advance. This is a new approach to the authoring process that facilitates large scale reuse.

\subsubsection{The "IF Statement" RIO Generation}

When the configuration concludes, an automatic process generates the RIO in the format selected. Figure 9.13 shows the "If Statement" RIO represented in a HTML. 


\section{Chapter 9.}

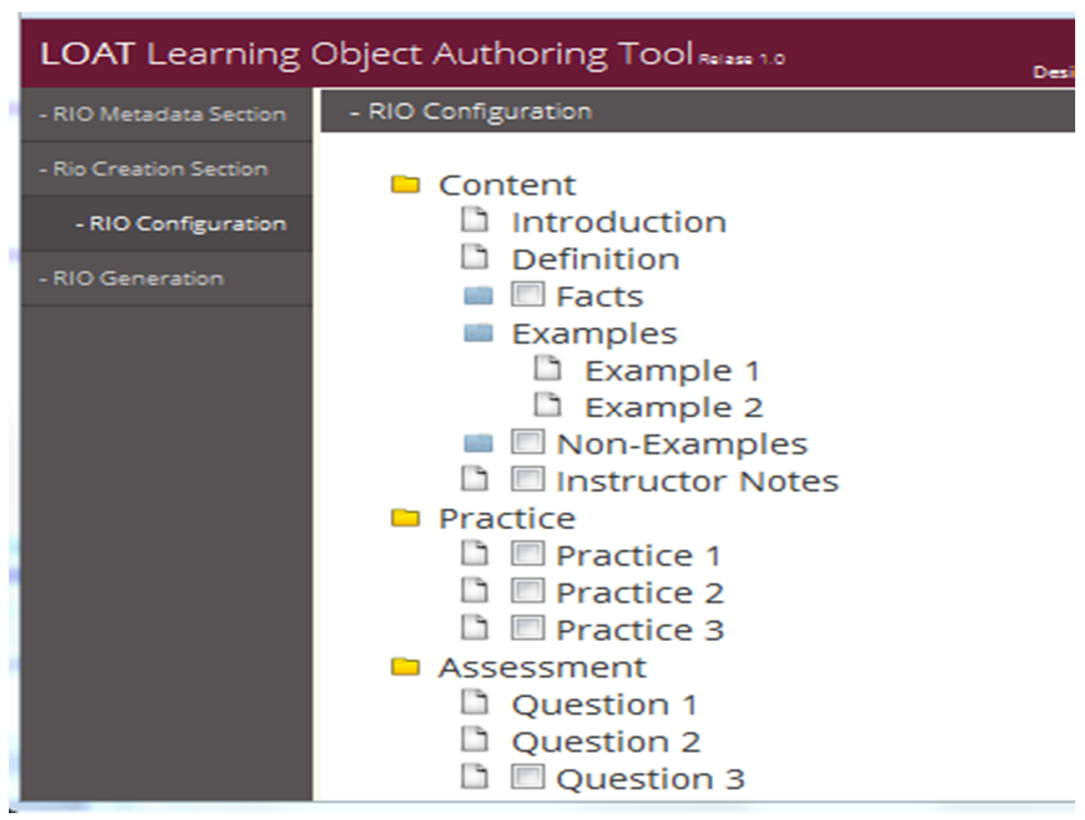

Figure 9.12 the "If Statement" RIO configuration

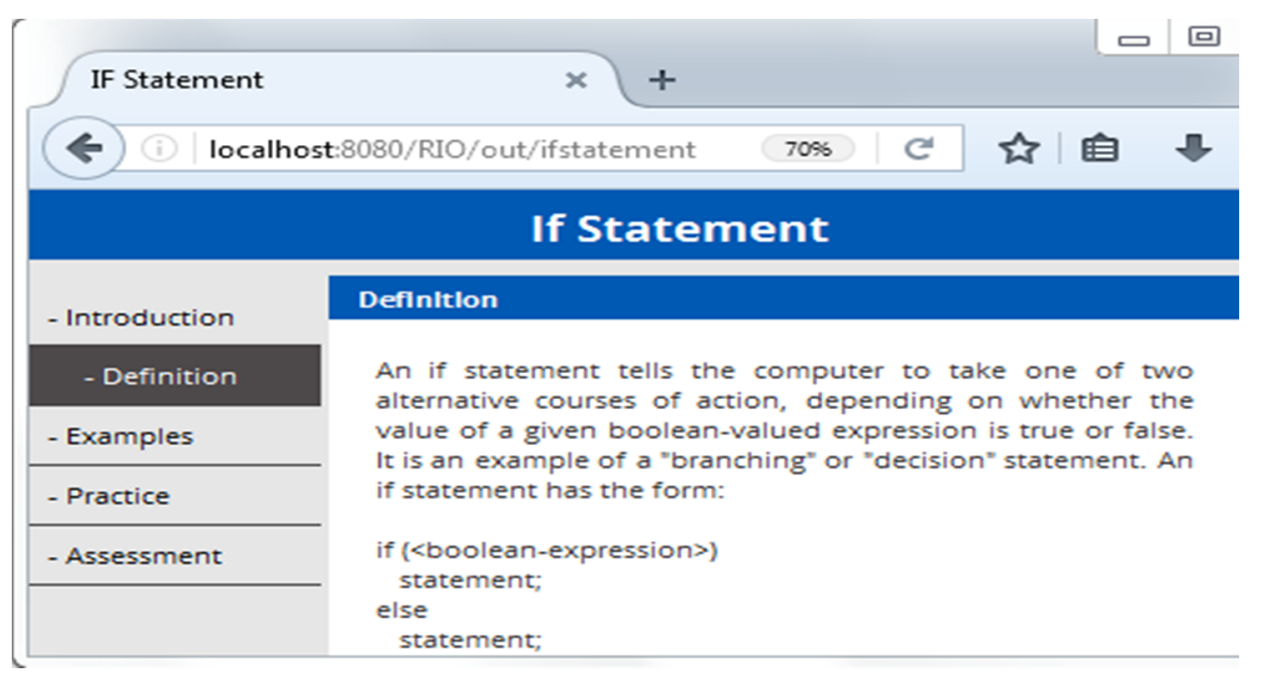

Figure 9.13 The generated "If Statement" RIO 
PART FOUR CONCLUSIONS 



\section{Chapter 10.}

\section{Conclusions and Further Work}




\section{Chapter 10.}

This part closes this thesis. The first section summarizes the contents of this thesis and presents the conclusions of the work. The second section presents the publications which have been produced throughout the development of this thesis, that have been published in journal of Computers in Human Behavior and international conferences. The last section presents future work that can be done to continue this research.

\subsection{Conclusions}

Learning materials form a pivotal point in the e-Learning domain for many of its participants (instructors, learners, etc.). For instance, instructors need to create learning contents suitable to learners in an easy and effective way, and learners need to absorb knowledge in a way that meets their individual characteristics, preferences and needs. The materials may require several improvements or new features, especially during the development process. If these requirements are not properly addressed, then the materials risk losing effectiveness and usefulness. As a result, instructors may become uncomfortable with the creation process and learners may lose interest due to the course not suiting their requirements. Learning material development thus acquires even more importance in issues such as Reusability, Customization, and Ease of Production, which are vital to obtaining the instructors/learners satisfaction in the e-Learning environment. Our motivation is to enforce and strengthen these issues during the learning material development process.

This thesis takes another step forward in the development of e-Learning material. Starting from existing points (e.g. metadata standards, LSMs, variability management, etc.), it provides a new contribution to the domain. We would like to emphasize the main contribution of this work, a combination of the following three models: the instructional content model, the personalization (customization) model, and the LO Product Line (LOPL) model. With these models instructors can not only develop learning materials, but also reuse (with several reusing criteria) and customize (with multi LSs) learning materials during development using the advantages of the Software Product Line Engineering (SPLE) and Document Product Line (DPL) techniques. 
The thesis proposes an ontology and product line-based framework to effectively represent and develop LOs. LO production using our product linebased framework can produce an LO with a specific configuration and a group of artifacts (components). These stages are supported by the DPL approach, which provides the methodological and technological background to create variable-content documents following the Model Driven Engineering paradigm. LO development using our product line-based framework provides the following advantages: (i) large-scale LO productivity, (ii) more efficient (re)-use of resources, and (iii) the ability to achieve mass customization. The Reuse of the core components in a strategic way gives the instructors additional advantages over other methods.

The Reuse strategy in our framework is dependent on several points:

- We have employed Cisco's RIO content model (The LO content model), which classifies LOs into different levels of granularity (Component, RIO, RLO). The advantage of granularity here is that it is concerned not only with the size of the LO but also with a single core concept. The RIO content model is grounded on the Learning Object Thinking Theory and structured on the basis of Modified Information Mapping.

- According to the LO content model, the LO and the Component are composed of two elements: data and Metadata. Metadata provides the information that describes and manages the LO and its Component. In our framework we have proposed the use of an Application Profile consisting of several metadata elements from the Dublin Core Metadata set, IEEE LOM Standard, and other elements to identify and describe the LSM associated with the LO.

- We have used the Feature Model (FM) for LO variability modeling. FM is also used as a domain-independent high-level specification for LO, especially when employed with SPLE. We have employed FM here to define the LO families (according to the RIO model) and provide the means to develop LO components that will be customized and reused during the $\mathrm{LO}$ creation process. 


\section{Chapter 10.}

Another issue introduced in this thesis is the enforcement of Customization (Personalization) during the learning materials development process. On the one hand, we used the LSM as the key element in the Customization (Personalization) strategy, due to its richness of individual characteristics and preferences. We studied several LSMs to select the most suitable one for us, however we found no consensus on a specific LSM and that many LSMs have partial similarity and overlapping in their structure, scientific bases, and characteristics. We therefore created a GLSMO on the basis of seven different LSMs selected from the literature. We also developed the GLSMO to guarantee the integration and interoperability of the different LSMs. The GLSMO was developed using an ontology development strategy in a mix of Buccella's hybrid-ontology approach for the integration process in the On-ToKnowledge methodology phases.

The GLSMO has several advantages in the e-learning domain, especially in the learning materials development process, such as: (i) it facilitates mapping between different LSMs, (ii) increases the reuse of learning materials with different e-learning systems that use different LSMs, (iii) reduces concept overlapping between the various LSMs, (iv) emphasizes the use of Multimodel LS in the development of customized (personalized) e-Learning frameworks and applications, (v) supports customized (personalized) learning material design and development, (vi) defines the criteria to be used by recommender systems to suggest materials according to Multi-LS model, (vii) assists instructors/learners to search for learning materials (with different LSMs) semantically, and (viii) enables knowledge reusability for both humans and systems.

Taking advantage of the LO content model and the learner's LS will enhance the development of the learning material process if they are integrated in a production framework that facilities the process for non-experts.

The third issue dealt with in our thesis is the Ease of LO production for nonexpert users, which can be achieved by the SPLE and DPL approaches. We propose an LOPL model that provides a method of modeling the commonality and variability of the LO family as a set of features (using FM). The LOPL model facilitates LO creation by employing the Domain Engineering process, 
which is responsible for ensuring that the available variability (in the LO family) is suitable for producing a specific LO and employs the Application Engineering process to build a specific LO by enforcing component reusability and exploiting variability.

We are at present implementing the Learning Object Authoring Tool (LOAT) for LO development. This tool integrates the LO product line-based framework containing the LO instructional content model, the customization (Personalization) model and the LOPL model. The LOAT architecture and framework elements have been properly presented and explained.

The LOAT was also compared with several authoring applications based on various criteria (see Table 10.1):

- The Metadata standard (M)

- The Instructional Method used to create learning material (IM)

- The Customization (Personalization) of learning material (C\&P)

- The learner's Preferences and Needs (P\&N)

- Employing learner's LS in the development process (LS)

- The use of Semantic Technology (ST)

- Recommending learning materials for customization and reusability (R)

Table 10.1 A comparison LOAT and other authoring applications

\begin{tabular}{|c|c|c|c|c|c|c|c|}
\hline & $\mathbf{M}$ & $\mathbf{I M}$ & C\&P & P\&N & $\mathbf{L S}$ & ST & $\mathbf{R}$ \\
\hline$C E D A R$ & $x$ & $\sqrt{ }$ & $x$ & $x$ & $x$ & $x$ & $x$ \\
\hline$D L N E T$ & $\checkmark$ & $x$ & $x$ & $x$ & $x$ & $x$ & $x$ \\
\hline LO Creator & $x$ & $x$ & $\checkmark$ & $x$ & $x$ & $x$ & $x$ \\
\hline LOC Tool & $x$ & $\checkmark$ & $x$ & $x$ & $x$ & $x$ & $x$ \\
\hline ViSH & $\sqrt{ }$ & $x$ & $x$ & $x$ & $x$ & $x$ & $x$ \\
\hline Wandering & $x$ & $\sqrt{ }$ & $x$ & $x$ & $x$ & $x$ & $x$ \\
\hline$T A N G R A M$ & $\checkmark$ & $x$ & $\checkmark$ & $\checkmark$ & $x$ & $\checkmark$ & $x$ \\
\hline$L O A T$ & $\checkmark$ & $\checkmark$ & $\checkmark$ & $\sqrt{ }$ & $\checkmark$ & $\checkmark$ & $\sqrt{ }$ \\
\hline
\end{tabular}


All the aforementioned LOAT elements were used in a case study that represents a part of the "Introduction to the Java Programming" course. The RIO generated described an example of a small chunk containing an explanation of an "If Statement". The process started with filling in the metadata profile associated with the RIO, then the Domain Engineering sub processes were introduced (the tool recommends several components to the instructor based on the GLSMO), and finally the Application Engineering sub processes were enacted and the final RIO generated in pdf or HTML format.

Some of the results offered in this thesis have been previously discussed in a number of international peer-reviewed forums. The results have also been published in one international journal and at two international conferences $\left(\mathrm{CORE}^{12} \mathrm{~B}\right)$ as listed below:

\subsection{Publications}

\section{International Journal}

- A. Ezzat Labib, José H. Canós, M. Carmen Penadés.On the way to learning style models integration: A Learner's characteristics ontology. Journal of Computers in Human Behavior, 73, pp 433-445, ISSN 0747-5632.

* Journal Impact factor 3.435 (2016 Journal Citation Report-Q1)

\section{International Conferences}

- A. Ezzat Labib, M. Carmen Penadés, José H. Canós, Abel Gómez. Enforcing reuse and customization in the development of learning objects: a product line approach. 30th ACM/SIGAPP Symposium On Applied Computing (SAC 2015), Apr2015, Salamanca, Spain. * Conference Ranking CORE'15: B

- A. Ezzat Labib, José H. Canós, M. Carmen Penadés. Integrating product line and learning style approaches to enforce reusability and personalization of learning objects. The 17th IEEE International Conference on Advanced Learning Technologies - ICALT2017, July 2017, Timisoara, Romania.

* Conference Ranking CORE'17: B

${ }^{12}$ CORE (COmputing Research Education): http://core.edu.au 


\subsection{Further Work}

As in any other research project, the content of this thesis is under continuous development. Firstly, the LOAT is now undergoing development and implementation and we expect that the fully-fledged version will be released in the near future. Secondly, after completing LOAT, we aim to evaluate our tool on a range of users and also to measure its scalability. Thirdly, the GLSMO now integrates the characteristics of seven LSMs, and we plan to extend GLSMO to include the learning activities of each LSM. Fourthly, we aim to develop a prototype recommendation system that implements the idea behind GLSMO. Fifthly, we intend to extend this metadata specification to deal with the personalization issue. Finally, we aim to generate several assessment tests (Exam, Assignment, Quiz, etc.) with several types of interactive questions (Draggable, Drawing, etc.) using the LOAT. 



\section{References}

Abante, M. E., Almendral, B. C., Manansala, J. E., \& Mañibo, J. (2014). Learning Styles and Factors Affecting the Learning of General Engineering Students. International Journal of Academic Research in Progressive Education and Development, 3(1).

Agostinho, S., Bennett, S., Lockyer, L., \& Harper, B. (2004). Investigating the suitability of pedagogical descriptors for digital learning resources. Proceedings of the World Conference on Educational Multimedia, Hyprtmedia and Telecommunications (pp. 3482-3489). Chesapeake: P. Kommers ; G. Richards.

Apache Maven 3.x documentation, version 3.5.0. (2017, April 3). Retrieved from Apache Maven: http://maven.apache.org/ref/3.5.0/

Aroyo, L., \& Dicheva, D. (2004). The new challenges for e-learning: The educational semantic web. Journal of Educational Technology \& Society, 7(4), 59-69.

Barak, M., \& Ziv, S. (2013). Wandering: A web-based platform for the creation of location-based interactive learning objects. Computers \& Education, 62, 159-170. doi:10.1016/j.compedu.2012.10.015

Barrit, C., Lewis, D., \& Wieseler, W. (1999). CISCO Systems Reusable Information Object Strategy. Cisco Systems.

Begam, M. F., \& Ganapathy, G. (2012). SEALMS: Semantically Enhanced adaptive learning management system. Proceedings of International Conference on Soft Computing, Artificial Intelligence (SAI-12).

BERLANGA, A., \& GARCÍA-PEÑALVO, F. (2008). Learning Design in Adaptive Educational Hypermedia Systems. Journal of Universal Computer Science, 14(22), 3627-3647.

Bloom, B. S., Englehart, M. D., Furst, E. J., Hill, W. H., \& Krathwell, D. R. (1956). A taxonomy of educational objectives. Handbook I: Cognitive domain. New York: David McKay. 


\section{References}

Bozkurt, O., \& Aydoğdu, M. (2009). A Comparative analysis of the effect of Dunn and Dunn learning styles model and traditional teaching method on 6th grade students' achievement levels and attitudes in science education lesson. Elementary Education Online, 8(3), 741-754.

Braun, C. L. (2002). Reuse. Encyclopedia of Software Engineering, pp. 1055-1069.

Brusilovsky, P. (1996). Methods and techniques of adaptive hypermedia. User Modeling and User Adapted Interaction, 6(2-3), 87-129.

Brusilovsky, P. (2001). Adaptive hypermedia. User Modeling and User-Adapted Interaction, 11(1-2), 87-110.

Brusilovsky, P., \& De Bra, P. (1998). Proceedings of the Second Workshop on Adaptive Hypertext and Hypermedia at Ninth ACM International Hypertext Conference Hypertext '98. Computer Science Report 98/12. Eindhoven University of Technology. Retrieved 7 2, 2017, from http://wwwis.win.tue.nl/ah98/Proceedings.html

Buccella, A., Cechich, A., \& Brisaboa, N. R. (2003). An Ontology Approach to Data Integration. Journal of Computer Science \& Technology, 3(2), 62-68.

Bürger, T., \& Simperl, E. (2008). Measuring the benefits of ontologies. In On the Move to Meaningful Internet Systems: OTM 2008 Workshops (pp. 584-594). Springer Berlin Heidelberg. doi:10.1007/978-3-540-88875-8_82

Burgos, D., Tattersall, C., \& Koper, R. (2007). How to represent adaptation in elearning with IMS - learning design. Interactive Learning Environments, 15(2), 161-170.

Chen, L., Ali Babar, M., \& Ali, N. (2009). Variability management in software product lines: a systematic review. Proceedings of 13th International Conference on Software Product Lines, (pp. 81-90). San Francisco, California, USA.

Chen, Y. H., \& Chen, P. J. (2015). MOOC study group: Facilitation strategies, influential factors, and student perceived gains. Computers and Education, 86, 55-70. doi:http://doi.org/10.1016/j.compedu.2015.03.008

Cheng, G., Du, Q., \& Ma, H. (2008). The design and implementation of ontology and rules based knowledge base for transportation. international conference 
on computer science and software engineering, (pp. 1035-1038). doi:10.1109/CSSE.2008.1405

Chrysafiadi, K., \& Virvou, M. (2013). Student modeling approaches: A literature review for the last decade. Expert Systems with Applications, 40(11), 47154729 .

Cisco_Systems. (2003). Reusable learning object strategy: Designing and developing learning objects for multiple learning approaches. Cisco Systems.

Clark, R. C. (2009). Developing Technical Training: A Structured Approach for Developing Classroom and Computer-Based Instructional Materials (3rd ed.). Hoboken, NJ : John Wiley \& Sons, Inc.

Coffield, F., Moseley, D., Hall, E., \& Ecclestone, K. (2004). Learning styles and pedagogy in post-16 learning A systematic and critical review. Learning and Skills Research Centre. doi:http://doi.org/10.1016/S0022-5371(81)90483-7

Curry, L. (1983). An Organization of Learning Styles Theory and Constructs. Educational Research Information Centre (ERIC).

Davis, S. (1987). Future Perfect. Boston, Massachusetts: Addison-Wesley.

Dolphin, I., \& Miller, P. (2002). Learning Objects and the Information Environment. Ariadne, Web Magazine for Information Professionals. Retrieved 0225 , 2017, from http://www.ariadne.ac.uk/issue32/iconex

Dominic, M., \& Francis, S. (2015). An adaptable e-learning architecture based on learners' profiling. Modern Education and Computer Science, 3, 26-31.

Duval, E., Wayne, H., Sutton, S., \& Weibel, S. L. (2002). Metadata Principles and Practicalities. D-Lib Magazine, 8(4).

Eclipse Modeling Framework Project (EMF). (2012). Retrieved from Eclipse Foundation: http://www.eclipse.org/modeling/emf/

El-Hmoudova, D. (2015). Self-efficacy for Learning vs ILS Results in a group of English Learning Bachelor Students. Procedia - Social and Behavioral Sciences, $\quad 199, \quad 563-570$. doi:http://doi.org/http://dx.doi.org/10.1016/j.sbspro.2015.07.548 


\section{References}

Essalmi, F., Ben Ayed, L. J., Jemni, M., Graf, S., \& Kinshuk. (2015). Generalized metrics for the analysis of E-learning personalization strategies. Computers in Human Behavior, 48, 310-322.

eXe. (2017). Retrieved 2 20, 2017, from https://exelearning.org/

Felder, R. M. (1996). Matters of Style. ASEE Prism, 6(4), 18-23.

Felder, R., \& L.K., S. (1988). Learning and teaching styles in engineering education. Engineering education, 78(7), 674-681.

Gibbons, A. S., Nelson, J., \& Richards, R. (2002). The nature and origin of instructional objects. In D. A. Wiley (Ed.), The Instructional Use of Learning Objects: Online Version. Association for Instructional Technology. Retrieved 03 25, 2017, from http://reusability.org/read/chapters/gibbons.doc

Gómez, A., Penadés, M. C., Canós, J. H., Borges, M. R., \& Llavador, M. (2014). A framework for variable content document generation with multiple actors. Information and Software Technology.

Gordillo, A., Barra, E., \& Quemada, J. (2014). Facilitating the creation of interactive multi-device Learning Objects using an online authoring tool. Proceedings of the 2014 Frontiers in Education Conference.

Gordillo, A., Barra, E., \& Quemada, J. (2015). Enhancing Web-Based Learning Resources With Existing and Custom Quizzes Through an Authoring Tool. IEEE Revista Iberoamericana de Tecnologias del Aprendizaje, 10, pp. 215222.

Graf, S., Kinshuk, \& Liu, T.-C. (2009). Supporting Teachers in Identifying Students' Learning Styles in Learning Management Systems: An Automatic Student Modelling Approach. Educational Technology \& Society, 12(4), 3-14. doi:http://doi.org/10.1016/j.lindif.20

Graf, S., Liu, T. C., \& Kinshuk. (2010). Analysis of learners' navigational behaviour and their learning styles in an online course. Journal of Computer Assisted Learning, 26(2), 116-131. 


\section{References}

Graf, S., Liu, T. C., Kinshuk, Chen, N. S., \& Yang, S. J. (2009). Learning styles and cognitive traits - Their relationship and its benefits in web-based educational systems. Computers in Human Behavior, 25(6), 1280-1289.

Gregorc, A. (1979). Learningteaching styles potent forces behind them. Educational Leadership, 36, 234-237.

Gregorc, A. (2006). The mind styles model: Theory, principles and application. AFC.

Gregorc, A. F. (1982). An adult's guide to style. Columbia : CT: Gregorc Associates.

Hamel, C. J., \& Ryan-Jones, D. (2002). Designing Instruction with Learning Objects. International Journal of Educational Technology, 3(1).

Heng, S. (2002). Learning Objects-Where next? Retrieved 02 25, 2017, from available at http://mms.ecs.soton.ac.uk/mms2003/papers/26.pdf

Hibernate ORM documentation 5.2. (2017). Retrieved from http://hibernate.org/orm/documentation/5.2/

Hitzler, M., K., Parsia, B., Patel-Schneide, P., \& Rudolph, S. (2012, December 11). OWL 2 web ontology language primer (second edition). (2). Retrieved from https://www.w3.org/TR/2012/REC-owl2-primer-20121211/

Hodgins, H. (2002). The future of learning objects. In D. Wiley (Ed.), The instructional use of learning objects (Online Version ed.). D.A. Wiley. Retrieved from http://reusability.org/read/chapters/hodgins.doc

Honey, P., \& Mumford, A. (1992). The manual of learning styles. Maidenhead: Peter Honey Publications.

Honey, P., \& Mumford, A. (2000). The learning styles helper's guide. Maidenhead: Peter Honey Publications Ltd.

Honey, P., \& Mumford, A. (2006). Learning styles questionnaire: 80-item version. London: Maidenhead.

Horn, R. (1998). Structured writing as a paradigm. In A. Romiszowski, \& C. Dills, Instructional development: state of the art. Englewood Cliffs, N. J., Educational Technology. 


\section{References}

Huang, C., Liu, L., Tang, Y., \& Lu, L. (2011). Semantic web enabled personalized recommendation for learning paths and experiences. Information and Management Engineering: International Conference, ICCIC 2011 (pp. 258267). Wuhan, China: Springe Berlin Heidelberg. doi:10.1007/978-3-64224022-5_43

Huang, C., Liu, L., Tang, Y., \& Lu, L. (2011). Semantic web enabled personalized recommendation for learning paths and experiences information and management engineering. Springe.

IEEE. (1997). IEEE Standard for Developing Software Life Cycle Processes in IEEE Std 1074-1997. New York, USA: IEEE.

IEEE-LTSC. (2002). Std 1484.12.1 - IEEE Learning Technology Standard Committee (LTSC) - Standard for Learning Object Metadata (LOM). IEEE.

Ip, A., Morrison, I., \& Currie, M. (2001). What is a learning object, technically? WebNet 2001 World Conference on the WWW and Internet, (pp. 580-586). $\begin{array}{lllll}\text { Retrieved } & 002 & 20, & \text { 2017, }\end{array}$ http://users.tpg.com.au/adslfrcf/lo/learningObject(WebNet2001).pdf

Isik, B., \& Kuzudisli, S. (2015). Learning Anatomy Of Nursing And Medical Students. Procedia - Social and Behavioral Sciences, 197, 1079-1084. doi:http://doi.org/10.1016/j.sbspro.2015.07.346

Jovanović, J., GaLsević, D., \& Devedžić, V. (2006). Dynamic Assembly of Personalized Learning Content on the Semantic Web. In Y. Sure, \& J. Domingue (Eds.), Lecture Notes in Computer Science (pp. 545-559). Springer-Verlag Berlin Heidelberg.

Jovanovic, J., GaLsevic, D., Knight, C., \& Richards, G. (2007). Ontologies for effective use of context in e-learning settings. Journal of Educational Technology \& Society, 10(3), 47-59.

Jung, C. G. (1990). Psychological Types (3rd ed.). New York.: R.F.C. Hull, Trans.

Kang, K., Cohen, S., Hess, J., Nowak, W., \& Peterson, S. (1990). Feature-Oriented Domain Analysis (FODA) Feasibility Study. Carnegie Mellon University: Software Engineering Institute. 
Keirsey, D. (1998). Please understand me II: Temperament, character, intelligence. Del Mar, CA: Prometheus Nemesis.

Kolås, L. (2005). Variation and Reusability in E-learning: not Compatible? In G. R. (ed.) (Ed.), E-learn 2005 Proceedings.

Kolb, A. Y., \& Kolb, D. A. (2005). The Kolb Learning Style Inventory - Version 3 . 1 - Technical Specifi cations. LSI Technical Manual. doi:http://doi.org/10.1016/S0260-6917(95)80103-0

Kolb, A. Y., \& Kolb, D. A. (2006). Learning styles and learning spaces: A review of the multidisciplinary application of experiential learning in higher education. In R. Sims, \& S. Sims (Ed.), Learning styles and learning: A key to meeting the accountability demands in education. Nova Publishers.

Koohang, A., Floyd, K., \& Stewart, C. (2011). Design of an Open Source Learning Objects Authoring Tool - The LO Creator. Interdisciplinary Journal of ELearning and Learning Objects, 7.

Kraus, L. A., Reed, W. M., \& Fitzgerald, G. E. (2001). The effects of learning style and hypermedia prior experience on behavioral disorders knowledge and time on task: A case-based hypermedia environment. Computers in Human Behavior, 17(1), 124-140.

Kurilovas, E., Kubilinskiene, S., \& Dagiene, V. (2014). Web3.0-Based personalisation of learning objects in virtual learning environments. Computers in Human Behavior, 30, 654-662.

Kurilovas, E., Zilinskiene, I., \& Dagiene, V. (2014). Recommending suitable learning scenarios according to learners' preferences: An improved swarm based approach. Computers in Human Behavior, 30, 550-557.

Labib, A. E., Canós, J. H., \& Penadés, M. C. (2017). Integrating product line and learning style approaches to enforce reusability and personalization of learning objects. The 17th IEEE International Conference on Advanced Learning Technologies - ICALT2017. Timisoara, Romania.

Labib, A. E., Canós, J. H., \& Penadés, M. C. (2017). On the way to learning style models integration: A Learner's characteristics ontology. Computers in Human Behavior, 433-445. doi:https://doi.org/10.1016/j.chb.2017.03.054 


\section{References}

Labib, A. E., Penadés, M. C., Canós, J. H., \& Abel, G. (2015). Enforcing reuse and customization in the development of learning objects: a product line approach. 30th ACM/SIGAPP Symposium On Applied Computing (SAC 2015). Salamanca, Spain.

L'Allier, J. J. (1997). Frame of Reference: NETg's Map to the Products, Their Structure and Core Beliefs. Retrieved from http://web.archive.org/web/20020615192443/www.netg.com/research/whit epapers/frameref.asp

Lawrence, W. K. (2015). Learning and personality: The experience of introverted reflective learners in a world of extroverts. Newcastle upon Tyne, UK: Cambridge Scholars Publishing.

Llana, A. G. (2012). Model Driven Software Product Line Engineering: System Variability View and Process Implications. Dessirtation. Valencia, Spain: Universidad Politecnica de Valencia.

Londoño, J., \& Duitama, J. (2012). Model-Driven Web Engineering Methods: a Literature Review. Facultad de Ingeniería Universidad de Antioquia, 63, 69-81.

LTSC. (2000). Retrieved from Learning Technology standards committee website: http://ltsc.ieee.org/

Luna, V., Quintero, R., Torres, M., Moreno-Ibarra, M., Guzman, G., \& Escamilla, I. (2015). An ontology-based approach for representing the interaction process between user profile and its context for collaborative learning environments. Computers in Human Behavior, 51, 1387-1394.

Mahadevan, S. (2002). A Learning Object Model For Electronic Learning. Virginia Polytechnic Institute and State University. Dissertation.

Merrill, M. (2002). Knowledge Objects and Mental-Models. In D. A. Wiley (Ed.), The Instructional Use of Learning Objects: (pp. 261-280). Washington DC: Agency for Instructional Technololgy \& Association for Educational Communications and Technology. Retrieved from http://reusability.org/read/chapters/merrill.doc

Merrill, M. D. (1983). Component display theory. In Instructional design theories and models. Erlbaum Associates. 
Meyer, M., \& Lehnerd, A. (1997). The Power of Product Platforms. New York: Free Press.

Monachesi, P., Simov, K., Mossel, E., Osenova, P., \& Lemnitzer, L. (2008). What ontologies can do for e-learning. International Conference on Interactive Mobile and Computer Aided Learning, IMCLO8.

Montgomery, S. (2002). People Patterns: A Modern Guide to the Four Temperaments (1st ed.). Archer Publications.

Morrison, G., Ross, S., Kemp, J., \& Kalman, H. (2010). Designing Effective Instruction (6 ed.). John Wiley \& Sons.

Mumford, A. (1997). Putting learning styles to work. In A. Mumford, Action learning at work (illustrated ed., pp. 121-135). VT: Gower.

Murphy, E. (2004). Moving from Theory to Practice in the Design of Web-Based Learning using a Learning Object Approach. e-Journal of Instructional Science and Technology, 7(1).

Mutlu, M. (2006). The relation between the learning styles of the students in Anatolian high schools, Anatolian teachers' high schools, science high schools and their attitudes towards biology. International Journal of Environmental and Science Education, 1(2), 148-162.

Muzio, J. A., Heins, T., \& R. Mundell. (2002). Experiences with reusable E-learning objects; From theory to practice. The Internet and Higher Education, 5, 2134.

Myers, I. B., McCaulley, M. H., Quenk, N. L., \& Hammer, A. L. (1998). MBTI Manual: A Guide to the Development and Use of the Myers-Briggs Type Indicator. (3rd ed.). Palo Alto, CA: Consulting Psychologists.

Navy-ILE. (2009). Navy ILE Content Developer's Handbook. Retrieved from http://www.netc.navy.mil/ile/_Documents/ILESpecific/ILE-HDBK-1C.pdf

NCES. (2014). $\quad$ Retrieved 2 15, 2017, from https://nces.ed.gov/fastfacts/display.asp?id=80

Nicol, D. (2004). Conceptions of Learning Objects: Social and Educational Issues Commentary by David Nicol on Littlejohn, A. (2003) Reusing Online Resources, Chapter 2: Granularisation, by Charles Duncan. Journal of 


\section{References}

Interactive Media in Education(4). doi: http://doi.org/10.5334/2003-1reuse-04

OMG. (2011). Business Process Model and Notation (BPMN) Version 2.0 (formal/2011-01-03). Retrieved from http://www.omg.org/spec/BPMN/2.0/

Oppermann, R., \& Rashev, R. a. (n.d.).

Oppermann, R., Rashev, R., \& Kinshuk. (1997). Adaptability and Adaptivity in Learning Systems. In A. Behrooz (Ed.), Proceedings of the International Conference on Knowledge Transfer, 2, pp. 173-179. London, Pace.

Overview, Eclipse Platform Technical. (2006, April 19). Retrieved from Eclipse: http://www.eclipse.org/articles/Whitepaper-Platform-3.1/eclipse-platformwhitepaper.html

Own, Z. (2006). The application of an adaptive web-based learning environment on oxidation-reduction reactions. International Journal of Science and Mathematics Education, 4(1), 73-96.

Özyurt, Ö., \& Özyurt, H. (2015). Learning style based individualized adaptive elearning environments: Content analysis of the articles published from 2005 to 2014. Computers in Human Behavior, 52, 349-358.

Özyurt, Ö., Özyurt, H., Güven, B., \& Baki, A. (2014). The effects of UZWEBMAT on the probability unit achievement of Turkish eleventh grade students and the reasons for such effects. Computers \& Education, 75, 1-18.

Paivio, A. (2006). Dual coding theory and education. Pathways to Literacy Achievement for High Poverty Children. The University of Michigan School of Education: Neuman, S.

Pask, G. (1988). Learning strategies, teaching strategies, and conceptual or learning style. In Schmeck.

Paul, J. (2009). SCORM 2004 4th Ed. Advanced Distributed Learning Initiative. Retrieved from http://www.adlnet.gov/scorm/

Piaget, J. (1999). Construction of reality in the child. London: Routledge \& Kegan Paul. 
Pohl, K., Bockle, G., \& van der Linden, F. (2005). Software Product Line Engineering: Foundations, Principles and Techniques. Springer.

Polsani, P. (2003). Use and abuse of reusable learning objects. Journal of Digital Information, 3(4).

Popescu, E. (2010). Adaptation provisioning with respect to learning styles in a webbased educational system: An experimental study. Journal of Computer Assisted Learning, 26(4), 243-257.

Quenk, N. L. (2009). Essential of Myers-Briggs Type Indicators Assessment. New York: NY: John Wiley.

Rani, M., Nayak, R., \& Vyas, O. P. (2015). An ontology-based adaptive personalized e-learning system, assisted by software agents on cloud storage. KnowledgeBased Systems, 90, 33-48. doi:http://doi.org/10.1016/j.knosys.2015.10.002

Riding, R. (1991). Cognitive Styles Analysis users' manual. Birmingham: Learning and Training Technology.

Riding, R., \& Rayner, S. (1998). Cognitive styles and learning strategies: understanding style differences in learning behaviour. London: David Fulton Publishers Ltd.

Ritzhaupt, A. (2010). Learning Object Systems and Strategy: A Description and Discussion. Interdisciplinary Journal of E-Learning and Learning Objects, 6(1), 217-238.

Rodríguez, V., \& Ayala, G. (2012). Adaptivity and Adpatability of Learning Objects Interface. International Journal of Computer Applications, 37(1).

Sabine, G., \& Kinshuk. (2013). Dynamic Student Modelling of Learning Styles for Advanced Adaptivity in Learning Management Systems. International Journal of Information Systems and Social Change, 4(1), 85-100.

Sadler-Smith, E., \& Riding, R. (1999). Cognitive style and instructional preferences. Instructional Science, 27(5), 355-371. doi:http://doi.org/10.1023/A:1003277503330

Saleena, B., \& Srivatsa, S. K. (2015). Using concept similarity in cross ontology for adaptive e-Learning systems. Journal of King Saud University-Computer and Information Sciences, 27(1), 1-12. 


\section{References}

Sangineto, E., Capuano, N., Gaeta, M., \& Micarelli, A. (2008). Adaptive course generation through learning styles representation. Universal Access in the Information Society, 7(1), 1-23.

Shaw, R. S. (2012). A study of the relationships among learning styles, participation types, and performance in programming language learning supported by online forums. Computers \& Education, 58(1), 111-120.

Sicilia, M., \& Garcia, E. (2003). On the Concepts of Usability and Reusability of Learning Objects. The International Review Of Research In Open And Distributed Learning, 4(2). doi:http://dx.doi.org/10.19173/irrodl.v4i2.155

Sinnema, M., Deelstra, S., Nijhuis, J., \& Bosch, J. (2004). COVAMOF: A Framework for Modeling Variability in Software Product Families. Softw Product Lines (SPLC3) (pp. 197-213). Springer.

Snae, C., \& Brüeckner, M. (2007). Ontology-driven e-learning system based on roles and activities for Thai learning environment. Interdisciplinary Journal of ELearning and Learning Objects, 3(1), 1-17.

Sottilare, R. A. (2006). Modeling the influences of personality preferences on the selection of instructional strategies in intelligent tutoring systems. Dissertation. Florida, University of Central Florida.

Staab, S., \& Studer, R. (2009). Handbook on Ontologies. Decision Support Systems. doi:http://doi.org/10.1007/978-3-540-92673-3

Stone, D. E., \& Guangzhi, Z. (2014). Learning Management Systems in a Changing Environment. In Handbook of Research on Education and Technology in a Changing Society. IGI Global.

Sure, S., \& Studer, Y. (2002). Methodology for development and employment of ontology based knowledge management applications. ACM SIGMOD, $31(4)$, pp. 18-23.

Thalmann, S. (2014). Adaptation criteria for the personalised delivery of learning materials: A multi-stage empirical investigation. Australasian Journal of Educational Technology, 30(1), 45-60. doi:http://doi.org/10.14742/ajet.v30i1.235 


\section{References}

(2001). The Dublin Core Metadata Element Set. National Information Standards Organization. Bethesda, Maryland, U.S.A: NISO.

Thiel, S., \& Hein, A. (2002). Systematic Integration of Variability into Product Line Architecture Design. Softw Product Lines (SPLC2), (pp. 67-102).

Thompson, K., \& Yonekura, F. (2005). Practical Guidelines for Learning Object Granularity from One Higher Education Setting. Interdisciplinary Journal of Knowledge and Learning Objects, 1, 163-179.

Torre, I. (2009). Adaptive systems in the era of the semantic and social web, a survey. User Modeling and User-Adapted Interaction, 19(5), 433-486.

Truong, H. M. (2016). Integrating learning styles and adaptive e-learning system: Current developments, problems and opportunities. Computers in Human Behavior, 55, 1185-1193. doi:http://doi.org/10.1016/j.chb.2015.02.014

Tseng, J. C., Chu, H. C., Hwang, G. J., \& Tsai, C. C. (2008). Development of an adaptive learning system with two sources of personalization information. Computers \& Education, 51(2), 776-786.

Valaski, J., Malucelli, A., \& Reinehr, S. (2011). Recommending learning materials according to ontology-based learning styles. the 7th international conference on information technology and application. Sydney.

Verbert, K., Klerkx, J., Meire, M., Najjar, J., \& Duval, E. (2004). Towards a Global Component Architecture for Learning Objects: an Ontology Based Approach. Proceeding of OTM 2004 Workshop on Ontologies, Semantics and E-learning. Agia Napa, Cyprus.

Vesin, B., Ivanovic, M., KlaLsNja-Milic Evic, A., \& Budimac, Z. (2012). Protus 2.0: Ontology-based semantic recommendation in programming tutoring system. Expert Systems with Applications, 39(15), 12229-12246.

Vesin, B., Ivanović, M., Klašnja-Milićević, A., \& Budimac, Z. (2011). Rule-based Reasoning for Altering Pattern Navigation in Programming Tutoring System. the proceedings of the 15th international conference on System theory, control and computing, (pp. 644-649). Sinaia, Romania.

Wagner, E. (2002). Steps to creating a content strategy for your organization. The eLearning Developers' Journal. 


\section{References}

Wang, F. H. (2008). Content recommendation based on education-contextualized browsing events for web-based personalized learning. Educational Technology \& Society, 11(4), 94-112.

Wang, F. -H., \& Chen, D.-Y. (2008). A Knowledge Integration Framework for Adaptive Learning Systems Based on Semantic Web Languages. Eighth IEEE International Conference on Advanced Learning Technologies, (pp. 64-68).

Wang, T. I., Tsai, K. H., Lee, M. C., \& Chiu, T. K. (2007). Personalized learning objects recommendation based on the semantic-aware discovery and the learner preference pattern. Journal of Educational Technology \& Society, 10(3), 84-105.

Watson, J., Dickens, A., \& Gilchrist, G. (2008). The LOC tool: creating a learning object authoring tool for teachers. Proceedings of Ed-Media 2008: World Conference on Educational Multimedia, Hypermedia and Telecommunications, (pp. 4626-4632 ). Chesapeake, USA. Retrieved from http://www.editlib.org/p/29030

Wiley, D. (2000). Connecting learning objects to instructional design theory: A definition, a metaphor, and a taxonomy. In D. Wiley (Ed.). Washington DC: Agency for Instructional. Retrieved 03 25, 2017, from http://reusability.org/read/chapters/wiley.doc

Witkin, H., Moore, C., Goodenough, D., \& Cox, P. (1977). Field-dependent and field- independent cognitive styles and their educational implications. Educational Research, 47, 1-64.

$\begin{array}{llllll}\text { Xerte. } & \text { (2017). } & \text { Retrieved } & 2 & 2017, & \text { from }\end{array}$ https://www.nottingham.ac.uk/xerte/index.aspx

Yang, D., \& Yang, Q. (2005). Customizable distance learning: criteria for developing learning objects and learning model templates. Proceedings of the 7th international Conference on Electronic Commerce, ICEC '05. 113, pp. 765-770. Xi'an, China: ACM Press, New York, NY. Retrieved 0220 , 2017, from http://doi.acm.org/10.1145/1089551.1089691 


\section{References}

Yang, Y. J., \& Wu, C. (2009). An attribute-based ant colony system for adaptive learning object recommendation. Expert Systems with Applications, 36, 3034-3047.

Zapata, A., V. H. Menendez, \& M. E. Prieto. (2009). Discovering Learning Objects Usability Characteristics. Ninth International Conference on Intelligent Systems Design and Applications, (pp. 1126-1130). Pisa. doi:doi: 10.1109/ISDA.2009.184 



\section{APPENDICES}


Appendices

Appendix A LSM Characteristics

A.1 LSM Dimensions Characteristics

\begin{tabular}{|c|c|c|c|}
\hline Model & Dimension & Pole & Characteristic \\
\hline \multirow[t]{17}{*}{ Kolb } & \multirow[t]{7}{*}{ Grasping } & \multirow{7}{*}{$\begin{array}{l}\text { Concrete } \\
\text { Experience }\end{array}$} & Concrete Thinking \\
\hline & & & Direct, Hands-on Experience \\
\hline & & & Literal Manner \\
\hline & & & Practical \\
\hline & & & Realistic outlook \\
\hline & & & Tangible Facts \\
\hline & & & People Oriented \\
\hline & & \multirow{4}{*}{$\begin{array}{l}\text { Active Experi- } \\
\text { mentation }\end{array}$} & Engage in Projects \\
\hline & & & Experimentalists \\
\hline & & & Working with Others in Groups \\
\hline & & & An Active, Doing Approach \\
\hline & \multirow{6}{*}{$\begin{array}{l}\text { Transform- } \\
\text { ing }\end{array}$} & \multirow{6}{*}{$\begin{array}{l}\text { Abstract Con- } \\
\text { ceptualization }\end{array}$} & Imagination \\
\hline & & & Logical Thinking \\
\hline & & & Look at The Big Picture \\
\hline & & & Theoretical Connections \\
\hline & & & Analytical \\
\hline & & & Rational Evaluation \\
\hline & & & \\
\hline
\end{tabular}


Appendixes

\begin{tabular}{|c|c|c|c|}
\hline & & Reflective Ob- & Introspection \\
\hline & & & A Tentative Approach to learning \\
\hline & & & Observation of Others \\
\hline & & & Theoreticians \\
\hline & & & Introvert \\
\hline MBTI & Gathering & Sensing & Natural Organizer \\
\hline & & & Tactile \\
\hline & & & Tangible Facts \\
\hline & & & Realistic outlook \\
\hline & & & Practical \\
\hline & & & Literal Manner \\
\hline & & & Attention to Details \\
\hline & & Intuitive & Saw the world in Endless Possibilities \\
\hline & & & Integrated with Imagination \\
\hline & & & Theoretical Connections \\
\hline & & & Imagination \\
\hline & & & Look at The Big Picture \\
\hline & Decision & Thinking & Objective Decisions \\
\hline & & & Use Analytical Logic \\
\hline & & & \\
\hline
\end{tabular}




\section{A ppendices}

\begin{tabular}{|c|c|c|}
\hline & \multirow[t]{3}{*}{ Feeling } & Subjective Decisions \\
\hline & & Interpersonal Interactions \\
\hline & & Search for Harmony \\
\hline \multirow{7}{*}{$\begin{array}{l}\text { Outside } \\
\text { World Atti- } \\
\text { tude }\end{array}$} & \multirow[t]{4}{*}{ Judging } & Planning \\
\hline & & Meeting Deadlines \\
\hline & & Decision-Making \\
\hline & & Organization \\
\hline & \multirow[t]{3}{*}{ Perceiving } & Collect Information \\
\hline & & Spontaneity \\
\hline & & Adaptive and Flexible \\
\hline \multirow{9}{*}{$\begin{array}{ll}\text { Life } & \text { Atti- } \\
\text { tude } & \end{array}$} & \multirow[t]{3}{*}{ Extravert } & Social Interaction \\
\hline & & Applications \\
\hline & & Actions \\
\hline & \multirow[t]{6}{*}{ Introvert } & Reflective \\
\hline & & Isolated \\
\hline & & Working Quietly \\
\hline & & Independent Thinkers \\
\hline & & Concepts and Idea \\
\hline & & Introspection \\
\hline
\end{tabular}


Appendixes

\begin{tabular}{|c|c|c|c|}
\hline \multirow{18}{*}{$\begin{array}{l}\text { Felder- } \\
\text { Silver- } \\
\text { man }\end{array}$} & \multirow[t]{11}{*}{ Perception } & \multirow[t]{6}{*}{ Sensing } & Memorizing Facts \\
\hline & & & Patient with Details \\
\hline & & & Doing Hands-on Work \\
\hline & & & Practical and Careful \\
\hline & & & Concerned with Procedures \\
\hline & & & Concrete Thinking \\
\hline & & \multirow[t]{5}{*}{ Intuitive } & $\begin{array}{l}\text { Discovering Possibilities and Rela- } \\
\text { tionships }\end{array}$ \\
\hline & & & Like Innovation \\
\hline & & & Grasping New Concepts \\
\hline & & & $\begin{array}{l}\text { Abstractions and Mathematical For- } \\
\text { mulations }\end{array}$ \\
\hline & & & Work Faster \\
\hline & \multirow[t]{7}{*}{ Processing } & \multirow[t]{3}{*}{ Active } & Learning best by Doing \\
\hline & & & Working with Others in Groups \\
\hline & & & Experimentalists \\
\hline & & \multirow[t]{4}{*}{ Reflective } & Introspective processing \\
\hline & & & Independent Work \\
\hline & & & Theoreticians \\
\hline & & & Prefers Thinking through Things \\
\hline
\end{tabular}




\section{Appendices}

\begin{tabular}{|c|c|c|c|}
\hline & \multirow{9}{*}{$\begin{array}{l}\text { Understand- } \\
\text { ing }\end{array}$} & \multirow[t]{4}{*}{ Sequential } & Understanding in Linear Steps \\
\hline & & & Learns in Small Incremental Steps \\
\hline & & & Linear Thinking \\
\hline & & & Orderly \\
\hline & & \multirow[t]{5}{*}{ Global } & $\begin{array}{llll}\begin{array}{l}\text { Absorbing } \\
\text { domly }\end{array} & \text { Material almost Ran- } \\
\end{array}$ \\
\hline & & & Holistic Thinking \\
\hline & & & Learns in Intuitive Leaps \\
\hline & & & See the Connections no one else sees \\
\hline & & & Systems Thinkers \\
\hline & \multirow[t]{4}{*}{$\begin{array}{ll}\text { Input } & \text { Mo- } \\
\text { dality } & \end{array}$} & \multirow[t]{2}{*}{ Verbal } & $\begin{array}{l}\text { Prefers Written and Spoken Explana- } \\
\text { tions }\end{array}$ \\
\hline & & & Verbal Ability \\
\hline & & \multirow[t]{2}{*}{ Visual } & Prefers Visual Representations \\
\hline & & & Visual Ability \\
\hline \multirow[t]{3}{*}{ Riding } & \multirow{3}{*}{$\begin{array}{l}\text { Organizing } \\
\text { and Pro- } \\
\text { cessing }\end{array}$} & \multirow[t]{3}{*}{ Wholist } & Global View of Information \\
\hline & & & Information is presented in Holistic \\
\hline & & & $\begin{array}{l}\text { Information is presented with a Con- } \\
\text { tent Map }\end{array}$ \\
\hline
\end{tabular}


Appendixes

\begin{tabular}{|c|c|c|c|}
\hline & & & Tend to be Social \\
\hline & & Analytical & Information is presented in Parts \\
\hline & & & Tend to be Isolated \\
\hline & & & Interested in Details \\
\hline & Information & Verbal & Prefers Textual/Verbal Information \\
\hline & $\begin{array}{l}\text { resentation } \\
\text { rentillat }\end{array}$ & & Tends to be Extraversion \\
\hline & & Imagery & Prefers Pictorial Information \\
\hline & & & Tends to be Introversion \\
\hline Gregorc & Perception & Concrete & Focus is on "Here and Now" \\
\hline & & & Literal Manner \\
\hline & & & Direct, Hands-on Experience \\
\hline & & & Practical Applications \\
\hline & & & Deal with Facts and Reality \\
\hline & & Abstract & Tends to be Intuitive \\
\hline & & & Tends to be Imaginative \\
\hline & & & Theories and Ideas \\
\hline & & & Analyzing and Interpreting \\
\hline & & & Thinking and Reflecting \\
\hline
\end{tabular}




\section{Appendices}

\begin{tabular}{|c|c|c|}
\hline \multirow[t]{9}{*}{ Ordering } & \multirow[t]{5}{*}{ Sequential } & Deals with data in a Linear manner \\
\hline & & $\begin{array}{l}\text { Deals with data in an Organized man- } \\
\text { ner }\end{array}$ \\
\hline & & Plan things out Step-By-Step \\
\hline & & Bottom-up Learner \\
\hline & & Details \\
\hline & \multirow[t]{4}{*}{ Random } & $\begin{array}{l}\text { Information in Chunks, Skipping } \\
\text { steps }\end{array}$ \\
\hline & & Non-Linear Approach \\
\hline & & Top-down Learner \\
\hline & & $\begin{array}{l}\text { Makes Connections between Con- } \\
\text { cepts and Ideas }\end{array}$ \\
\hline
\end{tabular}


Appendixes

A.2 Honey \& Mumford Learning Styles Characteristics

\begin{tabular}{|c|c|}
\hline Learning Style & Characteristic \\
\hline \multirow[t]{9}{*}{ Activist } & Here-and-Now Tasks \\
\hline & Brainstorming \\
\hline & Action Learning \\
\hline & Working in Small Groups \\
\hline & experience-driven \\
\hline & open-minded \\
\hline & enthusiastic about new situations \\
\hline & try anything once \\
\hline & act first and consider the consequences afterwards \\
\hline \multirow[t]{8}{*}{ Reflector } & Collects data \& Analyses \\
\hline & Observing and Thinking \\
\hline & Self-directed Learning \\
\hline & Cautious and Thoughtful \\
\hline & observing and listening to others \\
\hline & reviewing and pondering on experience \\
\hline & look at experience from different viewpoints \\
\hline & comprehensive compilation of information \\
\hline \multirow[t]{9}{*}{ Theorist } & Theories \& Facts \\
\hline & Analytical Reviewing \\
\hline & $\begin{array}{l}\text { Drawing information into a systematic and logical } \\
\text { Theory }\end{array}$ \\
\hline & Complex Tasks \\
\hline & Theoretical Connections \\
\hline & step-by-step upward logic \\
\hline & Tend to be perfectionists \\
\hline & systematic thinking \\
\hline & independent \\
\hline \multirow[t]{2}{*}{ Pragmatist } & Trying out new Ideas and Theories \\
\hline & Practical Applications \\
\hline
\end{tabular}




\section{Appendices}

Action Learning

Problem-Solving

Put Ideas into Practice 
